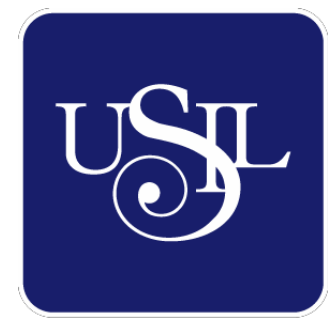

UNIVERSIDAD

SAN IGNACIO

DE LOYOLA

ESCUELA DE POSTGRADO

\title{
DISEÑO E INSTALACIÓN DE UNA FÁBRICA DE CHOCOLATES NUTRITIVOS
}

Tesis para optar el grado de:

ANDREA GISELLA MORA FÉLIX

Maestro en Ciencias Empresariales con Mención en Gestión de Salud

Ocupacional y Riesgos Laborales

\section{MARÍA ALEJANDRA RODRÍGUEZ RODRÍGUEZ}

Maestro en Ciencias Empresariales con Mención en Gestión de Proyectos

\author{
Asesor: \\ Luis Fernando Peredo Rojas \\ Lima - Perú \\ 2018
}


AGRADECIMIENTO

A Dios, por iluminar nuestro camino; y a nuestras familias por su amor y apoyo incondicional a lo largo de nuestras vidas. 


\section{RESUMEN EJECUTIVO}

El presente plan de negocios consiste en determinar la factibilidad para la instalación de una fábrica de chocolates nutritivos en la ciudad de Lima, Perú. El chocolate que se desarrollará es un producto saludable a base de cacao con gomitas fortificadas con hierro, zinc y vitamina $\mathrm{C}$, micronutrientes esenciales para prevenir la anemia.

El producto está dirigido a niños teniendo mayor relevancia en población vulnerable a adquirir anemia: niños, mujeres embarazadas y en etapa de lactancia. El producto se llama Chocovit y saldrá el mercado en tres presentaciones: tableta unitaria (de 30g), display de 24 unidades $(720 \mathrm{~g})$ y pack de 6 unidades $(180 \mathrm{~g})$, los que podrán encontrarse en supermercados, bodegas y tiendas especializadas. Cabe resaltar que Chocovit no es una golosina sino un chocolate nutritivo ideal para todos, pero se recomienda para los niños en etapa pre escolar y escolar.

Este proyecto nace por la oportunidad que se presenta en el mercado, debido a la tendencia del consumo de productos naturales, orgánicos y saludables, además de la preocupación del Gobierno para disminuir los niveles de anemia y desnutrición en todo el país. Se resalta también que, las personas que elaborarán el presente plan de negocios cuentan con los conocimientos técnicos y competencias necesarias para realizar el estudio. Un ingeniero en Industrias de Alimentos con experiencia en el rubro de chocolatería y un ingeniero Industrial con experiencia en el área de procesos y gestión de calidad.

La presente investigación persigue los siguientes objetivos específicos, en el ámbito financiero, evaluar la viabilidad de la implementación y la rentabilidad a obtener. En el área Comercial, obtener participación en el mercado. En el área Recursos Humanos, proveer, mantener y desarrollar un recurso humano calificado y motivado para el logro de los objetivos de la empresa. A nivel de tecnología, estandarizar y documentar todos los procesos operativos 
e implementar la fábrica con tecnología de punta. A nivel de logística, asegurar el abastecimiento de materia prima e insumos.

La planta se ubicará en el distrito de Lurín, que luego de una evaluación de macro y micro localización se determinó como óptima. Está conformada por planta central, área administrativa y área de tránsito, mide $1105 \mathrm{~m}^{2}$ y tiene una capacidad de producción de $114 \mathrm{~kg}$ de chocolate al día. Se contará con un total de 35 colaboradores, de los cuales alrededor del $60 \%$ es personal operario. Se contará con una Gerencia General y las áreas de Producción, Administración y Gestión Humana, Comercial, Logística y Mantenimiento. La planta estará equipada con maquinaria de última generación importada de Italia, que es donde se encuentra la mejor tecnología para el rubro de confitería y chocolatería.

Dentro de las estrategias de promoción y publicidad del producto, está el participar en dos ferias importantes en el ámbito de la chocolatería, además para llegar a los potenciales clientes se creará la página oficial en las redes sociales más importantes, y la suscripción a revistas de interés del público objetivo.

La inversión total para la implementación y puesta en marcha de la planta asciende a S/. 2,962,093 Soles. El 68\% se financiará con capital propio y para cubrir el 32\% restante, se aplicará a un préstamo a través de una entidad financiera. El costo de oportunidad del inversionista (COK) calculado es del $9.91 \%$ y el costo de capital promedio ponderado (WACC) es de $11.25 \%$. La Tasa Interna de Retorno Económica (TIRE) es de $15.77 \%$ y el Valor Actual Neto Económico (VANE) es de S/ 854,867 Soles. La Tasa Interna de Retorno Financiera (TIRF) es de $15.76 \%$ y el Valor Actual Neto Financiero (VANF) es de S/ 1,091,381 Soles.

El proyecto resulta ser rentable ya que el VAN económico y financiero son positivos y la TIRE es mayor al WACC y la TIRF es mayor al costo de oportunidad del inversionista. 


\section{TABLA DE CONTENIDO}

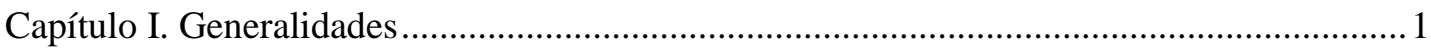

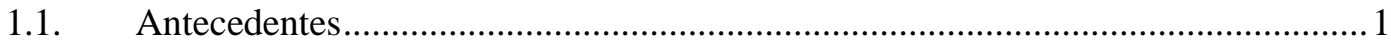

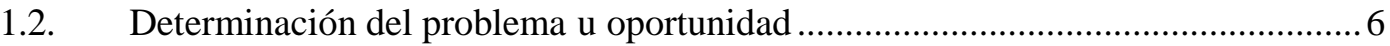

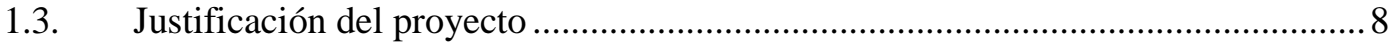

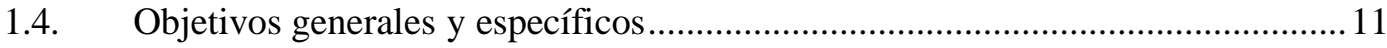

1.5. Alcances y limitaciones de la investigación ........................................................ 13

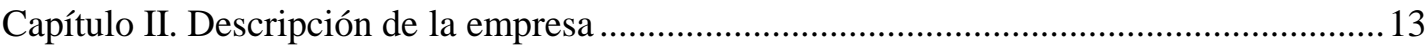

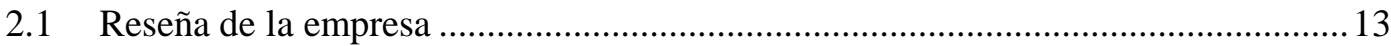

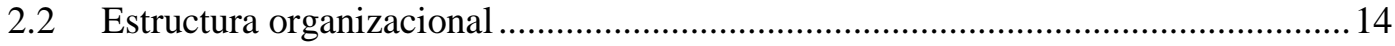

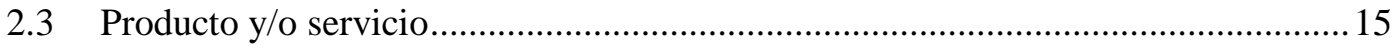

2.3.1 Ciclo de vida del producto y/o servicio ....................................................... 15

2.3.2 Características del producto y/o servicio ........................................................... 15

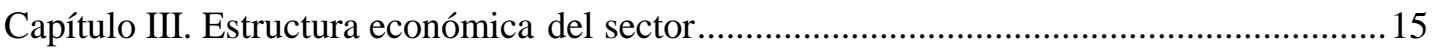

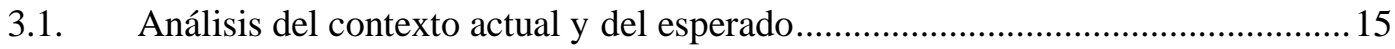

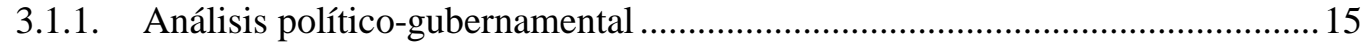

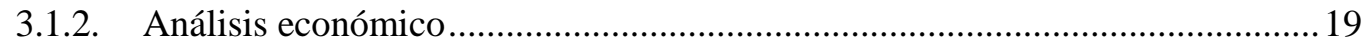

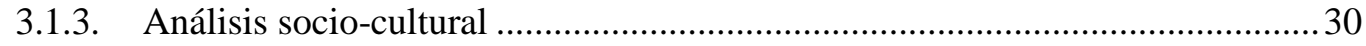

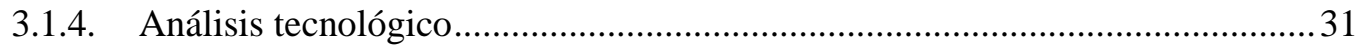

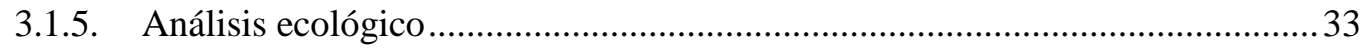




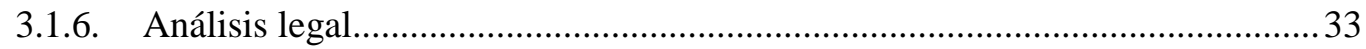

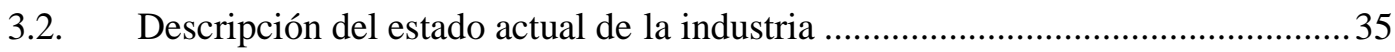

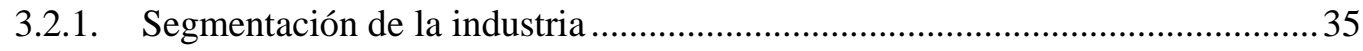

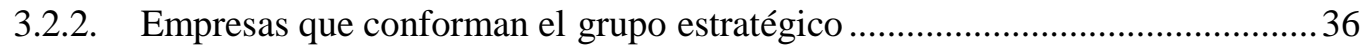

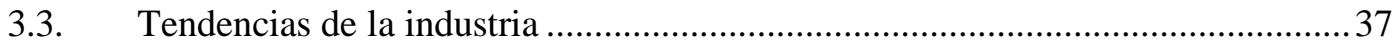

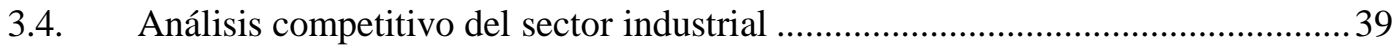

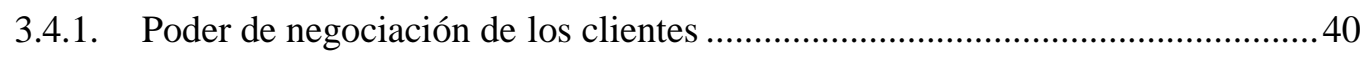

3.4.2. Poder de negociación de los proveedores .....................................................40

3.4.3. Amenaza de productos sustitutos............................................................... 41

3.4.4. Amenaza de nuevos competidores potenciales................................................41

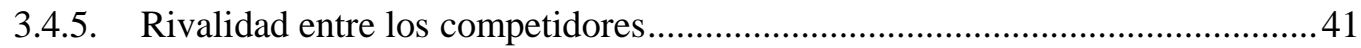

3.5. Análisis de la competencia directa ................................................................ 43

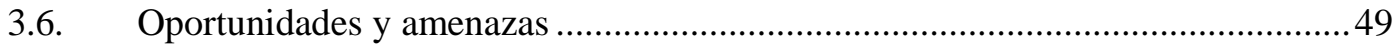

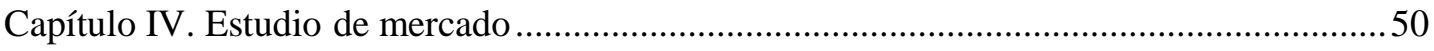

4.1. Selección del segmento de mercado.............................................................50

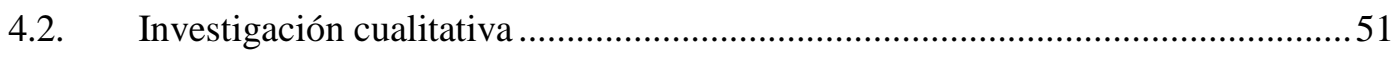

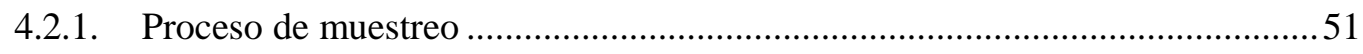

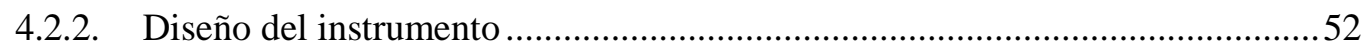

4.2.3. Análisis y procesamiento de datos.................................................................53

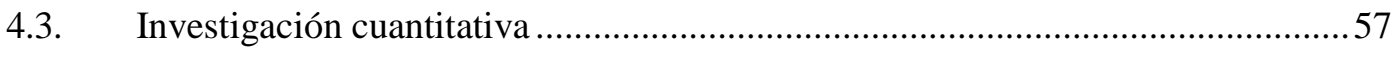

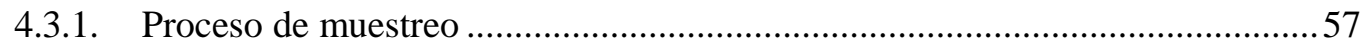


4.3.2. Diseño del instrumento 60

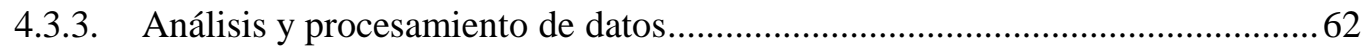

4.4. Conclusiones y recomendaciones del estudio cualitativo y cuantitativo ..............69

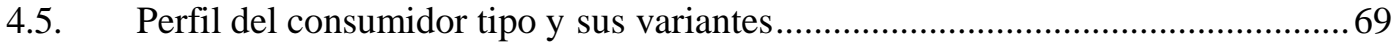

Capítulo V. Proyección del mercado objetivo ................................................................ 71

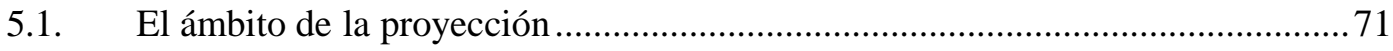

5.2. Selección del método de proyección ................................................................. 71

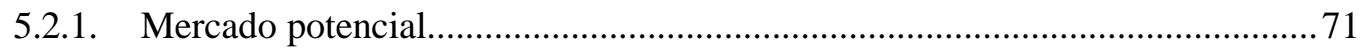

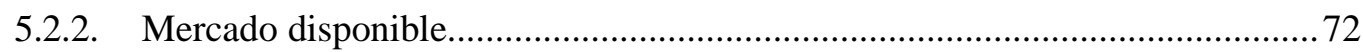

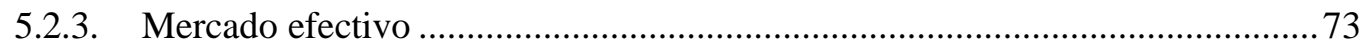

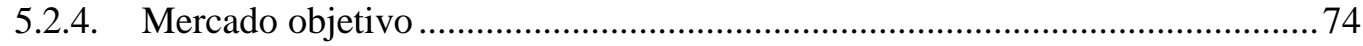

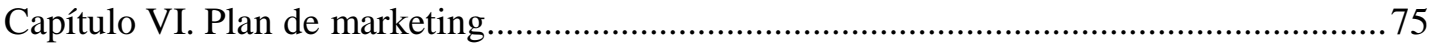

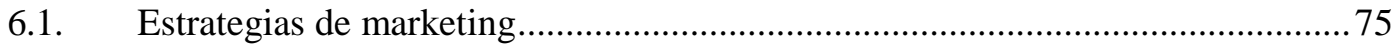

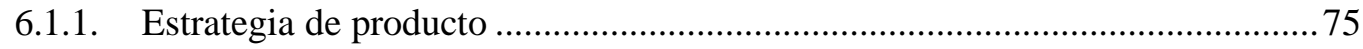

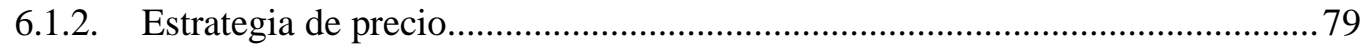

6.1.3. Estrategia de plaza y distribución .................................................................. 79

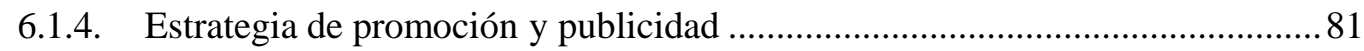

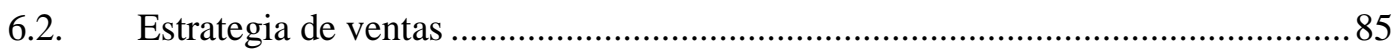

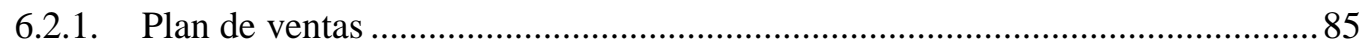

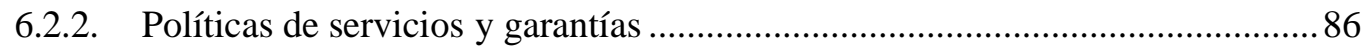

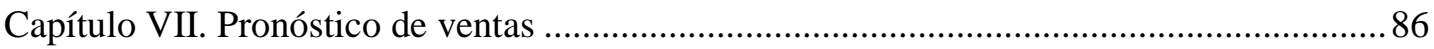


7.1. Fundamentos y supuestos

7.2. Análisis de los riesgos y aspectos críticos que impactan en el pronóstico..... 87

Capítulo VIII. Ingeniería del proyecto 88

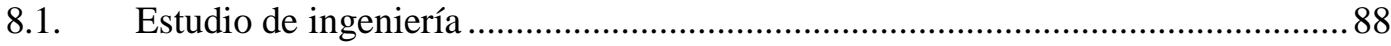

8.1.1. Modelamiento y selección de procesos productivos .......................................8 88

8.1.2. Selección del equipamiento ...........................................................................91

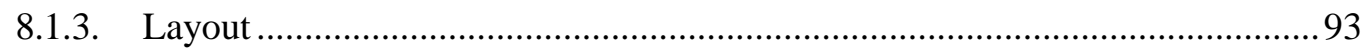

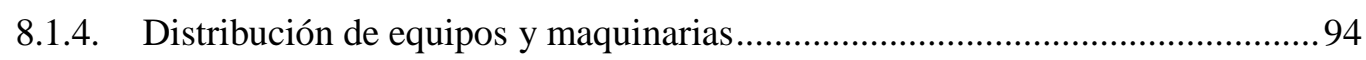

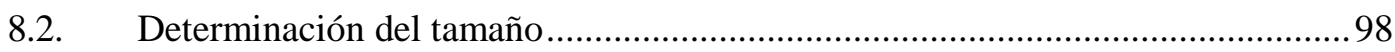

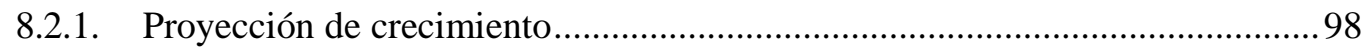

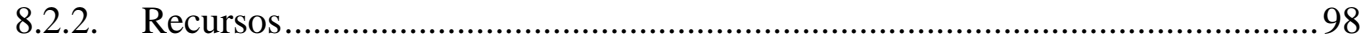

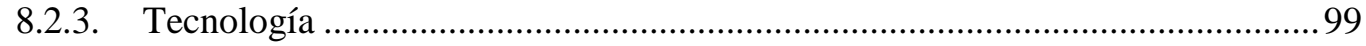

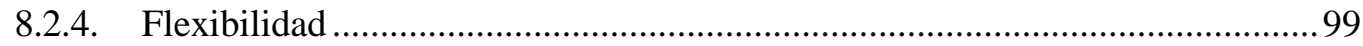

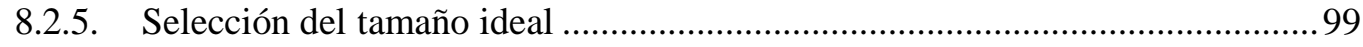

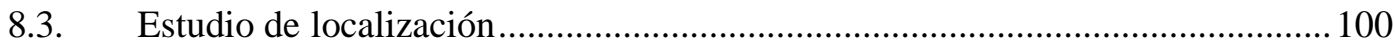

8.3.1. Análisis de la macrolocalización .................................................................... 100

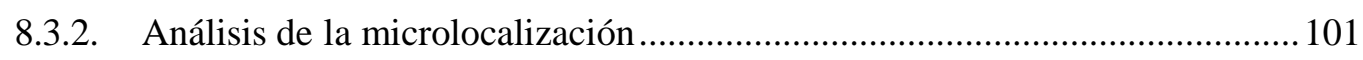

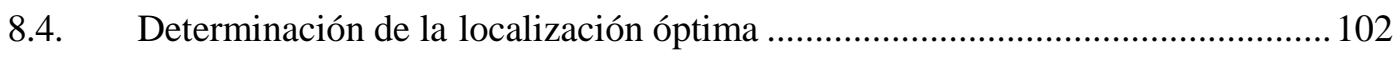

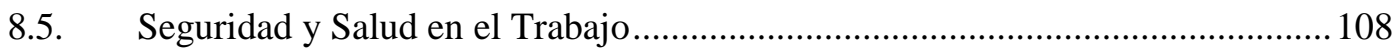

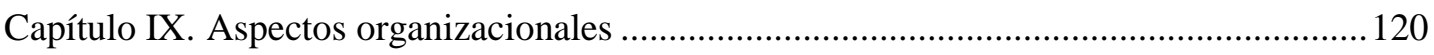

9.1. Caracterización de la cultura organizacional deseada .................................... 120 
9.1.1. Visión.

9.1.2. Misión

9.1.3. Principios

9.1.4. Factor de diferenciación y posicionamiento

9.2. Diseño de la estructura organizacional del proyecto

9.3. Diseño de los perfiles de puestos clave.

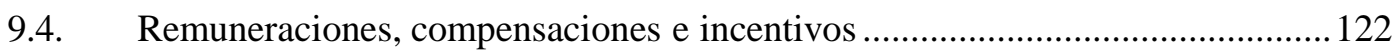

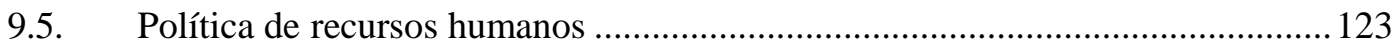

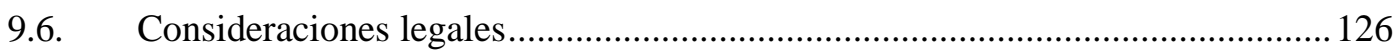

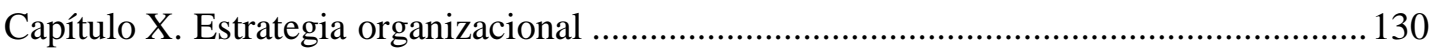

10.1. Formulación de estrategias del negocio............................................................130

10.2. Formación de la ventaja competitiva ............................................................. 130

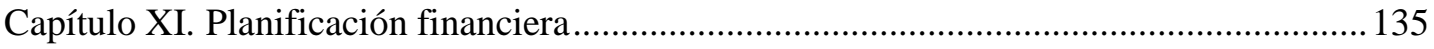

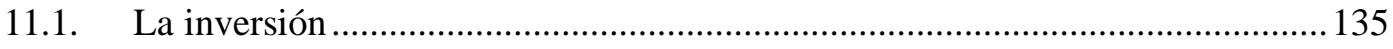

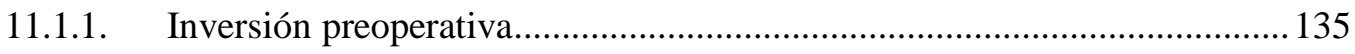

11.1.2. Inversión en capital de trabajo ............................................................... 136

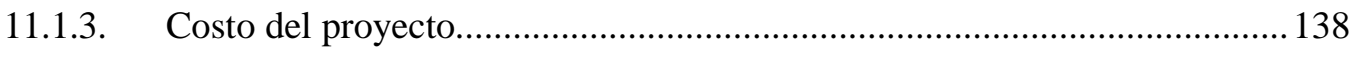

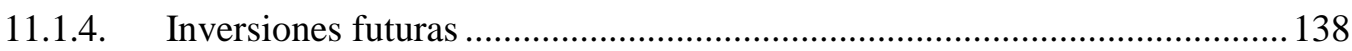

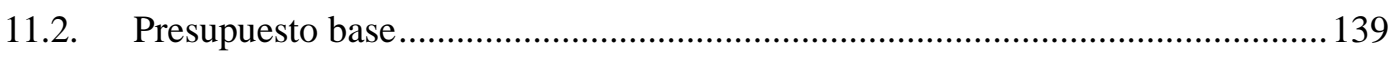

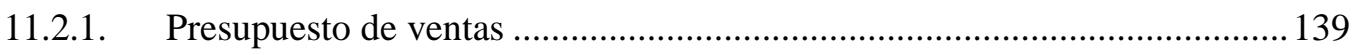

11.2.2. Presupuesto de costos de producción....................................................... 139 


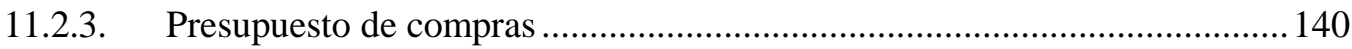

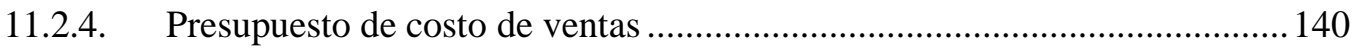

11.2.5. Presupuesto de gastos administrativos ...................................................... 141

11.2.6. Presupuesto de gastos de seguridad y salud ocupacional ........................... 142

11.2.7. Presupuesto de gastos de marketing y ventas .......................................... 142

11.2.8. Presupuesto de gastos financieros ............................................................... 143

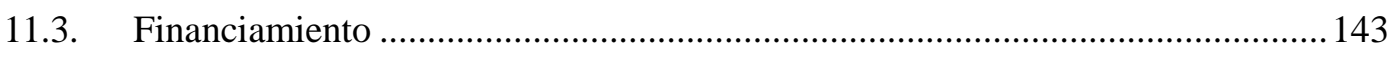

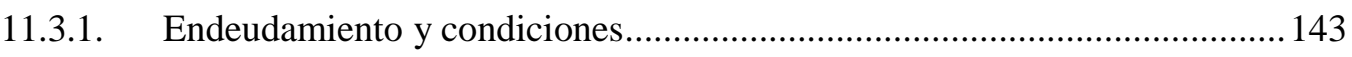

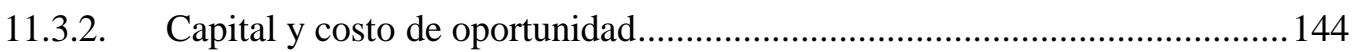

11.3.3. Costo de capital promedio ponderado.......................................................... 147

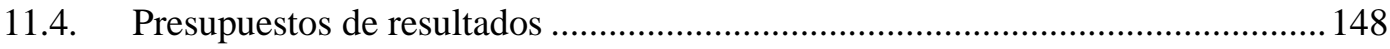

11.4.1. Estado de resultados proyectado ............................................................ 148

11.4.2. Estado de situación financiera proyectado.................................................. 148

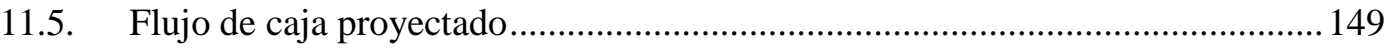

11.5.1. Flujo de caja económico ..................................................................... 149

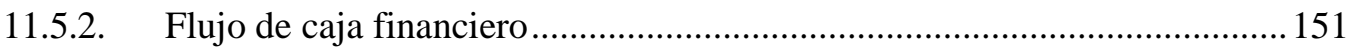

Capítulo XII. Evaluación económica financiera ............................................................... 153

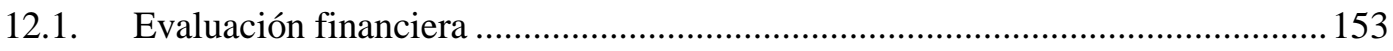

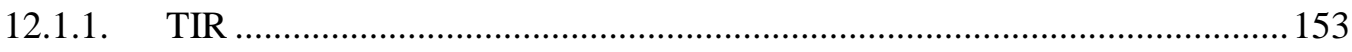

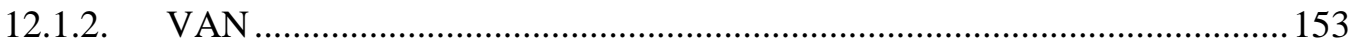

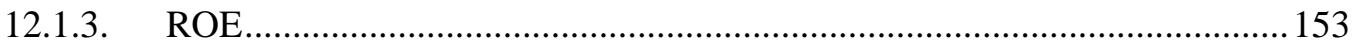


12.1.4. Ratios 153

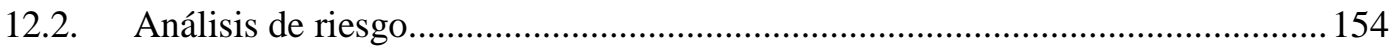

12.2.1. Análisis de punto de equilibrio ................................................................ 154

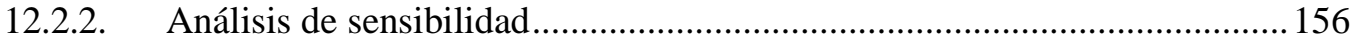

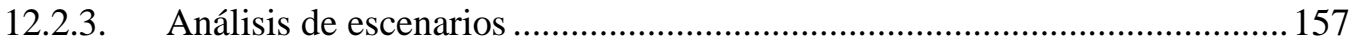

12.2.4. Análisis y evaluación de riesgos financieros ............................................ 157

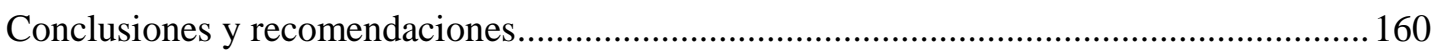

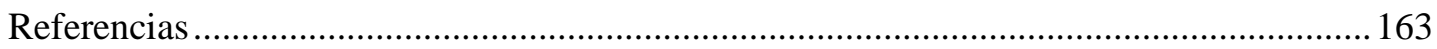




\section{INDICE DE TABLA}

Tabla 1. Metas de Reducción Nacional de Desnutrición y anemia infantil 2016 - 2021. . 19

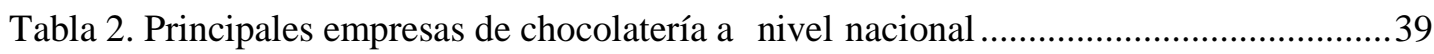

Tabla 3. Análisis de las cinco fuerzas de Porter en el sector chocolatería ...........................43

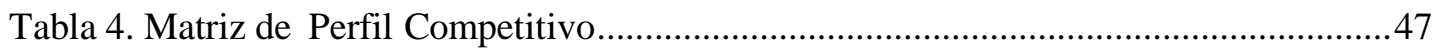

Tabla 5. Población y hogares según distritos en el año 2017 .............................................58

Tabla 6. Distribución de la población de las zonas 2, 3, 6 y 7 en los NSE A, B y C............59

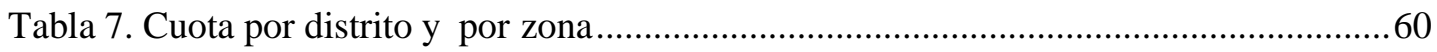

Tabla 8. Datos históricos de la población de catorce distritos de Lima Metropolitana:

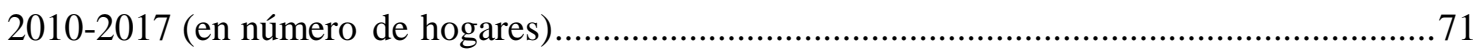

Tabla 9. Proyección de la población de catorce distritos de Lima Metropolitana: 2018-

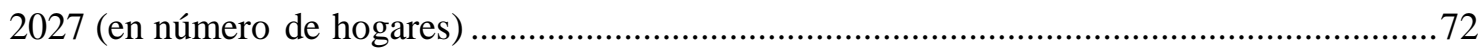

Tabla 10. Proyección del mercado disponible: 2018 - 2027 (en número de hogares) .........73

Tabla 11. Proyección del mercado efectivo: 2018 - 2027 (en número de hogares) .............74

Tabla 12. Proyección del mercado objetivo: 2018 - 2028 (en número de hogares) .............74

Tabla 13. Tabla nutricional del chocolate nutritivo ........................................................ 78

Tabla 14. Plan anual de ventas para el período enero a diciembre del 2019.......................85

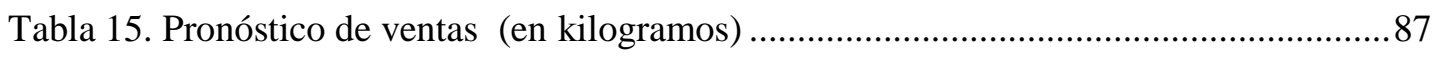

Tabla 16. Pronóstico de ventas (en número de unidades).................................................... 87

Tabla 17. Equipos para el procesamiento de tabletas de chocolate con gomitas fortificadas.

Tabla 18. Mobiliario del área de producción ........................................................................93

Tabla 19. Dimensión de las áreas de la fábrica de chocolates nutritivo.............................100

Tabla 20. Cuadro de enfrentamiento de factores locacionales para macrolocalización. .. 103

Tabla 21. Ponderación de factores para macrolocalización por localidad 103 
Tabla 22.Costos para evaluación de microlocalización

Tabla 23. Evaluación de Factores Objetivos (FOi) para localidades de Chorrillos, Lurín y

Chilca 105

Tabla 24. Cálculo del valor relativo Rij de los factores subjetivos .................................... 105

Tabla 25. Comparaciones pareadas por localidad según factores subjetivos ......................106

Tabla 26. Resumen de los valores relativos de factores subjetivos por localidad..............106

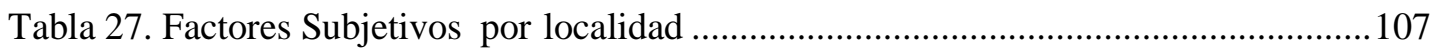

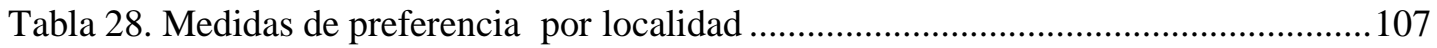

Tabla 29. Lista maestra de documentos del Sistema de Seguridad y Salud Ocupacional 109

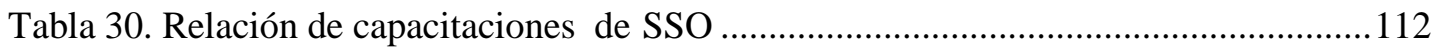

Tabla 31. Protocolo de EMO para administrativos .......................................................... 113

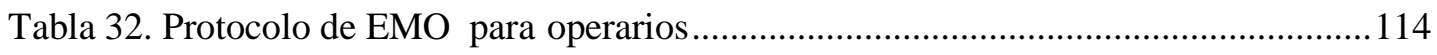

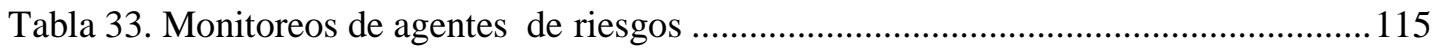

Tabla 34. Tipos de señalización y cantidad a instalar en la planta .....................................119

Tabla 35. Sistema de alarma y detección contra incendio .................................................120

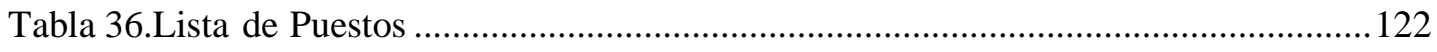

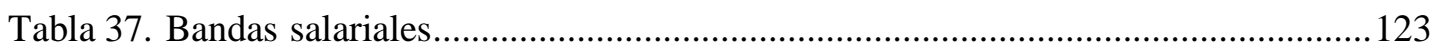

Tabla 38. Matriz de Planificación Ampliada (Área funcional de finanzas) ........................131

Tabla 39. Matriz de Planificación Ampliada (Área funcional comercial)...........................132

Tabla 40. Matriz de Planificación Ampliada (Área funcional recursos humanos) .............133

Tabla 41. Matriz de Planificación Ampliada (Área funcional logística).............................134

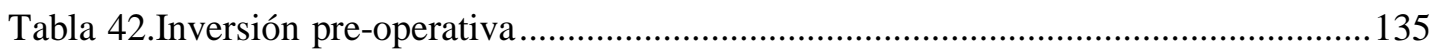

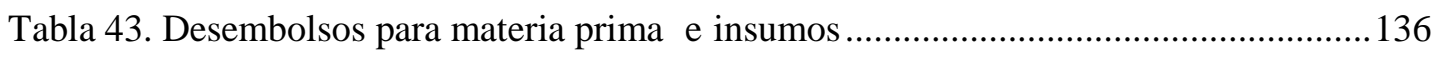

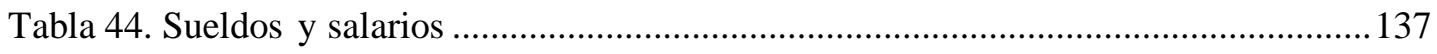

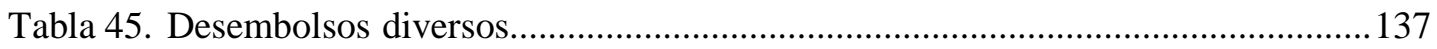


Tabla 46. Inversión Total. 138

Tabla 47. Presupuesto de ventas del 2019 al 2028

Tabla 48. Presupuesto de costo de producción 140

Tabla 49. Presupuesto de compras de materia prima directa para el año 2019 hasta 2028.

Tabla 50. Presupuesto de compras de materiales indirectos de fabricación para el año 2019 hasta 2028 140

Tabla 51. Presupuesto de costo de ventas para el año 2019 hasta 2028

Tabla 52. Presupuesto de Gastos Administrativos..... 142

Tabla 53. Presupuesto de Gastos de Seguridad y Salud Ocupacional 142

Tabla 54. Presupuesto de Gastos Marketing y Ventas 143

Tabla 55. Presupuesto de Gastos Financieros 143

Tabla 56. Pago de intereses y amortización del préstamo 144

Tabla 57. Valores promediados para el cálculo del rm y rf 146

Tabla 58. Costo de Capital Promedio Ponderado 147

Tabla 59. Estado de resultados del 2018 al 2028 148

Tabla 60. Estado de situación financiera proyectado al 2018 149

Tabla 61. Estado de situación financiera proyectado al 2019 149

Tabla 62. Flujo de caja económico del 2018 al 2028 150

Tabla 63. Flujo de caja económico mensual para el año 2019

Tabla 64. Flujo de caja económico mensual para el año 2020

Tabla 65. Flujo de caja financiero del 2018 al 2028 151

Tabla 66. Flujo de caja económico y acumulado proyectado a diez años. 152

Tabla 67.Flujo de caja económico, descuento y acumulado proyectado a diez años 152

Tabla 68. Determinación del ROE en los diez años proyectados 153 
Tabla 69. Evaluación económica financiera de ratios......................................................... 154

Tabla 70. Cálculo del punto de equilibrio para dos presentaciones de chocolate................155

Tabla 71. Cálculo del punto de equilibrio por kilo de chocolate........................................156

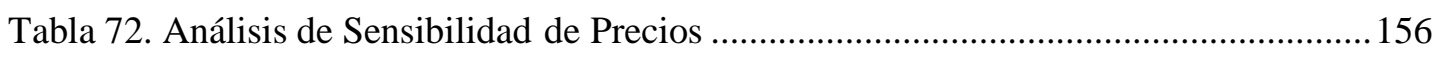

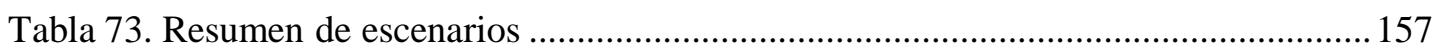

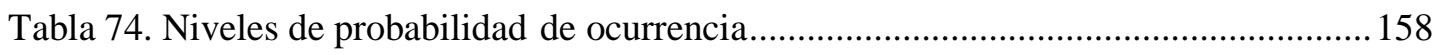

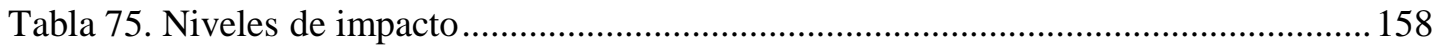

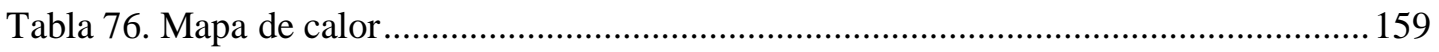

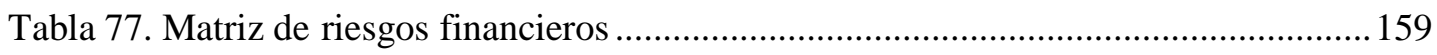




\section{INDICE DE FIGURAS}

Figura 1. Organigrama de la fábrica de chocolates nutritivos ............................................14

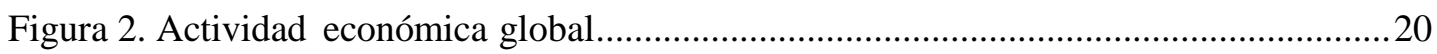

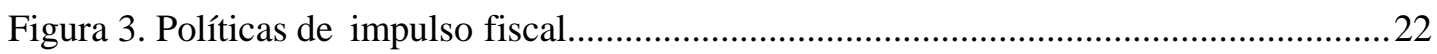

Figura 4. PBI Primer trimestre 2017 y proyectado (primario y no primario) ......................23

Figura 5. Variación porcentual del PBI en el 2017 ...........................................................23

Figura 6. Variación porcentual del PBI primario y no primario en el 2017.........................24

Figura 7. Exportaciones tradicionales y no tradicionales ...............................................24

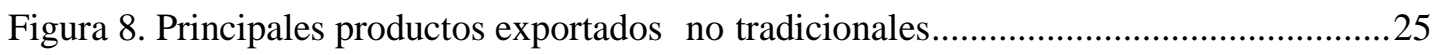

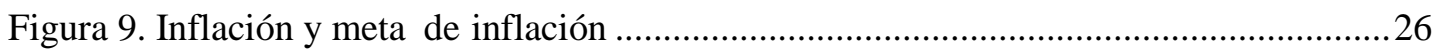

Figura 10. Actividades económicas demandantes de cacao, chocolate y otros derivados

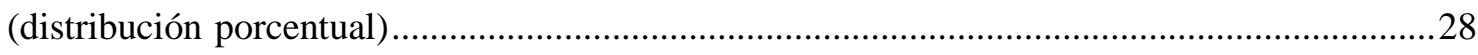

Figura 11. Producción de grano de cacao e insumos derivados del cacao (variación

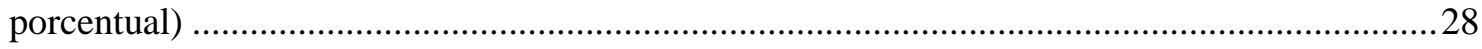

Figura 12. Evolución de exportaciones de cacao, chocolate y otros derivados (millones de US\$)

Figura 13. Importación de cacao, chocolate y otros derivados (millones de US\$) ...............30

Figura 14. Evolución de la producción de chocolates y cocoa en Perú..................................38

Figura 15. Información nutricional del producto Forticao.................................................46

Figura 16. Intención de compra de Chocovit ......................................................................62

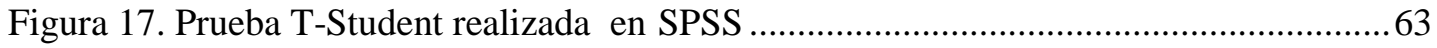

Figura 18. Distrito de procedencia. Distribución de la muestra por cada distrito donde se

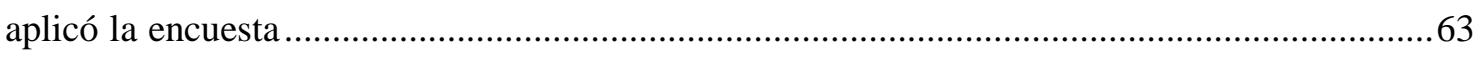

Figura 19. Representación edad. Distribución de la muestra por rangos de edad.................64

Figura 20. Ingreso familiar. Distribución de la muestra por rango de ingreso familiar.......64 
Figura 21. Frecuencia de consumo de chocolates. Pregunta 2. ¿Con qué frecuencia consume chocolates?

Figura 22. Preferencia del lugar de compra. Pregunta 3. ¿Dónde suele comprar chocolates?

Figura 23. Importancia en la característica al momento de compra. Pregunta 4. Al momento de comprar chocolate, ¿a cuál de estas características le da importancia? 66

Figura 24. Intención de compra del producto Chocovit. Pregunta 5. ¿Estaría usted interesado en comprar este producto? 66

Figura 25. Intención de frecuencia de compra de producto Chocovit. Pregunta 6. ¿Con qué frecuencia compraría este producto?

Figura 26. Selección del sabor de gomitas. Pregunta 7. ¿Qué sabor de gomita le gustaría que lleve el producto? Puede elegir más de una opción

Figura 27. Precio que pagaría el potencial cliente. Pregunta 8. ¿Cuánto estaría dispuesto a pagar usted por el producto? 68

Figura 28. Lugar donde compraría Chocovit. Pregunta 9. ¿En qué lugares le gustaría comprar este producto? 68

Figura 29. Proyección de la población de catorce distritos de Lima Metropolitana 2018 a

2027(en número de hogares) 72

Figura 30. Proyección de mercado objetivo: 2018 - 2027 ................................................ 75

Figura 31. Representación gráfica del logo de la empresa ..................................................76

Figura 32. Envase primario de las tabletas de chocolate nutritivo .....................................76

Figura 33. Envase secundario de la presentación de caja por 24 unidades .........................77

Figura 34. Envase secundario de la bolsa pack por 6 unidades ..........................................77

Figura 35. Canales de distribución de marketing (multicanal) .............................................. 80

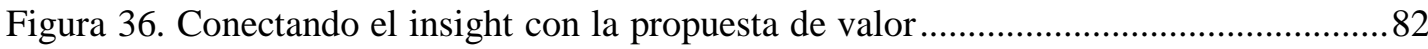


Figura 37. Imagen del fanpage de Chocovit en Facebook ................................................ 84

Figura 38. Flujograma del proceso de elaboración de tabletas de chocolate con gomitas

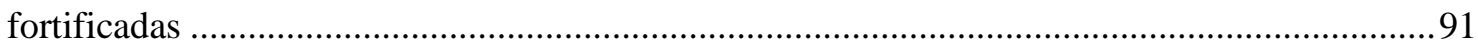

Figura 39. Layout de procesamiento de tabletas de chocolate nutritivo...............................94

Figura 40. Distribución de equipos y maquinarias de planta central...................................95

Figura 41. Distribución de equipos y mobiliario del segundo nivel de la fábrica de

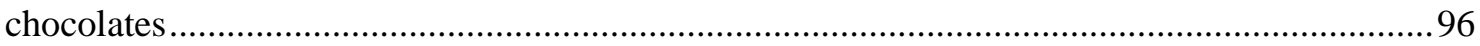

Figura 42. Distribución del área de tránsito del primer nivel de la fábrica de chocolates.. 97

Figura 43. Organización y funciones del Sistema de Gestión de SST ...............................111

Figura 44. Forma geométrica y significado general de las señales de seguridad...............118

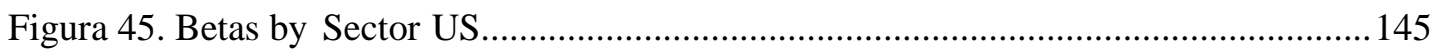

Figura 46. Annual Returns on Stock, T.Bonds and T.Bills: 1928 - Current ......................146 


\section{Capítulo I. Generalidades}

\subsection{Antecedentes}

El cacao y el chocolate.

El cacao es cultivado en el Perú desde la época Pre-Inca, el que fue utilizado para la elaboración de bebidas especiales. Hoy en día se produce principalmente en las zonas de Cusco, Ayacucho, Junín y San Martín, siendo Cusco la que concentra la mayor participación. Esta producción es desarrollada por productores muy pequeños, obteniéndose un rendimiento promedio anual de $400 \mathrm{~kg}$ de grano seco por hectárea por año, convirtiéndose en un exportador pequeño en el mercado internacional. Los grandes productores en el mundo son los países africanos e Indonesia (alrededor del 90\%), seguidos de Brasil y algunos países de Latinoamérica y El Caribe. Sin embargo, el Perú destaca por la producción de los cacaos orgánicos y finos, siendo un contribuyente importante en el mercado internacional (Pomareda, 2013).

En cuanto al mercado mundial de la industria del chocolate, IEES (2016) nos indica que los principales productores de chocolate están ubicados principalmente en Europa. A nivel nacional, IEES (2016) identificó a 128 empresas dedicadas a la producción de chocolates y productos de confitería, ubicadas principalmente en Lima, Cusco e Ica. En menor medida, se identificaron también empresas de este rubro en Arequipa, Cajamarca, Lambayeque, San Martín, La Libertad, Piura y Tacna. En el Perú, destaca la empresa Machu Picchu Trading y Exportadora Romex, que destinan su producción al mercado internacional y Compañía Nacional de Chocolates del Perú, cuya producción se destina a abastecer al mercado interno.

En cuanto a la importación, ésta se concentró principalmente en la partida arancelaria de chocolates y demás preparaciones tal como lo indica IEES (2016) quien reportó que esta partida concentró el 58,8\% del total importado (ver Anexo 1), el principal país donde se 
importan chocolates es Chile (ver Anexo 2) y la principal empresa importadora es ARCOR (ver Anexo 3)

El consumo diario de chocolate rico en cacao puede tener efectos positivos en la salud de las personas, reduciendo los riesgos de enfermedades cardiovasculares, incrementa la actividad antioxidante, modula la función plaquetaria e inflamación, disminuye la presión arterial sistólica y diastólica (Gómez-Juaristi \& Gonzáles-Torres, 2011).

La anemia y la alimentación.

La anemia por deficiencia de hierro se convierte en un problema de Salud Pública a nivel mundial (Selva \& Ochoa, 2011). La Organización Mundial de la Salud (OMS) posicionó a la deficiencia de hierro en el puesto 7 de 10 de los factores de riesgo de enfermedad, discapacidad y muerte.

Según la Organización Mundial de la Salud (OMS) el término "malnutrición” se refiere a las carencias, los excesos y los desequilibrios de la ingesta calórica y de nutrientes de una persona. Se clasifican en tres grandes grupos:

La desnutrición, que incluye la emaciación (un peso insuficiente respecto de la talla), el retraso del crecimiento (una talla insuficiente para la edad) y la insuficiencia ponderal (un peso insuficiente para la edad);

La malnutrición relacionada con los micronutrientes, que incluye las carencias de micronutrientes (la falta de vitaminas o minerales importantes) o el exceso de micronutrientes;

El sobrepeso, la obesidad y las enfermedades no transmisibles relacionadas con la alimentación.

La desnutrición conlleva a un retraso en el crecimiento, insuficiencia ponderal y carencias de vitaminas y minerales. El término para describir la insuficiencia del peso en relación a la talla se llama emaciación, y es la consecuencia de una desnutrición crónica o recurrente, que, 
dependiendo de la gravedad, podría ocasionar hasta la muerte. Esto como consecuencia de muchos factores, como las malas condiciones socioeconómicas (OMS).

Es necesario una adecuada ingesta de vitaminas y minerales, para producir enzimas, hormonas y otras sustancias esenciales para un adecuado crecimiento. Siendo el yodo, la vitamina A y el hierro de los más importantes.

La deficiencia de hierro es la carencia específica de micronutrientes más extendida y la principal causa de anemia en lactantes, niñas y niños hasta cinco años, en especial los menores de 24 meses (Selva \& Ochoa, 2011). La anemia es definida por la OMS como una concentración de hemoglobina por debajo de los niveles límites de referencia para la edad, sexo y tiempo de embarazo.

En el Perú, los niveles de anemia son altos, (es uno de los más afectados a nivel Sudamérica), a pesar de que el índice de pobreza ha disminuido en los últimos años. El porcentaje de niños menores de 5 años, afectados por esta enfermedad, va alrededor del $34 \%$. Los factores socio demográficos asociados a la anemia en el Perú, en niños menores de 3 años, son el vivir fuera de Lima y Callao, en un hogar de nivel socio económico bajo, tener madre adolescente y con bajo nivel educacional, falta o corto período de suplementación de hierro durante el embarazo, etc. La causa principal de anemia en la infancia es la deficiencia de hierro, aunque también pueden deberse a otras causas (Velásquez \& Gonzales, 2013).

De acuerdo a los autores Pajuelo, Miranda y Zamora (2015) la deficiencia de la vitamina A (DVA) es un problema de salud pública que perdura en el tiempo, siendo los más afectados los niños que viven en las áreas rurales y en la selva, y que es necesario mejorar la eficiencia e impacto de los programas de suplementación con Vitamina A y hierro. El estudio concluye que la prevalencia encontrada en DVA y deficiencia de hierro (AN) en niños menores de 5 años en el Perú, y que la causa de la AN es multifactorial, siendo de las más reconocidas la deficiencia de micronutrientes, como el hierro, la vitamina A, vitamina B12, folatos. 
Otras investigaciones concluyen que, existe un mayor riesgo de desarrollar una enfermedad respiratoria crónica (ERC) en los niños con anemia ferropriva y ferropenia. Se requiere de una buena nutrición para tratar a los pacientes con enfermedades crónicas, ya que algunas pueden ser de carácter grave. Un mal manejo nutricional propicia que enfermedad se siga desarrollando (Barja et al., 2013).

La anemia es también causa de una menor productividad y de un menor desarrollo cognitivo, afectando la calidad de vida.

El hierro hemínico.

En la naturaleza, el hierro $(\mathrm{Fe})$ se encuentra en dos formas químicas diferentes, la iónica y la hemínica, cuya fuente fundamental es la hemoglobina de la sangre. En Cuba se ha desarrollado productos anti anémicos a partir de sangre bovina, los que han demostrado ser más eficaces que los preparados a base de Fe iónico (García et al., 2013).

Dentro de los productos no hemínicos o iónicos se tiene alimentos de origen vegetales y el huevo. El hierro de origen hemínico posee mayor biodisponibilidad que el hierro no hemínico, es decir, logra ser más eficaz. El uso del hierro iónico ha sido más popular que el hierro hemínico por diversas razones, como el rechazo al uso de un producto a base de sangre animal, por cuestiones religiosas, éticas o regulatorias, sumado además la dificultad técnica para la recolección en condiciones estériles y la necesidad de contar con tecnología para su procesamiento.

En Cuba existen algunos productos a base de hierro hemínico como el Trofin, el NeoTrofin y NeoTrofinC, disponibles en tabletas, los que han demostrado una eficacia del 90\%, no reportándose reacciones adversas gastrointestinales.

Vitamina C.

La vitamina $\mathrm{C}$ se encuentra en algunas frutas y vegetales, tales como los cítricos, guayabas, kiwis, pimentón, brócoli y coles, son ejemplos de algunos vegetales. No se 
reportan efectos adversos significativos por la ingesta de la vitamina C. Los efectos adversos más comunes son gastrointestinales, pero debido al exceso en la ingesta de la vitamina C. La vitamina C ayuda a la absorción del hierro. (García-Casal et al., 2013).

Las infecciones respiratorias son motivo frecuente de visitas al pediatra, en especial en los meses de invierno. Afecta a los niños, con pérdidas en los estudios, hospitalización, etc. El grupo de niños más afectado es el menor a los 2 años de edad, dependiendo de la gravedad, podría llegar hasta la muerte.

Para un efectivo y eficiente tratamiento de las enfermedades respiratorias, la suplementación profiláctica con betaglucanos procedentes de P.ostreatus y vitamina C es beneficiosa, particularmente en niños con un factor recurrente (Sapena, Picó et al., 2015) Zinc.

En los años 60, el zinc fue reconocido como oligoelemento necesario para la nutrición humana. Previamente el zinc se había utilizado como nutriente esencial para la mejoría de plantas y animales. Hoy en día, este elemento adquiere una especial connotación en niños con DEN Desnutrición (Hernández \& Izquierdo, 2009).

La cantidad de zinc en el organismo no solo depende de la cantidad que se consume sino también de la biodisponibilidad en los alimentos o dietas. Algunos facilitadores que ayudan en su absorción son las proteínas como las carnes rojas, pescados y aves. No se han reportado efectos adversos por consumo excesivo de zinc proveniente de alimentos, pero si se han reportado algunas alteraciones por exceso de consumo crónico de suplementos de zinc que incluyen la deficiencia de cobre y con menos frecuencia la supresión de la respuesta inmunitaria y la disminución de lipoproteínas de alta densidad (García-Casal et al., 2013).

De acuerdo a los autores Hernández \& Izquierdo (2009), en una investigación realizada en lactantes desnutridos, la suplementación con zinc acelera la recuperación nutricional, 
disminuye el número y la duración de los eventos infecciosos, el consumo de antibióticos y el uso de la UTIP.

El Zinc cumple funciones estructurales, catalíticas y reguladoras indispensables para muchos sistemas biológicos. El Zinc participa como elemento estructural de numerosas enzimas, y es un estabilizador de estructuras a nivel de los constituyentes subcelulares y sus membranas. Este mineral es parte fundamental de numerosas metaloenzimas, y también activador de muchas otras. Está demostrado el papel esencial del Zinc en la transcripción y traducción de los polinucleótidos, y por lo tanto, en el proceso de la expresión genética. Es, además, un estabilizador de las membranas biológicas, participa en la unión de las proteínas a tales estructuras, e impide la peroxidación lipídica de determinados tejidos mediante la inhibición de radicales libres. (Hernández \& Izquierdo 2009, p. 282).

\subsection{Determinación del problema u oportunidad}

Hay que destacar que, desde el inicio de este siglo, el análisis de las fuentes de información ha permitido constatar año a año, que la mayor parte de las políticas públicas carece de sentido ante la realidad social en la que se desenvuelve más del 50\% de la población peruana. No es en vano mencionar que aquel niño o niña bien alimentado, con altos niveles de inmunización ante enfermedades crónicas y agudas, y con grados educativos acordes para su edad junto con capacidad intelectual de buen nivel, elimina en el largo plazo aquella posibilidad de generar pobreza en un nivel adulto. El Perú no es ajeno a esta realidad, y hoy en día hay una preocupación constante con relación al problema de la anemia y la desnutrición en los niños, preocupación que se ha expresado y materializado en el documento "Plan Nacional para la reducción de la desnutrición crónica infantil y la prevención de la anemia en el país para el período 2017 - 2021”. El objetivo principal que se ha esbozado en el plan, ha sido el "promover el desarrollo infantil como una inversión pública en el capital 
humano del país para permitir el progreso económico y social de todos los peruanos, con inclusión y equidad social".

Por otro lado, hace unos años, se viene apreciando un crecimiento en el consumo de productos saludables a nivel mundial. El Perú no se ha quedado atrás en este sentido, no solo en el ámbito de los alimentos, sino también en la compra de productos cosméticos elaborados a base de ingredientes naturales. Los productos orgánicos están abriéndose mayor mercado a nivel nacional, entendiéndose que existe una fuerte preocupación por el cuidado de la salud y el medio ambiente.

Según un estudio realizado por la asociación internacional Unión para el Biocomercio Ético (UEBT) más del 90\% de los peruanos demanda a las empresas de alimentos, bebidas y cosméticos información sobre cómo se abastecen de los ingredientes naturales (Ortiz, 2012).

En el caso particular de la industria del chocolate, son muy pocos los productos que cumplen con el porcentaje mínimo para considerárseles como tal. Es un mercado que ofrece predominantemente golosinas, según lo indicó el Ministerio de Agricultura y Riego (MINAGRI) en los últimos días (Villar, 2017). El porcentaje mínimo que indica la nueva reglamentación es de $35 \%$ de cacao y del $25 \%$ de cacao si se trata de chocolate con leche.

Asimismo, puede considerarse una oportunidad la falta de competencia. Se ha investigado, y en el mercado peruano existe solo un producto de chocolate fortificado con hierro. El producto, materia de estudio que plantea este proyecto, tiene el valor agregado de, no solo otorgar fortificación con el hierro, que incrementará los niveles de hemoglobina en la sangre en los niños, reduciendo riegos como anemia, desnutrición, desaceleración del desarrollo cognitivo y crecimiento; sino que tendrá vitamina $\mathrm{C}$ y Zinc.

Con el refuerzo de la vitamina $\mathrm{C}$ se logra en el organismo, tener una mayor defensa para las enfermedades, en especial para las enfermedades respiratorias, que afectan a los niños en 
etapa pre escolar, y dependiendo de la magnitud de estas, pueden llegar hasta producir la muerte.

Por otro lado, el zinc es un complemento que ayuda en la recuperación nutricional y a mantener una salud estable.

Una oportunidad además para la ejecución de este proyecto, es que el Gobierno Peruano junto con organismos internacionales, están apoyando las iniciativas que se forjan en el país para las mypes, a través de cursos de capacitación para una mejor producción, de calidad, con eficiencia, para certificarse u homologarse y convertirse en proveedores con altos estándares de calidad, competitivos a nivel mundial. Para el caso del cacao, el gobierno está promoviendo la producción de cacao de calidad y la formación de valor agregado.

Crear y desarrollar un producto saludable, a base de cacao y gomitas fortificadas con hierro, zinc y vitamina C para niños comprendidos entre 3 y 10 años.

\subsection{Justificación del proyecto}

El plan de negocio se enfoca a la instalación de una fábrica de chocolates nutritivos, en su etapa inicial se orientará a la elaboración de tabletas de chocolate con leche con incrustaciones de gomitas masticables de jugo concentrado de frutas fortificadas con hierro, zinc y vitamina $\mathrm{C}$, en la siguiente etapa se innovarán los productos para asegurar un posicionamiento manteniendo la línea de productos nutritivos. El segmento de mercado es principalmente niños en la etapa pre-escolar y escolar (el rango de edad va de 0 a 10 años) pero este producto es apto para el público en general. El chocolate con leche va cumplir con las especificaciones del Codex Alimentario Internacional de la FAO/OMS (1981) quien indica que:

El chocolate con leche deberá contener, en relación con el extracto seco, no menos del $25 \%$ de extracto seco de cacao (incluido un mínimo del 2,5\% de extracto seco magro de 
cacao) y un mínimo especificado de extracto seco de leche entre el 12\% y el 14\% (incluido un mínimo entre el 2,5\% y el 3,5\% de materia grasa de la leche). (p. 2).

Con este plan de negocio se desea ofrecer al consumidor un verdadero chocolate que además contribuye con su salud al contener vitaminas y minerales, para desterrar de su mente que el chocolate es una golosina.

La fábrica que se plantea va comprender todos los procesos de producción para la transformación del cacao en tableta de chocolate con leche, iniciando por el tostado del grano, descascarillado, molienda, refinado, temperado y tableteado. El grano de cacao se va comprar a comunidades nativas a las que se les ofrecerá un precio justo con respecto a la calidad de su grano para incentivarlos a que trabajen bajo estándares de calidad en la cosecha, fermentado y secado del grano, así le darán un mayor valor a su materia prima. Con esto se quiere promover el consumo del cacao peruano no sólo para que la población disfrute de su fino aroma y sabor, sino también para que se beneficien en la salud.

El chocolate está entre los alimentos concentrados en polifenoles, particularmente en flavonoides como procianidinas, catequinas y epicatequinas. Un grupo creciente de evidencias sugieren que el consumo regular de los productos del cacao o el uso de sus principios activos como agentes terapéuticos podrían influir favorablemente en la lucha contra las enfermedades cardiovasculares e incluso en otras patologías como el cáncer (Gutiérrez, 2002, p 149).

En el Perú, hay un alto nivel de desnutrición para lo cual la tableta de chocolate nutritiva se presenta como una alternativa para prevenir la enfermedad y evitar que ésta vaya en aumento en nuestro país. Se eligió chocolate y gomitas por ser productos de confitería con mayor aceptación por la población infantil. Pierdant \& Gordillo (2014) indicaron que el hierro que contienen las gomitas de grenetin enriquecidas fue absorbido y bien tolerado. Estas gomitas contenían $69 \mathrm{mg}$ de hierro, 294 mg de ácido ascórbico y ácido fólico y fueron 
aplicadas a 10 voluntarios en la ciudad de México. Esto demuestra que la vitamina $\mathrm{C}$ y el hierro aplicados en gomitas tienen buena absorción en seres humanos. Los productos elaborados con cacao que son fortificados con hierro también han presentado buena absorción, tal como indica Quijano (1998) que después del consumo de la cocoa fortificada con hierro el $83 \%$ de la población en estudio se recuperó del estado anémico. Dicha cocoa contenía 66.6 mg de hierro y se les suministró a 74 niños en la etapa escolar del poblado Alto Shumbuyacu, Lamas, San Martín. El producto antes mencionado fue sometido a otro estudio, la población fueron niños de 12 a 36 meses de la zona rural de Tabalosos (San Martín) con estado anémico y adelgazados a quienes se les suministró por 10 semanas $5 \mathrm{~g}$ de cocoa fortificada al día. Delgado (2001) indica que en anemia hubo una tasa de recuperación del 73\%. El indicador Peso / Talla mostró un incremento absoluto promedio de $0.8 \mathrm{Kg}$.

El plan de negocio de diseño e instalación de una fábrica de chocolates nutritivos presenta un mercado potencial que va en aumento, Euromonitor International (2016) indica que el valor de ventas de la industria de chocolatería a precio constante al 2016 se espera un crecimiento a CAGR (tasa anual compuesta de crecimiento) de $4 \%$ del mismo periodo, mientras que el volumen de ventas se espera un crecimiento a CAGR de $3 \%$. Asimismo, se destaca que este plan de negocio se enfoca en ofrecer al consumidor un producto que sea agradable al paladar y saludable.

Misión

Fomentamos la nutrición saludable a través de nuestros productos a base de cacao y súper alimentos para contribuir con la mejora de la calidad de vida de los hogares peruanos.

Visión

Ser líder en la industria chocolatera peruana ofreciendo a nuestros clientes productos saludables y agradables al paladar. 
Factor de diferenciación

El factor de diferenciación del producto es "Un chocolate que alegra y nutre a tu hijo, cerca de ti"

Factor de posicionamiento

Producto nutritivo y agradable al paladar de los niños. Fortificado con micronutrientes como el hierro, vitamina $\mathrm{C}$ y zinc. Agradable al paladar de los niños por las gomitas de jugos de pura fruta.

No tiene un límite máximo de consumo por día.

Cumple con el porcentaje de cacao requerido por la nueva legislación para el chocolate de leche.

Chocolate elaborado con 100\% cacao, asegurando una buena calidad.

Disponibilidad y al alcance del cliente, presencia en supermercados, mayoristas, tiendas especializadas y bodegas.

1.4. Objetivos generales y específicos

Objetivo General.

Crear y desarrollar un producto saludable a base de cacao con gomitas fortificadas con hierro, zinc y vitamina $\mathrm{C}$, a través de la instalación de una fábrica de chocolates.

Objetivos Específicos.

Financiero

o Evaluar la viabilidad financiera del proyecto, obteniendo indicadores positivos (VANE, VANF $>0$, TIRE $>$ WACC, TIRF $>$ COK).

o Ser una empresa rentable, logrando como mínimo un ROE del $10 \%$.

o Ser una empresa que cuente con liquidez, obteniendo una liquidez corriente y prueba ácida con valores superiores a 1 .

o Optimizar costos. Mantener un margen mínimo del 25\% 


\section{Comercial}

o Obtener 3\% de participación en el mercado.

o Elaborar el plan de marketing para el lanzamiento del producto e implementarlo como mínimo al $90 \%$.

o Incrementar las ventas en un $3 \%$ anual.

o Realizar por lo menos una (01) alianza estratégica con alguna comunidad productora de cacao

o Ofrecer al mercado un producto de calidad que cumpla con los requisitos de la nueva regulación, las tabletas de chocolate tendrán 50\% de cacao.

o Obtener el $10 \%$ de las ventas por el canal directo (página web)

\section{Recursos Humanos}

o Cumplir los requisitos legales y regulatorios que apliquen a la empresa: DL728, Ley 29783, etc., logrando obtener cero (0) multas por incumplimientos.

o Proveer, mantener y desarrollar un recurso humano calificado y motivado para el logro de los objetivos de la empresa, teniendo que, el $100 \%$ de los colaboradores tengan una calificación mínima del $80 \%$ en la evaluación de desempeño anual.

o Implementar el 100\% de las Descripciones de Puestos por Competencias

o Implementar el $100 \%$ del sistema de compensación y beneficios

o Retener el talento humano. Rotación de personal no mayor al 10\% anual.

Producción y Tecnología

o Estandarizar y documentar el $100 \%$ de los procesos operativos, comerciales y administrativos.

\section{Logística}

o Negociar buen precio del cacao, $15 \%$ de descuento. 
o Negociar buen precio maquinaria, $5 \%$ de descuento.

o Negociar buen precio materia prima y empaques, $10 \%$ de descuento.

o Asegurar el abastecimiento de las gomitas y del cacao con buena calidad

o Implementar el $100 \%$ del Plan de mantenimiento preventivo

o Implementar el $100 \%$ de la herramienta de gestión de inventarios

o Implementar proceso de evaluación de proveedores. Proveedores calificados con nota mínima de 14.

1.5. Alcances y limitaciones de la investigación

Alcances.

El producto está dirigido a niños, teniendo mayor relevancia en población vulnerable a adquirir anemia: niños, mujeres embarazadas y en etapa de lactancia. El producto será distribuido en la ciudad de Lima.

La localización de la fábrica será en Lima Metropolitana.

Limitaciones.

No se va realizar estudios de biodisponibilidad de vitaminas y minerales en seres humanos porque el producto se ha desarrollado en base a estudios científicos previos.

\section{Capítulo II. Descripción de la empresa}

\subsection{Reseña de la empresa}

La empresa por constituir es una Sociedad de Responsabilidad Limitada (S.R.L.), conformada por tres socios, Sra. Andrea Gisella Mora Félix, de nacionalidad peruana, identificada con número de identidad nacional 40346765 y domiciliada en Calle 24 N²90 Dpto.301 Urbanización Córpac San Isidro, Sra. María Alejandra Rodríguez Rodríguez, de nacionalidad peruana, identificada con número de identidad nacional 43213785 y domiciliada en Calle Botticelli $N^{\circ} 134$ Dpto. 302 San Borja y Srta. Silvia Patricia Rodríguez Aliaga de nacionalidad peruana, identificada con número de identidad nacional 46144642 y domiciliada 
en Avenida Pershing 146, letra D, Magdalena del Mar. La razón social de la empresa será MARAN S.R.L y el nombre de la empresa y marca del producto será Chocovit.

\subsection{Estructura organizacional}

La estructura organizacional de la fábrica de chocolates nutritivos se encuentra en la Figura 1. Esta tiene una estructura vertical e integral; a la cabeza se encuentra el gerente general apoyado por el asistente de gerencia y supervisa a los jefes. El jefe de mantenimiento tiene a su cargo dos auxiliares de limpieza, uno para la fábrica y otro para oficinas; el jefe de logística cuenta con apoyo de un asistente, quien supervisa a los operarios de almacén (3); el jefe de producción supervisa a un asistente de laboratorio fisicoquímico, un asistente de laboratorio microbiológico y dos auxiliares de producción, éstos últimos tiene a su cargo 17 operarios. El jefe de administración y gestión humana contará con un asistente y el jefe comercial delegará algunas funciones al vendedor de Lima, quien tendrá a su cargo dos mercaderistas una para el área de supermercados y una para bodegas o tiendas especializadas.

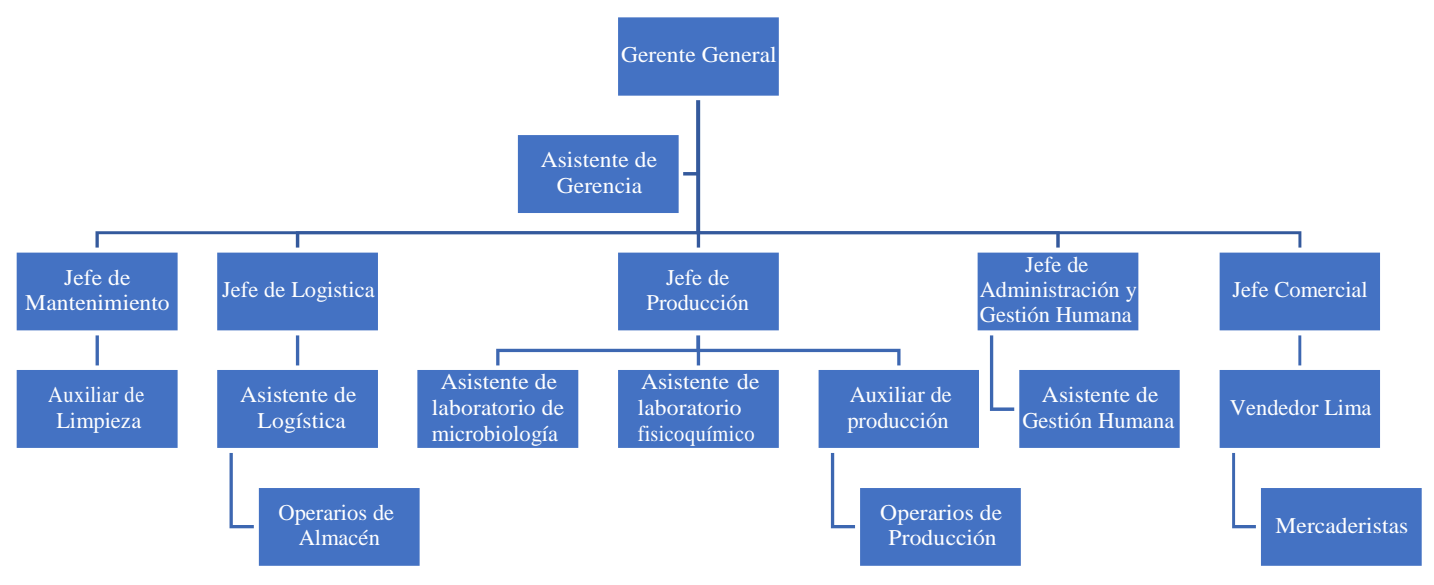

Figura 1. Organigrama de la fábrica de chocolates nutritivos. Fuente: elaboración propia. 


\subsection{Producto y/o servicio}

\subsubsection{Ciclo de vida del producto y/o servicio.}

El producto se encuentra en desarrollo y el segundo año del proyecto estará en introducción.

\subsubsection{Características del producto y/o servicio.}

El producto que se va elaborar es una tableta de chocolate de leche con incrustaciones de gomitas fortificadas con hierro, vitamina $\mathrm{C}$ y zinc, estas gomitas tendrán jugo concentrado de frutas, en el estudio de mercado se definirá el sabor de mayor preferencia, las alternativas a elegir son guanábana, maracuyá, naranja, piña, aguaymanto, limón y sauco.

Estas tabletas pesarán $30 \mathrm{~g}$ y tendrán dos presentaciones para la venta al público en supermercados, las cuales son bolsa pack por 6 unidades con un precio de S/ 11.80 Soles y caja de 24 unidades a S/ 45.76 Soles. En bodegas y tiendas de productos naturales la presentación será por unidad a un precio de S/2.00 Soles.

Las características fisicoquímicas, microbiológicas y sensoriales del producto se encuentran en la ficha técnica del Anexo 4.

\section{Capítulo III. Estructura económica del sector}

\subsection{Análisis del contexto actual y del esperado}

\subsubsection{Análisis político-gubernamental}

Panorama general.

En la actualidad política peruana, el entorno está bastante convulsionado. El gobierno de PPK ya tiene más de un año gobernando, y en este tiempo se han dado una serie de acontecimientos que le dan inestabilidad política al país, como la huelga de los maestros acatada a nivel nacional que duró poco más de dos meses, la huelga de médicos, las censuras y salidas de ministros por diversas razones, entre otros. Desde que inició el Gobierno de PPK han salido: Mariano Gonzales (Defensa) por escándalo amoroso, Jaime Saavedra (Educación) 
fue interpelado y censurado por el Congreso de mayoría fujimorista por supuestas irregularidades en la compra de computadoras y malos manejos públicos, Martin Vizcarra (Transportes y Comunicaciones) presentó su renuncia por supuestas irregularidades en la licitación para la construcción del aeropuerto de Chincheros en Cusco. Este caso Chinchero también se propició la salida de Alfredo Thorne (Economía), según indicó Redacción Perú 21 (mayo 2017). La última crisis política se dio con el cambio de gran parte del Gabinete Ministerial en el mes de setiembre 2017.

La corrupción.

La corrupción es un mal que no solo ataca al Perú sino a varios países en América Latina. La ciudadanía reclama combatirla, ya que son los principales afectados. Las amenazas transnacionales requieren respuestas multilaterales y cooperación internacional. El Gobierno Peruano ha asumido la responsabilidad de encarar ese desafío. Ha logrado que el tema central de la Cumbre de las Américas que se realizará en Lima, en abril 2018, sea gobernabilidad democrática y lucha contra la corrupción. La agenda plantea identificar las medidas que sean objeto de análisis y debate presidencial en la cumbre continental. El objetivo fundamental es que el encuentro de los jefes de Estado americanos en Lima constituya un avance significativo para combatir con éxito la epidemia de corrupción extendida a través de toda la región, según señaló el Centro de Noticias de la Organización de Estados Americanos [OEA] (2017).

El caso de corrupción más sonado en los últimos tiempos en el Perú es Odebrecht, o también llamado Lava Jato. El gigante brasilero de la construcción repartió alrededor de US\$ 788 millones dólares en sobornos en Brasil y otros once países, que incluye a Perú, obteniendo más de 100 contratos que le generaron ganancias por US\$ 3,300 millones. Odebrecht financió campañas presidenciales no solo en Brasil sino en varios países en América Latina. Lava Jato es la mayor operación en la lucha contra la corrupción en la 
historia de Brasil. Se han abierto denuncias contra empresarios y políticos y también se han visto involucrados los ex presidentes Lula Da Silva y Dilma Rousseff. En el Perú, muchos políticos están involucrados en el Caso Odebrecht, como Félix Moreno y Gil Shavit, por la ampliación de la Costa Verde, el ex presidente Alejandro Toledo, por la Carretera Interoceánica, Alan García, Enrique Cornejo, Oswaldo Placencia, entre otros por la Línea 1 del Metro de Lima. (RPP, 2017).

Ante los casos de corrupción que se vienen dando en los últimos años, el gobierno de PPK ha firmado la ley de imprescriptibilidad de los delitos de corrupción, la que fue aprobada por el Congreso de la República en el mes de agosto. La norma permite que los funcionarios, servidores públicos o particulares que cometan delitos de corrupción sean perseguidos por la justicia hasta que se aclare su responsabilidad o no en el proceso. Se aplica tanto para corruptores, como corrompidos, así como a terceros que resulten responsables. La imprescriptibilidad se aplicará “en los supuestos más graves”. Entre estos podrían estar el cohecho, peculado, colusión, negociación incompatible, abuso de autoridad, malversación, tráfico de influencias y enriquecimiento ilícito. (Diario Gestión, 2017).

Otras políticas del gobierno.

Mayor acceso y calidad de los servicios sociales para los pobres: Se han logrado avances significativos en relación a esta medida, según información del Banco Mundial en el Perú (2017), particularmente en las áreas asociadas a la seguridad, educación y salud básica. La cobertura de programas de redes de salud como el programa Juntos aumentó de 700 a 900 distritos, incluyendo ahora a los distritos más pobres del país. En educación, el Banco Mundial apoyó en la implementación de un sistema de evaluación basado en el aprendizaje de los alumnos, entre otros. El acceso a los servicios de administración de justicia también ha mejorado mediante el establecimiento de centros de ayuda legal. 
Conectando a los pobres con los servicios y los mercados: La cobertura y la calidad de los servicios de agua y desagüe han mejorado tanto en áreas urbanas como rurales. El Programa de Transporte Rural Descentralizado rehabilitó 3,277 kilómetros de carreteras rurales, lo que ha reducido el tiempo de viaje a las escuelas en $24.2 \%$. Además, se incorporó un modelo de electrificación rural financiado por el Banco para el desarrollo continuo. Se aprobó un préstamo por US\$300 millones dólares para la construcción de la Línea 2 del Metro de Lima.

Gobernanza inclusiva y desempeño de la administración pública: El apoyo del GBM se ha enfocado en el fortalecimiento de la gestión fiscal y las inversiones públicas a nivel nacional e internacional. Los resultados iniciales han sido alentadores. El GBM también ha estado trabajando con el Ministerio de Economía y Finanzas para definir una estrategia para analizar el ciclo de inversión a nivel regional y para hacer recomendaciones orientadas a reducir obstáculos y costos transnacionales, con vistas a mejorar la eficiencia de las inversiones públicas (Banco Mundial, 2017).

Medidas del Gobierno contra la anemia.

A nivel político, el Estado Peruano tiene interés de disminuir los niveles de anemia producto de la desnutrición en el entorno nacional. Es por ello que se cuenta con el "Plan Nacional para la reducción de la desnutrición crónica infantil y la prevención de la anemia en el país para el período 2017 - 2021”, cuyo objetivo planteado es el de reducir la anemia y desnutrición infantil en especial en las familias con las niñas y niños menores de tres años y gestantes.

La situación actual se detalla a continuación (ver Tabla 1), tomado del documento referido del Ministerio de Salud (MINSA). 
Tabla 1.

Metas de Reducción Nacional de Desnutrición y anemia infantil 2016 - 2021.

\begin{tabular}{|c|c|c|c|}
\hline & 2015 & 1er Sem 2016 & META 2021 \\
\hline \multicolumn{4}{|l|}{ Anemia } \\
\hline Niños 6-35 meses & $\begin{array}{l}43.50 \% \\
\text { (6 de cada } 10 \text { entre } 6 \\
\text { y } 18 \text { meses) }\end{array}$ & $\begin{array}{l}43.60 \% \\
(53.2 \% \mathrm{R} / \\
39.8 \% \mathrm{U})\end{array}$ & $19.0 \%$ \\
\hline \multicolumn{4}{|l|}{$\begin{array}{l}\text { Desnutrición } \\
\text { crónica }\end{array}$} \\
\hline Menores de 5 años & $14.40 \%$ & $13.50 \%$ & $6.4 \%$ \\
\hline Área rural & $27.70 \%$ & $27 \%$ & \\
\hline Área urbana & $9.20 \%$ & $8 \%$ & \\
\hline
\end{tabular}

Según la OMS, la anemia se convierte en un problema de salud pública cuando el porcentaje es superior al $20 \%$.

Dentro de los objetivos del plan nacional está el de tratar de y prevenir la anemia con suplementos de hierro, ya sea en gotas, jarabe o pastillas, y fortificación casera.

Además, dentro del plan nacional se ha establecido indicadores de seguimiento de las intervenciones (cobertura) para el logro de la meta.

\subsubsection{Análisis económico}

\section{Panorama general.}

El Perú ha tenido un crecimiento sostenido de la economía en los últimos 10 años, uno de los de más rápido crecimiento en toda la región, con una tasa promedio de $5.9 \%$ en un contexto de baja inflación. Todo esto como consecuencia de un entorno favorable y políticas macroeconómicas prudentes y reformas estructurales. Además, el sólido crecimiento del empleo e ingresos redujo las tasas de pobreza (6.5 millones de personas dejaron de ser pobres entre el 2005 y el 2015). El crecimiento del PBI tuvo una aceleración en el 2016, debido a que una serie de proyectos mineros de gran tamaño entraron a la fase de producción, sin embargo, para el 2017 se espera una desaceleración debido a una estabilización en el sector 
minero y una débil inversión privada. La inversión privada se ha visto afectada en este año por las condiciones globales adversas y la incertidumbre relacionada con los escándalos de corrupción de los proyectos firmados en años anteriores. (Banco Mundial, 2017)

Según el Banco Mundial, además, las proyecciones de crecimiento de la economía peruana son vulnerables a los impactos externos en relación a los precios de los commodities, la desaceleración de la economía de China, volatilidad de los mercados de capital, la velocidad de ajuste de la política monetaria en los Estados Unidos y a cuestiones climática como el Fenómeno del Niño.

Por el lado de la economía global, de acuerdo al MEF (2017), los factores detrás del fuerte crecimiento global son: el fuerte crecimiento en China (2016: 6.7\% vs 1S2017: 6.9\%) impulsado por la aceleración de la inversión privada y la producción industrial. Y que se ha acelerado el dinamismo en la zona Euro (de 1,9\% en el 1T2017 a 2,1\% en el 2T2017) ante el mayor crecimiento de la inversión y la consolidación del mercado laboral.

En la Figura 2 se muestra la evolución de la actividad económica global entre los meses de enero 2014 a mayo 2017. La actividad económica se mantiene al alza y los indicadores de confianza señalan que esta tendencia continuará en los próximos meses.

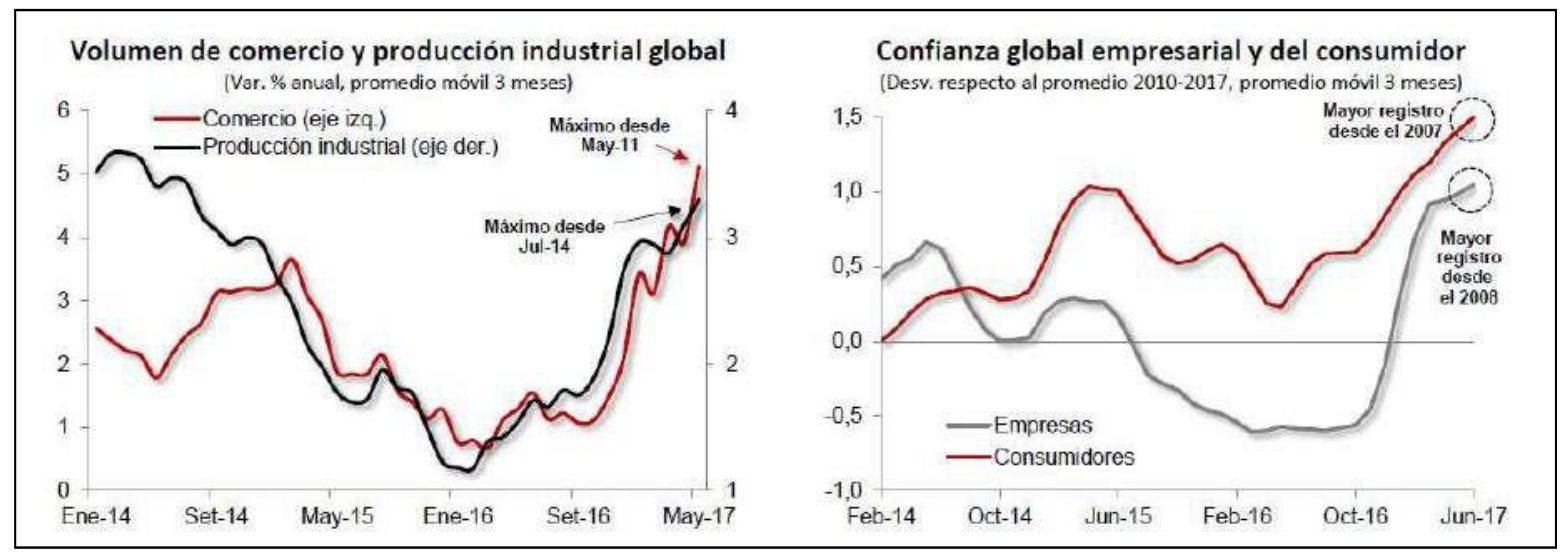

Figura 2. Actividad económica global. Tomado de "Panorama Económico, Agosto 2017", por el Ministerio de Economía y Finanzas (MEF), 2017. Recuperado de https://www.mef.gob.pe/contenidos/archivosdescarga/panorama_economico_14082017.pdf 
Por el lado del Ministerio de Economía y Finanzas, en su documento técnico Marco Macroeconómico Multianual (MMM) 2018 - 2021, la economía peruana se encuentra en fase de recuperación, la que se caracteriza por la implementación de una política macroeconómica contra cíclica, la disipación de los choques adversos y un contexto internacional favorable. Se estima que el PBI tendrá un crecimiento del 2.8\% en el 2017 y se acelerará a 4\% en el 2018. La estrategia de la recuperación se tiene planeada en tres fases:

Fase 1. Segundo semestre del 2017: Con una política fiscal expansiva orientada principalmente a la reconstrucción y al despliegue de infraestructura de los Juegos Panamericanos. Esto lograría que la economía crezca en un 3.2\% en el segundo semestre del 2017. Esta expansión fiscal dinamiza la actividad económica y mejora las expectativas de los agentes económicos.

Fase 2. 2018: Se iniciará con el fuerte impulso del 2017 con un crecimiento del 5\% del PBI desestacionalizado anualizado en el cuarto trimestre. Para el 2018, se espera una aceleración de la inversión pública (17.5\%). Y se estima que la inversión privada crecerá $3.5 \%$ en el 2018, luego de cuatro años de contracción, en un contexto de mayores precios en los metales y avance de grandes proyectos de infraestructura y mineros.

Fase 3. Consolidación de la recuperación 2019 - 2021. Se espera que la economía alcance su potencial de crecimiento del $4 \%$, en un contexto de retiro gradual del impulso fiscal, mayor dinamismo del sector privado y condiciones externas favorables.

En la Figura 3 se presenta el avance físico de obras públicas e inversión del gobierno en general y el impacto de la inversión pública sobre la inversión privada lo que lleva como consecuencia al impulso del despliegue fiscal 


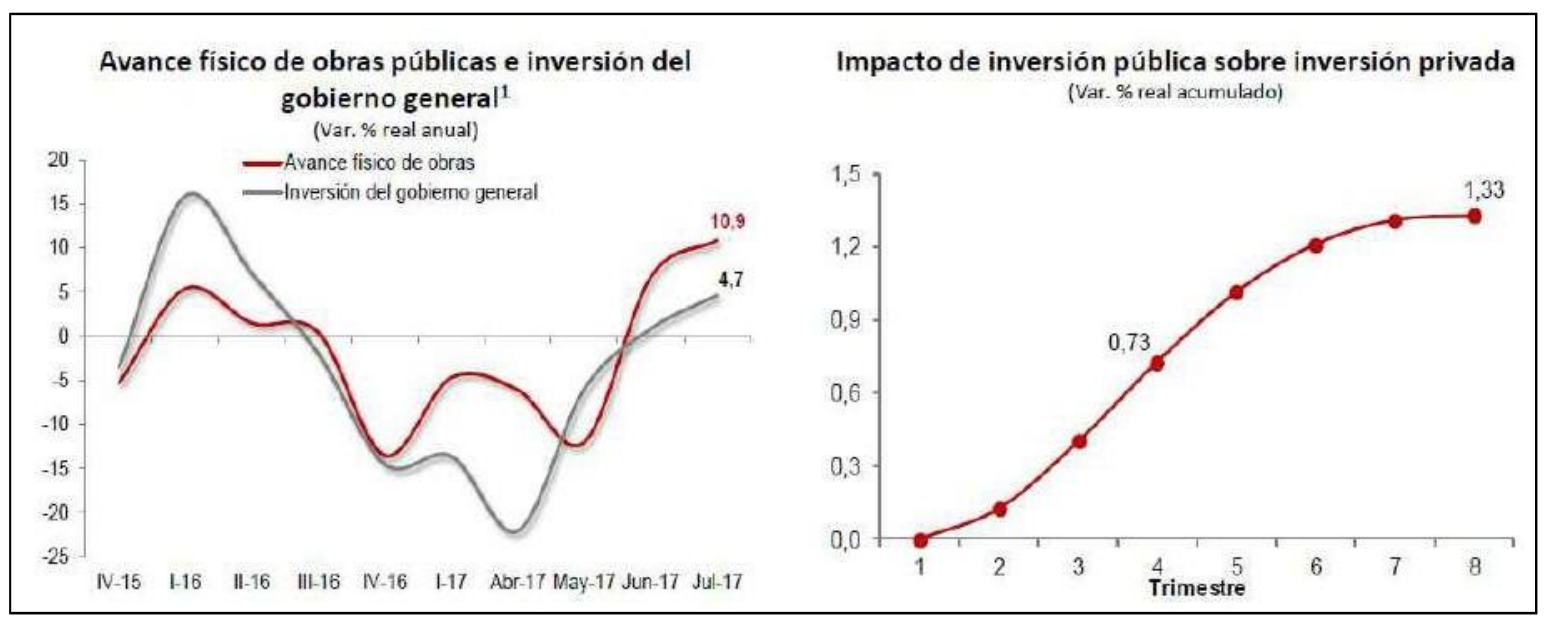

Figura 3. Políticas de impulso fiscal. Tomado de "Panorama Económico, Agosto 2017”, por el Ministerio de Economía y Finanzas (MEF), 2017. Recuperado de Recuperado de

https://www.mef.gob.pe/contenidos/archivos-descarga/panorama_economico_14082017.pdf

Evolución del PBI.

De acuerdo a cifras del Ministerio de Economía y Finanzas [MEF] (2017), la economía peruana habría crecido alrededor del 3\% en mayo, con lo cual, se habría acumulado 94 meses de crecimiento ininterrumpido, acumulando una expansión del 2\% en los primeros 5 meses del año y de $3 \%$ en los últimos doce meses. Luego de los primeros meses del año, en que se dio el Fenómeno del Niño, mayo presentó un crecimiento importante. Se espera un repunte importante de la actividad comercializadora y de servicios, en especial en la zona norte del país.

Para el sector primario, destaca el elevado crecimiento del sector pesquero (+280\%) por la mayor captura de anchoveta. Por el lado agropecuario, se estimada una caída del 2\%, lo que refleja en parte, los efectos de El Niño Costero.

La aceleración económica se sostendría en todo el 2017, impulsado por una mayor inversión pública. El Ministro de Economía, Fernando Zavala señaló que "esta estimación nos indica que la economía estaría dejando atrás los severos choques que recibió a inicios de año como son El Niño Costero y Lava Jato; sin embargo, es imprescindible apuntalar y 
acelerar este ritmo de expansión lo antes posible para generar puestos de trabajo formales y reducir las brechas sociales existentes".

En la Figura 4, se muestra el PBI en el primer trimestre del 2017 y las proyecciones estimadas para el resto del año.

\begin{tabular}{|c|c|c|c|c|}
\hline Componentes & $1 T 2017$ & Jun-17 & $2 T 2017$ & \multirow{15}{*}{$\begin{array}{l}\text { Dato estimado/proyectado. } \\
\text { Dato efectivo. }\end{array}$} \\
\hline PBI & 2,1 & 3,6 & 2,4 & \\
\hline PBI primario & 4,6 & 8,6 & 6,7 & \\
\hline Agropecuario & $-0,8$ & 7,0 & 0,9 & \\
\hline Pesca & 37,9 & 52,0 & 128,8 & \\
\hline Minería e hidrocarburos & 4,1 & 6,2 & 1,9 & \\
\hline Minería & 3,9 & 6,9 & 3,5 & \\
\hline Hidrocarburos & 5,3 & 2,5 & $-7,1$ & \\
\hline Manufactura primaria & 12,0 & 17,2 & 31,7 & \\
\hline $\mathrm{PBI}$ no primario & 1,1 & 2,0 & 0,9 & \\
\hline Manufactura no primaria & $-1,5$ & $-3,2$ & $-5,2$ & \\
\hline Electricidad, gas y agua & 1,0 & 3,6 & 1,5 & \\
\hline Construcción & $-5,3$ & 4,1 & $-2,7$ & \\
\hline Comercio & 0,1 & 1,5 & 0,8 & \\
\hline Servicios & 2,9 & 3,0 & 2,7 & \\
\hline
\end{tabular}

Figura 4. PBI Primer trimestre 2017 y proyectado (primario y no primario). Tomado de "Panorama Económico, Agosto 2017”, por el Ministerio de Economía y Finanzas (MEF), 2017. Recuperado de Recuperado de https://www.mef.gob.pe/contenidos/archivos-descarga/panorama_economico_14082017.pdf

En la Figura 5 y 6 se muestran la evolución del PBI en el 2017. En los primeros meses, bajo los efectos de El Niño Costero. En junio se presentó el mayor crecimiento (3.6\%).

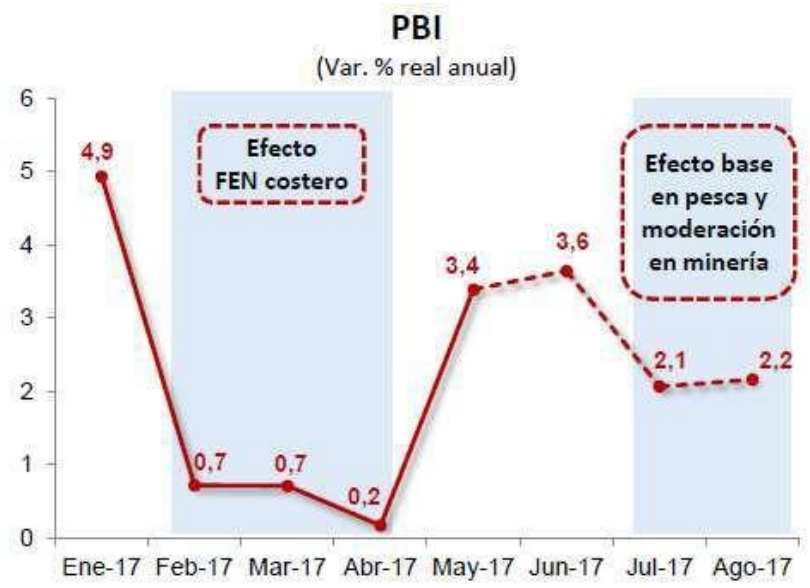

Figura 5. Variación porcentual del PBI en el 2017. Tomado de "Panorama Económico, Agosto 2017", por el Ministerio de Economía y Finanzas (MEF), 2017. Recuperado de Recuperado de https://www.mef.gob.pe/contenidos/archivos-descarga/panorama economico 14082017.pdf 


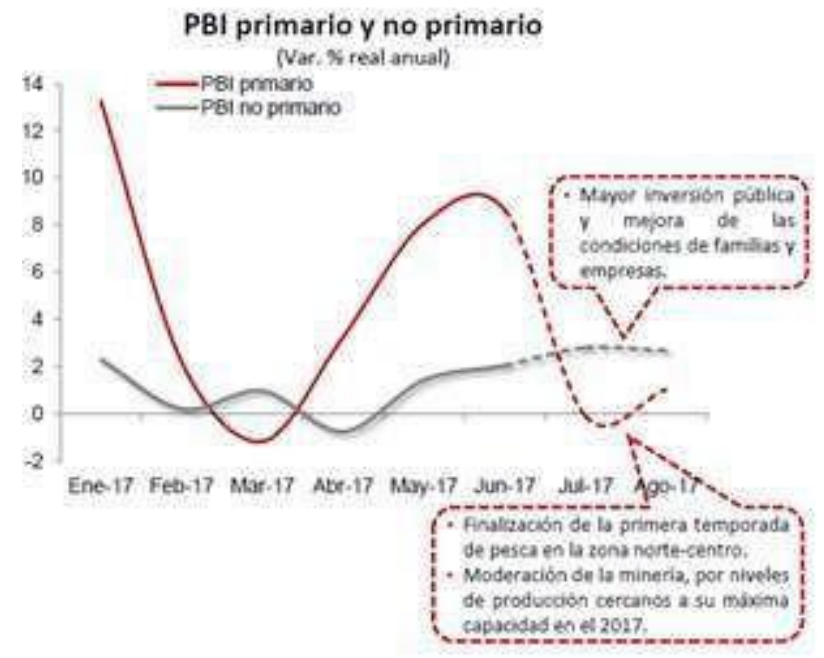

Figura 6. Variación porcentual del PBI primario y no primario en el 2017. Tomado de "Panorama Económico, Agosto 2017”, por el Ministerio de Economía y Finanzas (MEF), 2017. Recuperado de Recuperado de https://www.mef.gob.pe/contenidos/archivos-descarga/panorama economico 14082017.pdf

\section{Exportaciones.}

En la Figura 7 se muestra la evolución de las exportaciones tradicionales y no tradicionales, lo que refleja una mayor demanda externa y en la Figura 8, los principales productos exportados no tradicionales.

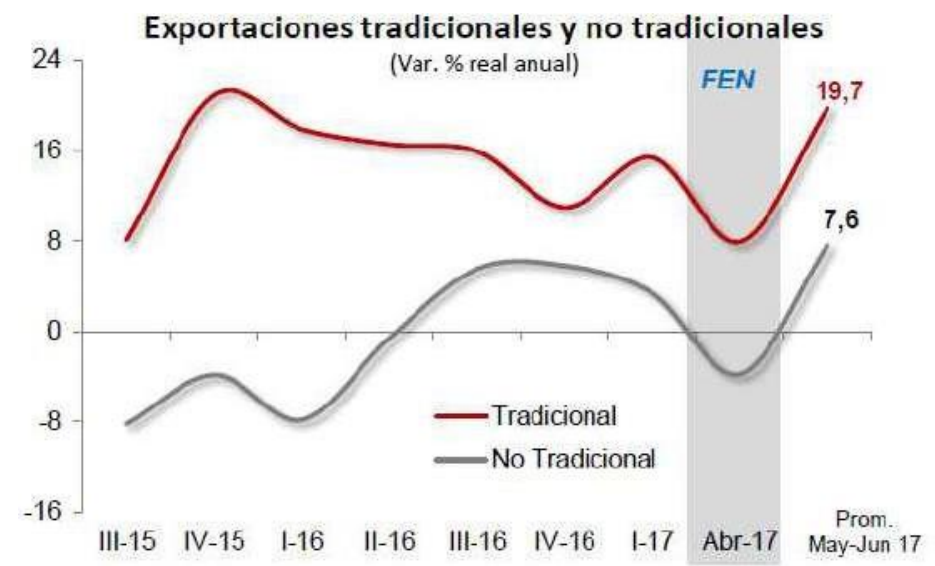

Figura 7. Exportaciones tradicionales y no tradicionales. Tomado de "Panorama Económico, Agosto 2017", por el Ministerio de Economía y Finanzas (MEF), 2017. Recuperado de Recuperado de https://www.mef.gob.pe/contenidos/archivos-descarga/panorama_economico_14082017.pdf 


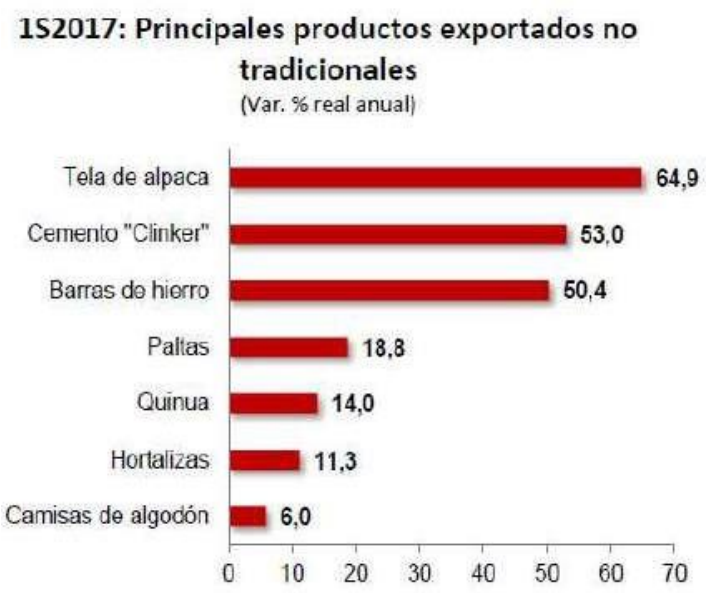

Figura 8. Principales productos exportados no tradicionales. Tomado de "Panorama Económico, Agosto 2017”, por el Ministerio de Economía y Finanzas (MEF), 2017. Recuperado de Recuperado de https://www.mef.gob.pe/contenidos/archivos-descarga/panorama_economico_14082017.pdf

Consumo privado.

El consumo privado, está teniendo un crecimiento, pero a un ritmo lento. Se estima que en los próximos meses mejore por el mayor despliegue de la inversión pública y privada.

Tipo de cambio.

De acuerdo al Reporte de Inflación del Banco Central de Reserva [BCR] (2017),

En el período de marzo a mayo 2017, el tipo de cambio registró una ligera depreciación de 0.2\%, pasando de S/ 3.263 a S/ 3.271 por dólar, con ello el sol mantiene una apreciación de 2.6\% en lo que va del año. Sin embargo, dentro del periodo el sol mostró una evolución diferenciada.

Entre marzo y abril, el sol se apreció $0.6 \%$ ante la depreciación del dólar a nivel global, el ingreso de capitales y por la venta de dólares de corporativos para cumplir con sus pagos de regularización de impuestos. Posteriormente, en mayo el sol se depreció $0.8 \%$ al verse afectado por la caída de los precios de los commodities (petróleo) y las expectativas de alza de tasas de interés de la Reserva Federal de Estados Unidos. (Reporte de Inflación, 2017, p 78). 


\section{Inflación.}

En mayo del 2017, el índice de precios al consumidor (IPC) fue de 3.04\%. La inflación sin alimentos y energía continuó con la tendencia decreciente registrada desde mayo 2016 (3.33\%). Por su parte, los precios de alimentos y energía disminuyeron su ritmo de crecimiento porcentual, de $4.01 \%$ en febrero a $3.62 \%$ en mayo. En esta evolución fue determinante la reversión de los precios de los alimentos perecibles observada entre abril y mayo, luego del alza extraordinaria en marzo por efectos del Fenómeno El Niño Costero.

(Reporte de inflación, 2017).

En la Figura 9 se presenta la evolución variación porcentual de los últimos 12 meses de la inflación y del IPC sin alimentos y energía.

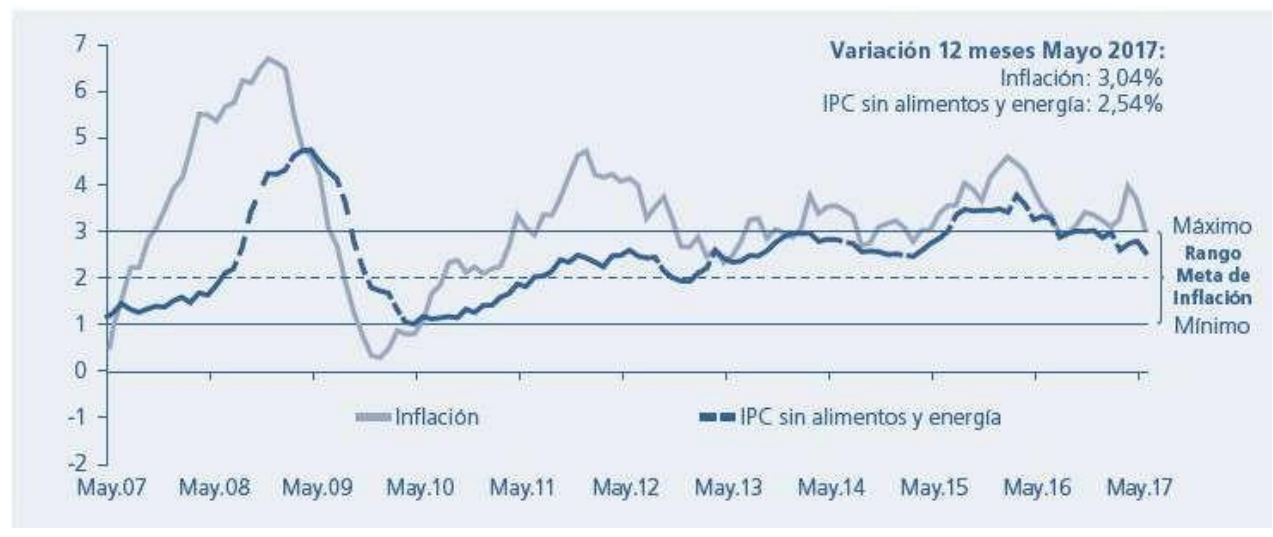

Figura 9. Inflación y meta de inflación. Tomado de "Reporte de Inflación Junio 2017. Panorama actual y proyecciones marcroeconómicas 2017-2018”, por Banco Central de Reserva del Perú (BCR), 2017.

Recuperado de http://www.bcrp.gob.pe/docs/Publicaciones/Reporte-Inflacion/2017/junio/reporte-de-inflacionjunio-2017.pdf

Economía para el sector del cacao.

Según el Instituto de Estudios Económicos [IEES] de la Sociedad Nacional de Industrias (2016), los principales productores de cacao se encuentran en Europa, a pesar de que el cacao crezca mayormente en zonas tropicales, lo que confirma la necesidad de potenciar la producción de productos de mayor valor agregado en el país.

En el Perú, la producción de cacao se ha convertido en una fuente importante de ingresos. Los principales productores a nivel nacional por departamentos son: San Martín, Junín, 
Cusco, Ayacucho, Amazonas, Huánuco, Ucayali y Cajamarca. También destacan Pasco, Tumbes y Piura. Esta producción de cacao ha mejorado sistemáticamente desde inicios del siglo XXI, lo que ha traído como consecuencia mejores oportunidades y condiciones de negociación en cuanto a precio y volumen.

De acuerdo a información del MINAGRI, la producción de cacao se ha triplicado en los últimos 15 años. Los productos que se pueden obtener del cacao son el grano seco, licor o pasta de cacao, torta de cacao y manteca de cacao, insumos para la industria chocolatera y de confitería. Siendo el grano de cacao el que ha cobrado la mayor relevancia y se ha convertido en los últimos años en el producto más exportado, dentro de la canasta de cacao, chocolates y otros derivados.

Según el último Censo de Establecimiento Manufactureros se identificaron 128 empresas dedicadas a la producción de chocolates y de confitería, ubicadas en Lima, Cusco e Ica, principalmente, y en menor cuantía, en las regiones de Arequipa, Cajamarca, Lambayeque, San Martín, La Libertad, Piura y Tacna.

En el entorno del comercio exterior de cacao, chocolates y otros derivados, se tienen dos situaciones. Una en la que la balanza comercial es positiva para el grano de cacao y manteca de cacao; y por otro lado la balanza comercial presenta déficit en la partida que agrupa a chocolates y demás preparaciones a base de cacao. (IEES, 2016).

Según fuente del INEI, el $12.6 \%$ de la producción de cacao, chocolates y otros derivados se destina al mercado externo, destacando Holanda, Estados Unidos y Bélgica. Mientras que el $87.4 \%$ de la producción se consume en el mercado interno (22,2\% como demanda intermedia y 65,2\% como demanda final). Otro dato de INEI, es que en el Perú, el cacao, chocolate y otros derivados son demandados por empresas productoras de chocolate y confitería, panadería y pastelería, fabricación de productos lácteos y restaurantes. Lo hogares 
son los que más demandan. Consumen el $65.2 \%$ del total de cacao, chocolates y otros derivados. (IEES, 2016). Ver Figura 10.

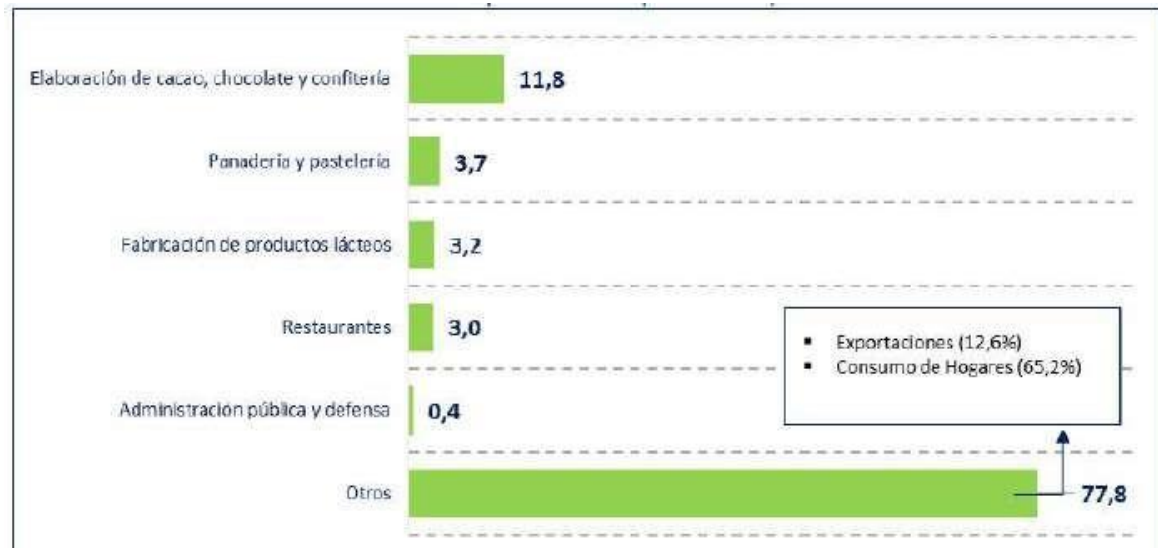

Figura 10. Actividades económicas demandantes de cacao, chocolate y otros derivados (distribución porcentual). Tomado de "Industria del cacao, chocolate y otros derivados" por el Instituto de estudios económicos y sociales (IEES), 2016. Recuperado de http://www.sni.org.pe/wp-content/uploads/2017/01/Junio2016-Industria-del-cacao-chocolate-y-otros-derivados.pdf

La producción de cacao e insumos derivados del cacao ha incrementado en los últimos años. Según Figura 11 que se muestra a continuación, el desempeño ha sido positivo, el que se ha visto impulsado especialmente por la creciente demanda externa. El cacao en grano ha pasado a ser el producto más exportado dentro del grupo conformado por cacao, chocolates y otros derivados.

Mientras que el desempeño de la producción de los insumos derivados del cacao ha sido mixto (MINAGRI, 2016)

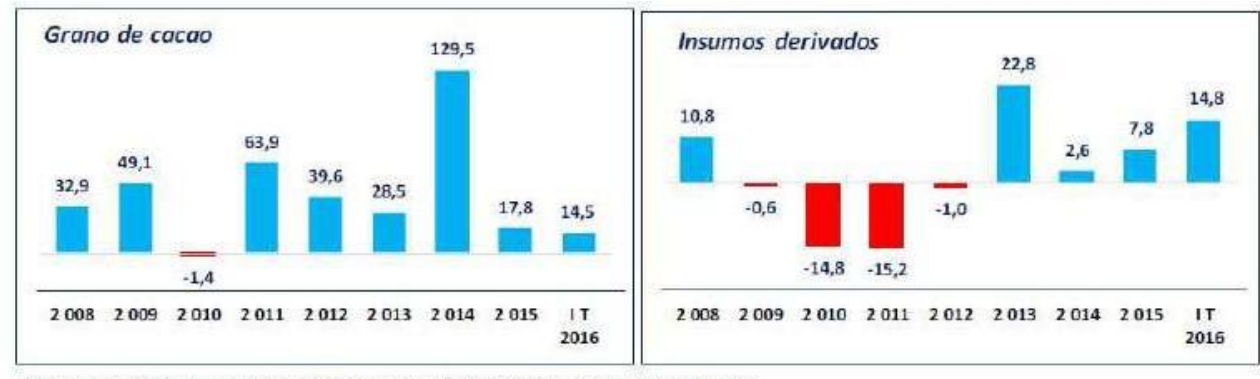

*Insumos de rivados: se considera al licor, manteca y torta de cacoo, cacoa y polvo de cacoo

Figura 11. Producción de grano de caco e insumos derivados de cacao (variación porcentual). Tomado de "Industria del cacao, chocolate y otros derivados" por el Instituto de estudios económicos y sociales (IEES), 2016. Recuperado de http://www.sni.org.pe/wp-content/uploads/2017/01/Junio-2016-Industria-del-cacaochocolate-y-otros-derivados.pdf 
Según PRODUCE, si se analiza la producción industrial de chocolate medidas a través del índice de volumen físico, ha demostrado un desempeño negativo en los últimos dos años. Sin embargo, de enero a mayo del 2016 tuvo un crecimiento de $1.2 \%$.

El crecimiento de las exportaciones de cacao, chocolate y derivados ha crecido notablemente en los últimos diez años, ver Figura 12. En el 2006 el volumen era de 17,258 toneladas y en el 2015 la cifra alcanzó las 74,394 toneladas. Hacia el 2008 lo que más se exportaba era manteca, grasa y aceite de cacao, sin embargo, a partir del 2009 la exportación de grano seco de cacao cobró mayor importancia. En el 2015, las exportaciones de cacao, chocolate y sus derivados destacaron hacia Holanda $(35,4 \%)$. Le siguió Estados Unidos con 12,4\% y Bélgica $12,3 \%$.

Las importaciones de cacao, chocolates y derivados han incrementado 5.5 veces desde el 2006, ver Figura 13. En cuanto a las importaciones, durante el 2015, provinieron principalmente de Ecuador (27,4\%), Chile (11,7\%) y Estados Unidos $(8,5 \%)$.

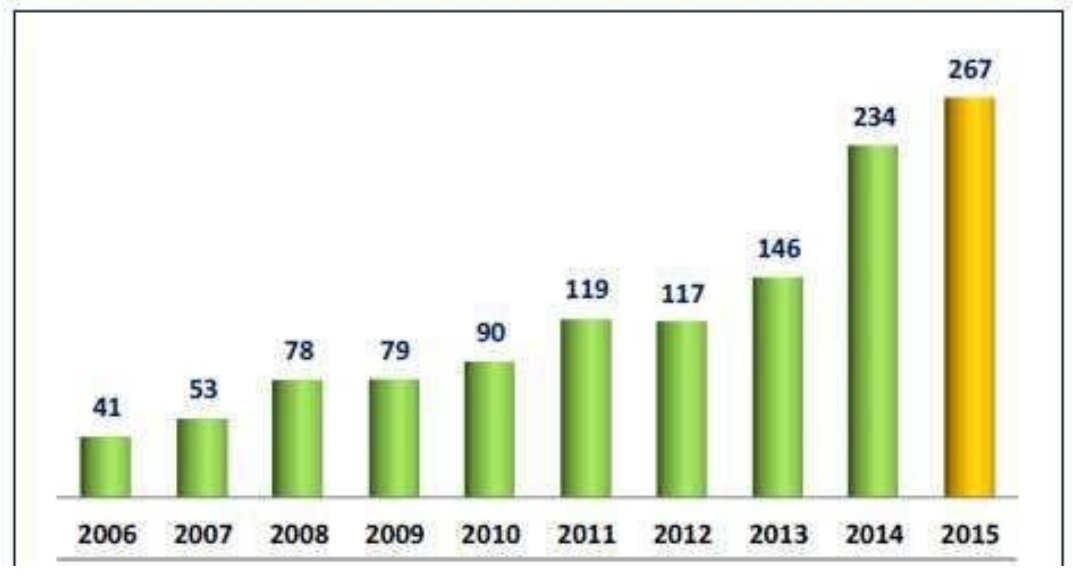

Figura 12. Evolución de exportaciones de cacao, chocolate y otros derivados (millones de US\$). Tomado de "Industria del cacao, chocolate y otros derivados" por el Instituto de estudios económicos y sociales (IEES), 2016. Recuperado de http://www.sni.org.pe/wp-content/uploads/2017/01/Junio-2016-Industria-del-cacaochocolate-y-otros-derivados.pdf 


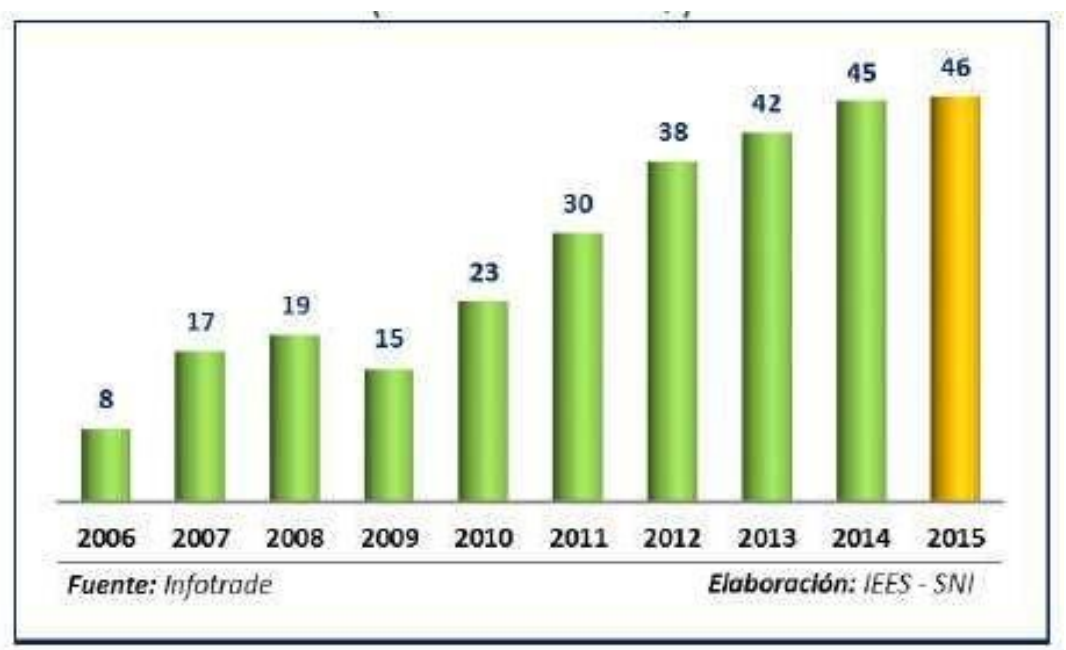

Figura 13. Importación de cacao, chocolate y otros derivados (millones de US\$). Tomado de "Industria del cacao, chocolate y otros derivados" por el Instituto de estudios económicos y sociales (IEES), 2016. Recuperado de http://www.sni.org.pe/wp-content/uploads/2017/01/Junio-2016-Industria-del-cacao-chocolate-y-otrosderivados.pdf

Dentro de las importaciones de cacao, chocolate y derivados por empresa, destacan Nestlé, Kraft Foods y Arcor.

\subsubsection{Análisis socio-cultural}

De acuerdo a las estadísticas indicadas por el MINSA (2017), en el Perú los niveles de desnutrición crónica infantil están alrededor del 13\% para niños menores de 5 años, y la tasa de anemia para niños y niñas entre 6 y 36 meses desde el 43.6\%. Esto producto de una mala alimentación, ocasionando la deficiencia de hierro en la sangre.

A nivel nacional, el departamento con mayor porcentaje de anemia en niños menores de 3 años es Puno con 76\%, seguido de Madre de Dios, Pasco y Apurímac. A nivel del departamento de Lima, el distrito con mayor porcentaje de anemia en niños menores de 3 años es Cieneguilla con 70\%, seguido de Lurigancho con 58.4\%. (Sistema de Información del Estado Nutricional SIEN, 2015).

Algunas de las causas que la anemia sea tan elevada en el Perú es por la pobre ingesta de alimentos ricos en hierro, especialmente hierro de buena biodisponibilidad (hemínico) de origen animal en niños desde los 6 meses; reducción de la lactancia materna exclusiva; 
brecha entre el consumo de hierro y lo que demanda el organismo (se incluye a la madre gestante); baja adherencia al consumo de suplementos; infecciones y malos hábitos de higiene; acceso limitado a servicios de salud. (MINSA, 2017).

Los malos hábitos alimenticios se dan por el nivel socioeconómico al que pertenece la familia, de recursos limitados, por el nivel de educación, principalmente de las madres adolescentes, quienes en etapa de gestación no se suministran adecuadamente de suplementos de hierro afectando al desarrollo del feto, teniendo como consecuencia al momento del nacimiento a un bebé anémico.

\subsubsection{Análisis tecnológico}

El proceso productivo del chocolate se presenta en la Figura 38. Antes de iniciar el proceso industrial, el cacao es desgranado, fermentado y secado. El proceso industrial inicia con la limpieza y selección, seguido el tostado y quebrantado del grano, etapas fundamentales del proceso productivo ya que se desarrollan procesos físicos y químicos que brindan el sabor y aroma al chocolate. Luego viene la molienda, donde la pasta de cacao logra mayor firmeza. En el presando, se separa la parte sólida del cacao de la parte líquida. En el mezclado, se combina de acuerdo al producto que se quiera obtener, pudiendo ser leche, azúcar y manteca. Esta mezcla pasa por un proceso de refinamiento para reducir la granulometría de la pasta de cacao. Luego viene el proceso de conchado para reducir acidez y remover gases indeseables. Finalmente, el atemperado y enfriamiento para luego el empaque (IEES, 2016)

El punto de partida de todo el proceso productivo es la producción de cacao en grano. Los productores de cacao requieren de insumos agrícolas, como las semillas de cacao, de buena calidad. Además, necesitan apoyo en cuanto a recursos financieros, capacitación y apoyo de empresas manufactureras. Al intervenir la empresa manufacturera, se asegura la calidad del grano, el que impactará directamente en la calidad de su producto final. 
Los productores de cacao en el Perú no cuentan con buena infraestructura, recursos, capacitación y sus tierras son de baja extensión y calidad, para lo cual, estos se juntan en asociaciones o cooperativas para poder negociar mejor los precios y volumen de ventas.

Los acopiadores locales o cooperativas cacaoteras e intermediarios de empresas exportadoras recolectan el cacao y lo distribuyen a las empresas manufactureras de chocolate o al mercado exterior. En el Anexo 5 se presenta la Cadena productiva del cacao, chocolate y derivados.

Durante el 2015, el Estado Peruano apoyó a la Mype e Industria, así por ejemplo se dio asesoría técnico-productiva a cargo de DIGITSE, otorgando un monto S/ 2,440,364. Consistió en brindar servicios de capacitación y asistencia técnica en temas técnico productivos y en gestión de la calidad para la mejora de la productividad. También se instalaron servicios tecnológicos para el desarrollo de cadenas productivas agroindustriales de algunos productos en la Provincia de Huara. Y capacitación sobre acceso a certificaciones u homologaciones, de tal manera, que estas empresas puedan alinearse a las exigencias de calidad, seguridad, inocuidad, etc. (Ministerio de la Producción, Sumario Regional Lima, 2016).

A nivel mundial, la innovación abunda en la industria de confitería y chocolates. A.M.P. Rose es una de las empresas líderes del mundo en maquinaria para la industria de chocolates y snacks. A.M.P Rose integra temas electrónicos, software, sensores, etc. Bosch Packaging Technology, para el empaquetado. Bühler, ofrece una unidad de preparación de masa y una unidad de corte transversal. CM-OPM ofrece la Nano Chocoline, una pequeña línea para la preparación de chocolate de pequeña y mediana categoría. Chocotech, soluciones para masas de caramelos jaleas, fondants, gomitas, etc. Existen otras tecnologías más. (Industria Alimenticia, 2017). 
Las mejores máquinas para el procesamiento del chocolate y sus derivados están en Europa, así por ejemplo, en la zona industrial más antigua de los Países Bajos se encuentran la mayor parte de fábricas de proceso de cacao y manteca de cacao. (Industria Alimenticia, 2017).

\subsubsection{Análisis ecológico}

El Estado Peruano, junto con el Ministerio de Ambiente tienen la iniciativa de mejorar y consolidar el sistema sectorial de gestión ambiental, a través de la supervisión y control del aprovechamiento sostenible de los recursos naturales, en lo subsectores pesquería e industria. El Perú, como parte de su compromiso con el medio ambiente, forma parte del Protocolo de Montreal, relativo a las sustancias Agotadoras de la Capa de Ozono. Las partes acordaron acelerar la eliminación gradual de la producción de los Hidroclorofluorocarbonos (HCFC) y se midió su avance al 2015, verificándose el cumplimiento de su compromiso (Anuario Estadístico, 2015).

\subsubsection{Análisis legal}

El 12 de abril del 2017 se firmó la Resolución Ministerial del Ministerio de Salud para aprobar el Documento Técnico Plan Nacional para la Reducción y Control de la Anemia Materno Infantil y la Desnutrición Crónica Infantil en el Perú 2017 - 2021.

El Ministerio de Agricultura y Riego (MINAGRI) ha indicado que en el mes de septiembre 2017 se contará con un proyecto reglamento técnico para el uso del cacao en los productos elaborados como el chocolate. Algunos productos hoy en día no cumplen con la norma por lo que hace necesario la creación de una reglamentación para obligar al cumplimiento de la ley. Representantes del MINAGRI se reunirán con representantes tanto del sector público como privado para la creación de este documento. A raíz del problema de la leche, siguió el tema de los chocolates, y es el inicio para la reglamentación de diversos productos como refrescos, bebidas y otros productos que contengan frutas. 
La reglamentación del uso del cacao puede traer como consecuencia un impacto en positivo en la demanda a los productores de cacao en el Perú. Además, traería como consecuencia también, el incremento de consumo de artículos saludables.

Algunas de las normativas que aplican al sector en el que incursionará el presente plan de negocios se listan a continuación.

NTP ISO 2451:2011. Granos de cacao. Especificaciones. Establece los requisitos para los granos de cacao.

NTP-CODEX STAN87-2013. Chocolates y productos del chocolate. Requisitos. La Norma se aplicará al chocolate y los productos de chocolate destinados al consumo humano. El chocolate y los productos de chocolate deben ser preparados a partir de cacao o derivados del cacao con azúcares y podrán contener.

NTP-CODEX STAN86-2013. Cacao y chocolate. Requisitos. Establece los requisitos para manteca de cacao empleada como ingrediente en la fabricación de chocolate y productos del chocolate.

NTP-CODEX STAN141: 2014. CACAO Y CHOCOLATE. Cacao en pasta (Licor de cacao/chocolate) y torta de cacao. Se aplica al Cacao en pasta o Licor de Cacao/Chocolate, y a la Torta de Cacao, según se definen, para uso en la fabricación de productos de cacao y chocolate. Estos productos podrán venderse también directamente al consumidor.

NTP 208.007 2007. CACAO Y CHOCOLATE. Cacao en polvo (Cocoa) y mezclas secas de cacao y azúcar. Requisitos. Establece los requisitos para el cacao en polvo (cocoa) y mezclas de cacao y azúcar. (INACAL, Normas Técnicas Peruanas de Agroindutria). 


\subsection{Descripción del estado actual de la industria}

\subsubsection{Segmentación de la industria}

El plan de negocio pertenece a la actividad manufacturera, dentro de esta a la actividad productiva del subsector no primario y específicamente a la industria de alimentos el cual se va ubicar en Lima Metropolitana el cual pertenece a la región de Lima.

En la última década el PBI manufacturero registró una tasa anual de crecimiento moderado de 4,0\% en promedio. Sin embargo, en el último quinquenio el desempeño de este sector no presentó tasas tan favorables, debido al menor impulso externo asociado a un escenario internacional menos favorable y de incertidumbre, sumándose además la reducción de la demanda interna por el descenso de la inversión privada (-4,4\%) (Ministerio de la Producción, 2015, p 13).

La actividad manufacturera a nivel nacional se ha visto fuertemente afectada por la inestabilidad internacional, pero se espera que con las políticas de desarrollo que el gobierno vaya promocionando esta actividad presente un crecimiento en los próximos años. Para el 2015, esta actividad representó el 13.5\% sobre el PBI Nacional tal como indica el Ministerio de la Producción (2015). Asimismo, la actividad manufacturera en la región Lima en el 2014 representó el 19.5\% del Valor Agregado Bruto tal como lo indica la Dirección de Estudios Económicos de Mypee Industria [DEMI] (2016), siendo una de las principales actividades que realiza.

Según DEMI (2016), Lima tiene 47.5\% de las mipymes formales del Perú, siendo en total 766843 empresas. En el rubro de chocolatería las principales empresas ubicadas en Lima son: Nestlé Perú S.A, Machu Picchu Foods S.A.C, Bombonería Di Perugia S.A.C, Theobroma Inversiones S.A.C, Maraná S.A.C, Comercializadora Cobertura Negusa S.A.C, Quilinaria Perú S.A.C, Chocomuseo S.A.C, F y D Inversiones S.A.C. 
Según América Economía (2014) la industria de alimentos en el Perú representa el 4\% del PBI nacional y $32 \%$ del PBI industrial. Asimismo, indica que tiene una demanda inelástica, su crecimiento está más ligado al aumento de la población que al avance económico. La producción nacional de chocolates confirma esta tendencia de crecimiento en la industria de alimentos, el Ministerio de la Producción (2015) reporta que en el 2012 se produjo 28303 $881 \mathrm{~kg}$ de chocolates y para el 2015 fue de $35639131 \mathrm{~kg}$ (dentro del rubro de chocolates no incluye: cacao, cocoa y manteca de cacao y bombones), este crecimiento fue de $26 \%$.

\subsubsection{Empresas que conforman el grupo estratégico}

En la industria de alimentos del Perú, la única empresa que vende tabletas de chocolates funcionales con fortificación de hierro es WAALA industrias nutricional y cosmética S.A.C. cuyo producto tiene una presentación en pote con 40 tabletas de 10 g cada una, su marca es Forticao y el precio es de S/60.00 incluyendo IGV, el único punto de venta son las farmacias INKAFARMA a nivel nacional.

El resto de empresas que producen tabletas de chocolate convencionales sin fortificación pero que tienen la denominación de chocolate tal como lo indica DIGESA (no se incluyen tabletas sabor chocolate o bañados con chocolate) cuyos productos se venden en supermercados, mayoristas o bodegas tenemos a Nestlé Perú S.A, Bombonería Di Perugia S.A.C, y La Ibérica. Los precios de sus tabletas con presentaciones menores a $50 \mathrm{~g}$ tienen precios que oscilan desde S/. 1.00 hasta S/ 5.00 Nuevos Soles la unidad.

En cuanto al sector de chocolatería que producen tabletas de chocolate orgánico sin fortificación y cumplen con la denominación de chocolate tenemos a Quilinaria Perú S.A.C, Chocomuseo S.A.C, Theobroma Inversiones S.A.C, Maraná S.A.C y Amaz Food S.A.C, sus productos se venden en supermercados y tiendas especializadas, las tabletas de chocolate tienen una presentación de 50 a 90 g y su precio varía de S/ 12.00 a S/ 22.00 Nuevos Soles la unidad. Estas empresas tienen su principal mercado en el extranjero. Cacaosuyo ya está 
presente en Francia, Inglaterra y Japón, con miras a cerrar próximamente contratos que le permitirá introducirse en el mercado de Estados Unidos (Lavaggi, Mori \& Rozas, 2016).

En la tabla 2 se detallan las principales empresas de chocolatería a nivel nacional con características de marca, volumen de ventas, número de trabajadores, ubicación y mercado.

\subsection{Tendencias de la industria}

El gobierno a través del Ministerio de Agricultura y Riego ha venido apoyando a los productores de cacao con asistencia técnica y capacitaciones para que mejoren en calidad y productividad, para así abastecer a la industria. Instituto de estudios económicos y sociales [IEES] (2016) nos indica que la producción de cacao en el Perú se ha triplicado en los últimos quince años. Asimismo, se han sumado ONGs, USAID y otras entidades para apoyar a las comunidades nativas y pequeños productores a darle valor agregado a los granos de cacao y en el proceso de asociatividad para lograr mejores mercados. Todas estas actividades han contribuido a asegurar la materia prima principal de la industria de chocolatería y permitir su crecimiento.

A nivel industrial, el Ministerio de la Producción apoya a las empresas con diferentes programas especializados tal como indica DEMI (2016) Produce invirtió en la región Lima S/ 2,400,364 Soles en el programa de Asesoría técnico-productivo, invirtió S/ 1,237,420 Soles en el programa Emprendedor Peruano y dio acceso a las MIPYME a participar en las Ferias Comerciales. La feria más importante en la industria de alimentos es la ExpoAlimentaria y del sector de chocolatería es el Salón del Cacao y chocolate en la que se busca impulsar el consumo de chocolate de alta calidad.

Según Sotomayor (2009) se prevé que el consumo per cápita de chocolates aumentará 20 por ciento en el presente 2009 debido a la mayor oferta de productos con valor agregado en el mercado local, así como por ejecución de estrategias y promociones para captar nuevos clientes. Asimismo, León (2016) indica que "actualmente el consumo per cápita de chocolate 
en nuestro país es de 500 gramos y se proyecta que dentro de dos años esa cifra se duplique alcanzando el kilo por persona al año". Ambas publicaciones nos confirman que el sector de chocolates está en crecimiento y con las debidas actividades de promoción el consumo va ir en aumento.

Según Sotomayor (2009) la categoría de chocolates ha crecido de manera sostenida en los últimos siete años, la producción de chocolatería diversa creció $7.9 \%$ en promedio y, solo en 2007, se expandió $26.7 \%$, teniéndose un estimado de mercado de alrededor de US\$ 85

millones. El mercado creció en un contexto de proliferación de nuevos productos y formatos con márgenes de ganancia limitados por el alza en costos de su principal insumo, el cacao, cuya cotización creció $12.7 \%$ en promedio en los dos últimos años. Tal como se observa en la Figura 14 la producción de chocolates diversos en el 2000 era cercana a las 8 mil toneladas, se ve crecimiento anualmente hasta el 2007 en que casi alcanza las 14 mil toneladas luego hay un pequeño declive en el 2008 debido al aumento del precio del cacao.

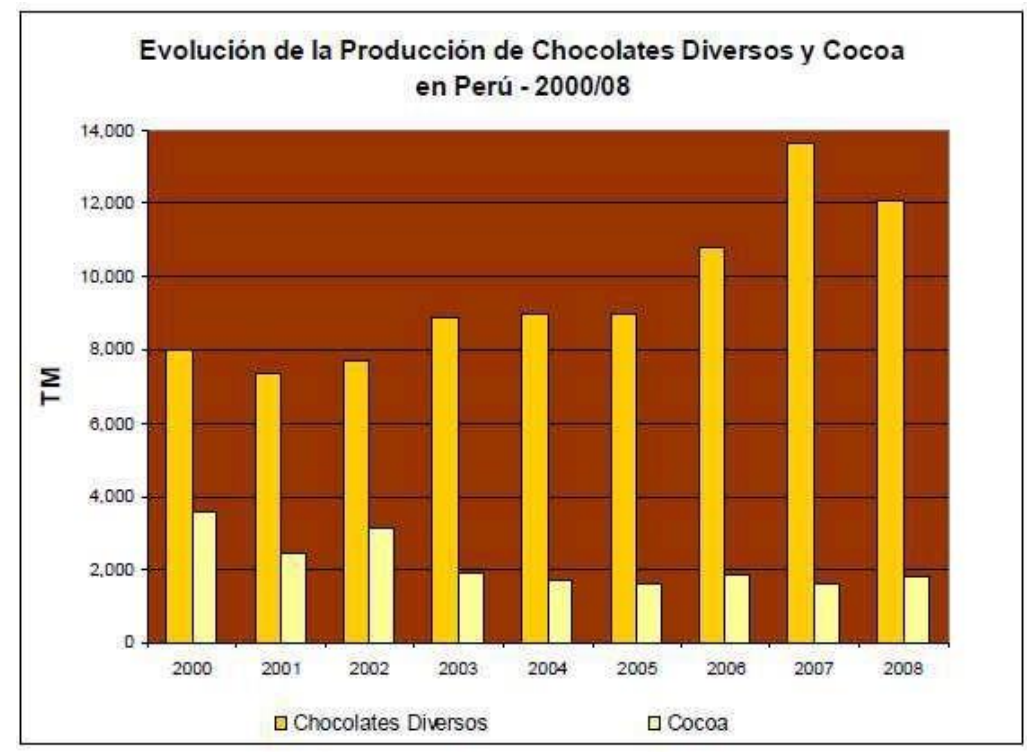

Figura 14. Evolución de la producción de chocolates y cocoa en Perú. Tomado de "Estudio del mercado interno para determinación y caracterización del consumo actual y potencial de derivados industriales del cacao" por Sotomayor, 2009. 
Tabla 2.

Principales empresas de chocolatería a nivel nacional.

\begin{tabular}{|c|c|c|c|c|c|}
\hline Razón Social & Marca & $\begin{array}{l}\text { Volumen de } \\
\text { ventas } \\
\text { anuales (S/. } \\
\text { millones) }\end{array}$ & $\begin{array}{c}\text { Nro de } \\
\text { trabajadore } \\
\mathrm{s}\end{array}$ & Ubicación & Me rcado \\
\hline $\begin{array}{c}\text { WAALA } \\
\text { industrias } \\
\text { nutricional y } \\
\text { cosmética S.A.C }\end{array}$ & Forticao & - & $\begin{array}{c}\text { Menos de } \\
200\end{array}$ & Lima & Nacional \\
\hline $\begin{array}{l}\text { Machu Picchu } \\
\text { Foods S.A.C }\end{array}$ & $\begin{array}{l}\text { Machu } \\
\text { Picchu } \\
\text { Foods } \\
\text { Servicio } \\
\text { maquila }\end{array}$ & $\begin{array}{c}67.6(\$ y \\
2011)(* *)\end{array}$ & 200 a más & Lima & $\begin{array}{l}\text { Nacional e } \\
\text { internacional }\end{array}$ \\
\hline Nestlé Perú S.A & $\begin{array}{l}\text { Sublime, } \\
\text { Triángulo, } \\
\text { Princesa }\end{array}$ & $\begin{array}{l}438.8(\$ y \\
2011)(* *)\end{array}$ & 200 a más & Lima & $\begin{array}{l}\text { Nacional e } \\
\text { internacional }\end{array}$ \\
\hline $\begin{array}{l}\text { Bombonería Di } \\
\text { Perugia S.A.C }\end{array}$ & $\begin{array}{c}\text { Di Perugia, } \\
\text { Bouquet, } \\
\text { Cuore }\end{array}$ & 16 & $\begin{array}{c}\text { Menos de } \\
200\end{array}$ & Lima & Nacional \\
\hline $\begin{array}{c}\text { Theobroma } \\
\text { Inversiones } \\
\text { S.A.C }\end{array}$ & Cacaosuyo & - & $\begin{array}{c}\text { Menos de } \\
200\end{array}$ & Lima & $\begin{array}{l}\text { Nacional e } \\
\text { internacional }\end{array}$ \\
\hline $\begin{array}{c}\text { Quilinaria Perú } \\
\text { S.A.C }\end{array}$ & Shatell & - & $\begin{array}{c}\text { Menos de } \\
200\end{array}$ & Lima & $\begin{array}{l}\text { Nacional e } \\
\text { internacional }\end{array}$ \\
\hline $\begin{array}{c}\text { Chocomuseo } \\
\text { S.A.C }\end{array}$ & $\begin{array}{c}\text { Chocomuse } \\
\text { o }\end{array}$ & - & $\begin{array}{c}\text { Menos de } \\
200\end{array}$ & Lima & Nacional \\
\hline Maraná SAC & Maraná & - & $\begin{array}{l}\text { Menos de } \\
200\end{array}$ & Lima & $\begin{array}{c}\text { Nacional e } \\
\text { internacional }\end{array}$ \\
\hline La Ibérica S.A.C & La Ibérica & $50(*)$ & 200 a más & Arequipa & $\begin{array}{c}\text { Nacionale } \\
\text { internaciona }\end{array}$ \\
\hline $\begin{array}{c}\text { F y D Inversiones } \\
\text { S.A.C }\end{array}$ & 2 cerritos & - & $\begin{array}{c}\text { Menos de } \\
200\end{array}$ & Lima & Nacional \\
\hline $\begin{array}{l}\text { AmazFood } \\
\text { S.A.C }\end{array}$ & Amaz & - & $\begin{array}{c}\text { Menos de } \\
200\end{array}$ & Lima & $\begin{array}{l}\text { Nacional e } \\
\text { internacional }\end{array}$ \\
\hline
\end{tabular}

Nota: los guiones indican que no se encontró información. Adaptado de (*) Perú Retail (8 de marzo del 2016). Ventas de La Ibérica crecieron un $24 \%$ en 2015. Perú Retail. Recuperado de http://www.peruretail.com/ventas-la-iberica-2015/.(**) América economia (2012) Las 500 mayores empresas del Perú 2012. Recuperado de :https://rankings.americaeconomia.com/2012/las-500-mayores-empresas-de-peru/ranking500-peru-451-500.php

\subsection{Análisis competitivo del sector industrial}

En base a las cinco fuerzas de Porter se va analizar el sector industrial del chocolate (Ver

Tabla 3), cada ítem ha recibido una calificación de bajo, medio y alto, cada fuerza de Porter cuenta con tres ítems. 


\subsubsection{Poder de negociación de los clientes}

Número de clientes a nivel canal moderno, gran número de supermercados como

Cencosud, Supermercados Peruanos y Tottus las cuales abarcan a nivel nacional, tienen altos márgenes de ganancia, exigen bajos precios, la comunicación no es fluida, altos trámites burocráticos y el pago va de 30 a 90 días.

Número de clientes a nivel mayorista y minorista, gran número de tiendas mayoristas, bodegas y tiendas especializadas, estas manejan bajos márgenes de ganancia, comunicación fluida, no hay trámites y el pago es a 30 días.

Número de ONG`s, UNICEF, Salgalú, Cáritas del Perú son algunas ONG’s que trabajan para combatir la desnutrición infantil.

Se califica como alto poder de negociación.

\subsubsection{Poder de negociación de los proveedores}

Número de proveedores de materia prima e insumos, el principal insumo es el cacao que se negocia con las comunidades nativas y asociaciones de productores que se les ofrece un precio en función de la calidad del grano de cacao. Para el caso de las gomitas fortificadas sólo hay un proveedor en el mercado por lo que se tiene que aceptar el precio este proponga. Los otros insumos que son azúcar, leche en polvo existe un gran número de proveedores.

Número de proveedores de empaques, existe gran número de proveedores.

Número de proveedores de equipos, en el Perú IMSA se dedica a la elaboración de maquinaria para chocolatería y en Italia la empresa que se dedica a elaborar maquinaria para fábricas artesanales a baja escala es Packint, esta última con mayor reconocimiento por su calidad y tecnología.

Se califica como bajo poder de negociación. 


\subsubsection{Amenaza de productos sustitutos}

Tipos de productos sustitutos, son las golosinas con sabor a chocolate que crea confusión en el consumidor al no saber distinguir la diferencia de calidad de ambos. El gobierno a través del impulso de ferias y normativas se está regulando dicho problema y la población está cada vez más informada.

Disponibilidad de sustitutos al alcance del cliente, se encuentran en los mismos puntos de venta. Compiten en precio.

Público informado frente a los productos sustitutos, el público que conoce la diferencia entre un verdadero chocolate y uno sucedáneo, va elegir el verdadero pues conoce la calidad y prefiere consumir productos que contribuyen a su salud

Se califica como bajo.

\subsubsection{Amenaza de nuevos competidores potenciales}

Barrera de entrada de tipo legal, debido a que se tiene que tramitar el Registro Sanitario con DIGESA y la licencia de funcionamiento con la Municipalidad.

Barrera de entrada de tipo financiero, en caso de implementar una fábrica (alrededor de S/ 3,000,000 Soles de inversión aproximadamente), se considera alto capital a diferencia de una maquila que sólo invierte en materia prima, insumos y empaque (S/ 20,000 Soles aproximadamente)

Barrera de entrada de tipo técnico, para implementar una fábrica de chocolate se debe tener conocimiento técnico especializado de cada proceso.

Se califica a la fuerza de Porter como bajo.

\subsubsection{Rivalidad entre los competidores}

Número de competidores, existen pocos competidores, pero estos cuentan con marcas posicionadas en la mente del consumidor y tienen participación en el mercado importante. 
Disponibilidad de competidores al alcance del cliente, la competencia vende en supermercados, mayoristas y bodegas.

Perfil del consumidor, actualmente el consumidor no está fidelizado y está cada vez más dispuesto a probar nuevos sabores.

Se califica como medio. De acuerdo al análisis realizado, el sector de la industria de chocolates es medianamente competitivo. Se recomienda estrategias de diferenciación en cuanto a calidad e innovación del producto para que este sea valorado por los clientes. 
Tabla 3.

Análisis de las cinco fuerzas de Porter en el sector chocolatería.

\begin{tabular}{|c|c|c|c|c|}
\hline Fuerza de Porter & Aspecto a analizar & Análisis & Punt. & Conclusión \\
\hline \multirow{3}{*}{$\begin{array}{l}\text { Amenaza de } \\
\text { nuevos } \\
\text { competidores }\end{array}$} & $\begin{array}{l}\text { Barrera de entrada de tipo } \\
\text { legal }\end{array}$ & $\begin{array}{l}\text { Trámite burocrático que toma de } 15 \text { a } 30 \text { días obtener el registro sanitario para un } \\
\text { producto y la licencia de funcionamiento de la fábrica }\end{array}$ & Bajo & \multirow{3}{*}{ BAJO } \\
\hline & \multicolumn{3}{|c|}{$\begin{array}{c}\text { La instalación de una fábrica artesanal desde la compra de terreno, construcción y } \\
\text { equipamiento tiene un costo aproximado de } \mathrm{S} / 2,000,000 \text { Soles. El contar con } \\
\text { infraestructura propia permite atender a tiempo y cumplir con los requerimientos } \\
\text { Barrera de entrada de tipo de los clientes, y adaptarse a los cambios de las nuevas demandas del mercado. } \\
\text { financiero } \\
\begin{array}{l}\text { Existe en el sector empresas que dan el servicio de maquila, esto disminuye el } \\
\text { monto de inversión para las nuevas empresa, las desventajas son: mínimo } 100 \mathrm{~kg}\end{array} \\
\text { de cacao en grano, el tiempo de entrega del producto va de } 30 \text { a } 45 \text { días, requiere } \\
\text { un acuerdo de confidencialidad y se deben ceñir a los parámetros de producción } \\
\text { de la empresa maquiladora. }\end{array}$} & \\
\hline & $\begin{array}{l}\text { Barrera de entrada de tipo } \\
\text { técnico }\end{array}$ & Know- how sobre proceso de producción de chocolates & Medio & \\
\hline \multirow[t]{3}{*}{$\begin{array}{l}\text { Poder de } \\
\text { negociación de } \\
\text { proveedores }\end{array}$} & $\begin{array}{l}\text { Número de proveedores de } \\
\text { materia prima e insumos }\end{array}$ & $\begin{array}{l}\text { El principal insumo es el cacao que se negocia con las comunidades nativas y } \\
\text { asociaciones de productores que se les ofrece un precio en función de la calidad } \\
\text { del grano de cacao. Para el caso de las gomitas fortificadas sólo hay un proveedor } \\
\text { en el mercado por lo que tenemos que aceptar el precio que nos proponga. }\end{array}$ & Bajo & \multirow[t]{3}{*}{ BAJO } \\
\hline & $\begin{array}{l}\text { Número de proveedores de } \\
\text { empaque }\end{array}$ & Existe gran número de proveedores de empaque & Bajo & \\
\hline & $\begin{array}{l}\text { Número de proveedores de } \\
\text { equipos }\end{array}$ & $\begin{array}{l}\text { En el Perú hay una empresa que confecciona maquinaria para chocolateria pero } \\
\text { no tiene la calidad y tecnología de los equipos importados, principalmente de Italia. Med }\end{array}$ & & \\
\hline \multirow[t]{3}{*}{$\begin{array}{l}\text { Poder de } \\
\text { negociación de } \\
\text { compradores }\end{array}$} & $\begin{array}{l}\text { Número de clientes a nivel } \\
\text { canal moderno }\end{array}$ & $\begin{array}{l}\text { Existe un gran número de supermercados pero manejan altos márgenes de } \\
\text { ganancia, exigen bajos precios, la comunicación no es fluida, altos trámites } \\
\text { burocráticos y el pago va de } 30 \text { a } 90 \text { días. }\end{array}$ & Alto & \multirow{3}{*}{ ALTO } \\
\hline & $\begin{array}{l}\text { Número de clientes a nivel } \\
\text { mayorista y minorista }\end{array}$ & $\begin{array}{l}\text { Existe un gran número de mayoristas, bodegas y tiendas especializadas a nivel } \\
\text { Lima Metrpolitana, manejan bajos márgenes de ganancia, comunicación fluida, no } \\
\text { hay trámites y el pago es a } 30 \text { días. }\end{array}$ & Medio & \\
\hline & Número de ONG’s & $\begin{array}{l}\text { UNICEF, Salgalú, Cáritas del Perú son algunas ONG's que trabajan para } \\
\text { combatir la desnutrición infantil y a quienes les podríamos presentar nuestro } \\
\text { producto para que lo entreguen a las zonas vulnerables. }\end{array}$ & Alto & \\
\hline \multirow{3}{*}{$\begin{array}{l}\text { Amenaza de } \\
\text { productos } \\
\text { sustitutos }\end{array}$} & $\begin{array}{l}\text { Tipos de productos } \\
\text { sustitutos }\end{array}$ & $\begin{array}{l}\text { Como producto sustituto consideramos a las golosinas o chocolates sucedáneos, } \\
\text { no tienen la misma composición del chocolate ni la calidad. }\end{array}$ & Bajo & \multirow{3}{*}{ BAJO } \\
\hline & $\begin{array}{l}\text { Disponibilidad de sustitutos } \\
\text { al alcance del cliente }\end{array}$ & Estos productos se encuentran en los mismos puntos de venta. Compiten en precio Me & edio & \\
\hline & $\begin{array}{l}\text { Público informado frente a s } \\
\text { los productos sustitutos }\end{array}$ & $\begin{array}{l}\text { El público que conoce la diferencia entre un verdadero chocolate y uno } \\
\text { ucedáneo, va elegir el verdadero pues conoce la calidad y prefiere consumir } \\
\text { productos que contribuyen a su salud. }\end{array}$ & Bajo & \\
\hline \multirow[t]{3}{*}{$\begin{array}{l}\text { Rivalidad con } \\
\text { competidores }\end{array}$} & Número de competidores & $\begin{array}{l}\text { Hay productos importados y nacionales principalmente de las empresas Nestlé } \\
\text { Perú S.A, Bombonería Di Perugia S.A.C, y La Ibérica }\end{array}$ & Alto & \multirow{3}{*}{ MEDIO } \\
\hline & $\begin{array}{l}\text { Disponibilidad de } \\
\text { competidores al alcance del } \\
\text { cliente }\end{array}$ & Competidores están presentes en todos los canales de distribución & Medio & \\
\hline & Perfil del consumidor & $\begin{array}{l}\text { El consumidor está interesado en productos orientados a la salud y nuevos } \\
\text { sabores, el lograr esta diferenciación nos permitirá el posicionamiento }\end{array}$ & Medio & \\
\hline
\end{tabular}

Fuente: elaboración propia

\subsection{Análisis de la competencia directa}

El mercado de chocolates en general ascendió a 22,000 toneladas al año (Euromonitor, 2016). El consumo de chocolates de alto porcentaje de cacao (más del $30 \%$ para el caso de chocolate con leche y 50\% para el caso de chocolate bitter), ha crecido en el Perú desde el 2015, de las cuales el 15\% corresponde a chocolates con alto contenido de cacao (Andina, 2017). 
En el mercado del Perú existe un chocolate similar al producto materia de investigación del presente plan de negocio, se llama Forticao, el que se vende en la cadena de Boticas InkaFarma. Este producto nació a raíz de un proyecto que emprendió un grupo de investigadores peruanos y el Banco Mundial, que perseguían el objetivo de combatir la anemia en el Perú, problema severo de salud pública, que está asociado directamente a la desnutrición crónica infantil, siendo los niños, adultos mayores y mujeres embarazadas la población más vulnerable.

El producto Forticao es una combinación de cacao peruano y hierro hemínico, el que aporta hierro, calcio y zinc, micronutrientes esenciales para combatir la anemia y prevenirla. Forticao ha innovado en el uso del hierro hemínico, y el éxito ha sido demostrado por todos los años que ya se viene usando, dentro de los grupos más vulnerables, con óptimos resultados.

El producto Forticao se distribuye a nivel nacional en dos presentaciones:

Forticao polvo: precio de venta sugerido de S/. 54.00 por frasco de 80 gr.

Forticao chocolate: precio de venta sugerido de S/. 60.00 por frasco de 40 chocolatitos de 10 gr. Cada uno)

Forticao cápsulas: se encuentra en desarrollo

Información nutricional.

El producto Forticao contiene hierro, proteínas, calcio y zinc. (Ver Figura 15).

Otros productos de competencia directa con este plan de negocios son los que ofrecen las empresas La Ibérica, Di Perugia que cuentan con chocolates con alto porcentaje de cacao, y algunos chocolates orgánicos. La empresa Nestlé, que ofrece productos con menores concentraciones de cacao (Sublime, Triángulo, Princesa), representan una competencia importante ya que cuentan con una participación en el mercado peruano de $41 \%$, de acuerdo a 
Euromonitor (2016). En segundo lugar, se encuentra Molitalia con la línea de chocolates

Costa.

La Ibérica viene operando en el mercado peruano desde 1909. Tiene diversas presentaciones de chocolate de leche y fondant para barras y tabletas entre otros productos de confitería. Para el presente plan de negocio, representan competencia directa las líneas de "Chocolates" (chocolate en barra y tabletas, pastillas de chocolate) y "La Ibérica Chocolatier" (Milky, nueva línea de tabletas). La Ibérica ha obtenido diversos reconocimientos nacionales e internacionales, como la "Medalla de Oro" en la Exposición de Muestras de Roma en 1927 y el "Honor al Mérito Industrial" otorgado por la Sociedad Nacional de Industrias del Perú.

Di Perugia tiene más de 20 años en el mercado peruano. Tiene dos líneas de producto, una destinada al consumidor final (bombones, tabletas y bañados) y la otra denominada Chocochef (chocolate negro, chocolate con leche, cocoa y derivados del cacao). Las tabletas de chocolate tienen diversas presentaciones como chocolate de leche, con naranja, con castaña, bitter, etc.

El producto que pretende elaborarse en la planta de chocolates descrita en este plan de negocios tendría: hierro, vitamina $\mathrm{C}$ y Zinc. Se asemeja a Forticao en que ambos tienen refuerzo con micronutrientes. Ambos productos tienen hierro y zinc. La diferencia con el Forticao, es que este nuevo producto estaría fortificado además con vitamina $\mathrm{C}$, la que se aplicaría en las gomitas. Otra diferencia es que este nuevo producto solo se presentaría en tabletas de chocolate, mientras que Forticao se presenta también en polvo y se encuentre en etapa de desarrollo la presentación en cápsulas. En el Anexo 6 se presenta la composición química de las diferentes presentaciones de Forticao y las dosis sugeridas. 


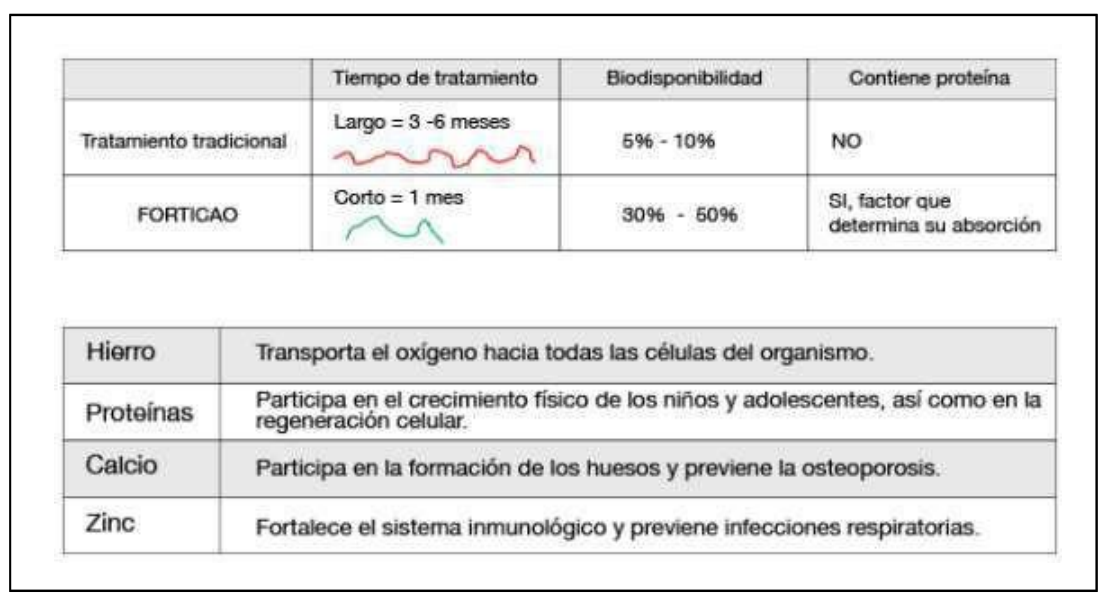

Figura 15. Información nutricional del producto Forticao. Recuperado de http://forticao.pe/

Participación de mercado de cada uno de ellos.

De acuerdo a información de Euromonitor (2016), la empresa Nestlé lidera el mercado de chocolates, teniendo el $40 \%$ del mercado, siendo la marca estrella el producto Sublime (27\%), seguido de Triángulo (7.8\%) y Princesa (4.7\%). El segundo lugar (20\%) lo tiene Molitalia con la marca de chocolates Costa. El resto está distribuido entre las demás marcas de chocolate y golosina.

El mercado de chocolates asciende a 8,600 toneladas al año, de los cuales el 15\% corresponde a chocolates con alto porcentaje de cacao (Andina, 2017).

Matriz de perfil competitivo.

La matriz de perfil competitivo (MPC) identifica a los principales competidores junto con sus fortalezas y debilidades y se compara con la empresa a evaluar o de interés. Para ello se deben identificar los factores críticos para el éxito, los que pueden incluir tanto cuestiones internas como externas, por lo tanto, estas cuestiones se clasifican en fortalezas y debilidades, donde 4 = fortaleza principal, 3 = fortaleza menor, $2=$ debilidad menor y $1=$ debilidad principal (David, 2008).

En la Tabla 4 se presenta de la matriz de perfil competitivo. Para elaborarla, se han considerado como factores críticos para el éxito los siguientes, dándole a cada uno de ellos un 
peso (entre 0.1 y 1 ), de acuerdo a la importancia para el proyecto, siendo el más importante la fortificación con micronutrientes, que es el factor de diferenciación. No entran en el análisis Nestlé ni Molitalia porque no tienen chocolates con $50 \%$ de cacao.

Participación en el mercado (0.20)

Alianzas estratégicas con alguna entidad (0.20)

Competitividad de precios $(0.15)$

Posición financiera $(0.10)$

Fortificación con micronutrientes $(0.25)$

Diversificación de productos $(0.10)$

Luego da darle el peso a cada factor, se procedió a otorgarle la calificación a Forticao, La Ibérica, Di Perugia, principales competidores en el rubro de chocolates con alto contenido de cacao, y al nuevo chocolate fortificado, en un rango de 1 a 4 de acuerdo a lo explicado previamente.

Tabla 4.

Matriz de Perfil Competitivo

\begin{tabular}{|c|c|c|c|c|c|c|c|c|c|}
\hline \multirow{2}{*}{$\begin{array}{l}\text { Factores Críticos para el } \\
\text { éxito }\end{array}$} & \multirow[b]{2}{*}{ Peso } & \multicolumn{2}{|c|}{ Chocovit } & \multicolumn{2}{|c|}{ Forticao } & \multicolumn{2}{|c|}{ La Ibérica } & \multicolumn{2}{|c|}{ Di Perugia } \\
\hline & & $\begin{array}{c}\text { Calificació } \\
\mathrm{n}\end{array}$ & $\begin{array}{c}\text { Calificació } \\
\text { n } \\
\text { Ponderada }\end{array}$ & $\begin{array}{c}\text { Calificació } \\
\mathrm{n}\end{array}$ & $\begin{array}{c}\text { Calificació } \\
n \\
\text { Ponderada }\end{array}$ & $\begin{array}{c}\text { Calificació } \\
\mathrm{n}\end{array}$ & $\begin{array}{c}\text { Calificació } \\
n \\
\text { Ponderada }\end{array}$ & $\begin{array}{c}\text { Calificació } \\
\mathrm{n}\end{array}$ & $\begin{array}{c}\text { Calificació } \\
n \\
\text { Ponderada }\end{array}$ \\
\hline $\begin{array}{l}\text { Participación en el } \\
\text { Mercado }\end{array}$ & 0.2 & 1 & 0.2 & 2 & 0.4 & 4 & 0.8 & 3 & 0.6 \\
\hline $\begin{array}{l}\text { Alianzas estratégicas } \\
\text { (UPCH, InkaFarma) }\end{array}$ & 0.2 & 1 & 0.2 & 4 & 0.8 & 4 & 0.8 & 4 & 0.8 \\
\hline $\begin{array}{l}\text { Competitividad de } \\
\text { Precios }\end{array}$ & 0.15 & 4 & 0.6 & 1 & 0.15 & 2 & 0.3 & 3 & 0.45 \\
\hline Posición Financiera & 0.10 & 1 & 0.1 & 4 & 0.4 & 4 & 0.4 & 3 & 0.3 \\
\hline $\begin{array}{l}\text { Fortificación con } \\
\text { micronutrientes }\end{array}$ & 0.25 & 4 & 1 & 4 & 1 & 1 & 0.25 & 1 & 0.25 \\
\hline $\begin{array}{l}\text { Diversificación de } \\
\text { productos }\end{array}$ & 0.1 & 1 & 0.1 & 3 & 0.3 & 4 & 0.4 & 4 & 0.4 \\
\hline Total & 1 & 12 & 2.2 & 18 & 3.05 & 19 & 2.95 & 18 & 2.8 \\
\hline
\end{tabular}

Fuente: Elaboración propia

Dentro de la categoría de chocolates con alto porcentaje de cacao, La Ibérica tiene una importante participación en el mercado, seguido de Di Perugia. Se estima que para el lanzamiento del nuevo chocolate y durante los primeros meses, Forticao tendrá mayor 
participación en el mercado, por ello se le otorga un puntaje de dos mientras que al nuevo producto solo uno. En cuanto a las alianzas estratégicas, el nuevo producto no las tiene, por lo que la puntuación es uno y para Forticao es de cuatro, representando una fortaleza principal, ya que trabaja de manera exclusiva con una cadena de farmacias a nivel nacional y tiene contacto con la Universidad Peruano Cayetano Heredia y otras entidades, con quienes trabajó al inicio de su proyecto. Por el lado de La Ibérica y Di Perugia cuentan con algunas alianzas estratégicas con algunas comunidades nativas productoras de cacao. En cuando a la competitividad en precios, para el nuevo producto se le da una puntuación de cuatro mientras que a Forticao de uno, ya que el nuevo producto ingresará al mercado a un precio menor que la competencia, quien además tiene un precio alto para el consumidor promedio. Los precios de La Ibérica son más elevados por ello se le da puntuación 2 y Di Perugia se han puntuado con valor 3. En cuanto a la posición financiera, Forticao ya tiene años operando en el mercado, y se ha financiado a través de entidades con la UPCH, mientras que para la implementación de la nueva plana de chocolates se recurrirá a un préstamo bancario y se tendrá deuda por algunos años, es por ello que la competencia tiene calificación de cuatro mientras que la nueva empresa solo uno. La Ibérica tiene 100 años en el mercado peruano, es una empresa sólida a nivel financiero. En cuanto a la fortificación con los micronutrientes, para ambos productos es de cuatro, ya que tienen los mismos componentes, y representa una fortaleza principal, mientras que para La Ibérica y Di Perugia la calificación es de uno, una debilidad mayor. Finalmente, para la diversificación de productos, Forticao tiene puntaje tres y La Ibérica y Di Perugia cuatro, por las diversas presentaciones y marcas que tienen. El nuevo chocolate solo saldrá en tabletas.

De la ponderación final, se tiene que el producto Forticao, tiene mayor ventaja competitiva, puesto que el elemento diferenciador, que es la fortificación con los micronutrientes, le da un mayor peso. En segundo lugar, se tiene a La Ibérica. El nuevo 
chocolate tiene la calificación final más baja, ya que se trata de un producto nuevo que recién entrará al mercado. El factor precio y la fortificación son los factores críticos de mayor importancia.

\subsection{Oportunidades y amenazas}

Las oportunidades identificadas son:

- Pocos competidores. Solo se tiene un producto similar en el mercado (Forticao) y algunos otros chocolates con alto contenido de cacao (La Ibérica y Di Perugia).

- Plan Nacional para la desnutrición crónica infantil y la prevención de la anemia en el país para el periodo 2017-2021, el cual propone una serie de objetivos, metas y estrategias a alcanzarse al 2021 para la reducción de la anemia y desnutrición.

- Nuevo estilo de vida en el mercado peruano con tendencia al consumo de comida saludable.

- Ferias nacionales e internacionales que van a permitir hacer más conocido el producto en el mercado nacional.

- Proyecto de reglamento técnico del uso de cacao del MINAGRI que va permitir tener clientes informados y con capacidad de elegir un mejor producto, favoreciendo el crecimiento del producto en el mercado peruano. En el Anexo 7 se presenta la Matriz FODA.

Las amenazas identificadas son:

- Falta de tecnología de punta en el país para la producción de derivados de cacao

- Ingreso de más competidores que ofrezcan productos similares

- Crecimiento del mercado de productos sustitutos

- Dificultad para obtener licencia de funcionamiento

- Sólo hay un proveedor de gomitas fortificadas en el mercado

- Competencia informal y desleal en el sector de chocolatería 
- Las bodegas y mayoristas no cuentan con sistema de ventilación y control de temperatura en sus almacenes. Este nuevo producto es sensible a temperaturas altas (mayor a $20^{\circ} \mathrm{C}$ ) sobre todo en verano.

- Inestabilidad por la desaceleración de la economía nacional.

\section{Capítulo IV. Estudio de mercado}

\subsection{Selección del segmento de mercado}

Segmentación.

Para la segmentación del mercado se tomará como población a las madres de familia con edades de 18 a 45 años, de los niveles socioeconómicos A, B, C y D, con hijos menores a 10 años que residen en 14 distritos.

Los criterios de segmentación son los siguientes:

Demográfico.

Se ha segmentado la población en edad y otra característica es que sean madres de familia con niños menores a 10 años. Se eligió todos los niveles socioeconómicos porque consideramos que el nivel socioeconómico A y B tienen interés en comprar alimentos saludables para sus hijos y capacidad de comprar regularmente nuestro producto. En cuanto al nivel socioeconómico C y D se lo tomará en cuenta por ser la población más vulnerable a adquirir anemia y se va estudiar su capacidad de adquirir nuestro producto.

Asimismo, se eligió a las madres de familia quienes son las que deciden la compra del producto solas o en conjunto con sus hijos.

Geográfico.

En cuanto al ámbito del mercado se ha tomado catorce distritos de Lima Metropolitana, se consideró Miraflores, San Isidro, San Borja, Santiago de Surco, La Molina, Magdalena del Mar, San Miguel, Lince, Pueblo Libre, Jesús María porque son los distritos con mayor 
porcentaje de población con NSE A y B; y se eligió los distritos Independencia, Los Olivos, San Martín, San Juan Lurigancho por tener el mayor porcentaje de población con NSE C y D.

\subsection{Investigación cualitativa}

De acuerdo a Malhotra (2008), se sugiere que cuando se tiene la posibilidad y acceso a especialistas con amplio conocimiento sobre la materia, se opte como mejor alterativa de investigación cualitativa, la técnica directa de entrevistas a profundidad. En este proyecto se entrevistó a tres expertos de los sectores de chocolatería, nutrición y de la industria alimentaria que está relacionado al plan de negocio, se utilizó esta técnica por ser la recomendada para profesionales y permite profundizar en los temas de interés.

\subsubsection{Proceso de muestreo}

El método utilizado fue entrevista en profundidad que según Malhotra (2008) es una entrevista no estructurada, directa y personal en la que un entrevistador altamente capacitado interroga a una sola persona.

Las entrevistas a profundidad duraron aproximadamente una hora, se iniciaron con temas generales relacionados al sector del experto y finalmente se abordó el tema específico del chocolate nutritivo.

En el sector de la industria de alimentos se entrevistó al Dr. Ingeniero en Industrias Alimentarias Antonio Ricardo Rodríguez Zevallos, catedrático de la Universidad Antenor Orrego de Trujillo, especialista en investigación sobre micronutrientes como vitamina C e innovación en productos alimentarios.

En el sector de chocolatería se entrevistó a Rolando Herrera, Gerente general de Finca San Antonio S.A.C, presidente de APPCACAO 2008-2010 y ex presidente del Consejo Directivo de Cooperativa Agraria Industrial Naranjillo, gran conocedor del cacao y sus derivados.

En el área de nutrición se entrevistó a Karem Delgado Coloma, Nutricionista y Dietista con Especialización en Ciencias de la Alimentación en Bélgica e Investigación 
Epidemiológica de la Universidad Peruana Cayetano Heredia. Actualmente es Investigadora en una ONG en el Perú dedicada a temas de alimentación y nutrición en niños en zonas rurales.

\subsubsection{Diseño del instrumento}

A continuación, se detallan las guías de las tres entrevistas a profundidad realizadas a expertos.

Entrevista $\mathrm{N}^{\circ}$ 1: Ingeniero en Industrias Alimentarias

Guía $\mathrm{N}^{\circ} 1$ : Entrevista Ingeniero en Industrias Alimentarias

La entrevista se enfocó en las tendencias de innovación del sector de industrias alimentarias y conceptos básicos sobre alimentos funcionales y nutracéuticos, alimentos enriquecidos y fortificados, todos englobados en nociones generales del sector que contribuyen a definir la categoría a la que pertenece el producto desarrollado. Los otros temas son más específicos a la problemática de la anemia y recomendaciones sobre el producto desarrollado.

Nociones generales del sector de industrias de alimentos

Tendencias en la industria alimentaria

Definición de alimentos funcionales y nutraceúticos

Definición de productos enriquecidos y fortificados

Con referencia a los tipos de productos para prevenir la anemia y la crítica sobre el producto desarrollado

Productos procesados para prevenir la anemia en el mercado

Opinión sobre la tableta de chocolate de leche con gomitas fortificadas con vitamina C, hierro y zinc

Recomendación para preservar los componentes nutricionales del chocolate desarrollado Entrevista $\mathrm{N}^{\circ}$ 2: Especialista en Chocolatería 
Guía N²: Especialista en Chocolatería

La entrevista se enfocó en las tendencias de innovación del sector de chocolatería, modificación en la normativa sobre denominación de "chocolate" y beneficios del chocolate, todos englobados en nociones generales del sector de chocolatería que contribuye a conocer los competidores. El otro tema es específico a crítica y recomendaciones sobre el producto desarrollado.

Nociones generales del sector de chocolatería

Cambios en la nueva normativa de la definición de derivados del cacao

Tendencias en el sector de chocolatería

Bondades del chocolate

Tipos de chocolates funcionales y nutracéuticos

Con referencia a la crítica sobre el producto desarrollado

Opinión y recomendación de mejoras sobre la tableta de chocolate de leche con gomitas fortificadas con vitamina $\mathrm{C}$, hierro y zinc

Entrevista $\mathrm{N}^{\circ}$ 3: Nutricionista

Guía N³: Nutricionista

Productos para combatir la anemia.

Programa del MINSA para combatir la anemia.

Problemática del MINSA que no logra erradicar la anemia.

Opinión sobre la tableta de chocolate de leche con gomitas fortificadas con vitamina C, hierro y zinc

Recomendación para mejorar el producto desarrollado.

\subsubsection{Análisis y procesamiento de datos}

En cuanto a la información que nos brindaron los especialistas, tenemos que el Dr.

Ricardo Rodriguez, Ingeniero en Industrias Alimentarias, informó que la tendencia de la 
industria es producir alimentos saludables y nutritivos (con adición de vitaminas y minerales), naturales es decir de bajo procesamiento y orgánicos con sabores exóticos que sean de rápido consumo para facilitar la vida de las personas que trabajan y no tienen tiempo de cocinar. Bajo esta tendencia es que han surgido los alimentos funcionales y nutraceúticos a los que se les agrega componentes que ayudan a los seres humanos a prevenir ciertas enfermedades. Asimismo, informó que no existe regulación para que las empresas agreguen hierro a los alimentos de mayor consumo como una medida para reducir la anemia, lo cual sería necesario. Actualmente existe regulación para el yodo y algunas vitaminas. En cuanto al producto desarrollado, el especialista opinó que éste puede tener gran aceptabilidad en el mercado y le pareció interesante. Por sus características el producto se podría disolver rápido en boca y por lo tanto el consumidor asimilaría fácilmente los nutrientes. En cuanto a los cuidados a tener en cuenta para conservar los nutrientes, recomienda usar envases herméticos que protejan al producto del contacto del sol, altas temperaturas y alto porcentaje de humedad.

Por su parte el Sr. Rolando Herrera, nos comentó que la delegación encargada de elaborar la nueva regulación sobre denominación de los derivados de cacao se están enfocando en que el producto que lleve la denominación de chocolate no tenga ningún porcentaje de grasa vegetal y se van a retirar los términos compuestos sólidos y magros del cacao que diferenciaban los tipos de chocolate y pasar a los términos de porcentaje de pasta pura y manteca de cacao, con la finalidad de facilitar la comprensión de la norma. En cuanto a la tendencia del sector, éste se enfoca en elaborar productos con mayor porcentaje de cacao, superiores a $70 \%$ y con sabores exóticos como aguaymanto y otros berries. En cuanto al procesamiento de chocolates, la tendencia es reducir los procesos como eliminar el tostado o reducir los días de fermentación para evitar la pérdida de compuestos fenólicos en el cacao, los cuales ayudan a prevenir enfermedades cardiovasculares. Los chocolates funcionales y 
nutracéuticos que se están desarrollando se enfocan en prevenir tres tipos de enfermedades: diabetes, anemia y enfermedades cardiovasculares. En cuanto al producto desarrollado, el especialista indicó que es innovador y está dentro de las tendencias actuales que demanda el mercado. Asimismo, recomendó incrementar el porcentaje de cacao a 50\% para reforzar las bondades nutritivas del cacao y reducir el dulzor del chocolate porque al combinarse con gomitas el contenido de azúcar podría ser muy alto.

En cuanto a la nutricionista, Karem Delgado Coloma, comentó sobre las diferentes alternativas de alimentación nutritiva, como la diversificación de la dieta, la suplementación y la fortificación. En cuanto a la diversificación de la dieta, comentó que es importante considerar el consumo de alimentos ricos en hierro como lo son las carnes rojas, el hígado y algunas vísceras. Dentro de la suplementación principalmente, consiste en tomar una cápsula de hierro, jarabe o pastillas. Y en fortificación, comentó sobre la línea de alimentos que en su proceso de industrialización añade algún micronutriente. En particular habló sobre el Forticao, que es un producto con fortificación de hierro, y su experiencia de trabajo con la inventora de este producto, con quien trabajó hace muchos años en los inicios del proyecto. Se inició como una investigación la presentación en polvo mezclado con la cocoa y el ferrimin, y se probó con niños en la localidad de Uchiza en la Provincia de Tocache, en la que se logró una buena aceptación. Se usó no solamente el producto en cocoa, sino galletas y con fudge. En su experiencia, cualquier producto a base de chocolate tiene una muy buena aceptación en la población infantil. Karem realizó luego una tesis para hacer un estudio de la eficacia del uso de la cocoa fortificada con hierro y si elevaba la hemoglobina en los niños en etapa pre escolar (de 3 a 5 años de edad). Se comprobó que en cuatro semanas se subía el nivel de hemoglobina. Luego se hicieron más estudios para probar en gestantes y sí, el uso de esta cocoa fortificada con hierro subía los niveles de hemoglobina entre cuatro y seis semanas. 
En suplementación, comentó que se está usando a nivel nacional dentro de un programa del Ministerio de Salud, un producto denominado "chispitas nutricionales", los que se reparten en todos los puestos de salud de manera gratuita para personas de bajos recursos (para niños hasta los 36 meses), y se usan para combatir la anemia y la desnutrición. Es un sobre que contiene micronutrientes como hierro, zinc, vitaminas A, D, E entre otras, que se pone directamente en el alimento. Comenta que se ha probado en varios países de Latinoamérica, y es muy efectivo. El problema es que muchas veces el niño come 2 o 3 cucharas y lo que deja se pierde junto con la chispita.

A pesar de estos programas que ha incluido el Estado Peruano aún no se logra mejorar los niveles de anemia y desnutrición en el Perú. No se llega a todos los lugares con este producto denominado chispitas, y por su lado, el Forticao y otros suplementos resultan costosos. Comenta Karem además que la anemia ocasiona no solo otros problemas a la salud, sino también de desarrollo intelectual y cognitivo en el niño. Comenta también, que no solo es la falta de hierro que ocasione la anemia, sino también el tener constantes cuadros infecciosos y diarreas por falta de higiene. En muchas zonas no hay agua potable o un buen sistema de eliminación de excretas. Y no basta todo lo que hace el Estado si es que no mejoran las condiciones de saneamiento.

A la pregunta sobre qué le parece este nuevo producto que pretende lanzar este plan de negocios, comenta que la idea le parece buena por el uso del hierro, además si va a incluir un buen porcentaje de chocolate, buenas grasas. Y con relación a las gomitas, comenta que le parece innovador y que en todo producto alimenticio el sabor es muy importante, y que estas pueden dar un buen sabor. La recomendación es cuidar los niveles de azúcar y enfocarnos en la campaña de marketing, que debe incluir cuáles son nuestras ventajas competitivas y diferenciadoras en relación a la competencia, que en realidad este producto tiene las de ganar, 
porque no existen productos similares. Y hay que aprovechar que el consumidor ahora se informa y tiende a consumir productos más saludables.

\subsection{Investigación cuantitativa}

\subsubsection{Proceso de muestreo}

La investigación de mercado para este producto se enfoca en el método no probabilístico por conveniencia. Para ello se realizaron encuestas en 14 distritos de Lima de los niveles socioeconómicos NSE A, B, C y D. Los distritos elegidos para la muestra son los de las zonas 2, 3, 6 y 7. Las zonas 6 y 7 se eligen por su representatividad en los NSE A y B. Para la zona 6, que comprende los distritos de Jesús María, Lince, Magdalena del Mar, Pueblo Libre y San Miguel, el 71.7\% de la población en esta zona es NSE A y B. Para la zona 7, que comprende los distritos de La Molina, Miraflores, San Borja, San Isidro y Santiago de Surco, el 79.2\% de la población de estos distritos es NSE A y B. Por otro lado, la zona 2, que comprende los distritos de Independencia, Los Olivos y San Martín de Porras, se elige por su representatividad en el NSE C, el 52.1\% de la población en esta zona se encuentra en esta categoría. Y finalmente la zona 3 que comprende el distrito de San Juan de Lurigancho se elige porque comprende el $44.2 \%$ de NSE C pero además hay un importante porcentaje de NSE B (19.1\%). (CPI Compañía Peruana de Estudios de Mercados y Opinión Pública, Market Report para el 2017).

Para obtener la muestra se basó en el número de hogares en cada uno de los 14 distritos indicados, información recogida también de CPI, la que se muestra en la tabla 5.

El objetivo de la encuesta es encontrar el porcentaje de personas que estarían dispuestas a comprar este nuevo chocolate de leche con gomitas fortificadas con Hierro, Vitamina C y Zinc.

Las encuestas se dirigieron a madres de familia con hijos entre 0 y 10 años de edad, de los distritos mencionados. 
Tabla 5.

Población y hogares según distritos en el año 2017.

\begin{tabular}{lll}
\hline DISTRITOS & Población & Hogares \\
\hline San Juan de Lurigancho & $1,121,300$ & 275,900 \\
San Martín de Porres & 722,300 & 175,200 \\
Los Olivos & 382,800 & 107,400 \\
Santiago de Surco & 357,600 & 107,800 \\
Independencia & 223,600 & 67,800 \\
La Molina & 178,200 & 48,000 \\
San Miguel & 140,900 & 44,800 \\
San Borja & 116,700 & 37,800 \\
Miraflores & 85,800 & 33,700 \\
Pueblo Libre & 79,400 & 27,700 \\
Jesús María & 74,700 & 23,900 \\
San Isidro & 56,800 & 23,200 \\
Lince & 52,400 & 18,900 \\
Magdalena del Mar & 56,900 & 19,000 \\
\hline Total & $3,649,400$ & $1,011,100$ \\
\hline
\end{tabular}

Fuente: Elaboración propia

Nota: Datos obtenido de CPI 2017

Tamaño de la muestra

Para determinar el tamaño de la muestra, se utilizó el método probabilístico para

poblaciones finitas, considerando un nivel de confianza del 95\%, una distribución normal

estandarizada $Z=1.96$, probabilidad de éxito (p) del 50\%, probabilidad de fracaso (q) del $50 \%$ y nivel de tolerancia o error (E) del $5 \%$.

El tamaño de la población finita $\mathrm{N}$ es conocido, es el número total de hogares indicados en los 14 distritos a estudiar. Ver tabla 4.

$\mathrm{N}=1,011,100$

Entonces, el tamaño de la muestra es:

$$
\square=\frac{\square^{\square} \cdot \square . \square . \square}{\square \square(\square-1)+\square \square . \square . \square}
$$

donde:

$\mathrm{Z}$ : nivel de confianza al $95 \%$ de confianza $=1.96$

p: proporción de personas que tienen interés en comprar el producto $=50 \%$ 
q: proporción de personas que no tienen interés en comprar el producto $=50 \%$

E: error máximo permisible $=5 \%$

$\mathrm{N}: 1,011,100$ hogares

$\mathrm{n}=384$

La muestra total para aplicar las encuestas será de 384.

Cuota por distritos

Para determinar la cuota a aplicar por zona se considera la proporción de la población en cada una de las zonas elegidas: 2, 3, 6 y 7 de Lima Metropolitana (ver Tabla 6).

Tabla 6.

Distribución de la población de las zonas 2, 3, 6 y 7 en los NSE A, B y C

\begin{tabular}{|c|c|c|c|c|c|c|c|}
\hline Zonas & \begin{tabular}{l}
\multicolumn{1}{c}{$\%$} \\
población \\
sobre Lima \\
Metropolitana
\end{tabular} & NSE A & NSE B & NSE C & NSE D & Factor & $\begin{array}{r}\mathrm{N}^{\circ} \mathrm{de} \\
\text { encuestas }\end{array}$ \\
\hline Zona 2 & $13 \%$ & $2.0 \%$ & $23.7 \%$ & $52.1 \%$ & $19.8 \%$ & 0.363 & 139 \\
\hline Zona 3 & $11 \%$ & $0.0 \%$ & $19.1 \%$ & $44.2 \%$ & $26.7 \%$ & 0.307 & 118 \\
\hline Zona 6 & $4 \%$ & $13.7 \%$ & $58.0 \%$ & $22.1 \%$ & $5.4 \%$ & 0.112 & 43 \\
\hline Zona 7 & $7.80 \%$ & $35.9 \%$ & $43.3 \%$ & $14.9 \%$ & $4.5 \%$ & 0.218 & 84 \\
\hline \multicolumn{7}{|c|}{ Total muestra } & 384 \\
\hline
\end{tabular}

Fuente: Elaboración propia

Nota: Datos obtenido de CPI 2017

La cuota por distrito se divide equitativamente (Ver tabla 7).

Selección de elementos de la muestra

La encuesta se dirigió a madres de familia con hijos entre 0 y 10 años residentes en los 14

distritos indicados, y se aplicó en dos modalidades:

Presenciales: para los distritos de las zonas 2 y 3.

Vía correo electrónico a través de un aplicativo web: para las zonas 6 y 7.

La encuesta se aplicó desde el domingo 10 hasta el viernes 29 de setiembre de 2017.

En el caso de las encuestas presenciales, se dirigió a diferentes zonas como Nido La Casita Amarilla en Surco, CC La Rambla en San Borja, Mercado de Independencia, Estación Metropolitano en Caquetá y Mercado de San Juan de Lurigancho. Y para las encuestas on 
line, se publicó el enlace en diferentes redes sociales como Facebook y blog El Baúl de

Antonia, cuyo público objetivo son madres de familia.

Tabla 7.

Cuota por distrito y por zona.

\begin{tabular}{lll}
\hline Distritos por zonas & Zonas & Cuota por distrito \\
\hline Independencia & Zona 2 & 46 \\
Los Olivos & 46 \\
San Martín de Porras & Zona 3 & 118 \\
San Juan de Lurigancho & & 9 \\
Jesús María & 9 \\
Lince & Zona 6 & 9 \\
Magdalena del Mar & & 8 \\
Pueblo Libre & & 8 \\
San Miguel & & 17 \\
La Molina & 17 \\
Miraflores & & 17 \\
San Borja & Zona 7 & 16 \\
San Isidro & & 17 \\
Santiago de Surco & & \\
\hline
\end{tabular}

Fuente: Elaboración propia

Nota: Datos obtenido de CPI 2017

\subsubsection{Diseño del instrumento}

A continuación, se presenta la encuesta aplicada.

Primero se solicitaron los datos de control para la segmentación.

\begin{tabular}{|c|c|c|c|c|c|c|c|c|}
\hline \multicolumn{9}{|c|}{ DATOS DE CONTROL } \\
\hline \multicolumn{4}{|c|}{ 1. Distrito de procedencia } & 3. Edad & De 18 a 25 años & ( & & \\
\hline \multirow{2}{*}{\multicolumn{4}{|c|}{ 2. ¿Tiene hijos menores de 10 años? }} & & De 26 a 30 años & ( & ) & \\
\hline & & & & & De 31 a 45 años & ( & ) & \\
\hline Sí & ( & ) & & & & & & \\
\hline & & ) & (Fin de laencuesta) & 4. Ingres & familiar mensual & & & \\
\hline & & & & & Menos de S/ 850 & ( & ) & (Fin de la encuesta) \\
\hline & & & & & $\mathrm{De} S / 850$ a S/ 2,000 & ( & ) & \\
\hline & & & & & $\mathrm{De} S / 2,000$ a $\mathrm{S} / 4,000$ & ( & ) & \\
\hline & & & & & Más de S/ 5,000 & ( & ) & \\
\hline
\end{tabular}

Y luego las preguntas del cuestionario. 
CUESTIONARIO

Buenos días / tardes como parte de una investigación en el rubro de chocolatería, le solicitamos nos pueda brindar un espacio de su valioso tiempo. La información brindada es de carácter confidencial y se utilizará únicamente para los fines de este estudio. Agradecemos su honestidad y transparencia. Muchas gracias.

\section{CONCEPTO DEL PRODUCTO}

1. ¿Suele usted consumir chocolates?

Sí

No
( )

) (Fin de la encuesta)
2. ¿Con qué frecuencia los consume?

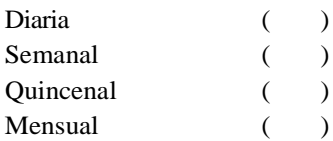

3. ¿Dónde suele comprar? Puede elegir más de una opción

Supermercados ( )

Minimarket ( )

Farmacias $\quad(-6)$

Bodegas

Quioscos

Otros

(especificar)

4. Al momento de comprar chocolate, a cuál de estas características le da importancia?

\section{Precio}

Prestigio de marca

Poder nutricional

Variedad de sabores

Insumos naturales ( )

Otros (especificar)
La e mpresa ofrecerá tabletas de chocolate (con porcentaje de cacao requerido por INDECOPI y DIGESA) con gomitas de hie rro, vitamina $\mathrm{C}$ y Zinc en presentación de 30 gr. El que se rvirá para prevenir la anemia y desnutrición.

5. ¿Estaría usted interesado en comprar este producto?

$\begin{array}{lll}\text { Definitivamente sí } & ( & (\quad) \\ \text { Probablemente sí } & ( & (\quad) \\ \text { No sabe } & ( & (\quad) \\ \text { Probablemente no } & ( & (\quad)\end{array}$

Definitivamente no

6. ¿Con qué frecuencia compraría este producto?

$\begin{array}{ll}\text { Diaria } & (\quad) \\ \text { Semanal } & (\quad) \\ \text { Quincenal } & (\quad) \\ \text { Mensual } & (\quad)\end{array}$

7. ¿Qué sabor de gomita le gustaría que lleve el producto? Puede elegir más de una opción

\begin{tabular}{|c|c|}
\hline Guanábana & ( \\
\hline Maracuyá & ( \\
\hline Sauco & ( \\
\hline Limón & ( \\
\hline Naranja & 8 \\
\hline Piña & \\
\hline Aguaymanto & ( \\
\hline
\end{tabular}

8. ¿Cuánto estaría dispuesto a pagar usted por el producto? (1 unidad)

De $\mathrm{S} / 1.50 \mathrm{a} \mathrm{S} / 2.00 \quad(\quad)$

$\mathrm{De} \mathrm{S} / 2.1 \mathrm{a} \mathrm{S} / 2.50 \quad(\quad)$

De S/. 2.60 a S/. $3.0 \quad(\quad)$

9. ¿Enqué lugares le gustaría comprar este producto? Puede elegir más de una opción

$\begin{array}{lll}\text { Supermercados } & ( & (\quad) \\ \text { Minimarket } & ( & (\quad) \\ \text { Farmacias } & ( & (\quad) \\ \text { Bodegas } & ( & (\quad) \\ \text { Quioscos } & (\end{array}$

Otros (especificar) 


\subsubsection{Análisis y procesamiento de datos}

Se procesó la data inicialmente en el programa SPSS para validar los resultados. En la Figura 16 se presentan las estadísticas de frecuencia en la intención de compra de Chocovit, donde 1 significa Definitivamente sí y Probablemente sí compraría, 2 significa que no está seguro de sí lo compraría y 3 significa que definitivamente no y probablemente no compraría el producto.

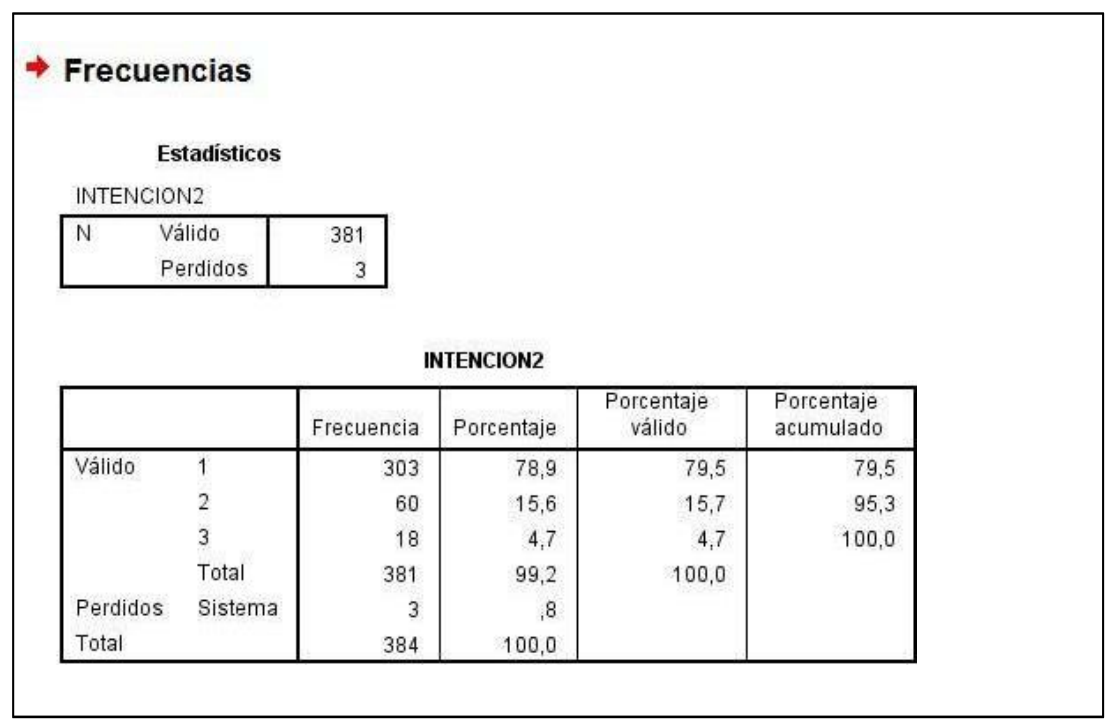

Figura 16. Intención de compra de Chocovit. Reporte de Frecuencia obtenida del SPSS. Elaboración propia.

Se realizó además la prueba T-Student cuyos resultados se presentan en la Figura 17. Se planteó la hipótesis para validar la aceptación de Chocovit superior al 75\%.

Hipótesis nula. H0: $\mathrm{p}<=0.75$

Hipótesis alternativa $\mathrm{H} 1: \mathrm{p}>0.75$

De acuerdo a los resultados de la prueba T-Student, el valor de sigma bilateral es 0.000 menor que 0.05 , con lo que se concluye que se rechaza la hipótesis nula, a un nivel de confianza del 95\%, aceptando la hipótesis alternativa, es decir se demuestra que la aceptación del producto es superior al $75 \%$

Del procesamiento de datos se tienen las siguientes estadísticas, las que se presentan a continuación. 
Se logró cumplir con la cuota designada por distrito. Total de encuestas: 384. En la Figura 18 se presenta la distribución por distrito de procedencia.

\section{Prueba T}

Estadísticas de muestra única

\begin{tabular}{|l|c|c|c|c|}
\hline & $\mathrm{N}$ & Media & $\begin{array}{c}\text { Desviación } \\
\text { estándar }\end{array}$ & $\begin{array}{c}\text { Media de } \\
\text { error } \\
\text { estándar }\end{array}$ \\
\hline INTENCION2 & 381 & 1,25 &, 533 &, 027 \\
\hline
\end{tabular}

Prueba de muestra única

\begin{tabular}{|c|c|c|c|c|c|c|}
\hline & \multicolumn{6}{|c|}{ Valor de prueba $=0.75$} \\
\hline & \multirow[b]{2}{*}{$t$} & \multirow[b]{2}{*}{ gl } & \multirow[b]{2}{*}{ Sig. (bilateral) } & \multirow{2}{*}{$\begin{array}{l}\text { Diferencia de } \\
\text { medias }\end{array}$} & \multicolumn{2}{|c|}{$\begin{array}{c}95 \% \text { de intervalo de confianza } \\
\text { de la diferencia }\end{array}$} \\
\hline & & & & & Inferior & Superior \\
\hline INTENCION2 & 18,395 & 380 & .000 & 502 & 45 & 56 \\
\hline
\end{tabular}

Figura 17. Prueba T-Student realizada en SPSS. Elaboración propia.

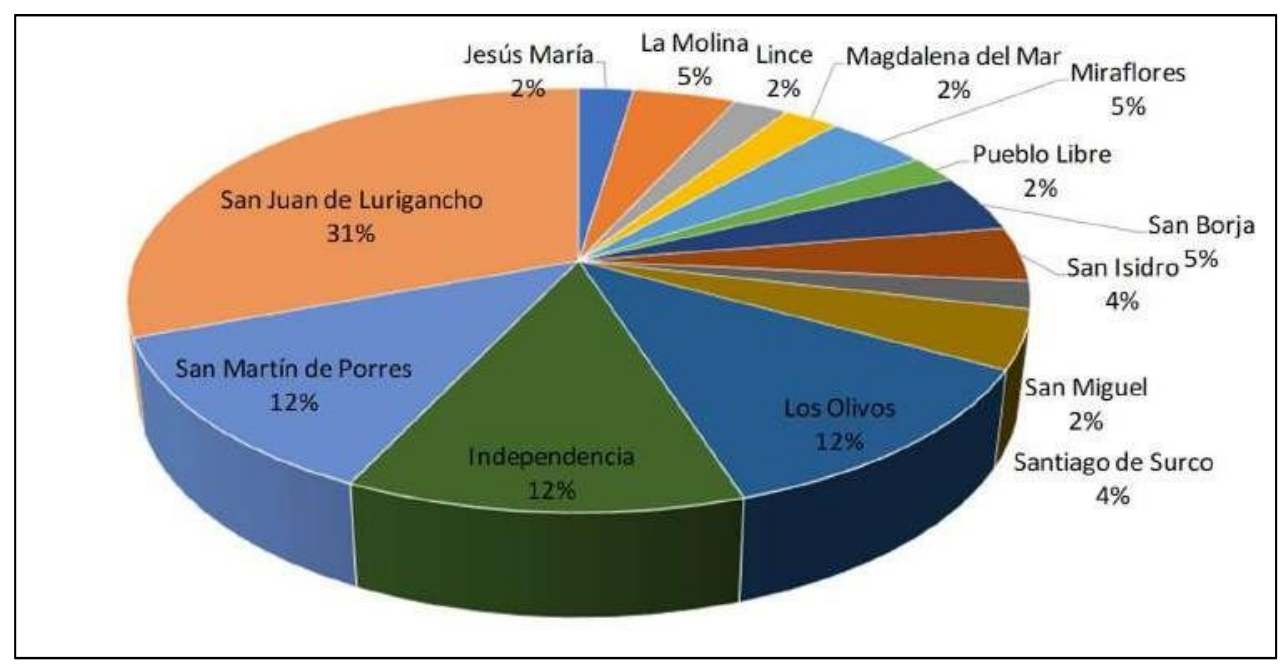

Figura 18. Distrito de procedencia. Distribución de la muestra por cada distrito donde se aplicó la encuesta. Elaboración propia.

El 100\% de las encuestadas tienen hijos entre 0 y 10 años de edad.

En la Figura 19 se presenta la distribución por edad. El 39\% de las encuestadas tienen edad entre 31 y 45 años, el 35\%, entre 26 y 30 años, el $24 \%$ entre 18 y 25 años y el $2 \%$ tiene más de 46 años. 


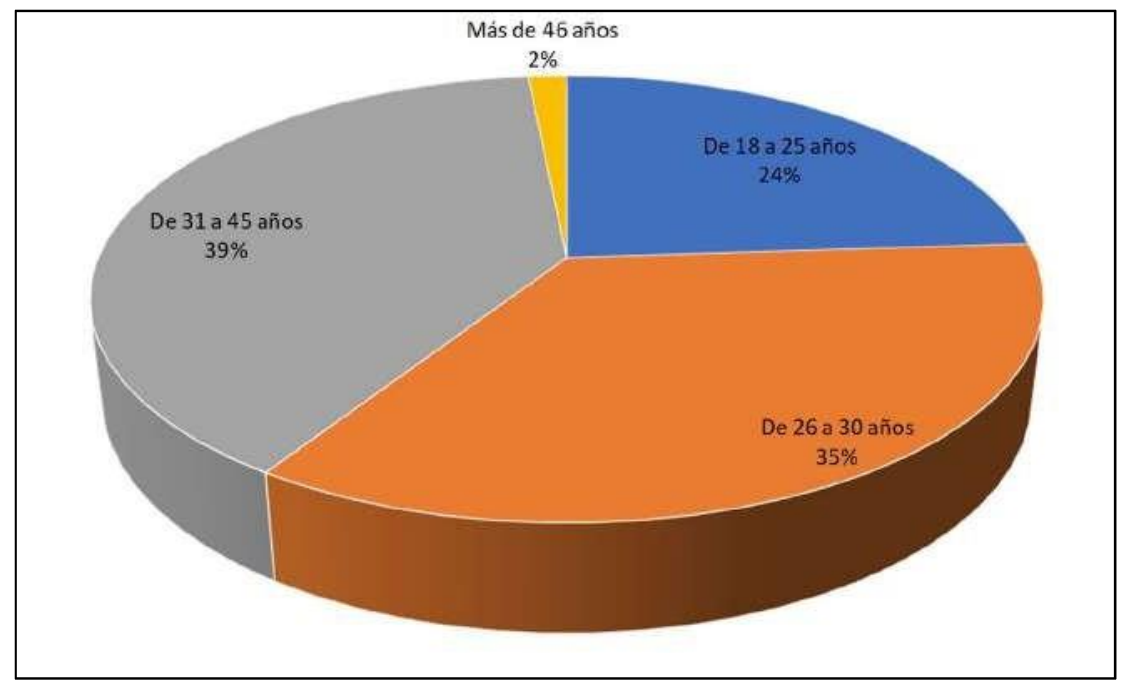

Figura 19. Representación edad. Distribución de la muestra por rangos de edad. Elaboración propia.

El $41 \%$ de las encuestadas tienen ingresos entre S/ 850 y S/ 1,999, el 24\% entre S/ 2,000 y S/ 5,000, el 20\% tiene ingreso mayor a S/ 5,000 y el 15\% menor a S/ 850. Ver Figura 20.

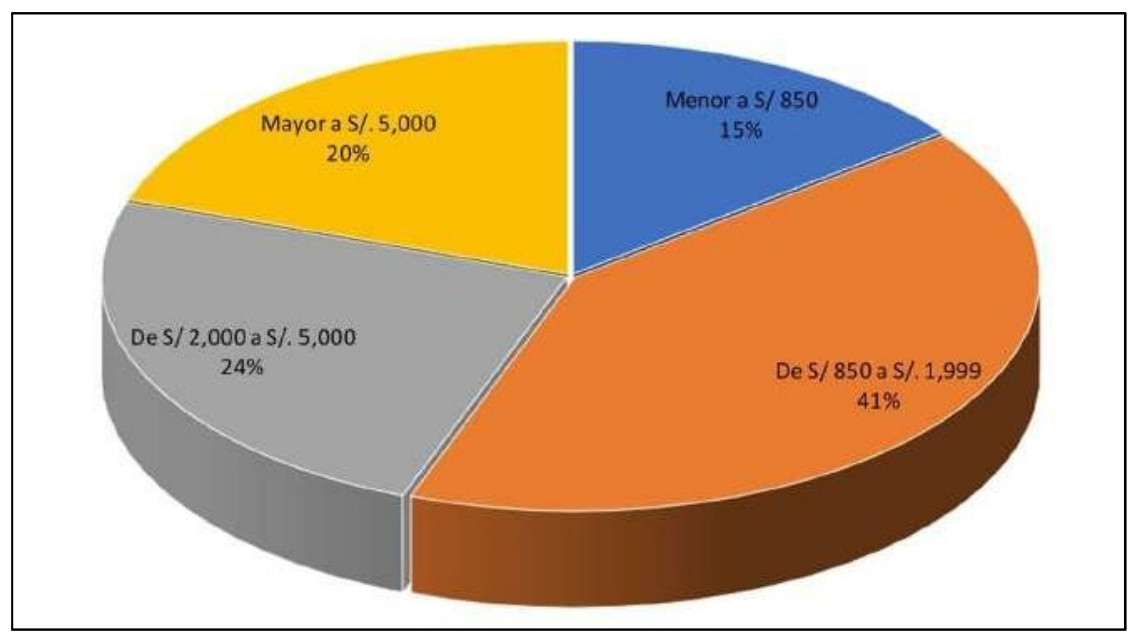

Figura 20. Ingreso familiar. Distribución de la muestra por rango de ingreso familiar. Elaboración propia.

Del total de encuestadas, el 98\% indicó que suele consumió chocolates, y el 2\% indicó que no consume.

Sobre la frecuencia en el consumo de chocolates (ver Figura 21), el $73 \%$ lo consumen entre semanal y quincenal, mientras que el $17 \%$ lo hace de manera mensual y solo el $11 \%$ de manera diaria. 


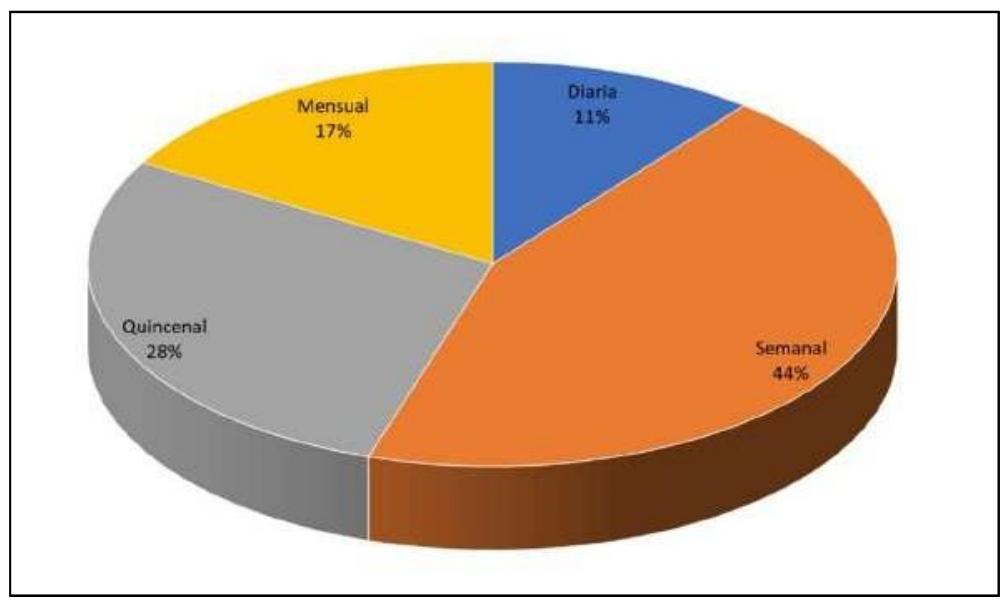

Figura 21. Frecuencia de consumo de chocolates. Pregunta 2. ¿Con qué frecuencia consume chocolates? Elaboración propia.

Sobre la preferencia del lugar compra de chocolates (Ver Figura 22), la pregunta que se realizó fue de opciones múltiples, es decir, podían escoger más de una opción. el 53\% indicó que prefiere realizarlo en supermercados, el $52 \%$ en bodegas, el $21 \%$ en minimarkets, el $14 \%$ en quioscos, el $3 \%$ en farmacias y el $2 \%$ indicó otros lugares.

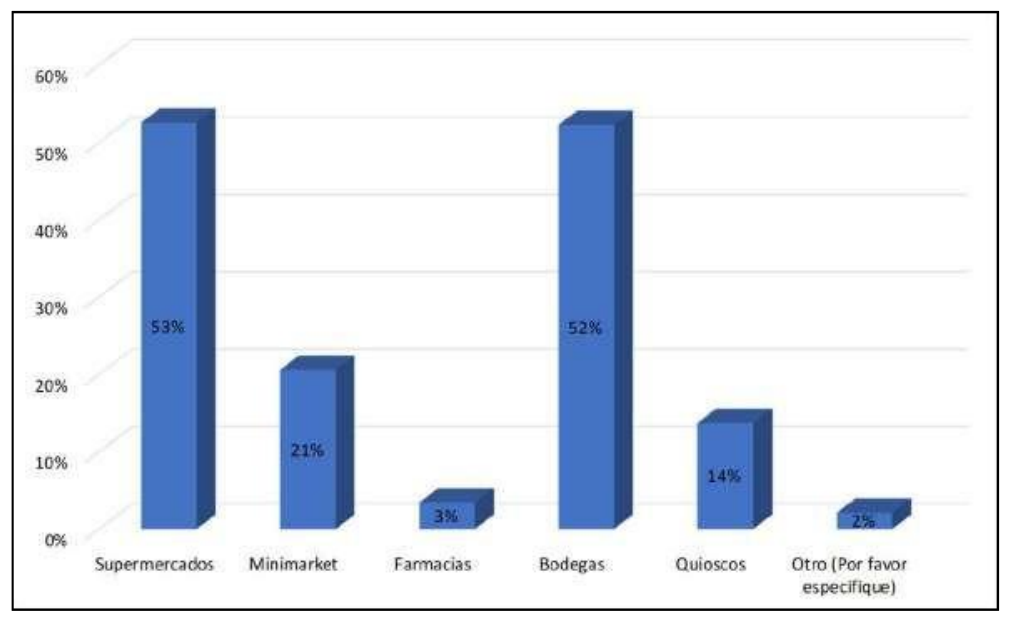

Figura 22. Preferencia del lugar de compra. Pregunta 3. ¿Dónde suele comprar chocolates? Puede elegir más de una opción. Elaboración propia.

En cuanto a la pregunta que se realizó sobre la característica que le dan mayor importancia al momento de comprar chocolates (también de opciones múltiples), el $48 \%$ eligió el prestigio de la marca, el $29 \%$ le da importancia al precio, el $22 \%$ valoran los insumos 
naturales, el $20 \%$ al valor nutricional, el $17 \%$ a la variedad de sabores y el $3 \%$ eligió otras características. Ver Figura 23.

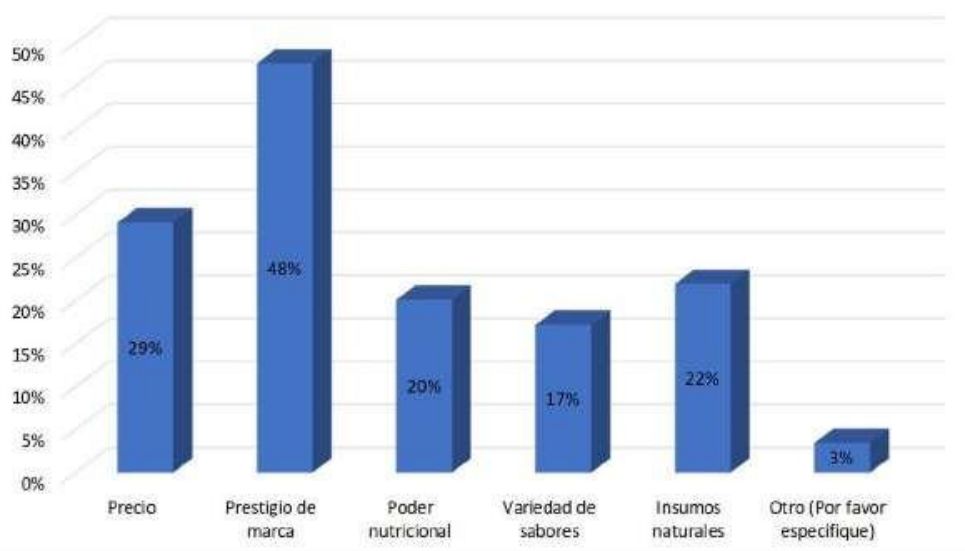

Figura 23. Importancia en la característica al momento de compra. Pregunta 4. Al momento de comprar chocolate, ¿a cuál de estas características le da importancia?. Puede elegir más de una opción. Elaboración propia.

A la pregunta de, si estarían dispuestas a comprar el nuevo chocolate Chocovit, con gomitas fortificadas de hierro, zinc y vitamina C, casi el 80\% indicó que definitivamente sí y probablemente sí, el 16\% no está segura y solo el 5\% indicó que probablemente no y definitivamente no. Ver Figura 24.

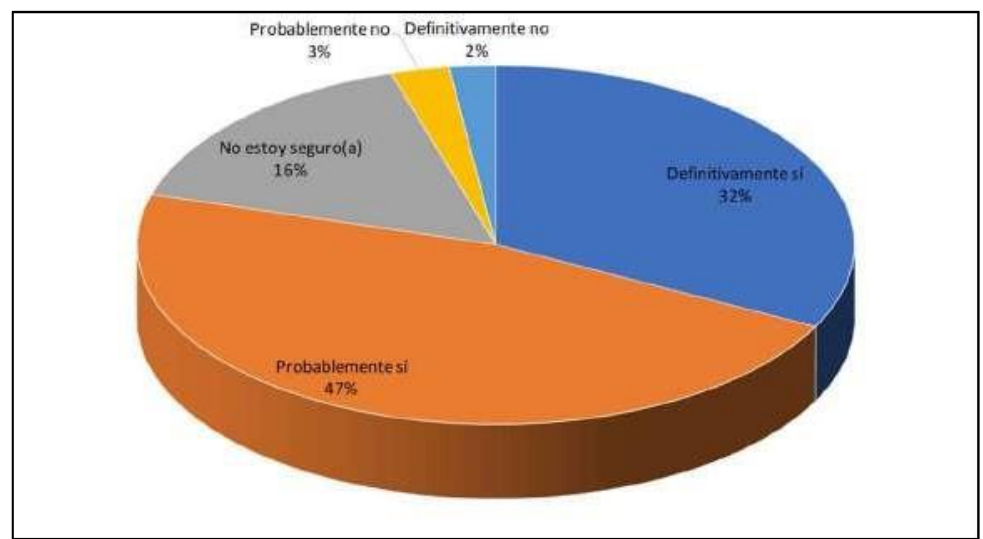

Figura 24. Intención de compra del producto Chocovit. Pregunta 5. ¿Estaría usted interesado en comprar este producto? Elaboración propia.

Sobre la pregunta, con qué frecuencia comprarían el nuevo producto Chocovit, se realizó la pregunta al 80\% que indicó que compraría el producto, es decir a 376 madres. El 39\% 
indicó que lo haría de manera semanal, el 24\% lo compraría quincenalmente, el 23\% mensual y el 14\% de manera diaria. Ver Figura 25.

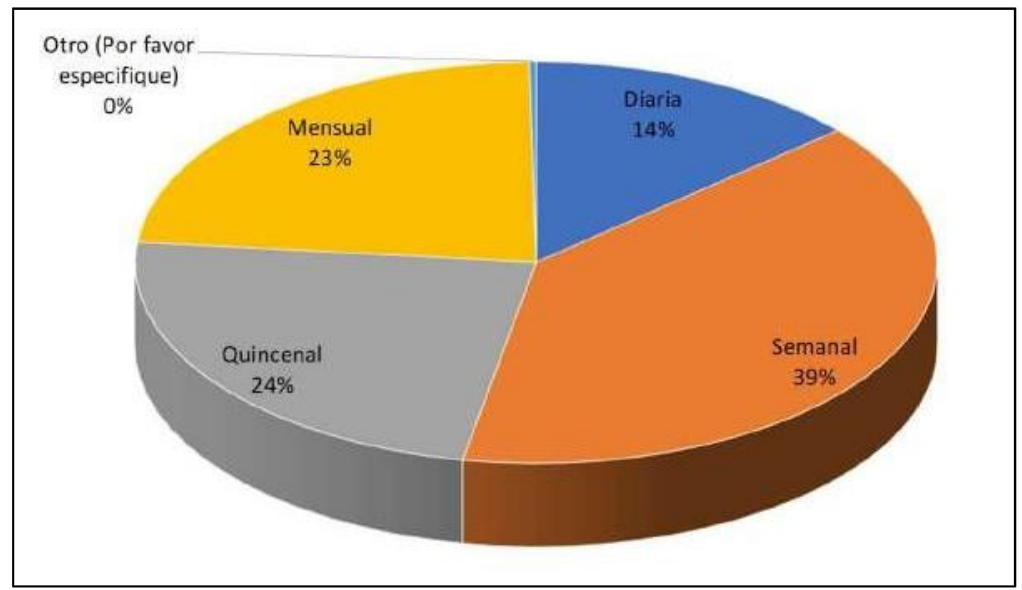

Figura 25. Intención de frecuencia de compra de producto Chocovit. Pregunta 6. ¿Con qué frecuencia compraría este producto? Elaboración propia.

Sobre el sabor de las gomitas, se recogieron las 376 respuestas. El sabor de mayor preferencia es de naranja (35\%), seguido de maracuyá (28\%) y piña (22\%). Ver Figura 26.

Sobre el precio que estarían dispuestas a pagar, el 64\% indicó que pagaría entre S/ 1.50 y S/ 2.00 , el $29 \%$ pagaría entre S/ 2.10 y S/ 2.50 y el $7 \%$ pagaría de S/ 2.60 a S/. 3.00. Ver Figura 27.

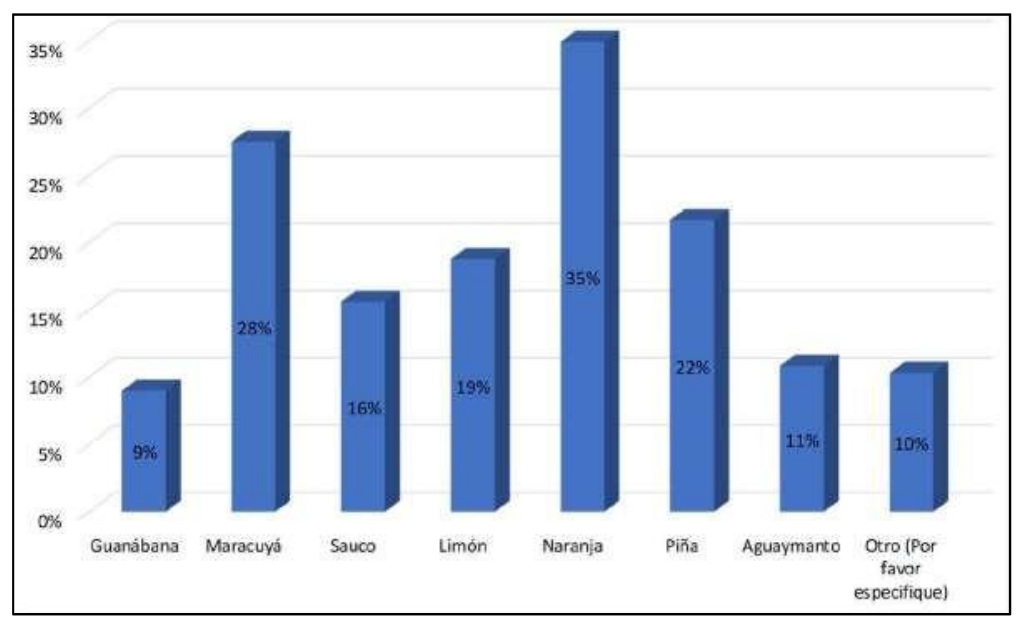

Figura 26. Selección del sabor de gomitas. Pregunta 7. ¿Qué sabor de gomita le gustaría que lleve el producto? Puede elegir más de una opción. Elaboración propia. 


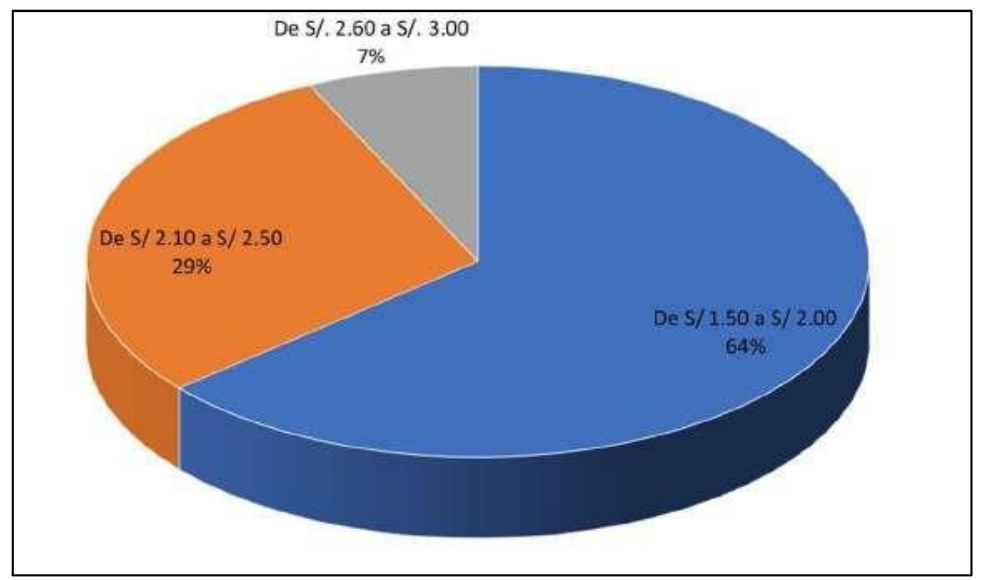

Figura 27. Precio que pagaría el potencial cliente. Pregunta 8. ¿Cuánto estaría dispuesto a pagar usted por el producto? (1 unidad). Elaboración propia.

Y a la pregunta sobre el lugar en el que les gustaría comprar Chocovit, preferentemente en supermercados (57\%) y bodegas (50\%). Ver Figura 28.

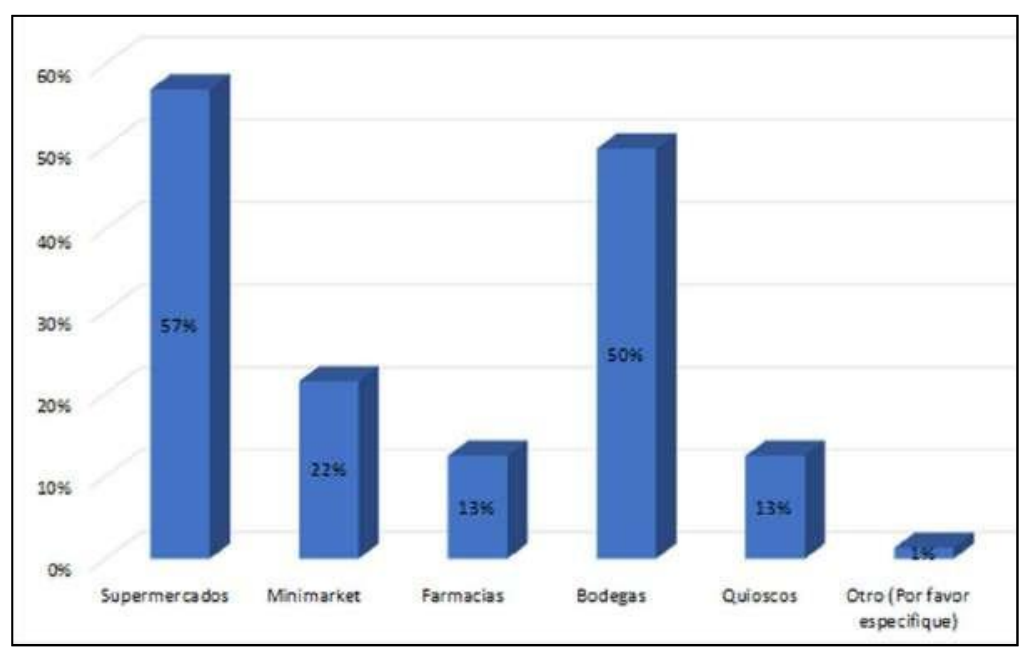

Figura 28. Lugar donde compraría Chocovit. Pregunta 9. ¿En qué lugares le gustaría comprar este producto? Puede elegir más de una opción. Elaboración propia.

Finalmente, se dio un espacio a las encuestadas para que pudieran dejar algún comentario o sugerencia de mejora. Y se encontró que existen algunas dudas en relación al uso de gomitas en este nuevo producto, ya sea por la creencia que la gomita es un producto dañino por el exceso de azúcar o por el uso de colorantes y preservantes. Además, comentan que el porcentaje de cacao debe ser superior al $40 \%$. 


\subsection{Conclusiones y recomendaciones del estudio cualitativo y cuantitativo}

Del estudio cuantitativo se concluye que, el producto Chocovit, chocolate fortificado con hierro, vitamina C y zinc, tendría una aceptación del $80 \%$ y solo el 5\% no estaría dispuesto a comprarlo. Existe un $15 \%$ que no sabe, y para efectos de este plan de negocios resulta retador poder captarlo.

Hay una preferencia por comprarlo en los supermercados y bodegas, de manera semanal y quincenal. En relación al precio, queda claro que más de la mitad pagaría un precio entre S/ 1.50 y S/ 2.00, el rango más bajo indicado en este plan de negocios. El sabor de las gomitas que más gustan son naranja, maracuyá y piña.

Finalmente, por los comentarios dejados por las encuestadas, se piensa aumentar el porcentaje de cacao, que inicialmente se había pensado en un $25 \%$, por tratarse de chocolate con leche. Sin embargo, se aumentará a 50\% de cacao, además de los comentarios de las encuestadas, por recomendación de los especialistas que se entrevistaron. Y en relación a las dudas que existen por las gomitas, se piensa realizar una campaña de difusión indicando que las gomitas que se usan en este producto son de jugos de fruta y no $100 \%$ colorantes e indicar claramente el porcentaje de azúcar que tendrá, que no sería muy alto.

\subsection{Perfil del consumidor tipo y sus variantes}

El público objetivo que plantea este plan de negocios, son mujeres madres de familia con niños hasta 10 años. Aunque el producto podría ser consumido por cualquier persona, pero por las características de la fortificación, principalmente si dirige a niños. El nivel socioeconómico es de los sectores, A, B, C y D de Lima. Se piensa en madres de familia, por ser las decisoras principales en cuestión de la alimentación de los hijos. Pueden ser madres trabajadoras o amas de casa. En el caso de las madres trabajadoras, buscan practicidad, pero al mismo tiempo que sus niños estén bien alimentados. Ambos grupos de madres buscan lo mejor para los hijos y son bastante cuidadosas, se informan, leen lo que contiene cada 
producto que consumirán sus niños. Los medios de comunicación que usan son la televisión, radio en el caso de amas de casa e internet y redes sociales más para el grupo de madres trabajadoras.

Los estilos de vida, de acuerdo a Arellano Marketing, serían dos: madres modernas y madres conservadoras. Las madres modernas son las que trabajan y estudian (incluye cursos de post grado) y que buscan su realización profesional, pero sin dejar de lado su rol de madre. Buscan estar bien arregladas, maquilladas, ser reconocidas ante la sociedad, independientes, reniegan del machismo, les gusta salir de compras, en especial seleccionan productos de calidad y de marca y que faciliten las tareas del hogar. Por otro lado, las madres conservadoras, son mujeres de tendencia religiosa y tradicional. Son típicas "mamás gallinas", persiguiendo el bienestar de sus hijos y de la familia en general, son las responsables del gasto familiar y las compras de la casa. Usan maquillaje de manera ocasional. Les gusta ver telenovelas y su pasatiempo favorito jugar con sus hijos. Ambos estilos de vida se encuentran en todos los NSE.

Según un estudio realizado por IPSOS para el perfil del ama de casa en el 2016, el $20 \%$ de amas de casa desempeña el papel de jefe del hogar, por ser el miembro que aporta más económicamente. Se indica, que este segmento está cambiando puesto que, a pesar de que muchas aún se dedican exclusiva al hogar, este número está disminuyendo, en vista que están teniendo trabajos eventuales o "cachuelos". Para el tema de compras, el 50\% de ellas suele estar atentas a las promociones, de las que se enteran principalmente en la televisión, en especial para las de los NSE A, B y C. Y al momento de realizar las compras, más de la mitad suele comprar productos que no pensaron comprar. Un tercio se declara fan de alguna marca, y el $62 \%$ de ellas suele recomendarla. En el ámbito de la imagen personal, la mitad de ellas tiene una gran preocupación por el cuidado y la belleza, y son asiduas a los salones de belleza. 


\section{Capítulo V. Proyección del mercado objetivo}

\subsection{El ámbito de la proyección}

Para el plan de negocio se utilizó como data histórica el número de hogares de Lima

Metropolitana de 14 distritos del año 2010 hasta el 2017 publicado por el INEI y APEIM,

encontrado en CPI. Con esta información se proyectó el número de hogares para el año 2018

al 2027.

\subsection{Selección del método de proyección}

El método seleccionado para la proyección es la ecuación de regresión lineal, se tomó los datos históricos del 2010 al 2017 del total de número de hogares de catorce distritos de Lima Metropolitana y se proyectó del 2018 al 2027 (ver Tabla 8 y 9). Se obtuvo un coeficiente de correlación (R) mayor a 90\% (ver Figura 28).

Tabla 8.

Datos históricos de la población de catorce distritos de Lima Metropolitana: 2010-2017 (en número de hogares).

\begin{tabular}{|c|c|c|c|c|c|c|c|c|}
\hline DISTRITOS & 2010 & 2011 & 2012 & 2013 & 2014 & 2015 & 2016 & 2017 \\
\hline $\begin{array}{l}\text { San Juan de } \\
\text { Lurigancho }\end{array}$ & 262000 & 249300 & 257200 & 261300 & 265100 & 267700 & 272000 & 275900 \\
\hline $\begin{array}{l}\text { San Martín de } \\
\text { Porres }\end{array}$ & 147800 & 140600 & 145200 & 146600 & 148800 & 171800 & 172500 & 175200 \\
\hline Los Olivos & 101000 & 93800 & 95600 & 100300 & 101800 & 91100 & 105800 & 107400 \\
\hline Santiago de Surco & 92700 & 89000 & 92400 & 97100 & 98600 & 84400 & 105900 & 107800 \\
\hline Independencia & 62900 & 59500 & 61200 & 63300 & 64200 & 53200 & 66800 & 67800 \\
\hline La Molina & 42000 & 40700 & 42400 & 43600 & 44300 & 42100 & 47200 & 48000 \\
\hline San Miguel & 40300 & 37700 & 38500 & 40200 & 40800 & 33200 & 44000 & 44800 \\
\hline San Borja & 33700 & 31500 & 32100 & 33500 & 34000 & 27500 & 37000 & 37800 \\
\hline Miraflores & 33800 & 25100 & 25100 & 29000 & 29500 & 20100 & 33000 & 33700 \\
\hline Pueblo Libre & 22900 & 21400 & 21800 & 24300 & 24600 & 18700 & 27100 & 27700 \\
\hline Jesús María & 22200 & 20300 & 20300 & 20900 & 21200 & 17600 & 23400 & 23900 \\
\hline San Isidro & 19900 & 16900 & 17100 & 19900 & 20200 & 13300 & 22700 & 23200 \\
\hline Lince & 18100 & 15800 & 15900 & 16700 & 16900 & 12300 & 18500 & 18900 \\
\hline Magdalena del Mar & 16500 & 15400 & 15600 & 16800 & 17000 & 13400 & 18600 & 19000 \\
\hline Total & 915800 & 857000 & 880400 & 913500 & 927000 & 866400 & 994500 & 1011100 \\
\hline
\end{tabular}

Fuente: Elaboración propia

\subsubsection{Mercado potencial}

Considerando que el mercado potencial son los consumidores que podrían necesitar el producto, se proyectó la población de los catorce distritos de Lima Metropolitana mediante 
regresión lineal. Para el 2018 el número de hogares sería 991,754, año a año va aumentando

la población y para el 2027 serían 1,133,836 hogares (ver Tabla 9).

Tabla 9.

Proyección de la población de catorce distritos de Lima Metropolitana: 2018-2027 (en número de hogares).

\begin{tabular}{|c|c|c|c|c|c|c|c|c|c|c|}
\hline DISTRITOS & 2018 & 2019 & 2020 & 2021 & 2022 & 2023 & 2024 & 2025 & 2026 & 2027 \\
\hline $\begin{array}{l}\text { San Juan de } \\
\text { Lurigancho }\end{array}$ & 276996 & 279926 & 282856 & 285786 & 288715 & 291645 & 294575 & 297505 & 300435 & 303364 \\
\hline $\begin{array}{l}\text { San Martín de } \\
\text { Porres }\end{array}$ & 179275 & 184433 & 189592 & 194750 & 199908 & 205067 & 210225 & 215383 & 220542 & 225700 \\
\hline Los Olivos & 104571 & 105676 & 106781 & 107886 & 108990 & 110095 & 111200 & 112305 & 113410 & 114514 \\
\hline $\begin{array}{l}\text { Santiago de } \\
\text { Surco }\end{array}$ & 104971 & 106968 & 108964 & 110961 & 112957 & 114954 & 116950 & 118946 & 120943 & 122939 \\
\hline Independencia & 64918 & 65486 & 66054 & 66621 & 67189 & 67757 & 68325 & 68893 & 69461 & 70029 \\
\hline La Molina & 47768 & 48652 & 49537 & 50421 & 51306 & 52190 & 53075 & 53960 & 54844 & 55729 \\
\hline San Miguel & 42493 & 43061 & 43629 & 44196 & 44764 & 45332 & 45900 & 46468 & 47036 & 47604 \\
\hline San Borja & 35686 & 36196 & 36707 & 37218 & 37729 & 38239 & 38750 & 39261 & 39771 & 40282 \\
\hline Miraflores & 29964 & 30254 & 30543 & 30832 & 31121 & 31411 & 31700 & 31989 & 32279 & 32568 \\
\hline Pueblo Libre & 26407 & 27039 & 27671 & 28304 & 28936 & 29568 & 30200 & 30832 & 31464 & 32096 \\
\hline Jesús María & 22275 & 22508 & 22742 & 22975 & 23208 & 23442 & 23675 & 23908 & 24142 & 24375 \\
\hline San Isidro & 21346 & 21835 & 22323 & 22811 & 23299 & 23787 & 24275 & 24763 & 25251 & 25739 \\
\hline Lince & 17093 & 17194 & 17295 & 17396 & 17498 & 17599 & 17700 & 17801 & 17902 & 18004 \\
\hline $\begin{array}{l}\text { Magdalena } \\
\text { del Mar }\end{array}$ & 17989 & 18312 & 18635 & 18957 & 19280 & 19602 & 19925 & 20248 & 20570 & 20893 \\
\hline Total & 991754 & 1007540 & 1023327 & 1039114 & 1054901 & 1070688 & 1086475 & 1102262 & 1118049 & 1133836 \\
\hline
\end{tabular}

Fuente: Elaboración propia

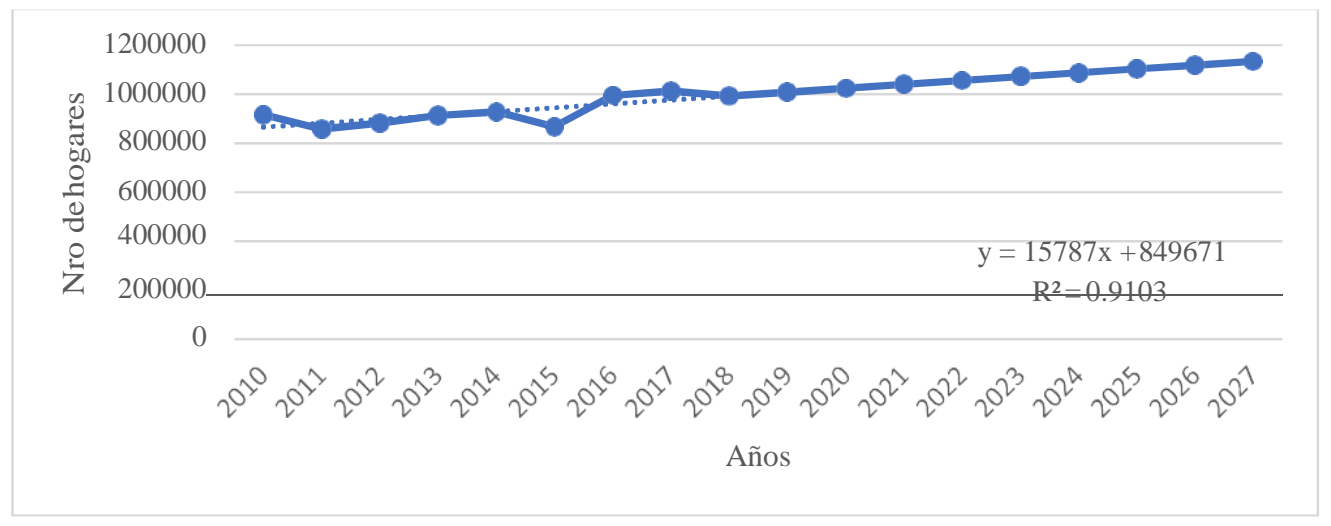

Figura 29. Proyección de la población de catorce distritos de Lima Metropolitana 2018 a 2027(en número de hogares). Elaboración propia.

\subsubsection{Mercado disponible}

Según Kotler \& Armstrong (2012) el mercado disponible es el conjunto de consumidores que tienen el deseo, renta y el acceso a una determinada oferta de mercado; para determinarlo se realizó un cuestionario (en página 60) a madres de familia con hijos menores de 10 años. 
En este cuestionario se consideró la pregunta $\mathrm{N}^{\circ} 1$ : ¿Suele Ud. consumir chocolates?, de 384 mujeres encuestadas, el 98\% respondió que sí consume chocolates y el 2\% no los consume (ver Tabla 10).

Tabla 10.

Proyección del mercado disponible: 2018 - 2027 (en número de hogares).

\begin{tabular}{lrrrrrrrrrr}
\hline DISTRITOS & 2018 & 2019 & 2020 & 2021 & 2022 & 2023 & 2024 & 2025 & 2026 & 2027 \\
\hline San Juan de Lurigancho & 271457 & 274328 & 277199 & 280070 & 282941 & 285812 & 288684 & 291555 & 294426 & 297297 \\
San Martín de Porres & 175690 & 180745 & 185800 & 190855 & 195910 & 200965 & 206021 & 211076 & 216131 & 221186 \\
Los Olivos & 102480 & 103563 & 104645 & 105728 & 106811 & 107893 & 108976 & 110059 & 111141 & 112224 \\
Santiago de Surco & 102872 & 104829 & 106785 & 108742 & 110698 & 112655 & 114611 & 116568 & 118524 & 120481 \\
Independencia & 63620 & 64176 & 64733 & 65289 & 65846 & 66402 & 66959 & 67515 & 68072 & 68628 \\
La Molina & 46813 & 47679 & 48546 & 49413 & 50280 & 51147 & 52014 & 52880 & 53747 & 54614 \\
San Miguel & 41643 & 42200 & 42756 & 43313 & 43869 & 44426 & 44982 & 45539 & 46095 & 46652 \\
San Borja & 34972 & 35473 & 35973 & 36474 & 36974 & 37475 & 37975 & 38476 & 38976 & 39477 \\
Miraflores & 29365 & 29649 & 29932 & 30216 & 30499 & 30783 & 31066 & 31350 & 31633 & 31917 \\
Pueblo Libre & 25879 & 26499 & 27118 & 27738 & 28357 & 28977 & 29596 & 30215 & 30835 & 31454 \\
Jesús María & 21830 & 22058 & 22287 & 22516 & 22744 & 22973 & 23202 & 23430 & 23659 & 23888 \\
San Isidro & 20920 & 21398 & 21876 & 22355 & 22833 & 23311 & 23790 & 24268 & 24746 & 25225 \\
Lince & 16751 & 16850 & 16949 & 17049 & 17148 & 17247 & 17346 & 17445 & 17544 & 17644 \\
Magdalena del Mar & 17630 & 17946 & 18262 & 18578 & 18894 & 19210 & 19527 & 19843 & 20159 & 20475 \\
\hline Total & 971919 & 987390 & 1002861 & 1018332 & 1033803 & 1049274 & 1064746 & 1080217 & 1095688 & 1111159 \\
\hline
\end{tabular}

Fuente: Elaboración propia.

\subsubsection{Mercado efectivo}

\section{Según Kotler \& Armstrong (2012) el mercado efectivo es el mercado}

cualificado disponible que está interesado en mi producto o servicio; para lo cual se tomó en cuenta la pregunta $\mathrm{N}^{\circ} 5$ del cuestionario (en página 60): ¿Estaría usted interesado en comprar este producto? Previamente a la encuestada se le explicó sobre las características del chocolate nutritivo. Teniendo en cuenta las respuestas Definitivamente sí y Probablemente sí, el porcentaje de la población que está seguro de comprar el producto es de $80 \%$ (ver Tabla $11)$. 
Tabla 11.

Proyección del mercado efectivo: 2018 - 2027 (en número de hogares).

\begin{tabular}{lrrrrrrrrrr}
\hline DISTRITOS & 2018 & 2019 & 2020 & 2021 & 2022 & 2023 & 2024 & 2025 & 2026 & 2027 \\
\hline San Juan de Lurigancho & 217165 & 219462 & 221759 & 224056 & 226353 & 228650 & 230947 & 233244 & 235541 & 237838 \\
San Martín de Porres & 140552 & 144596 & 148640 & 152684 & 156728 & 160772 & 164816 & 168861 & 172905 & 176949 \\
Los Olivos & 81984 & 82850 & 83716 & 84582 & 85449 & 86315 & 87181 & 88047 & 88913 & 89779 \\
Santiago de Surco & 82298 & 83863 & 85428 & 86993 & 88558 & 90124 & 91689 & 93254 & 94819 & 96384 \\
Independencia & 50896 & 51341 & 51786 & 52231 & 52676 & 53122 & 53567 & 54012 & 54457 & 54902 \\
La Molina & 37450 & 38143 & 38837 & 39530 & 40224 & 40917 & 41611 & 42304 & 42998 & 43691 \\
San Miguel & 33314 & 33760 & 34205 & 34650 & 35095 & 35540 & 35986 & 36431 & 36876 & 37321 \\
San Borja & 27978 & 28378 & 28778 & 29179 & 29579 & 29980 & 30380 & 30780 & 31181 & 31581 \\
Miraflores & 23492 & 23719 & 23946 & 24172 & 24399 & 24626 & 24853 & 25080 & 25306 & 25533 \\
Pueblo Libre & 20703 & 21199 & 21694 & 22190 & 22686 & 23181 & 23677 & 24172 & 24668 & 25164 \\
Jesús María & 17464 & 17647 & 17829 & 18012 & 18195 & 18378 & 18561 & 18744 & 18927 & 19110 \\
San Isidro & 16736 & 17118 & 17501 & 17884 & 18266 & 18649 & 19032 & 19414 & 19797 & 20180 \\
Lince & 13401 & 13480 & 13559 & 13639 & 13718 & 13797 & 13877 & 13956 & 14035 & 14115 \\
Magdalena del Mar & 14104 & 14357 & 14609 & 14862 & 15115 & 15368 & 15621 & 15874 & 16127 & 16380 \\
\hline Total & 777535 & 789912 & 802289 & 814666 & 827043 & 839419 & 851796 & 864173 & 876550 & 888927 \\
\hline \multicolumn{1}{c}{ Fuente: Elaboración } & propia & & & & & & & & &
\end{tabular}

Fuente: Elaboración propia.

\subsubsection{Mercado objetivo}

Según Kotler \& Armstrong (2012) un mercado objetivo es un grupo específico de

personas que has decidido hacerlas parte de tu base de clientes; para la estimación del

mercado objetivo se consideró 3\% de participación de mercado para el 2018, en base a las

acciones de marketing que la empresa va realizar. Para los siguientes años se consideró un

crecimiento de $3 \%$ anual, promedio por debajo del crecimiento del PBI del sector

manufacturero que es de $4 \%$ debido a que se tiene una postura conservadora (ver Tabla 12 y

Figura 30).

Tabla 12.

Proyección del mercado objetivo: 2018 - 2028 (en número de hogares).

\begin{tabular}{lrrrrrrrrrrr}
\hline DISTRITOS & 2018 & 2019 & 2020 & 2021 & 2022 & 2023 & 2024 & 2025 & 2026 & 2027 & 2028 \\
\hline San Juan de Luriganch & 6515 & 6710 & 6912 & 7119 & 7333 & 7553 & 7779 & 8013 & 8253 & 8501 & 8756 \\
San Martín de Porres & 4217 & 4343 & 4473 & 4608 & 4746 & 4888 & 5035 & 5186 & 5341 & 5502 & 5667 \\
Los Olivos & 2460 & 2533 & 2609 & 2688 & 2768 & 2851 & 2937 & 3025 & 3116 & 3209 & 3305 \\
Santiago de Surco & 2469 & 2543 & 2619 & 2698 & 2779 & 2862 & 2948 & 3036 & 3128 & 3221 & 3318 \\
Independencia & 1527 & 1573 & 1620 & 1668 & 1719 & 1770 & 1823 & 1878 & 1934 & 1992 & 2052 \\
La Molina & 1124 & 1157 & 1192 & 1228 & 1265 & 1302 & 1342 & 1382 & 1423 & 1466 & 1510 \\
San Miguel & 999 & 1029 & 1060 & 1092 & 1125 & 1159 & 1193 & 1229 & 1266 & 1304 & 1343 \\
San Borja & 839 & 865 & 890 & 917 & 945 & 973 & 1002 & 1032 & 1063 & 1095 & 1128 \\
Miraflores & 705 & 726 & 748 & 770 & 793 & 817 & 842 & 867 & 893 & 920 & 947 \\
Pueblo Libre & 621 & 640 & 659 & 679 & 699 & 720 & 742 & 764 & 787 & 810 & 835 \\
Jesús María & 524 & 540 & 556 & 572 & 590 & 607 & 626 & 644 & 664 & 684 & 704 \\
San Isidro & 502 & 517 & 533 & 549 & 565 & 582 & 599 & 617 & 636 & 655 & 675 \\
Lince & 402 & 414 & 427 & 439 & 452 & 466 & 480 & 494 & 509 & 525 & 540 \\
Magdalena del Mar & 423 & 436 & 449 & 462 & 476 & 490 & 505 & 520 & 536 & 552 & 569 \\
\hline Total & 23326 & 24026 & 24747 & 25489 & 26254 & 27041 & 27853 & 28688 & 29549 & 30435 & 31348 \\
\hline
\end{tabular}




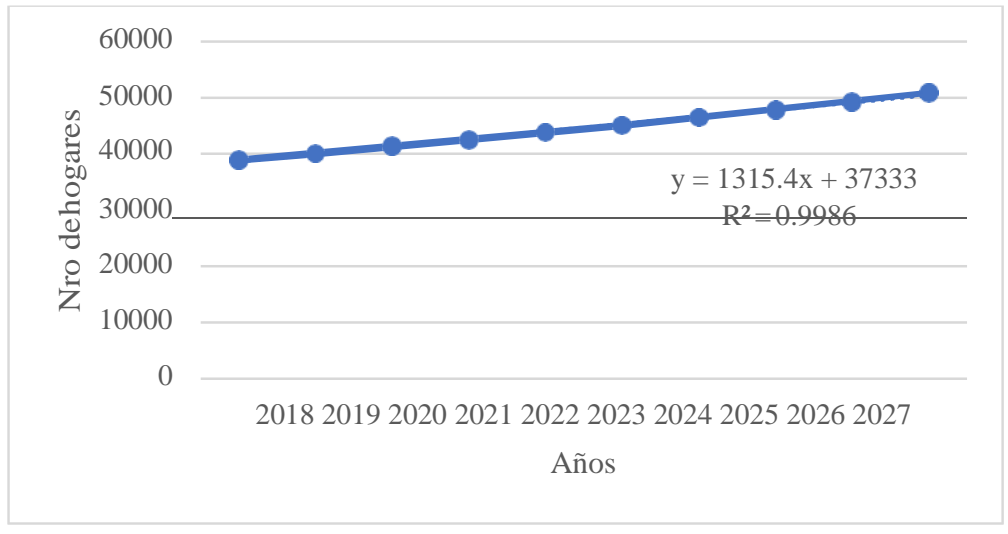

Figura 30. Proyección de mercado objetivo: 2018 - 2027. Fuente: elaboración propia.

\section{Capítulo VI. Plan de marketing}

\subsection{Estrategias de marketing}

\subsubsection{Estrategia de producto}

La estrategia de marketing es la diferenciación del producto ofreciendo tabletas de chocolate nutritivas con gomitas fortificadas con $200 \mathrm{mg}$ de vitamina C, $60 \mathrm{mg}$ de hierro y 60 mg de zinc, que previenen la anemia en niños de 3 a 10 años.

Se tramitará certificación Marca País otorgada por PromPerú y HACCP otorgada por DIGESA para que el cliente esté seguro de que el producto Chocovit es peruano y de calidad.

Nombre y logo

El nombre comercial de la empresa y la marca de los chocolates es Chocovit, el nombre representa la unión de las palabras chocolate y vitamina. Se considera que el término más común en las personas para relacionar el tema nutricional y de salud, es "vitamina". Todos los productos que se desarrollen en la empresa serán a base de cacao o al menos lo tendrán como componente por lo que hemos elegido usar el término "choco" en el nombre de la empresa y marca.

El logo es sencillo, de color marrón con las letras delineadas en forma de chocolate (ver Figura 31). 
El slogan es "un gusto que nutre" resaltando el aspecto saludable de la tableta de chocolate.

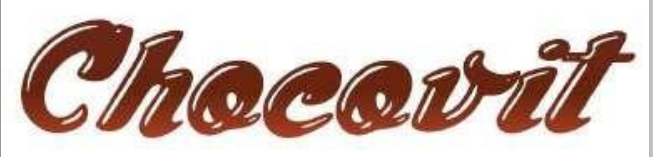

Figura 31. Representación gráfica del logo de la empresa. Elaboración propia.

Envase

La tableta de chocolate "Chocovit" tendrá un envase primario a base de foil de aluminio revestido por plástico tal como se observa en la Figura 32. Este tipo de envase protege al chocolate de humedad, insectos y radiación solar por lo que es altamente utilizado en este tipo de productos. Al consumidor le es fácil de manipular y verificar la información nutricional como la sanitaria, es decir si cuenta con registro sanitario y fecha de caducidad del producto. El gramaje de cada tableta será de $30 \mathrm{~g}$.

En cuanto al envase secundario, se ha considerado dos presentaciones, una en display y el envase es de cartulina, este contendrá 24 unidades y el gramaje será de 720g (Ver Figura 33). La otra presentación es pack x 6 unidades por lo que el envase es de bolsa de plástico y el gramaje será de 180g (Ver Figura 34).
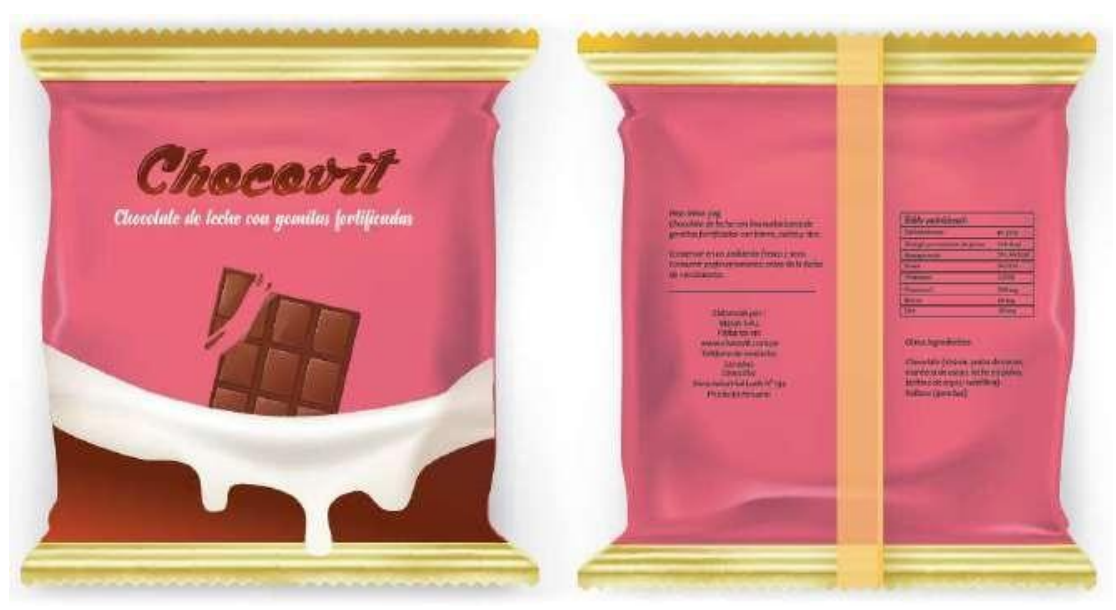

Figura 32. Envase primario de las tabletas de chocolate nutritivo. Elaboración propia. 


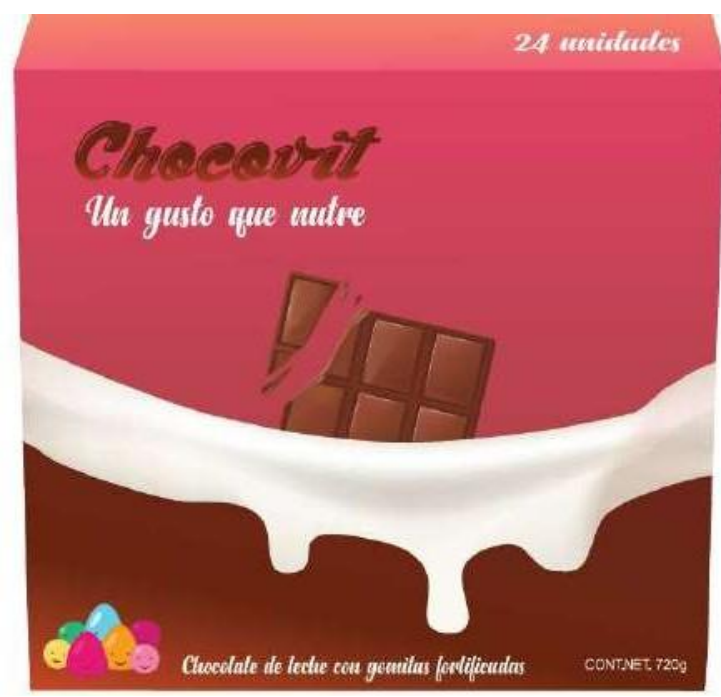

Figura 33. Envase secundario de la presentación de caja por 24 unidades. Elaboración propia.

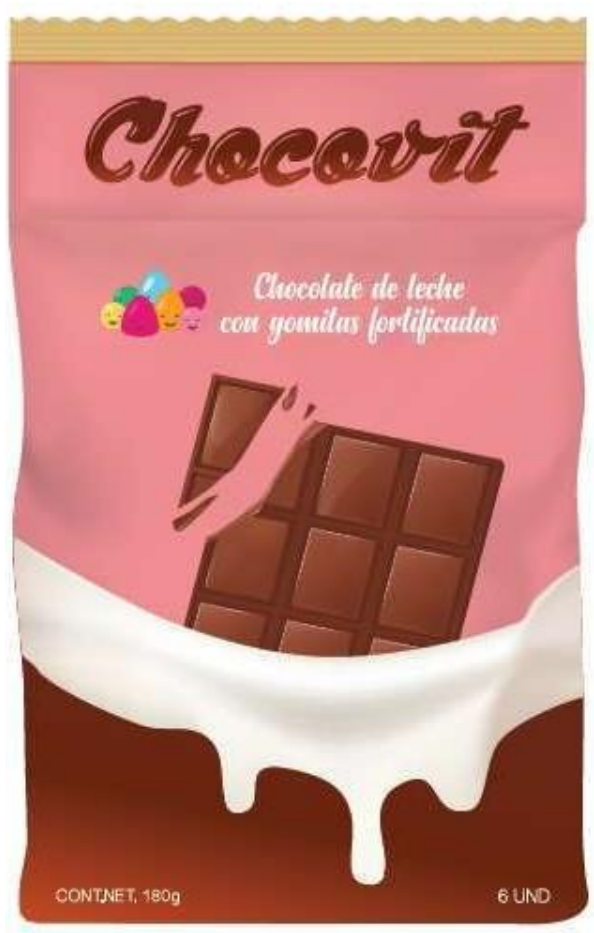

Figura 34. Envase secundario de la bolsa pack por 6 unidades. Elaboración propia.

\section{Etiqueta}

La información que se consigna en la etiqueta es la siguiente:

Datos de Producto

- Marca del producto: Chocovit 
Nombre del producto: Chocolate de leche con incrustaciones de gomitas fortificadas con hierro, vitamina $\mathrm{C}$ y zinc

Peso Neto: 30g (el gramaje va variar según el tipo de presentación tal como se menciona en el ítem anterior)

Ingredientes: Chocolate (azúcar, pasta de cacao, manteca de cacao, leche en polvo, lecitina de soya y vainillina). Relleno (gomitas)

Conservar en un ambiente fresco y seco, no mayor a $18^{\circ} \mathrm{C}$.

Consumir preferentemente antes de la fecha de vencimiento

Producto Peruano

Información nutricional:

Tabla 13.

Tabla nutricional del chocolate nutritivo Tamaño por porción: 1 (30g)

Porciones por envase: 1

\begin{tabular}{l|l}
\hline & 1 porción \\
\hline Carbohidratos: & $48.16 \%$ \\
\hline Energía proveniente de grasa: & $360 \mathrm{Kcal}$ \\
\hline Energía total: & $591.44 \mathrm{Kcal}$ \\
\hline Grasa: & $38.52 \%$ \\
\hline Proteínas: & $2.03 \%$ \\
\hline Vitamina C & $200 \mathrm{mg}$ \\
\hline Hierro & $60 \mathrm{mg}$ \\
\hline Zinc & $60 \mathrm{mg}$ \\
\hline
\end{tabular}

Fuente: elaboración propia.

Datos de la empresa

Elaborado por: Maran S.R.L

Nombre comercial: Chocovit

Visítanos en: www.chocovit.com.pe

Teléfono de contacto: 2274845

Dirección: Zona industrial Lurín $\mathrm{N}^{\circ} 134$ 


\section{Duración y conservación}

La vida útil del producto es de 6 meses desde su fabricación, teniendo en cuenta los parámetros de conservación que se han mencionado anteriormente. Una vez abierto se debe consumir cuanto antes o guardarlo en una bolsa de plástico hermético

\subsubsection{Estrategia de precio}

La estrategia de precio a utilizar es la fijación de precio. Según Kotler \& Armstrong (2012) la fijación de precio tiene tres estrategias, una basada en la valoración del cliente, basada en costos y basada en la competencia. Se va utilizar la estrategia basada en costos para el proyecto. Según Kotler \&Armstrong (2012) la fijación de precios basada en el costo consiste en establecer los precios según los costos de producción, distribución y venta del producto, más una tarifa justa de utilidades. Para la presentación de tableta de chocolate por $30 \mathrm{~g}$, el costo unitario es de S/.1.25 Soles, el margen de ganancia establecido es de $38 \%$ y el precio de venta es de S/2.00 Soles, para la bolsa pack por 6 unidades el costo unitario es de S/.7.50 Soles, el margen es de $36 \%$ y el precio de venta es de S/ 11.80 Soles y la caja de 24 unidades tiene un costo unitario de S/.30.00 Soles, un margen de $34 \%$ y un precio final de S/ 45.76 Soles. Se maneja un margen de ganancia de 34 a 38\%, lo cual nos da un precio competitivo en el mercado.

\subsubsection{Estrategia de plaza y distribución}

Para Kotler \& Armstrong (2012), el término que engloba a toda la cadena de suministro es "red de transferencia de valor", la que está formada por la compañía, los proveedores, los distribuidores y los clientes. Los socios ascendentes son los proveedores, quienes suministran las materias primas e insumos; y los socios del canal descendente de marketing son los mayoristas y minoritas.

Para poner el producto a disposición del consumidor final, se ha diseñado la siguiente estrategia utilizando canales de marketing directo e indirecto, es decir un Sistema de 
Distribución Multicanal (Ver Figura 35). De acuerdo a lo definido por Kotler \& Armstrong (2012), el canal de marketing directo es aquel que no requiere ningún intermediario para que el fabricante haga llegar su producto y/o servicio al consumidor final, mientras que el canal de marketing indirecto requiere de al menos un intermediario.

Canal de distribución directo: Venta del producto por internet: página web de la empresa y redes sociales (fan page).

Canal de distribución indirecto: Venta del producto a minoristas o detallistas como supermercados, bodegas y tiendas especializadas.

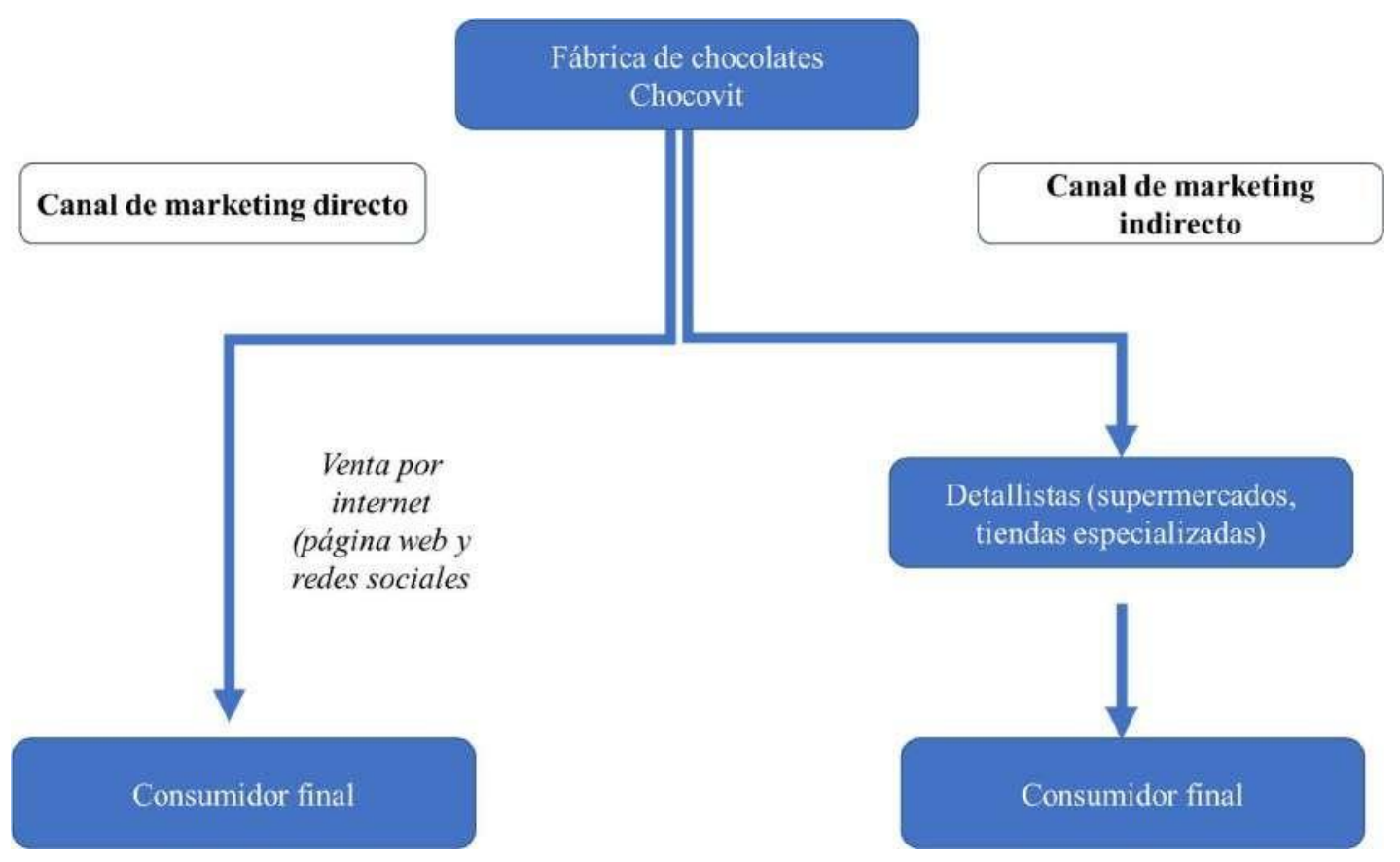

Figura 35. Canales de distribución de marketing (multicanal). Elaboración propia.

Esta estrategia responde a las necesidades que tiene esta nueva empresa, la que busca ser conocida en el mercado. Cada una de las estrategias tomadas tiene sus ventajas. Así, por ejemplo, el canal de distribución indirecto busca que el intermediario agregue valor al producto, como otorgar información de primera mano al consumidor final, ofrecer promociones para persuadir acerca de una oferta, encontrar y comunicarse con compradores 
potenciales (Kotler \& Armstrong, 2012). Además, permite ahorrar costos para llegar al cliente final.

La ventaja del canal de marketing directo es que hay cada vez más personas que utilizan los canales de internet para hacer compras. Los más jóvenes prefieren hacer compras por internet para ahorrar tiempo.

Asimismo, para optar por la estrategia de distribución multicanal, se consideró las necesidades de los potenciales clientes, quienes manifestaron sus intereses en las encuestas aplicadas, en la sección de Comentarios Finales. Pidieron encontrar en producto en supermercados, bodegas y tiendas especializadas, así como poder comprar el producto por internet.

\subsubsection{Estrategia de promoción y publicidad}

Para poder desarrollar una estrategia para la promoción y publicidad del producto, es importante encontrar una forma, tal que se fortalezca la conexión emocional con el consumidor, es decir, sobresalir entre el resto. Se trata de comunicar la propuesta de valor a los clientes.

En la Figura 36 se presenta la conexión entre el insight del consumidor con la propuesta de valor a ofrecer. Entiéndase por insight, como la forma en que la persona capta, internaliza, se siente identificado con el producto, de acuerdo a una experiencia previa. Se trata identificar, primero cuál es la necesidad del potencial consumidor o cliente. En este caso el consumidor serán los niños y los clientes (quienes efectuarán la compra serán las madres). Se ha identificado que el insight de las madres de niños entre 0 y 10 años (público objetivo) es que existe una preocupación constante por los productos que consumen sus hijos, y hoy en día están buscando alternativas sanas y nutritivas. Se citan los beneficios al consumir, sean emocionales y racionales, y finalmente se presenta la propuesta de valor. 
Identificado el insight del consumidor, se procede a diseñar una buena campaña de publicidad y promoción.

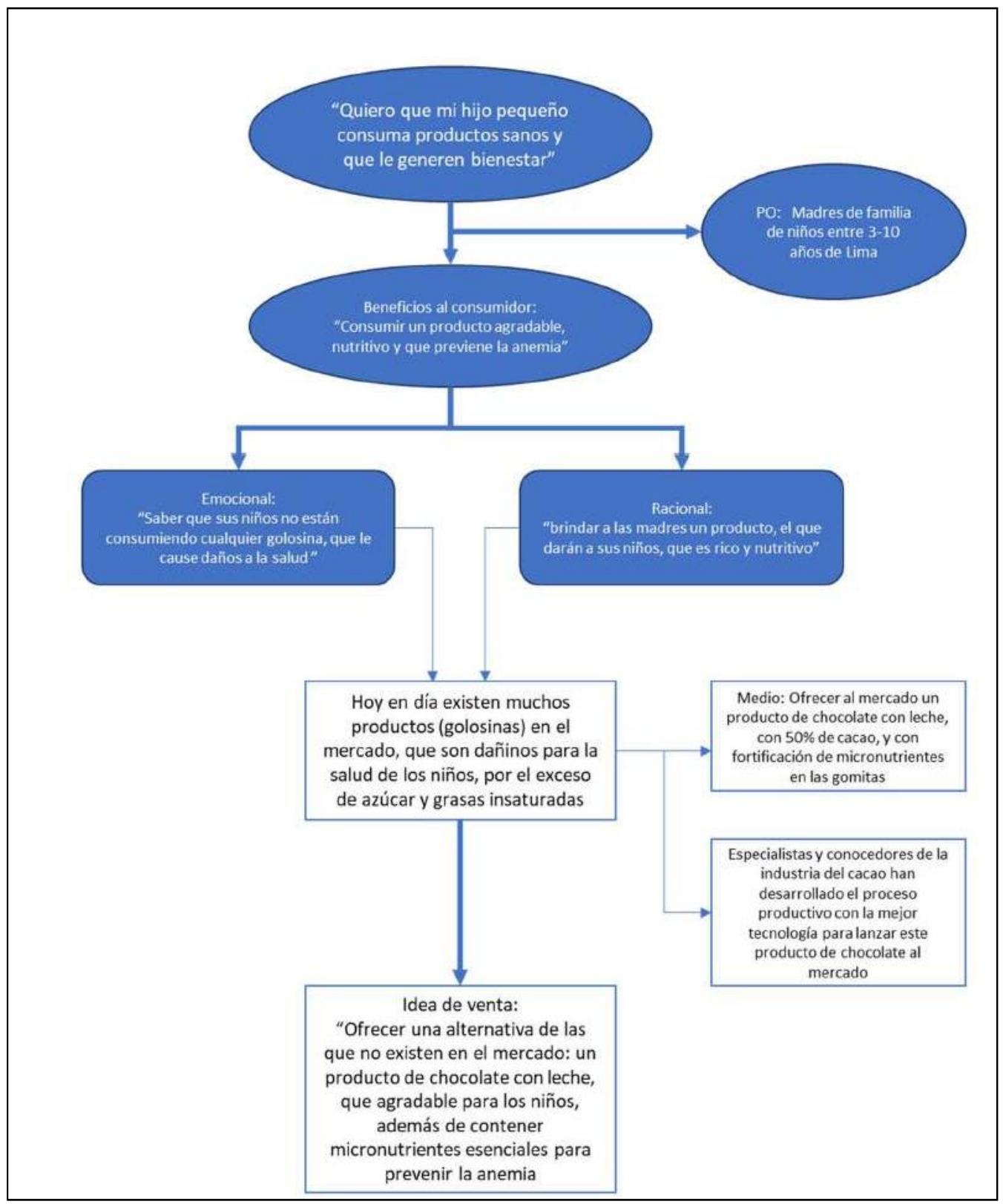

Figura 36. Conectando el insight con la propuesta de valor. Elaboración propia.

Publicidad: "Cualquier forma pagada de presentación y promoción no personales de ideas" (Kotler \& Armstrong, 2012) 
Aprovechando la nueva era digital en la que la tecnología juega un papel importante, se puede llegar a los clientes a través de muchos medios, como correo electrónico, redes sociales, blogs, sitios web de marcas y mucho más. A esta estrategia se le conoce como Comunicación de Marketing Integrada (IMC, por sus siglas en inglés), lo que significa que, se debe integrar y coordinar cuidadosamente los múltiples canales de comunicación de la empresa, para enviar un mensaje claro, congruente y convincente acerca del producto (Kotler \& Armstrong, 2012).

Los medios que se utilizarán en este proyecto son los siguientes:

Correo electrónico: Se recogerán datos de potenciales clientes, como nombre, teléfono correo electrónico) para armar una base de datos y siempre estar enviando correos publicitarios y promocionales. La base de datos se puede armar participando de las ferias de chocolate que se organizan en Lima y a nivel nacional. Se participará con un están, en la que ofrecerán el producto para degustación. Allí mismo, se pueden recoger los datos de los compradores y efectuar la venta.

Redes sociales: Se llegará a los potenciales clientes a través de la página de Facebook de Chocovit. En la página se presentarán promociones del momento, se describirán las bondades del producto, además de compartir temas de interés relacionados a la anemia y desnutrición. Si se logra concretar la participación en algún proyecto de índole alimenticia a través de una ONG o institución de ayuda a los niños, se compartirán fotos y toda experiencia vivida. En la siguiente Figura 38 se presenta la página de Chocovit.

Además, se hará uso de otras redes sociales como Instagram, donde se pondrán fotos, videos y anuncios para inspirar a las personas, dar a conocer a la empresa e impulsar las acciones.

Web de la empresa: Se creará la página web de la empresa en la que se publicarán algunos temas relevantes como quienes somos, misión y visión, estructura organizacional, 
sección de reclamos y quejas, teléfono para la atención al cliente para poder contactarse en caso tenga alguna dificultad con el producto. La página web estará linkeada a la página del Facebook.

Otros sitios de interés: Además, se aprovechará diferentes páginas de redes sociales de productos relacionados al producto o al insight de los clientes, para poder hacer conocido a Chocovit. En ellas también se llamará para visitar la propia página de Chocovit y lanzar algunas promociones.

Revistas: Se buscará hacer publicidad en revistas de alimentos y del hogar, las que son dirigidas principalmente a madres de niños pequeños.

En una primera etapa no está considerado realizar ninguna inversión de publicidad en televisión y radio.

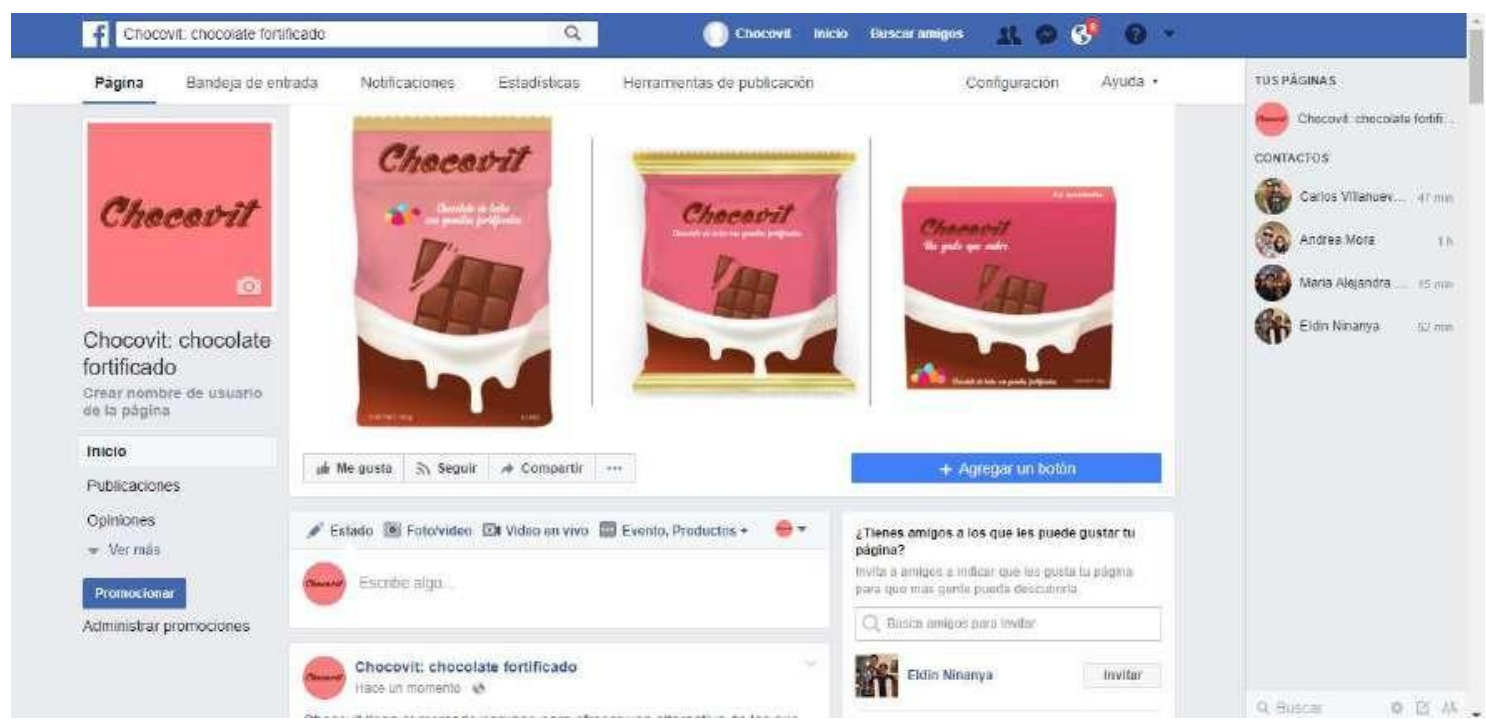

Figura 37. Imagen del fanpage de Chocovit en Facebook. Elaboración propia.

Promoción: Se entiende por promoción a la entrega de incentivos a corto plazo que fomentan la compra o venta de un producto o servicio." Las promociones de ventas incluirán descuentos, cupones, exhibiciones y demostraciones. (Kotler \& Armstrong, 2012) 


\subsection{Estrategia de ventas}

\subsubsection{Plan de ventas}

Del FODA comercial presentado en el capítulo VI, se tomó los objetivos relacionados

a las ventas y se elaboró el plan anual (Ver Tabla 14 y 32) definiendo las actividades, el

responsable y los plazos a ejecutarse. Se planteó un cronograma mensual para el año 2019 ya

que se considera que el 2018 se va efectuar la compra del terreno, la construcción de la

fábrica y la implementación de la maquinaria. En el cronograma 2019 se codificó al primer

trimestre del año como T1 y así sucesivamente continúan los meses hasta llegar al cuarto

trimestre como T4.

Tabla 14.

Plan anual de ventas para el período enero a diciembre del 2019.

\begin{tabular}{|c|c|c|c|c|c|c|c|}
\hline \multirow[b]{2}{*}{ Objetivo } & \multirow[b]{2}{*}{ Estrategia } & \multirow[b]{2}{*}{ Actividades } & \multirow[b]{2}{*}{ Responsable } & \multicolumn{4}{|c|}{ Cronograma } \\
\hline & & & & $\mathrm{T} 1$ & $\mathrm{~T} 2$ & T3 & $\mathrm{T} 4$ \\
\hline \multirow{8}{*}{$\begin{array}{c}\text { Obtener } \\
\text { participación en } \\
\text { el mercado }\end{array}$} & \multirow{8}{*}{$\begin{array}{l}\text { Elaborando plan } \\
\text { para penetración } \\
\text { en elmercado }\end{array}$} & El aborando li stado de $\mathrm{cl}$ ientes potencial es & Jefe Comerci al & & & & \\
\hline & & $\begin{array}{l}\text { Clasificando cl ientes (ONG, supermercados, bodegas } \\
\text { y tiendas especi alizadas) }\end{array}$ & Jefe Comerci al & & & & \\
\hline & & & Gerente General/Jefe & & & & \\
\hline & & Cali ficando clientes (A, B, C y D) e investi gándolos & Comerci al & & & & \\
\hline & & Preparando propuesta comercial & $\begin{array}{l}\text { Jefe Comercial/ } \\
\text { Vendedor }\end{array}$ & & & & \\
\hline & & Comunicarse con los clientes potenciales & Vendedor & & & & \\
\hline & & $\begin{array}{l}\text { Estableci endo las zonas y limites territoriales de } \\
\text { venta que se abarcarán en un límite de ti empo }\end{array}$ & Vendedor & & & & \\
\hline & & Reportando informe comercial & Vendedor & & & & \\
\hline \multirow{7}{*}{$\begin{array}{l}\text { Implementar } \\
\text { plan para el } \\
\text { lanzamiento del } \\
\text { producto }\end{array}$} & \multirow{7}{*}{$\begin{array}{l}\text { Implementando } \\
\text { plan publicitaria }\end{array}$} & & Gerente General/Jefe & & & & \\
\hline & & Creando e impl ementando página web & Comerci al & & & & \\
\hline & & Administrando página web & Jefe Comercial & & & & \\
\hline & & Creando perfi les en facebook, pinterest e i nstagram & $\begin{array}{l}\text { Gerente General /Jefe } \\
\text { Comerci al }\end{array}$ & & & & \\
\hline & & $\begin{array}{l}\text { Administrando y elaborando reportes de redes } \\
\text { sociales }\end{array}$ & Jefe Comerci al & & & & \\
\hline & & $\begin{array}{l}\text { Partici pando en Sal ón de cacao y chocol ate y } \\
\text { Expoal imentaria (ambos en Li ma) }\end{array}$ & Jefe Comerci al & & & & \\
\hline & & $\begin{array}{l}\text { Inscri pción en Revista Industria Al imentaria y } \\
\text { AgroNegocios Perú }\end{array}$ & Jefe Comercial & & & & \\
\hline \multirow{3}{*}{$\begin{array}{l}\text { Captar clientes } \\
\text { con estilo de } \\
\text { vida saludable }\end{array}$} & \multirow{3}{*}{$\begin{array}{l}\text { Participando en } \\
\text { ferias orgánicas de } \\
\text { Lima }\end{array}$} & El aborando li stado de ferias orgánicas por di strito & Jefe Comercial & & & & \\
\hline & & Organizando y diseñando stand & Jefe Comercial & & & & \\
\hline & & $\begin{array}{l}\text { El aborando propuesta comercial y participando de } \\
\text { ferias orgánicas }\end{array}$ & Jefe Comerci al & & & & \\
\hline
\end{tabular}

Fuente: Elaboración propia 


\subsubsection{Políticas de servicios y garantías}

En concordancia con la ley, la empresa evitará todo tipo de publicidad engañosa para el consumidor y/o comprador. El chocolate nutritivo que se ofrece al mercado peruano se considera nutritivo porque contiene $50 \%$ de cacao y fortificación en las gomitas con hierro, zinc y vitamina $\mathrm{C}$. El cacao tiene propiedades que, en proporciones adecuadas, le genera un bien al consumidor, ya que contiene grasas buenas que requiere el organismo. Las gomitas por su lado son de jugos naturales y la fortificación se da en las mismas gomitas. Este producto no es para combatir la anemia al consumidor, solamente la previene.

Como valor añadido, la empresa otorgará talleres en los mismos supermercados y tiendas especializadas, acerca de temas de nutrición saludable, cómo prevenir la anemia, diferencias entre una golosina y un chocolate de cacao, y algunos temas relacionados.

Si el consumidor tuviera algún problema con el producto, podrá llamar al teléfono indicado en la etiqueta o comunicarse a través de la web o de la página oficial de la red social Facebook. De aceptarse el reclamo, la empresa MARAN S.R.L. otorgará alguna cortesía al cliente, como una canasta de chocolates Chocovit.

\section{Capítulo VII. Pronóstico de ventas}

\subsection{Fundamentos y supuestos}

De acuerdo al Perfil del Jefe de Hogar 2015 de IPSOS APOYO, el 87\% de los hogares tiene en promedio 3 hijos y el 13\% restante solo 1 hijo; y el consumo per cápita de 0.5 kilogramos por año. Considerando esta información, estimamos el pronóstico de ventas para el proyecto para los años 2018 al 2027. Así para el año 2018 se tiene un pronóstico de ventas de 31.96 toneladas y para el año 2027, se tiene 41.7 toneladas (ver Tabla 15). Para estimar el número de unidades, se considera que cada tableta de chocolate contiene 30 gramos de cacao. Así para el año 2018 un total de 1,065,223 tabletas de chocolates y para el 2027 se tiene 1,389,874 tabletas de chocolate (ver Tabla 16). 
Tabla 15.

Pronóstico de ventas (en kilogramos).

\begin{tabular}{|c|c|c|c|c|c|c|c|c|c|c|c|}
\hline DISTRITOS & 2018 & 2019 & 2020 & 2021 & 2022 & 2023 & 2024 & 2025 & 2026 & 2027 & 2028 \\
\hline San Juan de Luriganch & 8925 & 9193 & 9469 & 9753 & 10046 & 10347 & 10658 & 10977 & 11307 & 11646 & 11995 \\
\hline San Martín de Porres & 5777 & 5950 & 6128 & 6312 & 6502 & 6697 & 6898 & 7105 & 7318 & 7537 & 7763 \\
\hline Los Olivos & 3370 & 3471 & 3575 & 3682 & 3792 & 3906 & 4023 & 4144 & 4268 & 4396 & 4528 \\
\hline Santiago de Surco & 3382 & 3484 & 3588 & 3696 & 3807 & 3921 & 4039 & 4160 & 4285 & 4413 & 4546 \\
\hline Independencia & 2092 & 2155 & 2219 & 2286 & 2354 & 2425 & 2498 & 2573 & 2650 & 2729 & 2811 \\
\hline La Molina & 1539 & 1585 & 1633 & 1682 & 1732 & 1784 & 1838 & 1893 & 1950 & 2008 & 2069 \\
\hline San Miguel & 1369 & 1410 & 1453 & 1496 & 1541 & 1587 & 1635 & 1684 & 1734 & 1787 & 1840 \\
\hline San Borja & 1150 & 1184 & 1220 & 1257 & 1294 & 1333 & 1373 & 1414 & 1457 & 1500 & 1545 \\
\hline Miraflores & 966 & 994 & 1024 & 1055 & 1087 & 1119 & 1153 & 1187 & 1223 & 1260 & 1298 \\
\hline Pueblo Libre & 851 & 876 & 903 & 930 & 958 & 986 & 1016 & 1047 & 1078 & 1110 & 1144 \\
\hline Jesús María & 718 & 739 & 761 & 784 & 808 & 832 & 857 & 883 & 909 & 937 & 965 \\
\hline San Isidro & 688 & 708 & 730 & 752 & 774 & 797 & 821 & 846 & 871 & 897 & 924 \\
\hline Lince & 551 & 567 & 584 & 602 & 620 & 638 & 658 & 677 & 698 & 719 & 740 \\
\hline Magdalena del Mar & 580 & 597 & 615 & 633 & 652 & 672 & 692 & 713 & 734 & 756 & 779 \\
\hline Total & 31,957 & 32,915 & 33,903 & 34,920 & 35,968 & 37,047 & 38,158 & 39,303 & 40,482 & 41,696 & 42,947 \\
\hline
\end{tabular}

Fuente: Elaboración propia

Tabla 16.

Pronóstico de ventas (en número de unidades).

\begin{tabular}{lrrrrrrrrrrr}
\hline DISTRITOS & 2018 & 2019 & 2020 & 2021 & 2022 & 2023 & 2024 & 2025 & 2026 & 2027 & 2028 \\
\hline San Juan de Luriganch & 297516 & 306442 & 315635 & 325104 & 334857 & 344903 & 355250 & 365908 & 376885 & 388191 & 399837 \\
San Martín de Porres & 192556 & 198332 & 204282 & 210411 & 216723 & 223225 & 229922 & 236819 & 243924 & 251242 & 258779 \\
Los Olivos & 112318 & 115688 & 119158 & 122733 & 126415 & 130207 & 134114 & 138137 & 142281 & 146550 & 150946 \\
Santiago de Surco & 112748 & 116130 & 119614 & 123202 & 126899 & 130705 & 134627 & 138665 & 142825 & 147110 & 151523 \\
Independencia & 69727 & 71819 & 73973 & 76193 & 78478 & 80833 & 83258 & 85755 & 88328 & 90978 & 93707 \\
La Molina & 51307 & 52846 & 54431 & 56064 & 57746 & 59478 & 61263 & 63101 & 64994 & 66943 & 68952 \\
San Miguel & 45641 & 47010 & 48420 & 49873 & 51369 & 52910 & 54497 & 56132 & 57816 & 59551 & 61337 \\
San Borja & 38329 & 39479 & 40664 & 41883 & 43140 & 44434 & 45767 & 47140 & 48554 & 50011 & 51511 \\
Miraflores & 32184 & 33150 & 34144 & 35168 & 36223 & 37310 & 38429 & 39582 & 40770 & 41993 & 43253 \\
Pueblo Libre & 28363 & 29214 & 30091 & 30993 & 31923 & 32881 & 33867 & 34883 & 35930 & 37008 & 38118 \\
Jesús María & 23925 & 24643 & 25382 & 26144 & 26928 & 27736 & 28568 & 29425 & 30308 & 31217 & 32153 \\
San Isidro & 22928 & 23616 & 24324 & 25054 & 25805 & 26580 & 27377 & 28198 & 29044 & 29916 & 30813 \\
Lince & 18359 & 18910 & 19477 & 20061 & 20663 & 21283 & 21922 & 22579 & 23257 & 23954 & 24673 \\
Magdalena del Mar & 19322 & 19902 & 20499 & 21114 & 21747 & 22399 & 23071 & 23764 & 24476 & 25211 & 25967 \\
\hline Total & $1.065,2231$ & $, 097,1791$ & 130,0951 & 163,9981 & $, 198,918$ & $, 234,8851,271,9321,310,0901,349,3921,389,8741,431,570$ \\
\hline
\end{tabular}

Fuente: Elaboración propia

\subsection{Análisis de los riesgos y aspectos críticos que impactan en el pronóstico}

Dentro de los aspectos críticos para el proyecto se tiene que las gomitas fortificadas se importan de Holanda, a través de la empresa Merfrut, dependiendo de la variación en el tipo de cambio del dólar, podría impactar en el costo de producción y en el precio que pagaría el consumidor final. Otro punto importante en relación a las gomitas es que, existen dudas en relación a si es un producto no muy saludable por la cantidad de azúcar que tiene. Es clave desarrollar una buena campaña de marketing para brindar toda la información pertinente del 
producto, y en particular de las gomitas fortificadas (éstas están elaboradas de jugo concentrado de frutas y sin colorantes).

Otro aspecto crítico es en relación al cacao, la materia prima más importante. Si la calidad de grano de cacao no es la esperada va a impactar en la calidad el producto final, y se podrían tener reclamos o lo peor, la pérdida de clientes por una mala imagen,

El hecho de que la maquinaria sea importada también podría tener un impacto en las ventas, ya que, si alguna de ellas presentara un desperfecto, el contactar con el proveedor en el extranjero puede demorar y la respuesta en dar solución, dependiendo del problema, podría ser aún mayor.

\section{Capítulo VIII. Ingeniería del proyecto}

\subsection{Estudio de ingeniería}

\subsubsection{Modelamiento y selección de procesos productivos}

El proceso productivo para la obtención de tabletas de chocolate con incrustaciones de gomitas fortificadas se detalla a continuación y el flujograma se observa en la figura 38.

Recepción de la materia prima, se recibirán los granos de cacao empaquetados en saco de yute de las comunidades nativas hacia los almacenes de granos de cacao. Asimismo, se recepcionará azúcar blanca, leche en polvo y gomitas fortificadas en los almacenes de materia prima.

Selección de la materia prima, se seleccionarán los granos eliminando impurezas (piedras, palos y otros objetos extraños) y granos con defectos (hongos, partidos, múltiples, germinados y pasillas).

Tostado, se tostará un batch de $35 \mathrm{~kg}$ de granos de cacao a las temperaturas de $160^{\circ} \mathrm{C}$ por $20 \mathrm{~min}$. 
Descascarillado, consiste en eliminar la cáscara del grano y trozar la almendra para facilitar su molienda, el producto en esta etapa cambia su denominación a granilla. La cáscara será vendida como abono para tierras de cultivo.

Pre refinado, la granilla será molida por rodillos hasta obtener pasta de cacao en flakes.

Refinado, la pasta de cacao en flakes será molida en un molino de billas hasta lograr licor de cacao.

Prensado, a través de una prensa hidráulica se extraerá la manteca de cacao del licor de cacao. El batch es de $20 \mathrm{~kg} / \mathrm{h}$ y se obtendrá $10 \mathrm{~kg}$ de manteca de cacao por hora aproximadamente.

Homogenizado, en esta etapa se realizará la mezcla de licor de cacao (50\%), manteca de cacao (10\%), azúcar blanca (28\%) y leche en polvo (12\%) hasta obtener la masa de chocolate.

Conchado, la masa de chocolate es amasada en un conchador a $30^{\circ} \mathrm{C}$ por 2 horas, esto facilitará el desarrollo de los aromas y la textura adecuada del chocolate. El batch es de $50 \mathrm{~kg}$.

Temperado, la masa de chocolate se va someter a una temperatura de $45^{\circ} \mathrm{C}$, luego se enfría a $27^{\circ} \mathrm{C}$ y finalmente se aumenta a $32^{\circ} \mathrm{C}$ en Baño Maria. Estos cambios de temperatura facilita que la manteca de cacao se mantenga estable durante su manipulación en el moldeo. El batch es de 25 kg.

Mezclado, en una mesa de acero inoxidable se mezclará la masa de chocolate de leche con las gomitas fortificadas.

Moldeo, la masa de chocolate con gomitas se colocará en moldes de 30g y se dará pequeños golpes contra la mesa para eliminar las burbujas de la masa de chocolate. 
Enfriado, los moldes se colocarán en túnel de refrigeración a $8^{\circ} \mathrm{C}$

aproximadamente por un espacio de 5 min y luego se retira la tableta de chocolate del molde.

Envasado, cada tableta se va forrar con bolsas de aluminio en forma manual, se sellará con selladora de pedal, luego se colocará en display o bolsas según el pedido de ventas y finalmente en cajas de distribución.

\ Almacenamiento, las cajas de chocolates debidamente rotulados se llevarán al almacén de producto terminado.

Durante todo el proceso se cumplirá con la adecuada trazabilidad, buenas prácticas de manufactura y los análisis fisicoquímicos y microbiológicos que la normatividad alimentaria exige. 
Elaboración de tabletas de chocolate con gomitas fortificadas

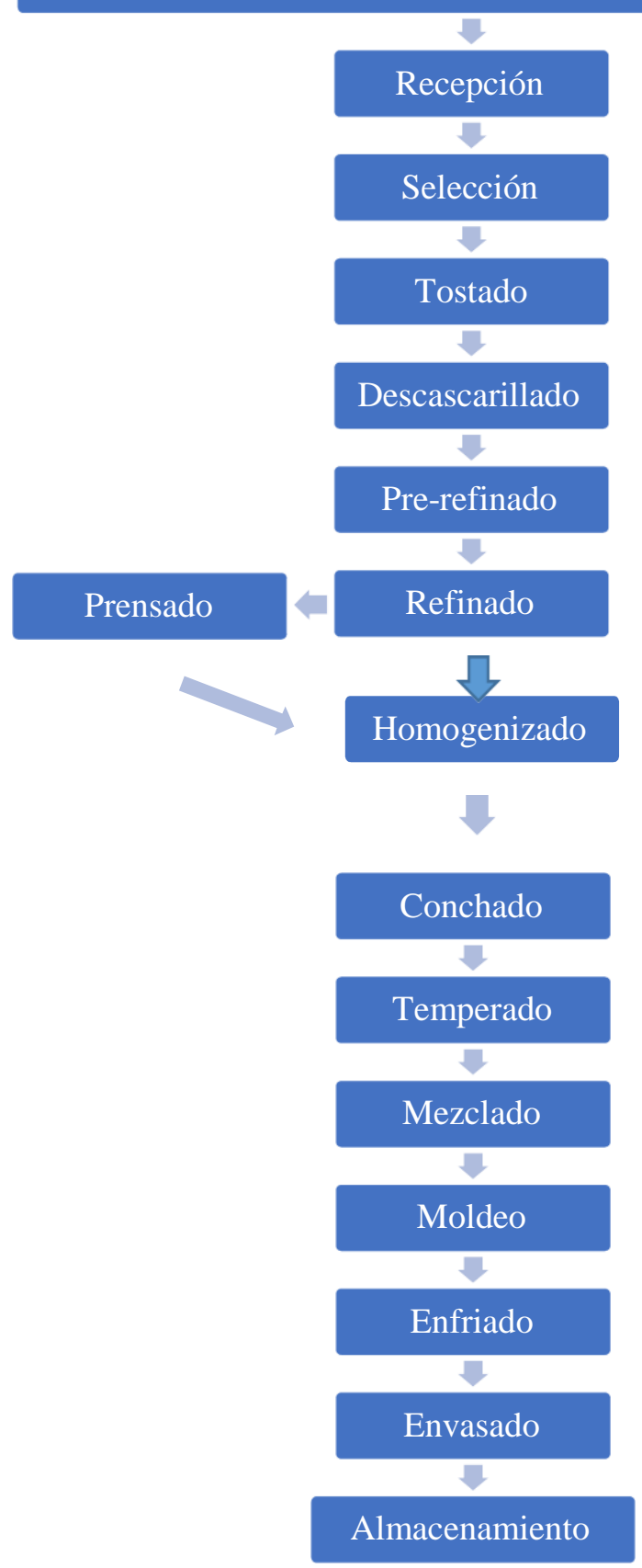

Figura 38. Flujograma del proceso de elaboración de tabletas de chocolate con gomitas fortificadas. Elaboración propia.

\subsubsection{Selección del equipamiento}

El equipamiento que se ha seleccionado está en función de cubrir la demanda anual, el cual se ha estimado en $32950 \mathrm{~kg}$ de tabletas de chocolate para el 2019. Considerando 12 
meses de producción y 24 días laborables al mes, se ha calculado una producción diaria de

$114 \mathrm{~kg}$ de tabletas de chocolate para el 2019. Los equipos a utilizar para el procesamiento de tabletas de chocolate nutritivas se detallan en la Tabla 17, el mobiliario del área de producción se encuentra en la Tabla 18.

Tabla 17.

Equipos para el procesamiento de tabletas de chocolate con gomitas fortificadas.

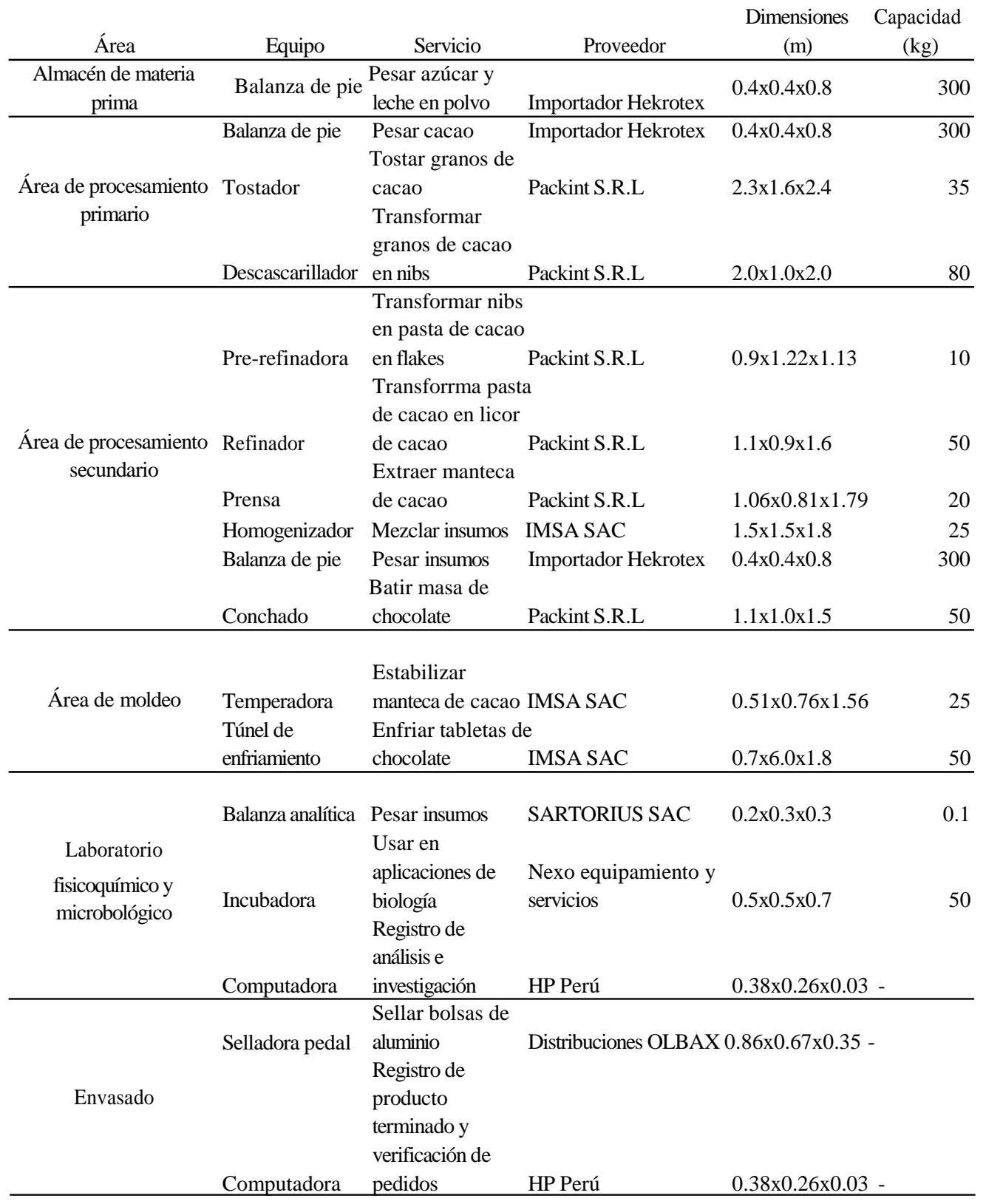

Fuente: elaboración propia 
Tabla 18.

Mobiliario del área de producción.

\begin{tabular}{|c|c|c|c|}
\hline Área & Mobiliario & Servicio & Dimensiones \\
\hline \multirow[t]{3}{*}{$\begin{array}{l}\text { Almacén de } \\
\text { materia prima }\end{array}$} & Escritorio & $\begin{array}{l}\text { Ejecutar trabajo } \\
\text { administrativo }\end{array}$ & $0.7 \times 1.2 \times 0.75$ \\
\hline & Silla & Sentarse & $0.45 \times 0.5 \times 0.45$ \\
\hline & Estante & $\begin{array}{l}\text { Almacenar } \\
\text { insumos }\end{array}$ & $0.9 \times 0.5 \times 2.1$ \\
\hline \multirow{4}{*}{\begin{tabular}{l}
\multicolumn{1}{c}{ Área de } \\
procesamiento \\
primario
\end{tabular}} & Escritorio & $\begin{array}{l}\text { Ejecutar trabajo } \\
\text { administrativo }\end{array}$ & $0.7 \times 1.2 \times 0.75$ \\
\hline & Silla & Sentarse & $0.45 \times 0.5 \times 0.45$ \\
\hline & Mesa de trabajo & Selección cacao & $1.20 \times 0.60 \times 0.87$ \\
\hline & Carro plataforma & $\begin{array}{l}\text { Transportar sacos } \\
\text { de cacao y bandejas } \\
\text { de nibs }\end{array}$ & $0.92 \times 0.62 \times 0.5$ \\
\hline \multirow[t]{2}{*}{ Área de moldeo } & Carro plataforma & $\begin{array}{l}\text { Transportar } \\
\text { bandejas con tableta } \\
\text { de chocolate }\end{array}$ & $0.92 \times 0.62 \times 0.5$ \\
\hline & Mesa de trabajo & $\begin{array}{l}\text { Moldeo de } \\
\text { tabletas de chocolate }\end{array}$ & $1.20 \times 0.60 \times 0.87$ \\
\hline \multirow[t]{4}{*}{ Envasado } & $\begin{array}{r}\text { Carretilla } \\
\text { construcción }\end{array}$ & $\begin{array}{l}\text { Transportar } \\
\text { cajones de } \\
\text { distribución }\end{array}$ & $0.5 \times 0.4 \times 0.5$ \\
\hline & Silla & Sentarse & $0.45 \times 0.5 \times 0.45$ \\
\hline & Mesa de trabajo & $\begin{array}{l}\text { Moldeo de } \\
\text { tabletas de chocolate }\end{array}$ & $1.20 \times 0.60 \times 0.87$ \\
\hline & Escritorio & $\begin{array}{l}\text { Ejecutar trabajo } \\
\text { administrativo }\end{array}$ & $1.8 \times 1.8 \times 0.75$ \\
\hline \multirow[t]{3}{*}{$\begin{array}{c}\text { Almacén de } \\
\text { producto terminado }\end{array}$} & $\begin{array}{r}\text { Carretilla } \\
\text { construcción }\end{array}$ & \begin{tabular}{l}
\multicolumn{1}{c}{ Transportar } \\
cajones de \\
distribución
\end{tabular} & $0.5 \times 0.4 \times 0.5$ \\
\hline & Silla & Sentarse & $0.45 \times 0.5 \times 0.45$ \\
\hline & Escritorio & $\begin{array}{l}\text { Ejecutar trabajo } \\
\text { administrativo }\end{array}$ & $0.7 \times 1.2 \times 0.75$ \\
\hline \multirow[t]{3}{*}{$\begin{array}{l}\text { Almacén de } \\
\text { empaques }\end{array}$} & Estante & $\begin{array}{l}\text { Almacenar } \\
\text { empaques }\end{array}$ & $0.9 \times 0.5 \times 2.1$ \\
\hline & Silla & Sentarse & $0.45 \times 0.5 \times 0.45$ \\
\hline & Escritorio & $\begin{array}{l}\text { Ejecutar trabajo } \\
\text { administrativo }\end{array}$ & $0.7 \times 1.2 \times 0.75$ \\
\hline
\end{tabular}

Fuente: elaboración propia

\subsubsection{Layout}

La distribución de la fábrica de tabletas de chocolate nutritivo se basa en el recorrido del producto por las diferentes etapas de procesamiento, desde el ingreso de la materia prima hasta la salida del producto terminado. Se han identificado 8 etapas (ver Figura 39), la etapa $\mathrm{N}^{\circ} 1$ es el ingreso del cacao a la etapa $\mathrm{N}^{\circ} 2$, también ingresa otro tipo de materia prima como 
azúcar, leche en polvo y otros a la etapa $\mathrm{N}^{\circ} 3$ y los empaques ingresan a la etapa $\mathrm{N}^{\circ}$. Los granos de cacao convertidos en nibs pasan de la etapa $\mathrm{N}^{\circ} 2$ a la etapa $\mathrm{N}^{\circ} 4$, los insumos que ingresaron a la etapa $\mathrm{N}^{\circ} 3$ pasan a la $\mathrm{N}^{\circ} 4$ para ser mezclados con los nibs y el producto final que es la masa de chocolate pasa a la etapa $\mathrm{N}^{\circ} 5$ para ser convertido en tabletas de chocolate, los cuales pasan a la etapa $\mathrm{N}^{\circ} 6$, se envían los empaques de la etapa $\mathrm{N}^{\circ} 7$ a la $\mathrm{N}^{\circ} 6$, las tabletas de chocolate quedan debidamente envasadas y etiquetadas para pasar a la etapa $\mathrm{N}^{\circ} 8 \mathrm{de}$ almacenamiento de producto terminado, de ahí el producto saldrá a despacho según programación del área de ventas.

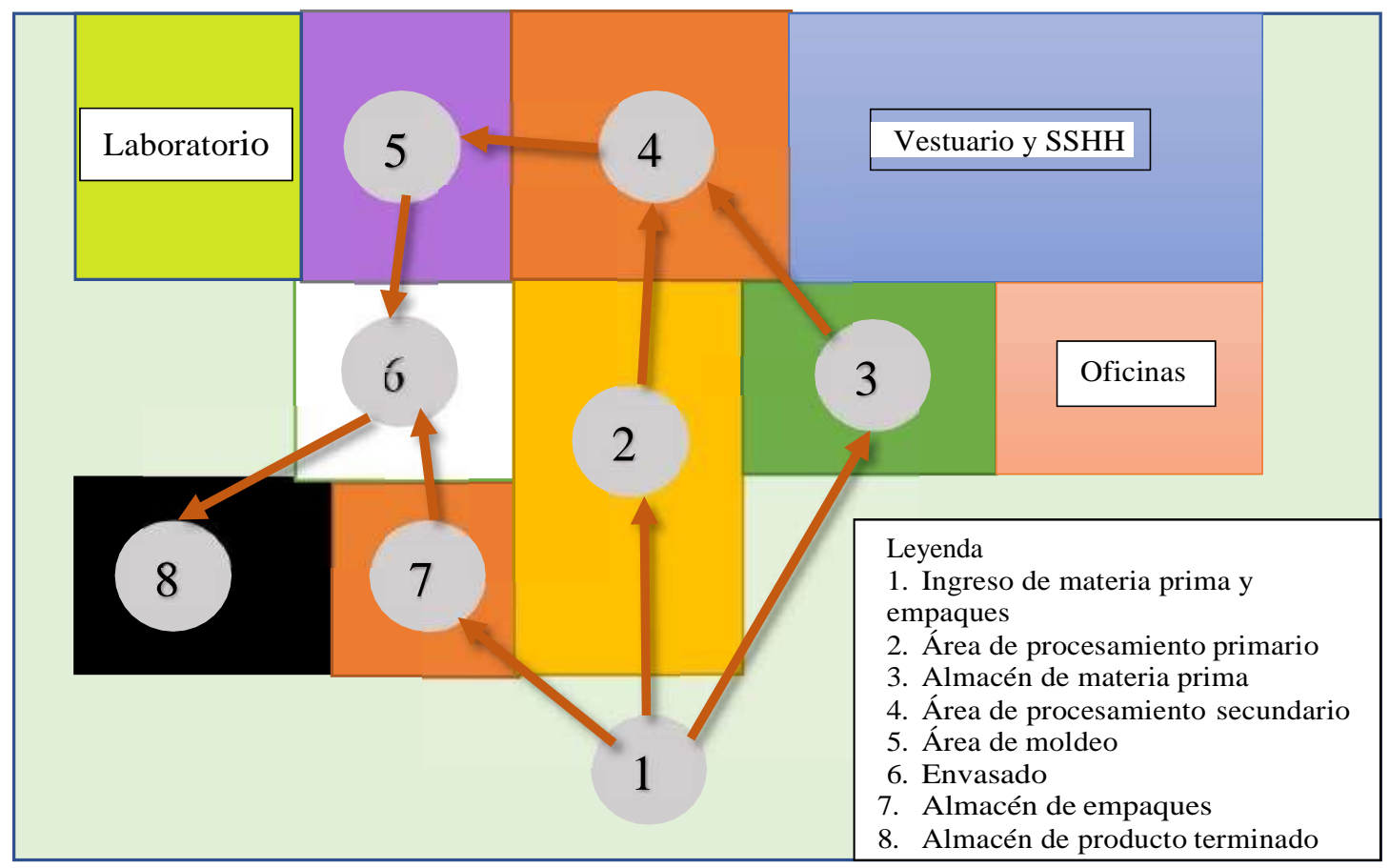

Figura 39. Layout de procesamiento de tabletas de chocolate nutritivo. Elaboración propia.

\subsubsection{Distribución de equipos y maquinarias}

La fábrica de chocolates está conformada por la planta central, área administrativa y área de tránsito. La planta central se encuentra en el primer nivel y la forman las áreas de almacén de materia prima, almacén de procesamiento primario, área de procesamiento secundario, área de moldeo, área de envasado, almacén de producto terminado y almacén de empaques, 
laboratorio fisicoquímico y laboratorio microbiológico (ver Figura 40). El área administrativa ocupa el primer y segundo nivel, cuenta con vestuarios, servicios higiénicos, comedor, sala de reuniones, oficinas de jefatura y gerencia (ver Figura 40 y 41). El área de tránsito está conformada por las áreas verdes, el patio de maniobras, estacionamiento y zona de tránsito peatonal (ver Figura 42).

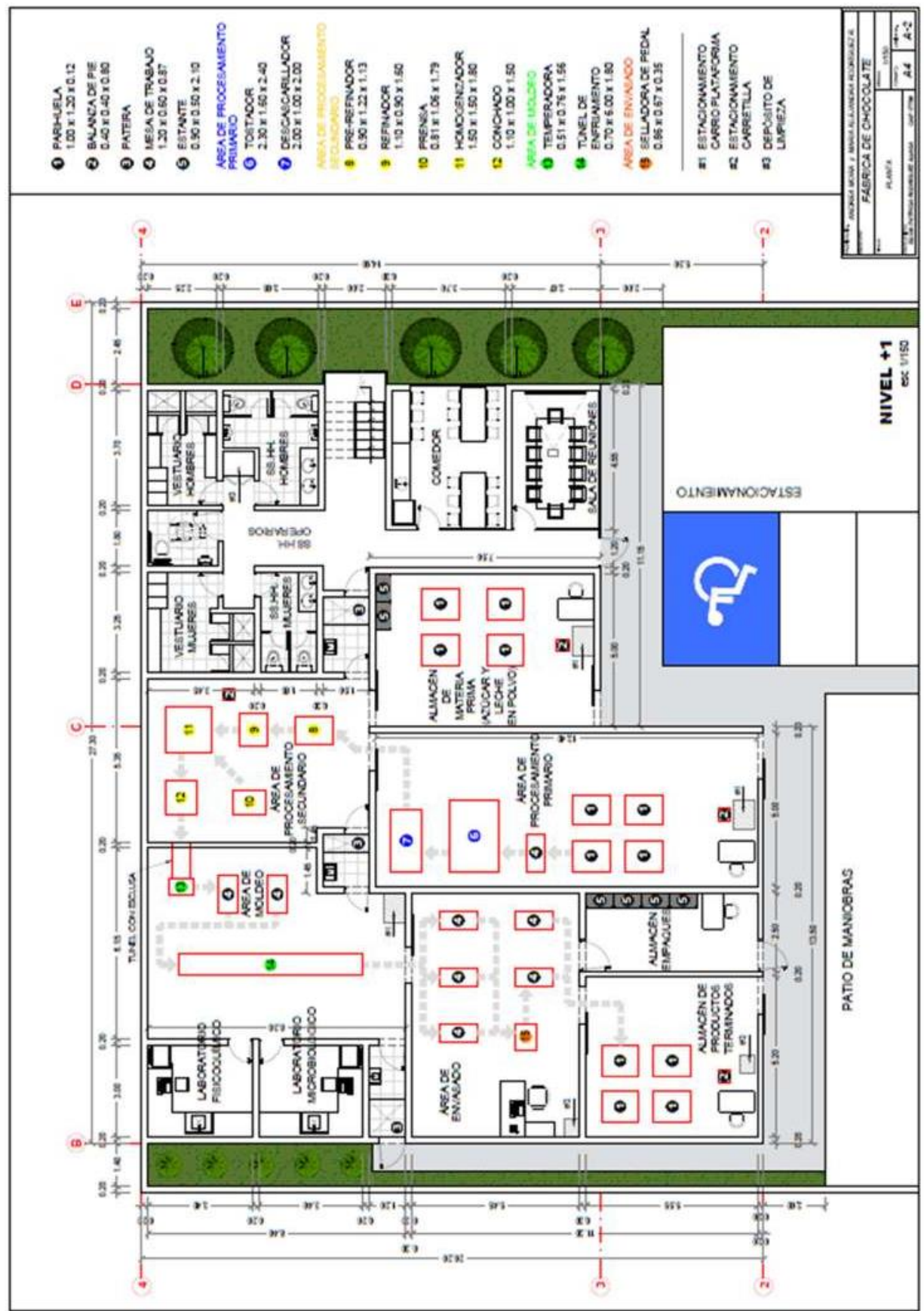

Figura 40. Distribución de equipos y maquinarias de planta central. Elaboración propia. 


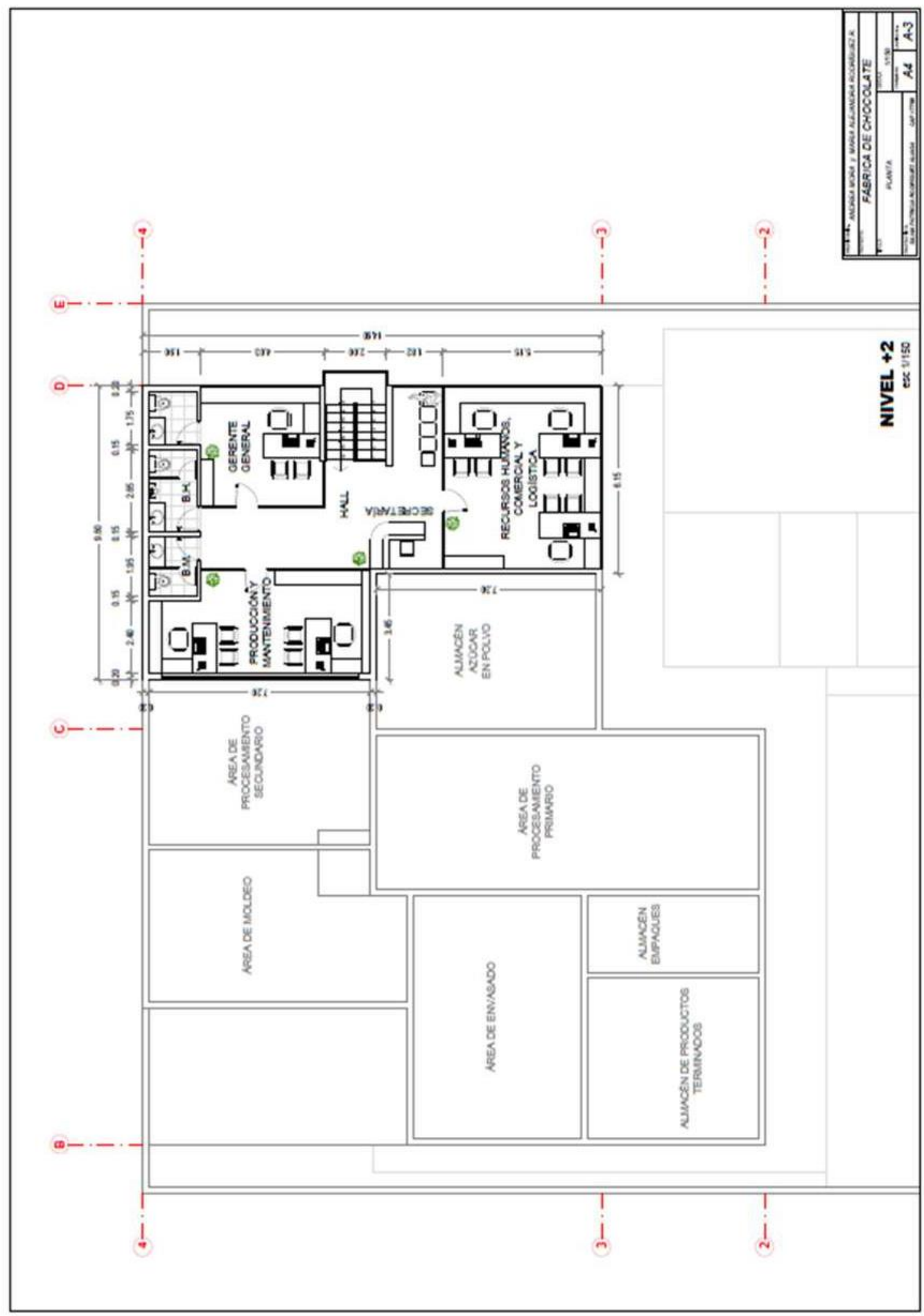

Figura 41. Distribución de equipos y mobiliario del segundo nivel de la fábrica de chocolates 


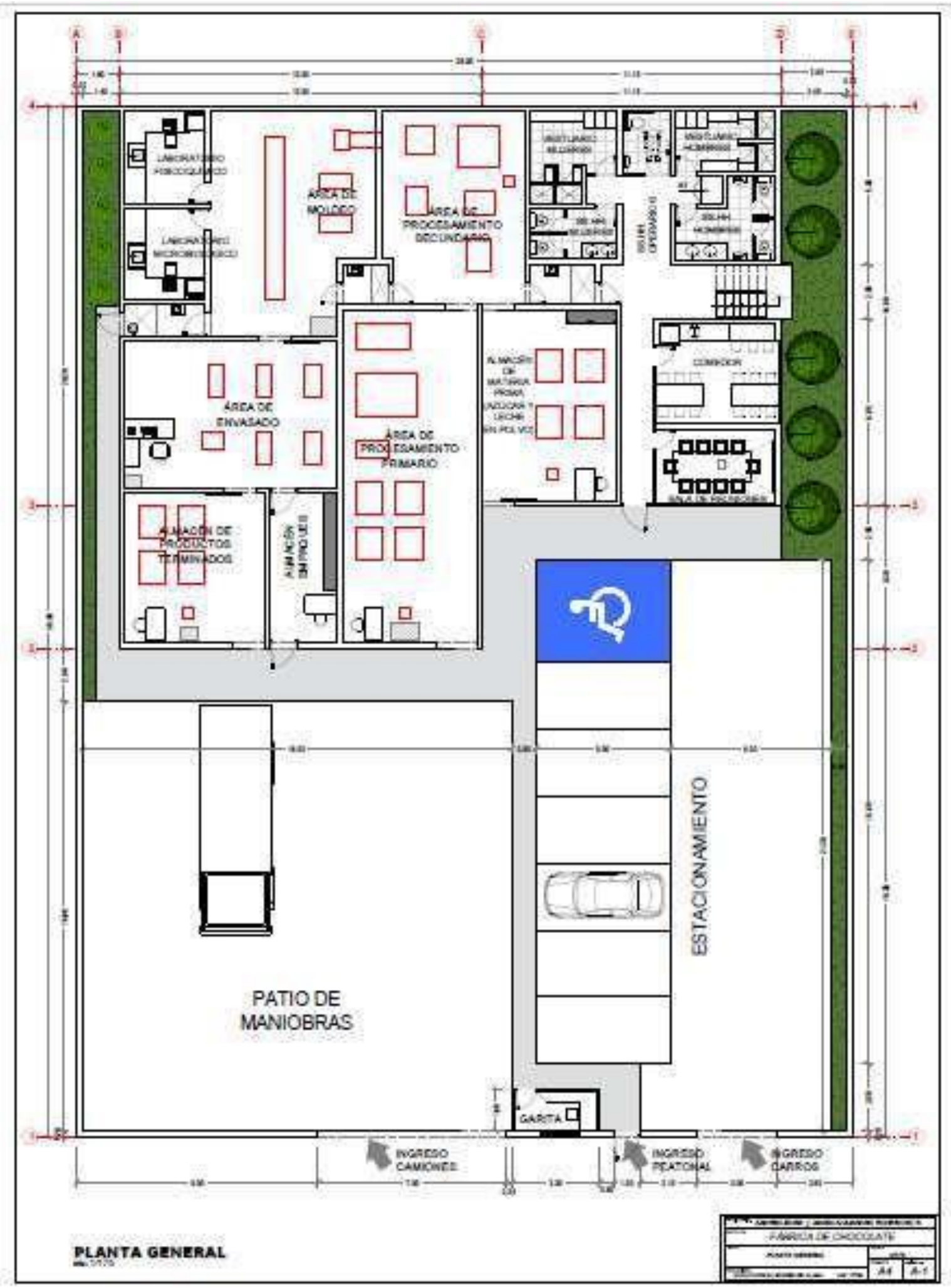

Figura 42. Distribución del área de tránsito del primer nivel de la fábrica de chocolates. Elaboración propia. 


\subsection{Determinación del tamaño}

\subsubsection{Proyección de crecimiento}

La proyección de crecimiento del plan de negocio es de 3\% anual durante los diez primeros años, luego se hará una nueva evaluación para aumentar o disminuir este índice.

La infraestructura de la fábrica se ha diseñado con bastante amplitud con la proyección de colocar máquinas adicionales conforme vaya creciendo las ventas, a partir del quinto año se podría adquirir un homogenizador (productividad $25 \mathrm{~kg} / \mathrm{h}$ ) y conchadora (productividad 50

$\mathrm{kg} / \mathrm{h}$ ) que reduciría el tiempo de elaboración de chocolates y/o permitiría contar con dos líneas de procesamiento de masa de chocolate, es decir no sólo contar con chocolate de leche sino chocolate bitter o una línea de chocolate orgánico.

\subsubsection{Recursos}

Los recursos a utilizar en este plan de negocio son humanos, tecnológicos y financieros.

Los recursos humanos serán clasificados según sus funciones, se cuenta con operarios de ambos sexos, auxiliar de laboratorio, jefe de producción, jefe de mantenimiento, jefe de logística, jefe de gestión humana, jefe de ventas y gerente general. Cada uno de los puestos que se han mencionado se detallarán sus funciones en el siguiente capítulo. Los servicios legales y de contabilidad se tercerizarán.

En cuanto a los recursos tecnológicos, se contará con maquinaria de última tecnología importada de Italia para las principales etapas del procesamiento y el equipo restante se adquirirá en el mercado nacional. Para el área administrativa se va implementar software de gestión financiera, operativa y de recursos humanos para pequeñas empresas.

Los recursos financieros serán adquiridos con una mezcla de capital propio y financiamiento, la estructura financiera se evaluará posteriormente. 


\subsubsection{Tecnología}

Las máquinas importadas de Italia serán las siguientes: tostador, descascarillador, prerefinadora, refinador, prensa y conchado; se requiere de tecnología de punta porque estos procesos deben tener alta precisión en el control de temperatura y granulometría para asegurar un producto de calidad.

Las máquinas nacionales son homogenizador, temperadora y túnel de enfriamiento. En el mercado nacional estas máquinas son de buena calidad y bajo precio.

\subsubsection{Flexibilidad}

La infraestructura de la fábrica cuenta con flexibilidad porque tiene capacidad de ampliación y se está trabajando al 50\% de la capacidad instalada. A continuación, se detalla el cálculo de capacidad instalada utilizada del tostador, si bien el proceso de elaboración de tabletas de chocolate nutritivo depende de varias máquinas se tomó el tostador como modelo porque es la primera máquina de todo el proceso y su capacidad es muy importante.

Determinación de la capacidad instalada utilizada del tostador.

Tostador

Capacidad instalada utilizada $=[$ cacao tostado pronosticado/mes $] /[$ capacidad del tostador/mes]

Capacidad instalada utilizada $=3360 / 6720=50 \%$

\subsubsection{Selección del tamaño ideal}

Se aplicó el Método de Gourchelt o método de las superficies planas para determinar el área mínima de la zona de producción, el área total que se determinó fue de $378.07 \mathrm{~m}^{2}$. Los cálculos se encuentran en el Anexo 8. Al distribuir los equipos y maquinarias en el plano de la fábrica de chocolates, la planta central tuvo un área de $330 \mathrm{~m} 2$, menor a la indicada en el método de Gourchelt, esta diferencia se debe a que en el método los espacios libres más muros y movimientos se consideran 35\% del tamaño, pero en el Reglamento Nacional de 
Edificaciones 2017 sólo se considera 30\% del tamaño de la planta. Asimismo, la distribución de equipos y maquinarias realizada en planos es específica para una fábrica artesanal de chocolates a diferencia del método de Gourchelt que es genérico y aproximado porque se aplica para diferentes tipos de fábricas. La zona de laboratorio, vestuario, servicios higiénicos y oficinas se calculó en base al Reglamento Nacional de Edificaciones 2017. En la Tabla 19 se detallan las dimensiones de todas las áreas de la fábrica de chocolates, logrando un total de $1105 \mathrm{~m}^{2}$.

Tabla 19. Dimensión de las áreas de la fábrica de chocolates nutritivo.

\begin{tabular}{ll}
\hline Área & Dimensión $\left(\mathrm{m}^{2}\right)$ \\
\hline Área de planta central & 330 \\
Área administrativa (primer piso) & 102 \\
Área administrativa (segundo piso) & 118 \\
Patio de maniobras y estacionamiento & 555 \\
Tamaño total de fábrica & 1105 \\
\hline
\end{tabular}

Fuente: elaboración propia

\subsection{Estudio de localización}

\subsubsection{Análisis de la macrolocalización}

Para la determinación de las características que debe tener el área del proyecto, es necesario fijar los criterios tanto económicos como estratégicos, institucionales y sociales que maximicen las utilidades y minimicen los costos de producción y gastos operativos. Al momento de localizar se identificarán zonas geográficas, desde un nivel macro (en una región del Perú), hasta un nivel micro (en la zona urbana o rural de esa región).

Factores para la macrolocalización

Para la determinación de la macrolocalización donde se ubicará el proyecto, se utilizará el método cualitativo por puntos. Este método consiste en definir los principales factores determinantes de una localización, para asignarles valores ponderados de peso relativo, de acuerdo con la importancia que se les atribuye.

Los factores a considerar son: 
- Costo del medio de transporte: Costo para transportar la materia prima (granos de cacao) hasta la ubicación de planta a evaluar.

- Costo de mano de obra: Se comparará el costo de mano de obrar en la localidad a evaluar o tasas de desempleo.

- Disponibilidad de insumos: Se evalúa si los insumos existen en la localidad a evaluar y el costo para traerlos de no existir en dicha localidad.

- Cercanía al mercado: El mercado principal se ubica en la ciudad de Lima. Se compara la distancia y tiempo de cada ubicación.

- Costo del terreno: Se incluye costo por alquiler o compra, predios y arbitrios.

- Comunicaciones: Disponibilidad y costo de los servicios básicos (luz, agua, teléfono, internet), hospitales, escuelas y soporte técnico.

- Clima: Se evalúa en cada localidad si el clima es favorable, es decir, que no afecte al proceso productivo.

\subsubsection{Análisis de la microlocalización}

Se utilizará el método de Brown y Gibson:

En el cual combinan factores posibles de cuantificar con factores subjetivos a los que asignan valores ponderados de peso relativo. El método consta de cuatro etapas:

- Asignar un valor relativo a cada factor objetivo FOi para cada localización optativa viable.

- Estimar un valor relativo de cada factor subjetivo FSi para cada localización optativa viable.

- Combinar los factores objetivos y subjetivos, asignándoles una ponderación relativa para obtener una medida de preferencia de localización MPL.

- Seleccionar la ubicación que tenga la máxima medida de preferencia de localización. (Sapag, N. \& Sapag,R. 2008, p. 210). 


\section{Factores objetivos (FOi)}

- Costo de materia prima (cacao). El costo es el mismo, así que este factor no es relevante para efectos de la evaluación.

- Costo de mano de obra: Se compara el costo laboral de 24 operarios en un año en cada ubicación.

- Costo del transporte: Costo de transportar 2 toneladas desde Junín, lugar de donde se traerá el cacao, hasta la planta en las diferentes ubicaciones a evaluar.

- Costo del terreno: Costo del metro cuadrado en las diferentes ubicaciones.

Factores subjetivos (FSi)

- Seguridad: Se refiere a la seguridad de la zona en la que se ubicaría la planta (bajos índices de delincuencia, número de posiciones de serenazgo, etc)

- Acceso: La facilidad de poder acceder a la planta, ya sea por los colaboradores o proveedores.

- Otros servicios: Como los servicios básicos de luz, agua, teléfono e internet, y acceso a hospitales y/o centros de salud.

\subsection{Determinación de la localización óptima}

Para hallar importancia de cada factor mencionado en el punto 8.3.1, se ha realizado el cuadro de enfrentamiento. Para la realización de estas ponderaciones se evalúa la importancia relativa de cada factor con respecto a otro, teniendo en cuenta la incidencia de cada uno sobre las operaciones de la planta, la importancia estratégica de una buena selección y la proyección de su relevancia en el tiempo.

A continuación, se muestra la evaluación de los factores en cada una de las locaciones seleccionadas. Las locaciones a considerar fueron: Junín, Lima y Cusco. Junín y Cusco por ser zonas productoras de cacao y Lima, por ser la zona principal de comercialización del producto. 
Tabla 20.

Cuadro de enfrentamiento de factores locacionales para macrolocalización.

\begin{tabular}{|c|c|c|c|c|c|c|c|c|c|}
\hline Factores & \begin{tabular}{l}
\multicolumn{1}{c}{ Costo } \\
medio de \\
transporte
\end{tabular} & $\begin{array}{l}\text { Costo } \\
\text { de mano } \\
\text { de obra }\end{array}$ & $\begin{array}{l}\text { Disponibilidad } \\
\text { de insumos }\end{array}$ & $\begin{array}{l}\text { Cercanía } \\
\text { al mercado }\end{array}$ & $\begin{array}{l}\text { Costo } \\
\text { del } \\
\text { terreno }\end{array}$ & Comunicaciones & Clima & $\Sigma$ & $(\%)^{\text {Real }}$ \\
\hline $\begin{array}{l}\text { Costo medio de } \\
\text { transporte }\end{array}$ & & 0 & 1 & 1 & 0 & 0 & 1 & 3 & $14 \%$ \\
\hline $\begin{array}{l}\text { Costo de mano } \\
\text { de obra }\end{array}$ & 1 & & 0 & 0 & 0 & 1 & 1 & 3 & $14 \%$ \\
\hline $\begin{array}{l}\text { Disponibilidad } \\
\text { de insumos }\end{array}$ & 0 & 1 & & 0 & 0 & 1 & 1 & 3 & $14 \%$ \\
\hline $\begin{array}{l}\text { Cercanía al } \\
\text { mercado }\end{array}$ & 0 & 1 & 1 & & 1 & 1 & 0 & 4 & $19 \%$ \\
\hline $\begin{array}{l}\text { Costo del } \\
\text { terrerno }\end{array}$ & 1 & 1 & 1 & 0 & & 1 & 1 & 5 & $24 \%$ \\
\hline Comunicaciones & 1 & 0 & 0 & 0 & 0 & & 1 & 2 & $10 \%$ \\
\hline \multirow[t]{2}{*}{ Clima } & 0 & 0 & 0 & 1 & 0 & 0 & & 1 & $5 \%$ \\
\hline & & & & & & & Total & 21 & \\
\hline
\end{tabular}

Fuente: elaboración propia.

Se ha considerado una calificación entre 2 y 7 , otorgando 2 para los departamentos que tienen problemas o carecen de dicha característica y el número 7 para las regiones con mayor oportunidad o gran cantidad de recurso de acuerdo a cada factor.

Tabla 21.

Ponderación de factores para macrolocalización por localidad.

\begin{tabular}{|c|c|c|c|c|c|c|c|}
\hline & & Junín & & Lima & & Cusco & \\
\hline Factor & Peso & Calificación & Ponderación & Calificación & Ponderación & Calificación & Ponderación \\
\hline $\begin{array}{l}\text { Costo medio de } \\
\text { transporte }\end{array}$ & 0.14 & 6 & 0.86 & 4 & 0.57 & 6 & 0.86 \\
\hline $\begin{array}{l}\text { Costo de mano } \\
\text { de obra }\end{array}$ & 0.14 & 6 & 0.86 & 5 & 0.71 & 6 & 0.86 \\
\hline $\begin{array}{l}\text { Disponibilidad } \\
\text { de insumos }\end{array}$ & 0.14 & 6 & 0.86 & 4 & 0.57 & 6 & 0.86 \\
\hline $\begin{array}{l}\text { Cercanía al } \\
\text { mercado }\end{array}$ & 0.19 & 3 & 0.57 & 7 & 1.33 & 4 & 0.76 \\
\hline $\begin{array}{l}\text { Costo del } \\
\text { terrerno }\end{array}$ & 0.24 & 6 & 1.43 & 5 & 1.19 & 6 & 1.43 \\
\hline \multicolumn{2}{|c|}{ Comunicaciones 0.10} & 3 & 0.29 & 7 & 0.67 & 3 & 0.29 \\
\hline \multirow[t]{2}{*}{ Clima } & 0.05 & 3 & 0.14 & 7 & 0.33 & 3 & 0.14 \\
\hline & & & 5.00 & & 5.38 & & 5.19 \\
\hline
\end{tabular}

Fuente: elaboración propia. 
De acuerdo al resultado final de la evaluación, la localización óptima para el proyecto sería Lima, con una calificación de 5.3, aunque ligeramente por encima de las otras dos locaciones.

Determinación de la microlocalización

Determinada la macrolocalización en Lima, se procede a determinar la microlocalización óptima, para lo cual se utilizará el método de Brown y Gibson, tal como se indicó en el punto 8.3.1.

Las tres potenciales ubicaciones a evaluar dentro de Lima son: Chorrillos, Lurín y Chilca.

Chorrillos se elige por fácil acceso al mercado en Lima y tener zona industrial. Lurín y Chilca se eligen porque en estos tiempos están surgiendo como nuevos parques industriales.

Factores objetivos (FOi)

A continuación, se presentan la evaluación de los factores objetivos, para lo que se presentan los costos de los factores a evaluar: materia prima, costo de terreno, mano de obra y costo del transporte.

Tabla 22.

Costos para evaluación de microlocalización.

Costo de Materia Prima (S/) costo de cacao por $\mathrm{kg} \quad 10$

\begin{tabular}{|c|c|c|c|}
\hline producción año 1 & 40320 & \multicolumn{2}{|l|}{$\mathrm{kg}$} \\
\hline Costo total MP & \multicolumn{3}{|l|}{403,200} \\
\hline Costo de terreno $(\mathrm{S} /)$ & área terreno $(\mathrm{m} 2)$ & \multicolumn{2}{|l|}{1105.4} \\
\hline Chorrillos & Lurín & \multicolumn{2}{|l|}{ Chilca } \\
\hline 1800 & 800 & \multicolumn{2}{|l|}{1100} \\
\hline $1,989,720.00$ & $884,320.00$ & \multicolumn{2}{|l|}{$1,215,940.00$} \\
\hline \multicolumn{2}{|c|}{ Costo MO por localidad anual (S/) } & $\mathrm{n}^{\circ}$ operarios & 24 \\
\hline & Chorrillos & Lurin & Chilca \\
\hline sueldo mensual & 1100 & 950 & 850 \\
\hline sueldo anual (todos) & $369,600.00$ & $319,200.00$ & $285,600.00$ \\
\hline Costo transporte $(\mathrm{S} /)$ & \multicolumn{3}{|c|}{ Desde Junín a la planta (para un promedio de $2 \mathrm{TON}$ ) } \\
\hline Chorrillos & Lurín & \multicolumn{2}{|c|}{ Chilca } \\
\hline $1,300.00$ & $1,100.00$ & \multicolumn{2}{|l|}{$1,200.00$} \\
\hline
\end{tabular}

Fuente: elaboración propia. 
En la Tabla 23 se presenta el cálculo de los factores objetivos, donde la localidad de Lurín resulta ser la mejor, al tener el mayor valor con relación a los otros dos. Si se ve en términos de costos, es el que represente el menor costo.

Tabla 23.

Evaluación de Factores Objetivos (FOi) para localidades de Chorrillos, Lurín y Chilca.

\begin{tabular}{|c|c|c|c|c|c|c|}
\hline Localización & $\begin{array}{l}\text { Mano de } \\
\text { Obra }\end{array}$ & Transporte & Terreno & Total Ci & $\begin{array}{l}\text { Recíproco } \\
(1 / \mathrm{Ci})\end{array}$ & FOi \\
\hline Chorrillos & $369,600.00$ & $1,300.00$ & $1,989,720.00$ & $2,360,620.00$ & 0.000000424 & 0.22073 \\
\hline Lurín & $319,200.00$ & $1,100.00$ & $884,320.00$ & $1,204,620.00$ & 0.000000830 & 0.43254 \\
\hline \multirow[t]{2}{*}{ Chilca } & $285,600.00$ & $1,200.00$ & $1,215,940.00$ & $1,502,740.00$ & 0.000000665 & 0.34673 \\
\hline & & & & Total & 0.000001919 & \\
\hline
\end{tabular}

Fuente: elaboración propia.

Factores subjetivos (FSi)

Se procede a realizar las comparaciones pareadas de los factores descritos en 8.3.1., donde 1 significa que el factor a evaluar es mejor en la localidad por lo que el otro factor comparado sería 0 . Si en ambas localidades es igual, ambas tienen puntuación de 1. Se suman las preferencias por cada factor y luego se calcula el índice de importancia relativa $(\mathrm{Wj})$, que es la inversa de la suma de preferencias.

Tabla 24.

Cálculo del valor relativo Rij de los factores subjetivos

\begin{tabular}{|c|c|c|c|c|c|}
\hline & \multicolumn{3}{|c|}{ Comparaciones pareadas } & \multirow{2}{*}{$\begin{array}{c}\text { Suma de } \\
\text { preferencias }\end{array}$} & \multirow{2}{*}{$\begin{array}{l}\text { Índice } \\
\text { de } \mathrm{Wj}\end{array}$} \\
\hline & 1 & 2 & 3 & & \\
\hline Seguridad & 1 & 1 & & 2 & 0.5 \\
\hline Acceso & 0 & & 1 & 1 & 0.25 \\
\hline Otros servicios & & 0 & 1 & 1 & 0.25 \\
\hline Total & & & & 4 & 1 \\
\hline
\end{tabular}

Fuente: elaboración propia.

La seguridad resulta ser el factor subjetivo de mayor relevancia.

Ahora se procede a evaluar estos tres factores en las diferentes localidades. El procedimiento de evaluación es el mismo al descrito en el paso anterior. 
Tabla 25.

Comparaciones pareadas por localidad según factores subjetivos.

\begin{tabular}{|c|c|c|c|c|c|}
\hline \multirow{3}{*}{$\begin{array}{l}\text { Factor } \\
\text { Localización }\end{array}$} & \multicolumn{5}{|c|}{ Seguridad } \\
\hline & \multicolumn{3}{|c|}{ Comparaciones pareadas } & \multirow{2}{*}{$\begin{array}{c}\text { Suma de } \\
\text { Preferencias }\end{array}$} & \multirow{2}{*}{ Ri1 } \\
\hline & 1 & 2 & 3 & & \\
\hline Chorrillos & 0 & 0 & & 0 & 0 \\
\hline Lurín & 1 & & 1 & 2 & 0.5 \\
\hline Chilca & & 1 & 1 & 2 & 0.5 \\
\hline TOTAL & & & & 4 & \\
\hline \multirow[t]{2}{*}{ Factor } & \multicolumn{3}{|c|}{ Acceso } & & \\
\hline & \multicolumn{3}{|c|}{ Comparaciones pareadas } & Suma de & Ri2 \\
\hline Localización & 1 & 2 & 3 & Preferencias & \\
\hline Chorrillos & 1 & 1 & & 2 & 0.5 \\
\hline Lurín & 0 & & 1 & 1 & 0.25 \\
\hline Chilca & & 0 & 1 & 1 & 0.25 \\
\hline TOTAL & & & & 4 & \\
\hline \multirow[t]{2}{*}{ Factor } & \multicolumn{3}{|c|}{ Otros servicios } & & \\
\hline & \multicolumn{3}{|c|}{ Comparaciones pareadas } & Suma de & Ri3 \\
\hline Localización & 1 & 2 & 3 & Preferencias & \\
\hline Chorrillos & 1 & 1 & & 2 & 0.667 \\
\hline Lurín & 0 & & 1 & 1 & 0.333 \\
\hline Chilca & & 0 & 0 & 0 & 0.000 \\
\hline TOTAL & & & & 3 & \\
\hline
\end{tabular}

Fuente: elaboración propia.

En Lurín y Chilca la seguridad es mejor que en Chorrillos. El acceso a la planta en

Chorrillos es mejor que en las otras dos locaciones y el acceso a otros servicios es mejor en

Chorrillos.

Tabla 26.

Resumen de los valores relativos de factores subjetivos porlocalidad

\begin{tabular}{llllr}
\hline \multirow{2}{*}{ Factor } & \multicolumn{2}{l}{ Puntaje relativo (Rij) } & \multicolumn{2}{c}{ Índice } \\
& Chorrillos & Lurín & Chilca & $\mathrm{Wj}$ \\
\hline Seguridad & 0.0000 & 0.5000 & 0.5000 & 0.5000 \\
Acceso & 0.5000 & 0.2500 & 0.2500 & 0.2500 \\
Otros servicios & 0.6667 & 0.3333 & 0.0000 & 0.2500 \\
\hline
\end{tabular}

Fuente: elaboración propia.

Finalmente, se procede a calcular los factores subjetivos por localidad. La sumatoria de multiplicar el valor relativo Rij por el índice de importancia relativa $\mathrm{Wj}$ 


$$
F S i=\sum_{j=1}^{n} R i j . W j
$$

Tabla 27.

Factores Subjetivos por localidad.

\begin{tabular}{ll} 
Localidad & Valor FSi \\
\hline Chorrillos & 0.291667 \\
Lurín & 0.395833 \\
Chilca & 0.3125 \\
\hline
\end{tabular}

Fuente: elaboración propia.

La localidad de Lurín represente el mayor puntaje de factor subjetivo.

Medida de preferencia

Una vez calculado en términos relativos los factores objetivos y subjetivos de localización, se procede a calcular la medida de preferencia de localización mediante la siguiente formula:

$$
M P L_{i}=K\left(F O_{i}\right)+(1-K)\left(F S_{i}\right)
$$

Donde $\mathrm{K}=3(1-\mathrm{K})$

$\mathrm{K}=0.75,1-\mathrm{K}=0.25$

Entonces, reemplazando en la fórmula:

Tabla 28.

Medidas de preferencia por localidad.

Localidad MPLi

Chorrillos $\quad 0.2385$

Lurín $\quad 0.4234$

Chilca $\quad 0.3382$

Fuente: elaboración propia.

Según medida de preferencia, Lurín es la mejor localidad, ya que representa el mayor puntaje de la evaluación.

En resumen, Lurín es el lugar elegido para ubicar la planta de chocolates artesanales. 


\subsection{Seguridad y Salud en el Trabajo}

En cumplimiento de la normativa aplicable relacionada a la Seguridad y Salud en el Trabajo Ley 29783, se implementará el Sistema de Gestión de Seguridad y Salud en el Trabajo, o también denominado Ocupacional, a nivel de toda la organización. Por ser empresa industrial, está catalogada como empresa de alto riesgo.

Lo primero que debe definirse es la Política de Seguridad y Salud Ocupacional, que es la declaración del compromiso de la empresa junto con los objetivos de SSO. En el anexo 9 y 10 se presentan ambos documentos.

\subsubsection{Documentación necesaria para el Sistema de Gestión de SSO}

Los documentos mínimos y necesarios son los siguientes, los que deben ser de conocimiento de todos los colaboradores;

- Reglamento Interno de Seguridad y Salud en el Trabajo

- Procedimientos para la identificación de peligros y evaluación de riesgos y para el registro e investigación de hallazgos de SST

- Plan de Emergencia e instructivos de emergencia

- Registros obligatorios de SST de acuerdo a la RM 050-2013-TR

En la Tabla 29 se presentan todos los documentos relacionados a SST que se implementarán en la empresa. 
Tabla 29.

Lista maestra de documentos del Sistema de Seguridad y Salud Ocupacional.

\begin{tabular}{|c|c|c|c|c|}
\hline Código & Área & Sección & Tipo documento & Nombre de documento \\
\hline SST-01 & $\begin{array}{l}\text { Administracióny } \\
\text { Gestión Humana }\end{array}$ & $\begin{array}{l}\text { Seguridad y Salud } \\
\text { Ocupacional }\end{array}$ & $\begin{array}{l}\text { Documento de } \\
\text { Gestión }\end{array}$ & Política de Seguridad y Salud Ocupaciona \\
\hline SST-02 & $\begin{array}{l}\text { Administracióny } \\
\text { Gestión Humana }\end{array}$ & $\begin{array}{l}\text { Seguridad y Salud } \\
\text { Ocupacional }\end{array}$ & $\begin{array}{l}\text { Documento de } \\
\text { Gestión }\end{array}$ & $\begin{array}{c}\text { Planificación para el logro de los Objetivos } \\
\text { de Seguridad y Salud Ocupacional }\end{array}$ \\
\hline SST-03 & $\begin{array}{l}\text { Administracióny } \\
\text { Gestión Humana }\end{array}$ & $\begin{array}{c}\text { Seguridad y Salud } \\
\text { Ocupacional }\end{array}$ & $\begin{array}{c}\text { Documento de } \\
\text { Gestión }\end{array}$ & $\begin{array}{c}\text { Programa Anual de Seguridad y Salud } \\
\text { Ocupacional } \\
\end{array}$ \\
\hline SST-04 & $\begin{array}{l}\text { Administracióny } \\
\text { Gestión Humana }\end{array}$ & $\begin{array}{l}\text { Seguridad y Salud } \\
\text { Ocupacional }\end{array}$ & $\begin{array}{c}\text { Documento de } \\
\text { Gestión }\end{array}$ & $\begin{array}{c}\text { Reglamento Interno de Seguridad y Salud } \\
\text { Ocupacional }\end{array}$ \\
\hline SST-05 & $\begin{array}{l}\text { Administracióny } \\
\text { Gestión Humana }\end{array}$ & $\begin{array}{l}\text { Seguridad y Salud } \\
\text { Ocupacional }\end{array}$ & $\begin{array}{l}\text { Documento de } \\
\text { Gestión }\end{array}$ & Plan de Emergencia \\
\hline SST-06 & $\begin{array}{l}\text { Administracióny } \\
\text { Gestión Humana }\end{array}$ & $\begin{array}{c}\text { Seguridad y Salud } \\
\text { Ocunacional }\end{array}$ & $\begin{array}{c}\text { Documento de } \\
\text { Gestión }\end{array}$ & $\begin{array}{l}\text { Matriz de Identificación de Peligros y } \\
\text { Evaluaciónde_Riesoos }\end{array}$ \\
\hline SST-07 & $\begin{array}{l}\text { Administracióny } \\
\text { Gestión Humana }\end{array}$ & $\begin{array}{l}\text { Seguridad y Salud } \\
\text { Ocupacional }\end{array}$ & $\begin{array}{c}\text { Documento de } \\
\text { Gestión }\end{array}$ & Mapa de Riesgos \\
\hline SST-08 & $\begin{array}{l}\text { Administracióny } \\
\text { Gestión Humana }\end{array}$ & $\begin{array}{l}\text { Seguridad y Salud } \\
\text { Ocupacional }\end{array}$ & Procedimiento & $\begin{array}{l}\text { Identificación de Peligros y Evaluación de } \\
\text { Riesgos de Seguridad y Salud Ocupacional }\end{array}$ \\
\hline SST-09 & $\begin{array}{l}\text { Administracióny } \\
\text { Gestión Humana } \\
\end{array}$ & $\begin{array}{l}\text { Seguridad y Salud } \\
\text { Ocupacional } \\
\end{array}$ & Procedimiento & $\begin{array}{c}\text { Registro e investigación de cuasi } \\
\text { accidentes, accidentes, y enfermedades }\end{array}$ \\
\hline SST-10 & $\begin{array}{l}\text { Administracióny } \\
\text { Gestión Humana }\end{array}$ & $\begin{array}{c}\text { Seguridad y Salud } \\
\text { Ocupacional }\end{array}$ & Instructivo & Evacuación en Caso de Incendio \\
\hline SST-11 & $\begin{array}{l}\text { Administracióny } \\
\text { Gestión Humana }\end{array}$ & $\begin{array}{l}\text { Seguridad y Salud } \\
\text { Ocupacional }\end{array}$ & Instructivo & Evacuación en Caso de Sismo \\
\hline SST-12 & $\begin{array}{l}\text { Administracióny } \\
\text { Gestión Humana }\end{array}$ & $\begin{array}{l}\text { Seguridad y Salud } \\
\text { Ocupacional }\end{array}$ & Instructivo & Primeros Auxilios \\
\hline SST-13 & $\begin{array}{l}\text { Administracióny } \\
\text { Gestión Humana }\end{array}$ & $\begin{array}{l}\text { Seguridad y Salud } \\
\text { Ocupacional }\end{array}$ & Instructivo & Amenaza de artefacto explosivo \\
\hline SST-14 & $\begin{array}{l}\text { Administracióny } \\
\text { Gestión Humana }\end{array}$ & Seguridad y Salud & Instructivo & Atención en caso de asalto \\
\hline SST-15 & $\begin{array}{l}\text { Administracióny } \\
\text { Gestión Humana }\end{array}$ & Seguridad y Salud & Instructivo & Atención en caso de conmoción social \\
\hline SST-16 & $\begin{array}{l}\text { Administracióny } \\
\text { Gestión Humana }\end{array}$ & Seguridad y Salud & Instructivo & Evacuación en caso de inundación \\
\hline SST-17 & $\begin{array}{l}\text { Administracióny } \\
\text { Gestión Humana } \\
\end{array}$ & Seguridad y Salud & Formato & Registro de Peligros \\
\hline SST-18 & $\begin{array}{l}\text { Administracióny } \\
\text { Gestión Humana }\end{array}$ & Seguridad y Salud & Formato & Registro de accidentes de trabajo \\
\hline SST-19 & $\begin{array}{l}\text { Administracióny } \\
\text { Gestión Humana }\end{array}$ & Seguridad y Salud & Formato & Registro de enfermedadesocupacionales \\
\hline SST-20 & $\begin{array}{l}\text { Administracióny } \\
\text { Gestión Humana }\end{array}$ & $\begin{array}{l}\text { Ocupacional } \\
\text { Seguridad y Salud }\end{array}$ & Formato & Registro de cuasi accidentes peligrosos y \\
\hline SST-21 & $\begin{array}{l}\text { Administracióny } \\
\text { Gestión Humana }\end{array}$ & $\begin{array}{c}\text { Ocupacional } \\
\text { Seguridad y Salud }\end{array}$ & Formato & $\begin{array}{l}\text { cuasi accidentes (incidentes) } \\
\text { Registro de monitoreo de agentes }\end{array}$ \\
\hline SST-22 & $\begin{array}{l}\text { Administracióny } \\
\text { Gestión Humana }\end{array}$ & $\begin{array}{c}\text { Ocupacional } \\
\text { Seguridad y Salud }\end{array}$ & Formato & Registro de inspecciones internas de SSO \\
\hline SST-23 & $\begin{array}{l}\text { Administracióny } \\
\text { Gestión Humana }\end{array}$ & $\begin{array}{c}\text { Ocupacional } \\
\text { Seguridad y Salud } \\
\end{array}$ & Formato & Formato de datos para registrode \\
\hline SST-24 & $\begin{array}{l}\text { Administracióny } \\
\text { Gestión Humana } \\
\end{array}$ & $\begin{array}{c}\text { Ocupacional } \\
\text { Seguridad y Salud } \\
\end{array}$ & Formato & $\begin{array}{c}\text { estadísticas de SSO } \\
\text { Registro de estadísticas de SSO }\end{array}$ \\
\hline SST-25 & $\begin{array}{l}\text { Administracióny } \\
\text { Gestión Humana }\end{array}$ & $\begin{array}{c}\text { Ocupacional } \\
\text { Seguridad y Salud }\end{array}$ & & Registro de equipos de seguridado \\
\hline SST-26 & $\begin{array}{l}\text { Administracióny } \\
\text { Gestión Humana }\end{array}$ & $\begin{array}{c}\text { Ocupacional } \\
\text { Seguridad y Salud }\end{array}$ & & $\begin{array}{c}\text { emergencia } \\
\text { Registro de inducción, capacitación, }\end{array}$ \\
\hline SST-27 & $\begin{array}{l}\text { Administracióny } \\
\text { Gestión Humana }\end{array}$ & $\begin{array}{c}\text { Ocupacional } \\
\text { Seguridad y Salud }\end{array}$ & & entrenamiento y simulacro de emergencia \\
\hline
\end{tabular}

Fuente: Elaboración propia

Ocupacional 


\subsubsection{Organización de SSO}

El área encargada y responsable de la Gestión de Seguridad y Salud en el Trabajo es Administración y Gestión Humana, quien trabajará en conjunto al área de Mantenimiento. Asimismo, trabajará en coordinación con el Comité de Seguridad y Salud en el Trabajo.

El Comité de Seguridad y Salud en el Trabajo debe formarse de acuerdo a la normatividad aplicable. Es un comité paritario, conformado 50\% a elección del empleador y 50\% a elección de los colaboradores. Para la elección de los miembros representantes de los colaboradores deben convocarse elecciones teniendo una vigencia de dos años. Para la empresa MARAN S.R.L estará conformados por cuatro personas, siendo los representantes del empleador, el Jefe de Gestión Humana y el Jefe de Mantenimiento. En el transcurso del año 2019 se convocarían las elecciones.

También se contará con un Equipo de Emergencia, el que estará formado por tres brigadas:

- Brigada de Evacuación

- Brigada de Primeros Auxilios

- Brigada de Lucha contra incendios

De acuerdo al rubro de la empresa, se debe contar con un médico ocupacional, para lo cual se contratará un servicio para la realización de la vigilancia médico ocupacional por un mínimo de 32 horas al mes.

\section{Funciones}

En la Figura 43 se presenta la organización y las funciones de cada una de las partes involucradas en el sistema de SSO. 


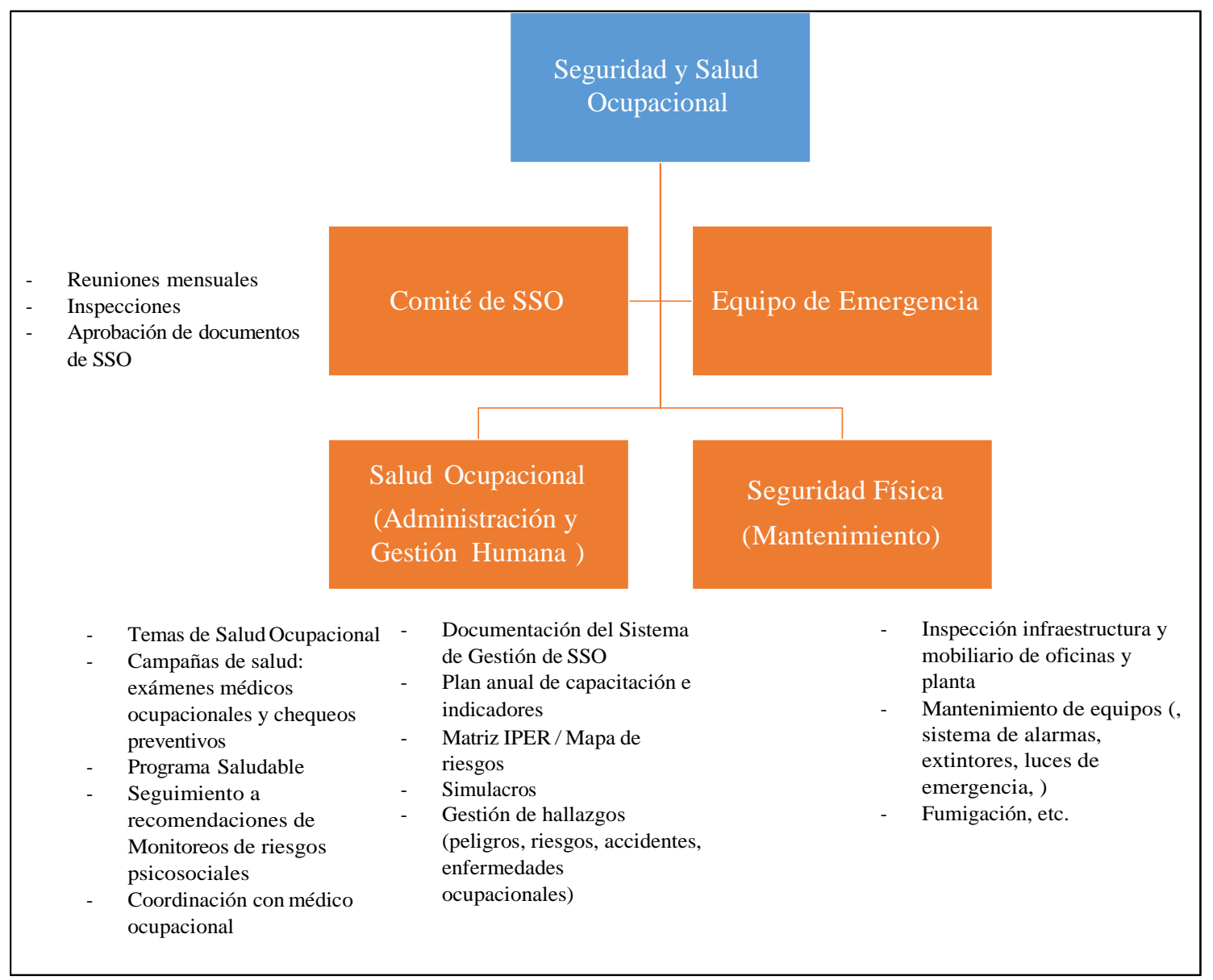

Figura 43. Organización y funciones del Sistema de Gestión de SST. Elaboración propia.

\subsubsection{Programa Anual de SSO}

Se ha elaborado un Programa de actividades de seguridad y salud ocupacional a trabajar desde el año 2019, año en que iniciarán las operaciones de la empresa.

A lo largo del año se han programado diversas capacitaciones, ya sean generales para todos los colaboradores, las especializadas para miembros de las brigadas y las capacitaciones para el Comité de SSO. También se coloca la oportunidad en la que se realizarán los exámenes médicos ocupacionales (EMOS), los monitoreos de agentes de riesgos, inspecciones, actividades de prevención, de mantenimiento, simulacros de emergencia (sismo, incendio), entre otras. En el anexo 11 se presenta el Programa Anual de SSO. 


\subsubsection{Capacitaciones y Programa de Sensibilización}

En el artículo 35, inciso (b) de la Ley de Seguridad y Salud en el Trabajo 29783, se indica que, es de responsabilidad del empleador el dar no menos de cuatro capacitaciones en el año en materia de seguridad y salud en el trabajo, a sus colaboradores. En el Programa Anual de SSO se han colocado las capacitaciones que deberían realizarse de manera obligatoria. Sin embargo, la empresa MARAN S.R.L. considera temas extras de sensibilización que podrían darse a los colaboradores. A continuación, en la Tabla 30, se listan los temas de capacitación y sensibilización para los colaboradores y personal de brigadas:

Tabla 30.

Relación de capacitaciones de SSO.

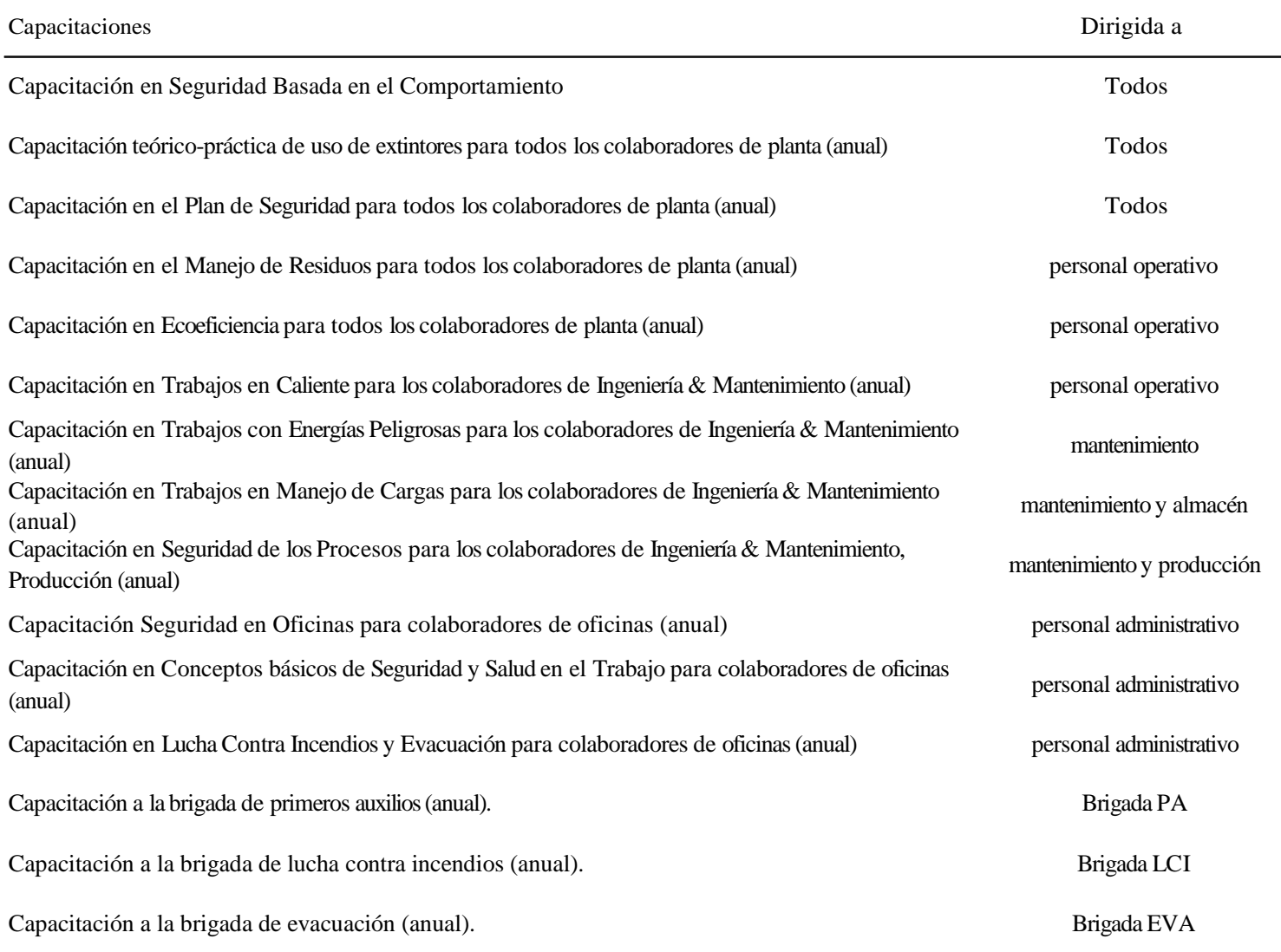
Fuente: Elaboración propia.

\subsubsection{Protocolo de exámenes médicos}

De acuerdo a lo estipulado en el Artículo 49, inciso (d) de la Ley 29783, el empleador debe realizar exámenes médicos ocupacionales (EMO) periódicos, de acuerdo a los riesgos a 
los que están expuestos los trabajadores. En cumplimiento de la ley, se han diseñado dos

protocolos de exámenes médicos ocupacionales, uno para personal administrativo y otro para personal operario.

De acuerdo a la R.M. 312-2011 MINSA Protocolos de Exámenes Médicos Ocupacionales, punto 6.5, se listan los exámenes médicos obligatorios por actividad. En las Tablas 31 y 32 se presentan los que se implementarán en la empresa.

Tabla 31.

Protocolo de EMO para administrativos.

EXAMEN MÉDICO OCUPACIONAL GENERAL

1.- Examen Clínico Ocupacional

Historia médica Ocupacional

Antecedentes

Examen físico

2.- Examen Oftalmológico

Agudeza visual (Visión de lejos)

Test de Visión de colores (Ishihara)

Motilidad ocular

Reflejos pupilares

4.- $\quad$ Examen Psicológico

EXÁMENES COMPLEMENTARIOS GENERALES

5.- $\quad$ Biometría Sanguínea

Hemograma completo

Hemoglobina ( $\mathrm{Hb})$

Hematocrito (Hto)

Recuento de hematíes

Fórmula leucocitaria

6.- Bioquímica Sanguínea: Glucosa (En ayunas)

7.- $\quad$ Grupo sanguíneo y Factor Rh

8.- $\quad$ Examen Completo de Orina

EXÁMENES COMPLEMENTARIOS ESPECÍFICOS

9.- $\quad$ Examen Músculo-esquelético

10.- $\quad$ Rayos X de Tórax: Frontal P-A

\section{OPCIONALES}

11.- Electrocardiograma: En reposo (A mayores de 40 años)

12.- Bioquímica Sanguínea

Triglicéridos

Colesterol

I.M.C $\geq 30$

Fuente: Elaboración propia 
Tabla 32.

Protocolo de EMO para operarios.

EXAMEN MÉDICO OCUPACIONAL GENERAL

1.- Examen Clínico Ocupacional

Historia médica Ocupacional

Antecedentes

Examen físico

2.- Examen Oftalmológico

Agudeza visual (Visión de lejos)

Test de Visión de colores (Ishihara)

Motilidad ocular

Reflejos pupilares

3.- Evaluación Dermatologica

4.- Examen Psicológico

EXÁMENES COMPLEMENTARIOS GENERALES

5.- Biometría Sanguínea

Hemograma completo

Hemoglobina $(\mathrm{Hb})$

Hematocrito (Hto)

Recuento de hematíes

Fórmula leucocitaria

6.- Bioquímica Sanguínea

Glucosa (En ayunas)

7.- $\quad$ Grupo sanguíneo y Factor Rh

8.- Examen Completo de Orina

EXÁMENES COMPLEMENTARIOS ESPECÍFICOS

9.- Examen Músculo-esquelético

10.- Rayos X de Tórax

Frontal P-A

11.- Audiometría

12.- Espirometría

Basal Forzada

13.- Bioquímica Sanguínea

Triglicéridos

Colesterol

14.- Laboratorio

VDRL;CULTIVO NASOFARINGEO

Fuente: Elaboración propia.

Antes del ingreso, se solicitará a los operarios gestionar y presentar su carnet de sanidad, como requisito. 


\subsubsection{Monitoreos de agentes de riesgos}

En el artículo 36 inciso (b) de la Ley 29783, se menciona que, el empleador debe hacer vigilancia de los factores del medio ambiente de trabajo y de las prácticas de trabajo que puedan afectar a la salud de los colaboradores. En el artículo 56, explícitamente se hace mención a la responsabilidad del empleador de prever que la exposición a los agentes físicos, químicos, biológicos, ergonómicos y psicosociales concurrentes en el centro de trabajo no generen daños a la salud de los colaboradores. En cumplimiento a estos puntos de la ley, se contratarán los servicios para el monitoreo y control de los agentes de riesgos físicos, químicos, biológicos, ergonómicos y psicosociales que se detecten producto de la identificación de peligros y evaluación de riesgos, los que se encontrarán en la Matriz IPER, los que se listan en la Tabla 33.

Tabla 33.

Monitoreos de agentes de riesgos.

\begin{tabular}{ll}
\hline Agentes físicos & Ruido \\
& Iluminación \\
& Radiación \\
& Estrés térmico \\
& Vibración \\
\hline Agentes químicos & Particulados / polvo \\
& Gases, vapores, neblinas \\
& Metales \\
\hline Agentes biológicos & Virus \\
& Bacterias \\
& Hongos \\
& Parásitos \\
\hline Ergonómicos & Fuerza \\
& Postura \\
\hline Psicosociales & Movimiento \\
& Estrés \\
& Moobing laboral \\
\hline
\end{tabular}

Fuente: Elaboración propia.

\subsubsection{Equipos de protección personal y de seguridad en la planta}

Dentro de las medidas de prevención que debe adoptar la empresa para minimizar, tratar y controlar los riesgos, es la implementación de los Equipos de Protección Personal (EPPs) y equipos de seguridad para la detección y la respuesta ante las emergencias que pudieran suscitarse producto de las labores. 
a) EPPs

Para el personal de planta se considerado entregar un uniforme y algunos equipos de protección personal (EPP) para minimizar los riesgos a los que se encuentran expuestos:

- Fajas (con tirantes ajustables y soporte lumbar) para personal en almacén.

- Zapatos de seguridad para Mantenimiento

- Botas de jebe blancas para los operarios

- Mandil con peto de pvc

- Mandil con mangas

- Gorros y redecillas para el cabello

- Guantes de nitrilo

- Mascarillas

b) Extintores

La cantidad de extintores está en función al tipo de riesgo de la instalación, y al tamaño del área (distancia de recorrido). Para poder estimar la cantidad de extintores a colocar en planta se revisó la Norma Técnica Peruana NTP 350.043 Extintores Portátiles.

Los extintores deben estar colocados de manera visible en todo momento y permanecer en el mismo lugar mientras no sean utilizados, los que deben ser lugares estratégicos, de fácil acceso y disponibilidad inmediata en caso se produzca un amago de incendio. Los extintores se colocarán a lo largo de los pasadizos, incluyendo las salidas de las áreas.

Se consideró adquirir seis extintores de PQS de 9 kilos cada uno, (cinco extintores en el primer nivel y uno en el segundo nivel), los que se colocarán en:

Extintores en el primer nivel

- A la salida de los laboratorios

- A la salida del procesamiento primario y secundario

- Área de Envasado, salida del Almacén de Empaques 
- Almacén de materia prima (azúcar, leche en polvo)

- A la salida del comedor

Extintor en el segundo nivel

- En el pasadizo cerca de las oficinas administrativas.

Cabe precisar que las zonas más vulnerables son las del procesamiento primario y secundario, en las que se utiliza combustible inflamable y se producen altas temperaturas. El resto de trabajos son manuales y a temperatura de $18^{\circ} \mathrm{C}$.

En los anexos 12 y 13 se presenta la ubicación de cada uno de los extintores.

c) Luces de emergencia

Se requiere iluminación de emergencia en la ruta de evacuación. El requerimiento de este punto de seguridad figura en el Reglamento Nacional de Edificaciones (A.130). Se ha estimado colocar seis luces de emergencia, las que se colocarían en los pasadizos y escaleras.

d) Señalética

La normativa que regula la señalización de seguridad es la NTP 399.010 Señales de Seguridad.

Son cinco tipos de señalización:

Obligatoriedad (de color azul)

Advertencia (amarillo). Para señalar los riesgos generales

Prohibición (blanco y rojo)

Evacuación (verde)

Contra Incendio (rojo)

En la figura 44 a continuación se presentan las formas de señalización y su significado. Y en la Tabla 34 se listan los avisos a implementar en la fábrica. 


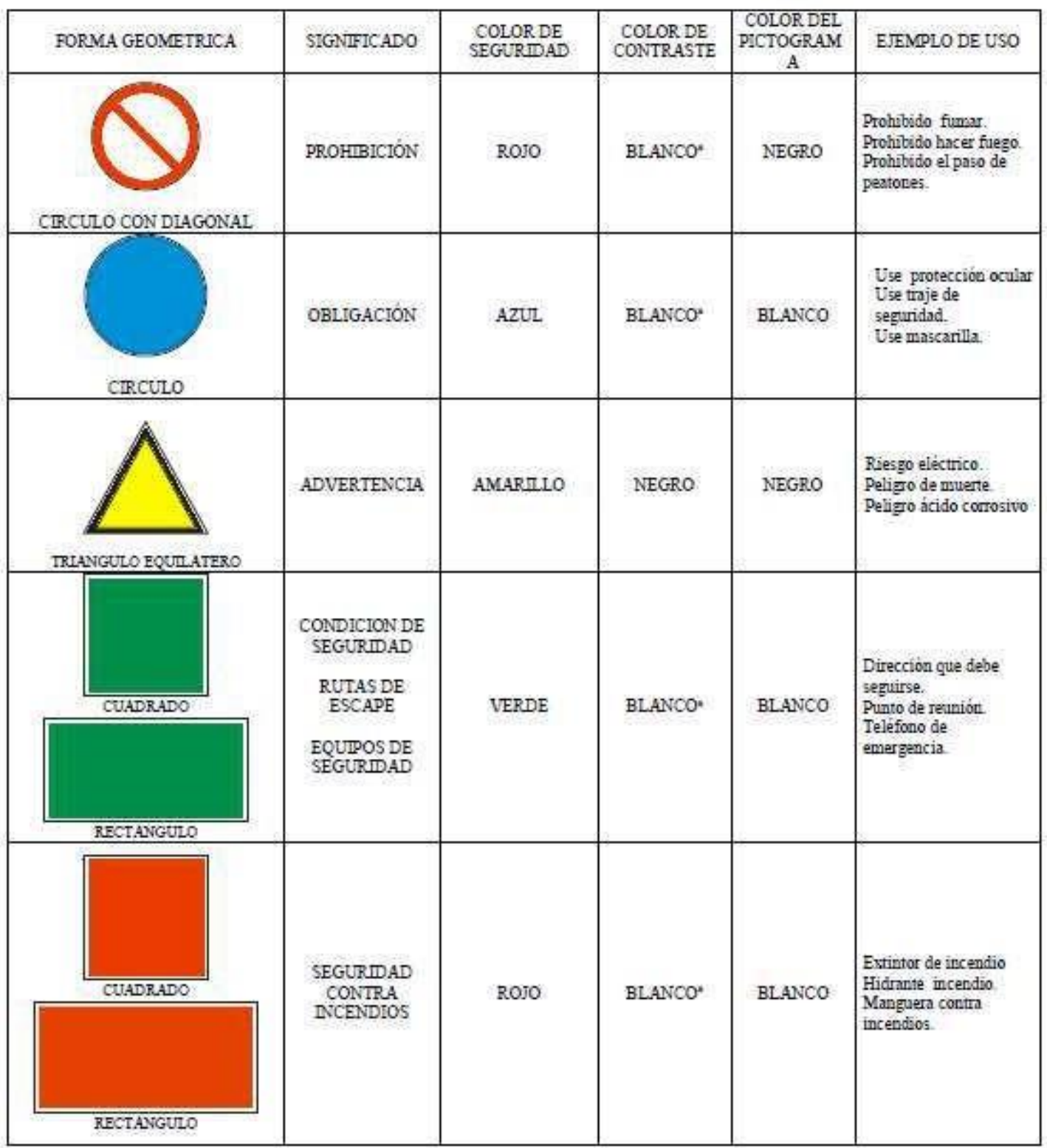

Figura 44. Forma geométrica y significado general de las señales de seguridad. Recuperado de NTP 399.010 Señales de Seguridad. 
Tabla 34.

Tipos de señalización y cantidad a instalar en la planta.

\begin{tabular}{|c|c|c|c|}
\hline $\begin{array}{l}\text { Tipo de } \\
\text { señal }\end{array}$ & Color & Nombre de aviso & Cantidad \\
\hline \multirow[t]{5}{*}{ Obligación } & \multirow[t]{5}{*}{ Azul } & Uso de faja & 3 \\
\hline & & Es obligatorio lavarse las manos & 2 \\
\hline & & $\begin{array}{l}\text { Uso obligatorio de mascarilla y } \\
\text { gorro }\end{array}$ & 5 \\
\hline & & Uso obligatorio de redecilla & 5 \\
\hline & & Uso de guantes & 5 \\
\hline \multirow[t]{4}{*}{$\begin{array}{l}\text { Prohibición / seguridad } \\
\text { contra incendio }\end{array}$} & \multirow[t]{4}{*}{ Rojo } & Extintor & 6 \\
\hline & & Alarma contra incendios & 3 \\
\hline & & Prohibido fumar & 4 \\
\hline & & Prohibido comer o beber & 2 \\
\hline \multirow[t]{4}{*}{ Riesgo de peligro } & \multirow[t]{4}{*}{ Amarillo } & Riesgo eléctrico & 5 \\
\hline & & Cuidado con sus manos & 5 \\
\hline & & Cuidad superficie caliente & 2 \\
\hline & & Atención peligro de caídas & 3 \\
\hline \multirow[t]{3}{*}{ Emergencia } & \multirow[t]{3}{*}{ Verde } & Zona segura en caso de sismo & 10 \\
\hline & & Salida & 10 \\
\hline & & Total señalización & 70 \\
\hline
\end{tabular}

Fuente: Elaboración propia.

En el anexo 14 se presentan los avisos de señalización a implementar en planta.

e) Sistema de alarma y detección contra incendios

La referencia normativa sobre este punto, se encuentra en el Reglamento Nacional de Edificaciones (A.130) y, en parte, en el Reglamento de Seguridad Industrial.(42-F). Para efectos de la planta, se ha considerado conveniente un sistema Photo Beam. Estos funcionan en par y abarcan 14 metros de protección aproximadamente, de lado a lado. Se requerirían dos pares de este sistema.

En el caso de las oficinas administrativas ubicadas en el segundo nivel, se implementará un sistema de detección convencional (iónico o foto eléctrico).

En la Tabla 35 se lista los equipos necesarios para la instalación de los sistemas de alarmas contra incendios. 
Tabla 35.

Sistema de alarma y detección contra incendio.

\begin{tabular}{l}
\hline Panel General de Control \\
\hline 02 photo beam, con su respectivo panel \\
20 detectores de humo, para la zona de oficina, con su respectivo panel \\
Cableado para todos los casos \\
Instalación y mano de obra
\end{tabular}

Fuente: elaboración propia.

\section{Capítulo IX. Aspectos organizacionales}

\subsection{Caracterización de la cultura organizacional deseada}

\subsubsection{Visión}

Ser líder en la industria chocolatera peruana ofreciendo a nuestros clientes productos saludables y agradables al paladar.

\subsubsection{Misión}

Fomentamos la nutrición saludable a través de nuestros productos a base de cacao y súper alimentos para contribuir con la mejora de la calidad de vida de los hogares peruanos.

\subsubsection{Principios}

Los principios de la empresa son los siguientes:

1. Nutrición, salud y felicidad.

2. Garantía en inocuidad de los productos.

3. Seguridad y salud ocupacional.

4. Comunicación permanente con proveedores y clientes.

5. Sostenibilidad medioambiental.

Los trabajadores en su desempeño dentro de la empresa deberán tener los siguientes principios, los que se traducirán en las competencias organizacionales:

1. Liderazgo y responsabilidad en las tareas encomendadas.

2. Comunicación con su par y jefe.

3. Armonía en su ambiente de trabajo 
4. Respeto del medioambiente

9.1.4. Factor de diferenciación y posicionamiento

El factor de diferenciación del producto es "Un chocolate que alegra y nutre a tu hijo, cerca de ti”. Los factores de posicionamiento son los siguientes:

Producto nutritivo y agradable al paladar de los niños. Fortificado con micronutrientes como el hierro, vitamina $\mathrm{C}$ y zinc. Agradable al paladar de los niños por las gomitas de jugos de pura fruta.

No tiene un límite máximo de consumo por día.

Cumple con el porcentaje de cacao requerido por la nueva legislación para el chocolate de leche.

Chocolate elaborado con $100 \%$ cacao, asegurando una buena calidad.

Disponibilidad y al alcance del cliente, presencia en supermercados, mayoristas, tiendas especializadas y bodegas.

9.2. Diseño de la estructura organizacional del proyecto

La estructura organizacional deseada de la fábrica de chocolates nutritivos se encuentra en la Figura 1.

9.3. Diseño de los perfiles de puestos clave

En la tabla 36 se listan todos los puestos de la empresa. En el Anexo 15 se presentan las descripciones de puesto. 
Tabla 36.

Lista de Puestos.

\begin{tabular}{|c|c|c|c|c|}
\hline Puesto & Área & Sección & Planilla & $\begin{array}{c}\mathrm{N}^{\circ} \\
\text { colaboradores } \\
\text { en el puesto }\end{array}$ \\
\hline Gerente General & Gerencia General & ------------ & Administrativo & 1 \\
\hline Asistente de Gerencia & Gerencia General & ----------- & Administrativo & 1 \\
\hline Jefe de Producción & Producción & ------------ & Administrativo & 1 \\
\hline Asistente de Laboratorio de Microbiología & Producción & Laboratorio & Administrativo & 1 \\
\hline Asistente de Laboratorio Fisicoquímico & Producción & Laboratorio & Administrativo & 1 \\
\hline Auxiliar de Producción & Producción & ----------- & Operario & 2 \\
\hline Operario de Procesamiento Primario & Producción & Procesamiento primario & Operario & 4 \\
\hline Operario de Procesamiento Secundario & Producción & Procesamiento secundario & Operario & 3 \\
\hline Operario de Moldeo & Producción & Moldeo & Operario & 4 \\
\hline Operario de Envasado & Producción & Envasado & Operario & 6 \\
\hline Jefe de Mantenimiento & Mantenimiento & ----------- & Administrativo & 1 \\
\hline Auxiliar de Limpieza & Mantenimiento & ---o--- & Operario & 2 \\
\hline Jefe de Logística & Logística & ---------- & Administrativo & 1 \\
\hline Asistente de Logística & Logística & --.--o- & Administrativo & 1 \\
\hline Operario de Almacén de Materia Prima & Logística & Almacén & Operario & 1 \\
\hline Operario de Almacénde Empaques & Logística & Almacén & Operario & 1 \\
\hline Operario de Almacén de Productos Terminados & Logística & Almacén & Operario & 1 \\
\hline Jefe de Administración y Gestión Humana & Gestión Humana & ------------ & Administrativo & 1 \\
\hline Asistente de Gestión Humana & Gestión Humana & ----------- & Administrativo & 1 \\
\hline Jefe Comercial & Comercial & ------------ & Administrativo & 1 \\
\hline Vendedor Lima & Comercial & ---------- & Administrativo & 1 \\
\hline \multirow[t]{2}{*}{ Mercaderista } & Comercial & ---------- & Administrativo & 2 \\
\hline & $\begin{array}{l}\mathrm{N}^{\circ} \text { administrativos } \\
\mathrm{N}^{\circ} \text { operarios }\end{array}$ & $\begin{array}{l}14 \\
24\end{array}$ & & \\
\hline
\end{tabular}

Fuente: elaboración propia.

\subsection{Remuneraciones, compensaciones e incentivos}

En la Tabla 37, se presenta las bandas salariales por nivel jerárquico de puesto. La escala de remuneraciones se ha determinado en base a las responsabilidades, exigencia de las funciones y grado académico. Se ha tenido como referencia, además, las remuneraciones del mercado, respetando para el caso de operarios lo que manda la ley, otorgar una RMV (remuneración mínima vital) de S/ 850 mensual.

Al inicio de actividades no se tienen puestos de gerencias, a excepción de la Gerencia General, ni de Analistas; sin embargo, se ha considerado en la definición de las bandas salariales por si se creara la posición en el futuro. El puesto de Vendedor tiene un sueldo básico de S/ 2,000 más comisiones según las ventas, del 3 al 5\% sobre las ventas y se ha considerado en la categoría de Asistente. El puesto de Mercaderista está considerado dentro de la categoría de Auxiliar Administrativo. 
Tabla 37.

Bandas salariales.

\begin{tabular}{lll}
\hline Categoría & Niveles & Rangos salariales $(\mathrm{S} /)$ \\
\hline Gerencia General & 1 & 8,000 a más \\
Gerencias & 2 & Entre 5,000 y 8,000 \\
Jefaturas & 3 & Entre 4,000 y 5,000 \\
Analista & 4 & Entre 3,000 y 4,000 \\
Asistentes & 5 & Entre 2,000 y 3,000 \\
Auxiliar & & \\
Administrativo & 6 & Entre 1,300 y 1,500 \\
Auxiliar Operarios & 7 & Entre 1,100 y 1,500 \\
Operario de & & Entre 1,000 y 1,100 \\
producción & 8 & Entre 900 y 1,000 \\
Operario de almacén & 9 & Entre 850 y 900 \\
Operario de limpieza & 10 &
\end{tabular}

Fuente: elaboración propia.

No se tienen ninguna compensación adicional al inicio de las actividades más que las legales: CTS, vacaciones, gratificaciones de fiestas patrias y navidad, pago a EsSalud, asignación familiar, SCTR (póliza de seguro complementario de trabajo de riesgos para los operarios), y pago a SENATI.

Se debe contratar una póliza para trabajo de riesgo: SCTR. Se cotizará con las diferentes compañías en el mercado y se tomará la mejor alternativa.

La contribución a SENATI aplica para empresa industriales con más de 20 trabajadores que realicen labores industriales. La base imponible está conformada por el monto total de las remuneraciones abonadas cada mes correspondiente al personal dedicado a la actividad industrial, siendo la tasa de contribución de $0.75 \%$ con pago mensual.

En el Anexo 16 se presenta la relación de puestos clasificados por gerencias, áreas, planilla, categoría, nivel y remuneración.

\subsection{Política de recursos humanos}

A continuación, se presentan las políticas de Gestión Humana: 


\section{Contratación}

De acuerdo a la normatividad vigente, la empresa se rige bajo el D.L. $\mathrm{N}^{\circ} 728$ Ley de Productividad y Competitividad Laboral aplicable al sector privado. La modalidad de contratación serán contratos de trabajo sujeto a modalidad a plazo determinado por inicio de actividad. Luego que la empresa tenga estabilidad en el tiempo, los colaboradores pasarían a la modalidad a plazo indeterminado, según manda la ley peruana.

Ingreso de nuevo colaborador

Todo nuevo colaborador debe presentar los siguientes documentos antes del ingreso, caso contrario no procede la contratación.

CV documentado

Copia del DNI del colaborador, cónyuge e hijos si tuviere

Copia de la partida de matrimonio y de nacimiento (si aplica)

Dos fotografías de frente tamaño carnet

Certificado de retención de 5ta categoría del trabajo anterior (si aplica)

Certificado de antecedentes policiales

Examen médico ocupacional

Nombre de entidad bancaria y $\mathrm{n}^{\circ}$ de cuenta para depósito de la remuneración y la CTS

Asistencia

Horario de trabajo: Será de lunes a sábados. Lunes a viernes de 8:00 a.m. a 05:30 p.m. y sábados de 08:00 a.m. a 12.30 p.m. Refrigerio de 45 minutos.

Tardanzas: Se otorgará tolerancia de 5 minutos, luego de los cuales se procederá al descuento equivalente a 1 hora de la jornada laboral, si llega dentro de la primera hora. Si el 
colaborador llega tarde a partir de la segunda hora, se procederá al descuento del día completo.

Horas extras: Las horas extras se podrán pagar o compensar a través de permisos. Se coordinará mensualmente con la jefatura respectiva cómo se realizaría el pago.

Permisos: El colaborador podrá solicitar permisos con anticipación mediante su jefe directo, el que deberá reportar al área de Gestión Humana. Las horas de permiso se descontarán de las horas acumuladas de horas extras.

Descansos médicos: El colaborador deberá presentar su descanso médico original y los documentos que se le entreguen durante su atención, como receta médica, orden para exámenes, resultados, boletas por los gastos desembolsados.

Faltas: Todo colaborador deberá justificar su falta por el día o días de inasistencia al área de Gestión Humana, el que deberá contar con la aprobación de su jefatura. Se evaluará cada caso si procede o no el descuento.

Vacaciones: Todo colaborador deberá tomar 30 días de vacaciones al cumplir su año de trabajo, los que deberá programar durante el año en curso hasta el término del período.

Ningún colaborador deberá tener vacaciones vencidas puesto que genera una contingencia a la empresa además de gastos extra laborales. Los períodos mínimos de vacaciones con de 7 días calendario y al menos en el año deberá tomar un período de 14 días consecutivos.

\section{Préstamos}

La empresa otorgará préstamos por salud y educación con un tope de una remuneración bruta, monto que se descontará en un máximo de 1 año, con cuotas dobles en julio y diciembre. El trabajador no podrá acceder a dos préstamos simultáneos. Todo préstamo deberá ser debidamente sustentado en un máximo de 7 días calendario.

\section{Vestimenta}


Los operarios deben asistir con el uniforme completo entregado por la empresa (mandil blanco para operarios de producción y almacén y verde para operarios de limpieza, redecilla más gorro para la cabeza y botas de plástico). Los empleados del laboratorio también deben usar el mandil de color blanco. Los administrativos pueden ir en ropa casual.

\section{Capacitación}

La empresa está afiliada a SENATI, para lo cual, cada colaborador puede acceder de manera gratuita a los diferentes cursos que se ofrezcan. La empresa otorgará los permisos correspondientes.

\section{Seguros}

Los empleados estarán afiliados a EsSalud, de acuerdo a lo estipulado por la ley peruana. La empresa hará contribuciones mensuales del 9\% sobre la remuneración bruta. El personal operario contará con la póliza SCTR por estar expuestos a actividades riesgosas.

\subsection{Consideraciones legales}

\subsubsection{Identificación del marco legal}

Para iniciar a las operaciones de planta es necesario revisar los aspectos legales, para determinar cómo la normatividad vigente afecta los beneficios y costos del proyecto.

A continuación, se listan las normas identificadas, según diferentes rubros.

a) Mercado

- Legislación sanitaria: La Dirección General de Salud Ambiental (DIGESA) exige un Registro Sanitario de alimentos y bebidas industrializados y una Habilitación Sanitaria de Establecimientos de fabricación de alimentos y bebidas.

o Ley N²6842, Ley General de Salud - MINSA

o D.S. $\mathrm{N}^{\circ}$ 007-98 SA Reglamento sobre vigilancia y control sanitario de alimentos y bebidas

o D.L. $\mathrm{N}^{\circ} 1062$ Ley de Inocuidad de los Alimentos 
o Norma Sanitaria para la aplicación del Sistema HACCP en la fabricación de alimentos y bebidas RM 449-2006/MINSA

o Norma Sanitaria que establece los criterios microbiológicos de calidad sanitaria e inocuidad para alimentos y bebidas de consumo humano RM-591/MINSA

- $\quad$ Proveedores y clientes

Contrato con los proveedores

Código de Protección y Defensa al Consumidor Ley 29571

Permisos y viabilidad sanitarios para el transporte del producto

b) Localización

- Estudios de posesión y vigencia de los títulos de bienes raíces

- Litigios, prohibiciones, contaminación ambiental, uso intensivo de agua en determinadas zonas

- Gastos notariales, transferencias, inscripción en Registro Público de la Propiedad y el Comercio

- Determinación de los honorarios de los especialistas o profesionales que efectúen todos los trámites necesarios

c) Estudio Técnico

- Compra de marcas y patentes. Pago de regalías

- Aranceles y permisos necesarios para la importación de la maquinaria de la planta de chocolate

- NTP ISO 2451:2011. Granos de cacao. Especificaciones. Establece los requisitos para los granos de cacao.

- NTP-CODEX STAN87-2013. Chocolates y productos del chocolate. Requisitos.

- NTP-CODEX STAN86-2013. Cacao y chocolate. Requisitos. 
- $\quad$ NTP-CODEX STAN141: 2014. CACAO Y CHOCOLATE. Cacao en pasta (Licor de cacao/chocolate) y torta de cacao.

- $\quad$ NTP 208.007 2007. CACAO Y CHOCOLATE. Cacao en polvo (Cocoa) y mezclas secas de cacao y azúcar. Requisitos.

d) Administración y organización

- Leyes que regulan la contratación de personal sindicalizado y de confianza. Pago de utilidades al finalizar el ejercicio.

- $\quad$ D.L. N ${ }^{\circ} 728$ Ley de Productividad y Competitividad Laboral. Prestaciones sociales a los trabajadores. Vacaciones, incentivos, seguridad social, ayuda a la vivienda, etc.

- Leyes sobre seguridad industrial mínima y obligaciones patronales en caso de accidentes de trabajo.

o DS 005-2012-TR. Reglamento de la Ley de Seguridad y Salud en el Trabajo. Comprende los requisitos legales que debe implementar toda organización para cumplir con brindar seguridad y salud en la realización de las actividades laborales.

o Ley 29783 Ley de Seguridad y Salud en el Trabajo. Marco regulatorio de la ley, contiene las obligaciones de los empleadores y trabajadores para con el Sistema de Seguridad y Salud en el Trabajo.

o NTP 350.043-1 2011. Extintores portátiles. Selección, distribución, inspección, mantenimiento, recarga y prueba hidrostática.

o NTP 399.010-1 2004. Señales de seguridad. Colores, símbolos, formas y dimensiones de señales de seguridad

o Reglamento de Seguridad Industrial D.S 042

o Reglamento Nacional de Edificaciones. Norma A.130 Requisitos de Seguridad

e) Aspecto financiero y contable

- $\quad$ D.L. N774 Ley del Impuesto sobre la Renta. 
- Leyes bancarias y de las instituciones de crédito (para el préstamo comercial solicitado)

\subsubsection{Ordenamiento jurídico de la empresa}

Forma societaria

La empresa por constituir es una Sociedad de Responsabilidad Limitada (S.R.L.), conformada por dos socios, Sra. Andrea Gisella Mora Félix, de nacionalidad peruana, identificada con número de identidad nacional 40346765 y domiciliada en Calle 24 N²90 Dpto.301 Urbanización Córpac San Isidro, Srta. Silvia Patricia Rodríguez Aliaga de nacionalidad peruana, identificada con número de identidad nacional 46144642 y domiciliada en Avenida Pershing 146, letra D, Magdalena del Mar y Sra. María Alejandra Rodríguez Rodríguez, de nacionalidad peruana, identificada con número de identidad nacional 43213785 y domiciliada en Calle Botticelli N 134 Dpto. 302 San Borja.

\section{Licencias}

Primero se debe tener en cuenta la normatividad aplicable para la construcción de una edificación.: Ley $\mathrm{N}^{\circ} 29090$ Regulación de Habitaciones urbanas y edificaciones y Ley 27157 Licencia de construcción.

Además, se debe gestionar la licencia de funcionamiento en la jurisdicción en la cual se construirá la empresa. La planta para la elaboración del chocolate Chocovit se ubicará en el distrito de Lurín y se debe cumplir con el procedimiento que exige dicha municipalidad.

Los requisitos generales para obtener la licencia de funcionamiento son los siguientes:

Solicitud con carácter de Declaración Jurada que incluya número de RUC, DNI o carné de extranjería.

Vigencia de poder del representante legal o carta poder con firma legalizada. Declaración jurada de observancia de condiciones de seguridad o inspección técnica de seguridad en defensa civil o multidisciplinaria, según corresponda al tamaño del local y giro del negocio. 
- Informe sobre el número de estacionamientos, si las normas lo requieren.

- Copia de autorización sectorial, si la ley lo establece.

- Para el caso de la Municipalidad de Lurín se debe presentar la siguiente documentación:

- Formulario de solicitud para obtención de Licencia de Funcionamiento

- Declaración Jurada de condiciones Básicas de Seguridad

- $\quad$ La legislación aplicable es: Ley N ${ }^{\circ}$ 28976, Ley Marco de Licencia de

Funcionamiento, Ordenanza que regula el otorgamiento de Licencia de Funcionamiento.

Registro de marcas

Se procederá a registrar la marca Chocovit junto con el diseño del logotipo e isotipo en la Oficina de Signos Distintivos (OSD) de INDECOPI.

En el anexo 17 se presenta el proceso de constitución de la empresa.

\section{Capítulo X. Estrategia organizacional}

10.1. Formulación de estrategias del negocio

Las macroestrategias para la empresa se obtuvieron del análisis interno y externo de cuatro áreas funcionales: Finanzas, Comercial, Recursos Humanos y Logística (Ver Tabla 38, 39, 40 y 41).

\subsection{Formación de la ventaja competitiva}

Las ventajas competitivas de la empresa son:

En el área funcional de finanzas, es la capacidad de obtener un crédito para la adquisición de terreno, maquinaria y la construcción de la infraestructura.

En el área funcional de recursos humanos, se cuenta con personal con experiencia en el rubro de chocolatería

En el área funcional comercial, se tiene producto nutritivo e innovador que va acorde a la tendencia del mercado. 
En el área funcional de logística, se cuenta con buenas relaciones con comunidades nativas que permitirían la compra directa de cacao y negociar bajo

precio.

Tabla 38.

Matriz de Planificación Ampliada (Área funcional de finanzas)

\begin{tabular}{|c|c|c|c|c|c|c|}
\hline FORTALEZAS & OBJETIVO & ESTRATEGIA & ACTIVIDADES & RESULTADO & INDICADOR & RESPONSABLE \\
\hline \multirow{2}{*}{$\begin{array}{l}\text { Ser sujetos de crédito ante } \\
\text { entidades financieras }\end{array}$} & $\begin{array}{l}\text { Comprar terreno } \\
\text { para instalar la } \\
\text { fábrica }\end{array}$ & \multirow{2}{*}{$\begin{array}{l}\text { Obteniendo un } \\
\text { préstamo y/o crédito } \\
\text { comercial con un } \\
\text { banco y/o entidad } \\
\text { financiera }\end{array}$} & \multirow{2}{*}{$\begin{array}{c}\text { Identificando los } \\
\text { principales bancos } \\
\text { y/o entidad financiera }\end{array}$} & $\begin{array}{c}\text { Se logró la compra } \\
\text { del terreno }\end{array}$ & Se tiene el terreno & Gerente General \\
\hline & $\begin{array}{c}\text { Comprar } \\
\text { maquinaria } \\
\text { necesaria para } \\
\text { montar la planta }\end{array}$ & & & $\begin{array}{l}\text { Se logró la compra } \\
\text { de la maquinaria }\end{array}$ & $\begin{array}{l}\text { Se tiene la } \\
\text { maquinaria }\end{array}$ & $\begin{array}{c}\text { Jefe de } \\
\text { Producción }\end{array}$ \\
\hline Competitividad en precios & $\begin{array}{l}\text { Ser una empresa } \\
\text { rentable }\end{array}$ & $\begin{array}{l}\text { Obteniendo el } \\
\text { mayor margen de } \\
\text { ganancia }\end{array}$ & $\begin{array}{l}\text { Optimizando los } \\
\text { costos de producción }\end{array}$ & $\begin{array}{l}\text { Se logró la } \\
\text { rentabilidad } \\
\text { esperada }\end{array}$ & ROE del $30 \%$ & Gerente General \\
\hline $\begin{array}{l}\text { Maquinaria importada } \\
\text { con tecnología de punta } \\
\text { para lograr productos de } \\
\text { alta calidad }\end{array}$ & $\begin{array}{l}\text { Optimizar los } \\
\text { costos }\end{array}$ & Liderazgo en costos & $\begin{array}{l}\text { Documentando, } \\
\text { estandarizando y } \\
\text { controlando los } \\
\text { procesos productivos, } \\
\text { comerciales y } \\
\text { administrativos } \\
\end{array}$ & $\begin{array}{l}\text { Se optimizaron los } \\
\text { costos }\end{array}$ & $\begin{array}{l}\text { Costos reducidos } \\
\text { en un } 10 \%\end{array}$ & $\begin{array}{l}\text { Jefe de } \\
\text { Producción }\end{array}$ \\
\hline DEBILIDADES & OBJETIVO & ESTRATEGIA & ACTIVIDADES & RESULTADO & INDICADOR & RESPONSABLE \\
\hline $\begin{array}{l}\text { No contar con informes } \\
\text { financieros previos }\end{array}$ & $\begin{array}{l}\text { Controlar los } \\
\text { gastos y } \\
\text { planificar los } \\
\text { recursos del } \\
\text { siguiente período }\end{array}$ & $\begin{array}{l}\text { Preparando un } \\
\text { presupuesto } \\
\text { financiero }\end{array}$ & $\begin{array}{l}\text { Presupuestando en } \\
\text { los diferentes rubros } \\
\text { (capital, operativo y } \\
\text { ventas) }\end{array}$ & $\begin{array}{l}\text { Se controla los } \\
\text { presupuestos } \\
\text { financieros }\end{array}$ & $100 \%$ & Gerente General \\
\hline $\begin{array}{l}\text { No conocer el efectivo } \\
\text { disponible con el que } \\
\text { contará la empresa }\end{array}$ & $\begin{array}{l}\text { Ser una empresa } \\
\text { que cuente con } \\
\text { liquidez }\end{array}$ & $\begin{array}{l}\text { Gestionando } \\
\text { eficazmente los } \\
\text { pagos clientes y } \\
\text { proveedores }\end{array}$ & $\begin{array}{l}\text { Buscando } \\
\text { herramientas que } \\
\text { permitan controlar } \\
\text { cómo y cuándo hay } \\
\text { que cobrar y pagar }\end{array}$ & $\begin{array}{l}\text { Se logró ser una } \\
\text { empresa con } \\
\text { liquidez. }\end{array}$ & Prueba ácida > 1 & Gerente General \\
\hline OPORTUNIDADES & OBJETIVO & ESTRATEGIA & ACTIVIDADES & RESULTADO & INDICADOR & RESPONSABLE \\
\hline $\begin{array}{l}\text { Crecimiento de centros } \\
\text { comerciales en Lima }\end{array}$ & $\begin{array}{l}\text { Lograr } \\
\text { crecimiento de } \\
\text { activos a largo } \\
\text { plazo: compra de } \\
\text { tiendas }\end{array}$ & $\begin{array}{l}\text { Implementando } \\
\text { tiendas propias }\end{array}$ & $\begin{array}{l}\text { Identificando los } \\
\text { centros comerciales } \\
\text { con mayor público }\end{array}$ & $\begin{array}{l}\text { Se logró la compra } \\
\text { de tienda }\end{array}$ & Se tiene la tienda & Gerente General \\
\hline $\begin{array}{l}\text { El país cuenta con } \\
\text { terrenos agrícolas } \\
\text { disponibles y de buena } \\
\text { calidad }\end{array}$ & $\begin{array}{l}\text { Lograr } \\
\text { integración hacia } \\
\text { atrás: compra de } \\
\text { terrenos } \\
\text { agrícolas }\end{array}$ & $\begin{array}{l}\text { Teniendo } \\
\text { plantaciones de } \\
\text { cacao }\end{array}$ & $\begin{array}{l}\text { Identificando y } \\
\text { evaluando terrenos } \\
\text { agrícolas }\end{array}$ & $\begin{array}{l}\text { Se logró la compra } \\
\text { de1 terreno agrícola }\end{array}$ & $\begin{array}{l}\text { Se tiene el terreno } \\
\text { agrícola }\end{array}$ & Gerente General \\
\hline $\begin{array}{l}\text { Herramientas } \\
\text { tecnológicas para gestión } \\
\text { financiera y operativa }\end{array}$ & $\begin{array}{l}\text { Tener una } \\
\text { herramienta } \\
\text { integrada para la } \\
\text { gestión de la } \\
\text { empresa: compra } \\
\text { de software } \\
\text { integrado }\end{array}$ & $\begin{array}{l}\text { Implementando } \\
\text { software de gestión }\end{array}$ & $\begin{array}{l}\text { Identificando } \\
\text { proveedores } \\
\text { disponibles en el } \\
\text { mercado }\end{array}$ & $\begin{array}{l}\text { Se compró y se } \\
\text { implementó el } \\
\text { software de gestión } \\
\text { para la empresa }\end{array}$ & $\begin{array}{l}\text { Se tiene el } \\
\text { software de } \\
\text { gestión }\end{array}$ & Gerente General \\
\hline AMENAZAS & OBJETIVO & ESTRATEGIA & ACTIVIDADES & RESULTADO & INDICADOR & RESPONSABLE \\
\hline $\begin{array}{l}\text { Inestabilidad política y } \\
\text { económica }\end{array}$ & $\begin{array}{l}\text { Evaluar nuevos } \\
\text { mercados, } \\
\text { productos: nueva } \\
\text { pastelería }\end{array}$ & $\begin{array}{l}\text { Analizando el rubro } \\
\text { de pastelería }\end{array}$ & $\begin{array}{l}\text { Elaborando un plan } \\
\text { de negocio para el } \\
\text { nuevo producto }\end{array}$ & $\begin{array}{l}\text { Se evaluó nuevo } \\
\text { plan de negocio del } \\
\text { rubro pastelería }\end{array}$ & $\begin{array}{l}\text { Se tiene el nuevo } \\
\text { plan de negocio }\end{array}$ & Gerente General \\
\hline
\end{tabular}

Fuente: elaboración propia. 
Tabla 39. Matriz de Planificación Ampliada (Área funcional comercial)

\begin{tabular}{|c|c|c|c|c|c|c|}
\hline FORTALEZAS & OBJETIVO & ESTRATEGIA & ACTIVIDADES & RESULTADO & INDICADOR & RESPONSABLE \\
\hline $\begin{array}{l}\text { Producto nutritivo e } \\
\text { innovador que va } \\
\text { acorde a la tendencia } \\
\text { industrial }\end{array}$ & $\begin{array}{l}\text { Obtener } \\
\text { participación en } \\
\text { el mercado }\end{array}$ & $\begin{array}{l}\text { Elaborando plan } \\
\text { estratégico para } \\
\text { penetración en el } \\
\text { mercado }\end{array}$ & $\begin{array}{l}\text { Realizando campañas de } \\
\text { promoción para el } \\
\text { lanzamiento (bajos precios, } \\
\text { ofertas, etc.) }\end{array}$ & $\begin{array}{l}\text { Se logró } \\
\text { participación en el } \\
\text { mercado }\end{array}$ & $3 \%$ & Gerente General \\
\hline $\begin{array}{l}\text { Producto para } \\
\text { prevenir la anemia, } \\
\text { enfermedad crónica } \\
\text { en nuestro país }\end{array}$ & $\begin{array}{l}\text { Ingresar como } \\
\text { proveedor del } \\
\text { Estado }\end{array}$ & $\begin{array}{l}\text { Cumpliendo con los } \\
\text { requisitos que pide } \\
\text { el Estado }\end{array}$ & $\begin{array}{l}\text { Participando de las } \\
\text { convocatorias que realiza el } \\
\text { Estado para la búsqueda de } \\
\text { proveedores }\end{array}$ & $\begin{array}{l}\text { Se es proveedor } \\
\text { del Estado }\end{array}$ & $\begin{array}{l}\text { Proveedor del } \\
\text { Estado }\end{array}$ & Jefe de Ventas \\
\hline DEBILIDADES & OBJETIVO & ESTRATEGIA & ACTIVIDADES & RESULTADO & INDICADOR & RESPONSABLE \\
\hline \multirow[t]{2}{*}{$\begin{array}{l}\text { Ser nueva en el } \\
\text { mercado y no } \\
\text { disponer de clientes }\end{array}$} & $\begin{array}{l}\text { Implementar } \\
\text { plan de } \\
\text { marketing para } \\
\text { el lanzamiento } \\
\text { del producto }\end{array}$ & $\begin{array}{l}\text { Implementando } \\
\text { estrategia } \\
\text { publicitaria }\end{array}$ & $\begin{array}{l}\text { Elaborando campaña de } \\
\text { difusión de bondades del } \\
\text { producto, marketing } \\
\text { digital, difusión por redes } \\
\text { sociales, creando fan page } \\
\text { del producto }\end{array}$ & $\begin{array}{l}\text { Plan de Marketing } \\
\text { implementado }\end{array}$ & $90 \%$ & Gerente General \\
\hline & $\begin{array}{l}\text { Alcanzar nivel } \\
\text { de ventas } \\
\text { proyectado }\end{array}$ & $\begin{array}{l}\text { Elaborando plan } \\
\text { anual de ventas }\end{array}$ & $\begin{array}{l}\text { Visitando a potenciales } \\
\text { clientes, participando en } \\
\text { ferias a nivel nacional } \\
\text { y ruedas de negocio }\end{array}$ & $\begin{array}{l}\text { Se logró } \\
\text { incrementar las } \\
\text { ventas }\end{array}$ & $3 \%$ & Jefe de Ventas \\
\hline OPORTUNIDADES & OBJETIVO & ESTRATEGIA & ACTIVIDADES & RESULTADO & INDICADOR & RESPONSABLE \\
\hline $\begin{array}{l}\text { Comunidades nativas } \\
\text { con disposición a } \\
\text { trabajar en conjunto } \\
\text { con el sector } \\
\text { industrial }\end{array}$ & $\begin{array}{l}\text { Tener una } \\
\text { alianza } \\
\text { estratégica con } \\
\text { comunidades } \\
\text { productoras de } \\
\text { cacao } \\
\end{array}$ & $\begin{array}{l}\text { Contactando con } \\
\text { diferentes } \\
\text { comunidades nativas }\end{array}$ & $\begin{array}{l}\text { Teniendo reuniones con los } \\
\text { jefes de las comunidades } \\
\text { nativas para conversar } \\
\text { sobre su compromiso y } \\
\text { necesidades }\end{array}$ & $\begin{array}{l}\text { Se logró la alianza } \\
\text { estratégica con } \\
\text { comunidad nativa }\end{array}$ & 1 & Gerente General \\
\hline $\begin{array}{l}\text { Plan Nacional para la } \\
\text { desnutrición crónica } \\
\text { infantil y la } \\
\text { prevención de la } \\
\text { anemia en el país } \\
\text { periodo 2017-2021 }\end{array}$ & $\begin{array}{l}\text { Llegar a zonas } \\
\text { con altos } \\
\text { índices de } \\
\text { anemia }\end{array}$ & $\begin{array}{l}\text { Contactando con } \\
\text { diferentes } \\
\text { organizaciones no } \\
\text { gubernamentales que } \\
\text { trabajan el tema de } \\
\text { alimentación en } \\
\text { niños }\end{array}$ & $\begin{array}{l}\text { Teniendo reuniones con los } \\
\text { directores de las ONGs } \\
\text { para ofrecer el producto y } \\
\text { negociar precio }\end{array}$ & $\begin{array}{l}\text { Se logró llegar a } \\
\text { una con altos } \\
\text { índices de anemia }\end{array}$ & 1 & Gerente General \\
\hline $\begin{array}{l}\text { Disponibilidad de } \\
\text { herramientas web } \\
\text { para ventas por } \\
\text { internet }\end{array}$ & $\begin{array}{l}\text { Vender el } \\
\text { producto por } \\
\text { internet }\end{array}$ & $\begin{array}{l}\text { Implementando una } \\
\text { página web con la } \\
\text { opción de la compra } \\
\text { por internet }\end{array}$ & $\begin{array}{l}\text { Buscando proveedores para } \\
\text { el desarrollo de la página } \\
\text { web }\end{array}$ & $\begin{array}{l}\text { Se logró tener } \\
\text { ventas por internet }\end{array}$ & $\begin{array}{l}10 \% \text { de ventas } \\
\text { vía internet }\end{array}$ & Jefe de Ventas \\
\hline $\begin{array}{l}\text { Proyecto de } \\
\text { reglamento técnico } \\
\text { del uso de cacao del } \\
\text { MINAGRI que va } \\
\text { permitir tener clientes } \\
\text { informados }\end{array}$ & $\begin{array}{l}\text { Ofrecer al } \\
\text { mercado un } \\
\text { producto de } \\
\text { calidad que } \\
\text { cumple con la } \\
\text { nueva } \\
\text { regulación }\end{array}$ & $\begin{array}{l}\text { Elaborando las } \\
\text { tabletas de chocolate } \\
\text { con } 50 \% \text { de cacao y } \\
\text { sin grasa vegetal }\end{array}$ & $\begin{array}{l}\text { Definiendo la formulación } \\
\text { e implementando en la } \\
\text { línea de proceso }\end{array}$ & $\begin{array}{l}\text { Se ofreció un } \\
\text { mercado un } \\
\text { chocolate nutritivo }\end{array}$ & $100 \%$ & $\begin{array}{l}\text { Jefe de } \\
\text { Producción }\end{array}$ \\
\hline AMENAZAS & OBJETIVO & ESTRATEGIA & ACTIVIDADES & RESULTADO & INDICADOR & RESPONSABLE \\
\hline $\begin{array}{l}\text { Ingreso de más } \\
\text { competidores que } \\
\text { ofrezcan productos } \\
\text { similares }\end{array}$ & $\begin{array}{l}\text { Desarrollar } \\
\text { nuevos } \\
\text { productos }\end{array}$ & $\begin{array}{l}\text { Buscando a nivel } \\
\text { nacional e } \\
\text { internacional las } \\
\text { nuevas tendencias de } \\
\text { productos }\end{array}$ & $\begin{array}{l}\text { Participando de ferias } \\
\text { alimentarias }\end{array}$ & Productos nuevos & 5 & Jefe de Ventas \\
\hline $\begin{array}{l}\text { Crecimiento del } \\
\text { mercado de } \\
\text { productos sustitutos }\end{array}$ & $\begin{array}{l}\text { Concientizar a } \\
\text { la población } \\
\text { sobre las } \\
\text { diferencias de } \\
\text { golosinas y del } \\
\text { chocolate } \\
\text { nutritivo }\end{array}$ & $\begin{array}{l}\text { Plan anual de } \\
\text { participación en los } \\
\text { diferentes } \\
\text { supermercados/ferias }\end{array}$ & $\begin{array}{l}\text { Realizando charlas/talleres } \\
\text { en los supermercados para } \\
\text { informar las diferencias } \\
\text { entre las golosinas y el } \\
\text { chocolate nutritivo }\end{array}$ & $\begin{array}{l}\text { Población } \\
\text { concientizada }\end{array}$ & $\begin{array}{l}80 \% \text { de } \\
\text { personas } \\
\text { evaluadas por } \\
\text { encuesta }\end{array}$ & Jefe de Ventas \\
\hline $\begin{array}{l}\text { Competencia } \\
\text { informal y desleal en } \\
\text { el sector de } \\
\text { chocolatería }\end{array}$ & $\begin{array}{l}\text { Patentar el } \\
\text { nombre y marca } \\
\text { del producto }\end{array}$ & $\begin{array}{l}\text { Contactando con } \\
\text { asesor legal para } \\
\text { patentar las marcas y } \\
\text { logos de la empresa }\end{array}$ & $\begin{array}{l}\text { Identificando los estudios } \\
\text { de abogados a realizar el } \\
\text { trabajo }\end{array}$ & $\begin{array}{l}\text { Logos, marcas y } \\
\text { procesos } \\
\text { patentados }\end{array}$ & $90 \%$ & Jefe de Ventas \\
\hline
\end{tabular}

Fuente: elaboración propia 
Tabla 40. Matriz de Planificación Ampliada (Área funcional recursos humanos)

\begin{tabular}{|c|c|c|c|c|c|c|}
\hline FORTALEZAS & OBJETIVO & ESTRATEGIA & ACTIVIDADES & RESULTADO & INDICADOR & RESPONSABLE \\
\hline $\begin{array}{l}\text { Colaboradores de la } \\
\text { alta dirección con } \\
\text { conocimiento técnico } \\
\text { en el procesamiento } \\
\text { de chocolates. }\end{array}$ & $\begin{array}{l}\text { Ser una } \\
\text { empresa con } \\
\text { personal } \\
\text { capacitado }\end{array}$ & $\begin{array}{l}\text { Colaboradores } \\
\text { de Alta } \\
\text { Dirección con } \\
\text { competencias } \\
\text { para el manejo } \\
\text { de la empresa }\end{array}$ & $\begin{array}{l}\text { Entrenando constantemente a } \\
\text { los colaboradores de la Alta } \\
\text { Dirección }\end{array}$ & $\begin{array}{l}\text { Personal } \\
\text { capacitado y } \\
\text { con las } \\
\text { competencias } \\
\text { requeridas }\end{array}$ & $95 \%$ & $\begin{array}{l}\text { Jefe de Gestión } \\
\text { Humana }\end{array}$ \\
\hline $\begin{array}{l}\text { Empresa que cumple } \\
\text { con la ley de } \\
\text { productividad y } \\
\text { competitividad } \\
\text { laboral (Ley } \mathrm{N}^{\circ} 728 \text { ) }\end{array}$ & \multirow{2}{*}{$\begin{array}{l}\text { Cumplir los } \\
\text { requisitos } \\
\text { legales y } \\
\text { regulatorios } \\
\text { que apliquen a } \\
\text { la empresa }\end{array}$} & $\begin{array}{l}\text { Alineados a la } \\
\text { Ley de } \\
\text { Productividad y } \\
\text { Competitividad } \\
\text { Laboral }\end{array}$ & $\begin{array}{l}\text { Cumpliendo los requisitos } \\
\text { indicados en la ley } 728\end{array}$ & \multirow{2}{*}{$\begin{array}{l}\text { Cumplimiento } \\
\text { del Decreto } \\
\text { Legislativo } 728 \\
\text { y la Ley de } \\
\text { SST } 29783\end{array}$} & $100 \%$ & $\begin{array}{l}\text { Jefe de Gestión } \\
\text { Humana }\end{array}$ \\
\hline $\begin{array}{l}\text { Empresa formal que } \\
\text { cumple con la ley de } \\
\text { seguridad y salud en } \\
\text { el trabajo (Ley } \mathrm{N}^{\circ} \\
\text { 29783) }\end{array}$ & & $\begin{array}{l}\text { Alineados a la } \\
\text { Ley de } \\
\text { Seguridad y } \\
\text { Salud en el } \\
\text { Trabajo } \\
\end{array}$ & $\begin{array}{l}\text { Cumpliendo los requisitos } \\
\text { indicados en la ley } 29783\end{array}$ & & $98 \%$ & $\begin{array}{l}\text { Jefe de Gestión } \\
\text { Humana }\end{array}$ \\
\hline DEBILIDADES & OBJETIVO & ESTRATEGIA & ACTIVIDADES & RESULTADO & INDICADOR & RESPONSABLE \\
\hline $\begin{array}{l}\text { Elevada dependencia } \\
\text { de personal operativo } \\
\text { para el área de } \\
\text { envasado }\end{array}$ & $\begin{array}{l}\text { Definir los } \\
\text { reemplazos } \\
\text { para todos los } \\
\text { puestos } \\
\text { operativos }\end{array}$ & $\begin{array}{l}\text { Identificando } \\
\text { procesos } \\
\text { críticos en área } \\
\text { de producción }\end{array}$ & $\begin{array}{l}\text { Capacitando al área de } \\
\text { producción en las funciones de } \\
\text { reemplazo que le son asignadas }\end{array}$ & $\begin{array}{l}\text { Reemplazos } \\
\text { definidos }\end{array}$ & $100 \%$ & $\begin{array}{l}\text { Jefe de Gestión } \\
\text { Humana }\end{array}$ \\
\hline $\begin{array}{l}\text { Por ser empresa } \\
\text { nueva, aún no se } \\
\text { cuenta con una } \\
\text { gestión de los } \\
\text { recursos humanos } \\
\text { (selección, } \\
\text { capacitación y } \\
\text { evaluación) }\end{array}$ & $\begin{array}{l}\text { Proveer, } \\
\text { mantener y } \\
\text { desarrollar } \\
\text { personal } \\
\text { calificado y } \\
\text { motivado para } \\
\text { lograr los } \\
\text { objetivos de la } \\
\text { empresa }\end{array}$ & $\begin{array}{l}\text { Implementando } \\
\text { la gestión por } \\
\text { competencias: } \\
\text { selección, } \\
\text { gestión de las } \\
\text { capacitaciones, } \\
\text { evaluación de } \\
\text { desempeño }\end{array}$ & $\begin{array}{l}\text { Seleccionando a un jefe de } \\
\text { recursos humanos que cuente } \\
\text { con las competencias necesarias } \\
\text { para implementar y liderar el } \\
\text { área de Talento Humano }\end{array}$ & $\begin{array}{l}\text { Se implementó } \\
\text { la gestión de } \\
\text { recursos } \\
\text { humanos por } \\
\text { competencias }\end{array}$ & $100 \%$ & $\begin{array}{l}\text { Jefe de Gestión } \\
\text { Humana }\end{array}$ \\
\hline $\begin{array}{l}\text { No se cuenta con las } \\
\text { descripciones de } \\
\text { puestos por } \\
\text { competencias }\end{array}$ & $\begin{array}{l}\text { Implementar } \\
\text { las } \\
\text { descripciones } \\
\text { de puestos por } \\
\text { competencias }\end{array}$ & $\begin{array}{l}\text { Definiendo las } \\
\text { funciones por } \\
\text { puesto e } \\
\text { identificando } \\
\text { las } \\
\text { competencias } \\
\end{array}$ & $\begin{array}{l}\text { Creando, aprobando e } \\
\text { implementando las } \\
\text { Descripciones de Puestos para } \\
\text { cada colaborador }\end{array}$ & $\begin{array}{l}\text { Se implementó } \\
\text { todas las } \\
\text { descripciones } \\
\text { de puestos por } \\
\text { competencias }\end{array}$ & $100 \%$ & $\begin{array}{l}\text { Jefe de Gestión } \\
\text { Humana }\end{array}$ \\
\hline $\begin{array}{l}\text { No se cuenta con } \\
\text { sistema de beneficios }\end{array}$ & $\begin{array}{l}\text { Implementar } \\
\text { sistema de } \\
\text { compensación } \\
\text { y beneficios }\end{array}$ & $\begin{array}{l}\text { Revisando la } \\
\text { tendencia en el } \\
\text { mercado y que } \\
\text { vaya a la par } \\
\text { con el } \\
\text { presupuesto }\end{array}$ & $\begin{array}{l}\text { Identificando los beneficios que } \\
\text { se darán a los colaboradores de } \\
\text { la empresa }\end{array}$ & $\begin{array}{l}\text { Sistema de } \\
\text { compensación } \\
\text { y beneficios } \\
\text { implementando }\end{array}$ & $100 \%$ & $\begin{array}{l}\text { Jefe de Gestión } \\
\text { Humana }\end{array}$ \\
\hline $\begin{array}{l}\text { Los procesos no } \\
\text { están documentados } \\
\text { y estandarizados }\end{array}$ & $\begin{array}{l}\text { Estandarizar y } \\
\text { documentar los } \\
\text { procesos } \\
\text { operativos, } \\
\text { comerciales y } \\
\text { administrativos } \\
\end{array}$ & $\begin{array}{l}\text { Identificando } \\
\text { macro procesos, } \\
\text { procesos, } \\
\text { procedimientos }\end{array}$ & $\begin{array}{l}\text { Relevamiento de los procesos e } \\
\text { instructivos de trabajo }\end{array}$ & $\begin{array}{l}\text { Documentación } \\
\text { estandarizada y } \\
\text { documentada }\end{array}$ & $100 \%$ & $\begin{array}{l}\text { Jefe de Gestión } \\
\text { Humana - Jefe de } \\
\text { Producción }\end{array}$ \\
\hline OPORTUNIDADES & OBJETIVO & ESTRATEGIA & ACTIVIDADES & RESULTADO & INDICADOR & RESPONSABLE \\
\hline $\begin{array}{l}\text { El Estado Peruano } \\
\text { brinda servicios de } \\
\text { capacitación en } \\
\text { gestión de la calidad }\end{array}$ & $\begin{array}{l}\text { Acogerse a } \\
\text { programas de } \\
\text { capacitación } \\
\text { del Estado } \\
\end{array}$ & $\begin{array}{l}\text { Buscando } \\
\text { programas de } \\
\text { capacitación del } \\
\text { Estado } \\
\end{array}$ & $\begin{array}{l}\text { Participando de las } \\
\text { capacitaciones que otorgue el } \\
\text { Estado }\end{array}$ & $\begin{array}{l}\text { Colaboradores } \\
\text { capacitados }\end{array}$ & $\begin{array}{l}\text { Se participó } \\
\text { de los } \\
\text { programas de } \\
\text { capacitación } \\
\end{array}$ & $\begin{array}{l}\text { Jefe de Gestión } \\
\text { Humana }\end{array}$ \\
\hline $\begin{array}{l}\text { Tendencia de las } \\
\text { empresas a tener } \\
\text { procesos } \\
\text { estandarizados }\end{array}$ & $\begin{array}{l}\text { Estandarizar y } \\
\text { documentar los } \\
\text { procesos }\end{array}$ & $\begin{array}{l}\text { Identificando } \\
\text { macro procesos, } \\
\text { procesos, } \\
\text { procedimientos }\end{array}$ & $\begin{array}{l}\text { Relevamiento de los procesos e } \\
\text { instructivos de trabajo }\end{array}$ & $\begin{array}{l}\text { Documentación } \\
\text { estandarizada y } \\
\text { documentada }\end{array}$ & $100 \%$ & $\begin{array}{l}\text { Jefe de Gestión } \\
\text { Humana - Jefe de } \\
\text { Producción }\end{array}$ \\
\hline AMENAZAS & OBJETIVO & ESTRATEGIA & ACTIVIDADES & RESULTADO & INDICADOR & RESPONSABLE \\
\hline $\begin{array}{l}\text { Fuga del talento } \\
\text { humano con el know } \\
\text { how de la empresa }\end{array}$ & $\begin{array}{l}\text { Retener el } \\
\text { talento } \\
\text { humano }\end{array}$ & $\begin{array}{l}\text { Manteniendo un } \\
\text { clima laboral } \\
\text { agradable para } \\
\text { los } \\
\text { colaboradores }\end{array}$ & $\begin{array}{l}\text { Implementando sistema de } \\
\text { compensación. Reconocimiento } \\
\text { a los buenos colaboradores } \\
\text { Realizando actividades de } \\
\text { integración. Otorgando } \\
\text { remuneración a la par con el } \\
\text { mercado }\end{array}$ & $\begin{array}{l}\text { Colaboradores } \\
\text { fidelizados con } \\
\text { la empresa }\end{array}$ & $\begin{array}{l}\text { Rotación de } \\
\text { personal }< \\
15 \%\end{array}$ & $\begin{array}{l}\text { Jefe de Gestión } \\
\text { Humana }\end{array}$ \\
\hline $\begin{array}{l}\text { Fuga de información } \\
\text { sobre los procesos } \\
\text { core del negocio }\end{array}$ & $\begin{array}{l}\text { Establecer } \\
\text { controles para } \\
\text { la seguridad de } \\
\text { la información }\end{array}$ & $\begin{array}{l}\text { Identificando } \\
\text { procesos } \\
\text { críticos y } \\
\text { sensibles }\end{array}$ & $\begin{array}{l}\text { Implementando controles en los } \\
\text { procesos críticos y sensibles }\end{array}$ & $\begin{array}{l}\text { Controles } \\
\text { implementados } \\
\text { en procesos } \\
\text { core }\end{array}$ & $90 \%$ & $\begin{array}{l}\text { Jefe de Gestión } \\
\text { Humana - Jefe de } \\
\text { Producción }\end{array}$ \\
\hline
\end{tabular}


Tabla 41.

Matriz de Planificación Ampliada (Área funcional logística).

\begin{tabular}{|c|c|c|c|c|c|c|}
\hline FORTALEZAS & OBJETIVO & ESTRATEGIA & ACTIVIDADES & RESULTADO & INDICADOR & RESPONSABLE \\
\hline $\begin{array}{l}\text { Compra directa a } \\
\text { comunidades nativas, } \\
\text { sin intermediarios }\end{array}$ & $\begin{array}{l}\text { Negociar buen } \\
\text { precio del } \\
\text { cacao }\end{array}$ & $\begin{array}{l}\text { Comprando } \\
\text { cacao de calidad } \\
\text { bajo estándares } \\
\text { definidos por la } \\
\text { empresa }\end{array}$ & $\begin{array}{l}\text { Coordinando } \\
\text { directamente con los } \\
\text { comuneros para lograr } \\
\text { obtener el mejor } \\
\text { precio a una buena } \\
\text { calidad del grano de } \\
\text { cacao }\end{array}$ & $\begin{array}{l}\text { Se tiene precio } \\
\text { bajo en cacao }\end{array}$ & $\begin{array}{l}\text { Se logró } \\
\text { descuento del } \\
15 \% \text { en el } \\
\text { precio del } \\
\text { cacao }\end{array}$ & Jefe de Logística \\
\hline $\begin{array}{l}\text { Compra directa de } \\
\text { maquinaria para } \\
\text { chocolatería al } \\
\text { fabricante en Italia, sin } \\
\text { intermediarios }\end{array}$ & $\begin{array}{l}\text { Negociar buen } \\
\text { precio de las } \\
\text { máquinas }\end{array}$ & $\begin{array}{l}\text { Logrando alianza } \\
\text { con proveedor de } \\
\text { maquinaria de } \\
\text { chocolatería }\end{array}$ & $\begin{array}{l}\text { Coordinando } \\
\text { directamente la } \\
\text { compra de la } \\
\text { maquinaria. }\end{array}$ & $\begin{array}{l}\text { Se tiene precio } \\
\text { bajo en } \\
\text { maquinaria }\end{array}$ & $\begin{array}{l}\text { Se logró } \\
\text { descuento del } \\
5 \% \text { en el } \\
\text { precio de la } \\
\text { maquinaria } \\
\end{array}$ & Jefe de Logística \\
\hline DEBILIDADES & OBJETIVO & ESTRATEGIA & ACTIVIDADES & RESULTADO & INDICADOR & RESPONSABLE \\
\hline $\begin{array}{l}\text { Dificultad para } \\
\text { conseguir repuestos } \\
\text { debido a que son } \\
\text { máquinas } \\
\text { especializadas e } \\
\text { importadas }\end{array}$ & $\begin{array}{l}\text { Asegurar el } \\
\text { abastecimiento } \\
\text { de repuestos de } \\
\text { maquinaria de } \\
\text { chocolatería }\end{array}$ & $\begin{array}{l}\text { Ampliando } \\
\text { proveedores de } \\
\text { máquinas y } \\
\text { repuestos en el } \\
\text { rubro de } \\
\text { chocolatería }\end{array}$ & $\begin{array}{l}\text { Identificando } \\
\text { empresas de repuestos } \\
\text { de maquinaria de } \\
\text { chocolatería a nivel } \\
\text { nacional e } \\
\text { internacional }\end{array}$ & $\begin{array}{l}\text { Se logró } \\
\text { proveedores } \\
\text { adicionales }\end{array}$ & 3 proveedores & Jefe de Logística \\
\hline $\begin{array}{l}\text { Dificultad para } \\
\text { conseguir servicio de } \\
\text { mantenimiento debido } \\
\text { a que las máquinas son } \\
\text { importadas }\end{array}$ & $\begin{array}{l}\text { Planificar } \\
\text { mantenimiento } \\
\text { preventivo }\end{array}$ & $\begin{array}{l}\text { Elaborando plan } \\
\text { anual de } \\
\text { mantenimiento }\end{array}$ & $\begin{array}{l}\text { Elaborando manual de } \\
\text { mantenimiento } \\
\text { preventivo anual }\end{array}$ & $\begin{array}{l}\text { Se implementó } \\
\text { plan de } \\
\text { mantenimiento } \\
\text { preventivo }\end{array}$ & $100 \%$ & $\begin{array}{l}\text { Jefe de } \\
\text { Mantenimiento }\end{array}$ \\
\hline $\begin{array}{l}\text { Altos inventarios al } \\
\text { inicio del proyecto }\end{array}$ & $\begin{array}{l}\text { Implementar } \\
\text { herramienta de } \\
\text { gestión de } \\
\text { inventarios }\end{array}$ & $\begin{array}{l}\text { Identificando } \\
\text { herramientas de } \\
\text { gestión de } \\
\text { inventarios }\end{array}$ & $\begin{array}{l}\text { Realizando búsqueda } \\
\text { de herramienta de } \\
\text { gestión en el mercado }\end{array}$ & $\begin{array}{l}\text { Se logró } \\
\text { herramienta de } \\
\text { gestión de } \\
\text { inventarios }\end{array}$ & $\begin{array}{l}\text { Se tiene } \\
\text { herramienta de } \\
\text { gestión de } \\
\text { inventarios }\end{array}$ & Jefe de Logística \\
\hline $\begin{array}{l}\text { Falta de proveedores } \\
\text { calificados por parte de } \\
\text { la empresa }\end{array}$ & $\begin{array}{l}\text { Implementar } \\
\text { proceso de } \\
\text { evaluación de } \\
\text { proveedores }\end{array}$ & $\begin{array}{l}\text { Identificando } \\
\text { método de } \\
\text { evaluación de } \\
\text { proveedores y } \\
\text { proporcionar } \\
\text { feedback a cada } \\
\text { uno de ellos } \\
\end{array}$ & $\begin{array}{l}\text { Implementando } \\
\text { método de evaluación } \\
\text { de desempeño de } \\
\text { proveedores y visita } \\
\text { anual a la fábrica de } \\
\text { cada proveedor. }\end{array}$ & $\begin{array}{l}\text { Se implementó } \\
\text { método de } \\
\text { evaluación de } \\
\text { desempeño de } \\
\text { proveedores }\end{array}$ & $90 \%$ & Jefe de Logística \\
\hline OPORTUNIDADES & OBJETIVO & ESTRATEGIA & ACTIVIDADES & RESULTADO & INDICADOR & RESPONSABLE \\
\hline $\begin{array}{l}\text { Gran número de } \\
\text { proveedores de azúcar } \\
\text { y leche en polvo. }\end{array}$ & $\begin{array}{l}\text { Negociar buen } \\
\text { precio de } \\
\text { materia prima }\end{array}$ & $\begin{array}{l}\text { Comprando } \\
\text { materia prima de } \\
\text { calidad bajo } \\
\text { estándares } \\
\text { definidos por la } \\
\text { empresa }\end{array}$ & $\begin{array}{l}\text { Firmando contratos } \\
\text { con proveedores de } \\
\text { materia prima bajo } \\
\text { condiciones ventajosas } \\
\text { para la empresa }\end{array}$ & $\begin{array}{l}\text { Se tiene precio } \\
\text { bajo en materia } \\
\text { prima }\end{array}$ & $\begin{array}{l}\text { Se logró } \\
\text { descuento del } \\
10 \% \text { en el } \\
\text { precio de } \\
\text { materia prima }\end{array}$ & Jefe de Logística \\
\hline $\begin{array}{l}\text { Gran número de } \\
\text { proveedores de } \\
\text { empaques }\end{array}$ & $\begin{array}{l}\text { Negociar buen } \\
\text { precio de } \\
\text { empaques }\end{array}$ & $\begin{array}{l}\text { Comprando } \\
\text { empaques de } \\
\text { calidad bajo } \\
\text { estándares } \\
\text { definidos por la } \\
\text { empresa }\end{array}$ & $\begin{array}{l}\text { Firmando contratos } \\
\text { con proveedores de } \\
\text { empaques bajo } \\
\text { condiciones ventajosas } \\
\text { para la empresa }\end{array}$ & $\begin{array}{l}\text { Se tiene precio } \\
\text { bajo en } \\
\text { empaques }\end{array}$ & $\begin{array}{l}\text { Se logró } \\
\text { descuento del } \\
10 \% \text { en el } \\
\text { precio de } \\
\text { empaques }\end{array}$ & Jefe de Logística \\
\hline AMENAZAS & OBJETIVO & ESTRATEGIA & ACTIVIDADES & RESULTADO & INDICADOR & RESPONSABLE \\
\hline $\begin{array}{l}\text { Sólo hay un proveedor } \\
\text { de gomitas fortificadas } \\
\text { en el mercado }\end{array}$ & $\begin{array}{l}\text { Asegurar el } \\
\text { abastecimiento } \\
\text { de gomitas } \\
\text { fortificadas }\end{array}$ & $\begin{array}{l}\text { Ampliando } \\
\text { proveedores de } \\
\text { gomitas } \\
\text { fortificadas }\end{array}$ & $\begin{array}{l}\text { Identificando } \\
\text { empresas de gomitas } \\
\text { fortificadas a nivel } \\
\text { nacional e } \\
\text { internacional }\end{array}$ & $\begin{array}{l}\text { Se logró } \\
\text { proveedores } \\
\text { adicionales de } \\
\text { gomitas } \\
\text { fortificadas } \\
\end{array}$ & 3 proveedores & Jefe de Logística \\
\hline $\begin{array}{l}\text { Las bodegas y } \\
\text { mayoristas no cuentan } \\
\text { con sistema de } \\
\text { ventilación y control } \\
\text { de temperatura en sus } \\
\text { almacenes, nuestro } \\
\text { producto es sensible a } \\
\text { temperaturas altas } \\
\text { (mayor a } 20^{\circ} \mathrm{C} \text { ) sobre } \\
\text { todo en verano. }\end{array}$ & $\begin{array}{l}\text { Implementar } \\
\text { proceso de } \\
\text { evaluación de } \\
\text { almacenes a } \\
\text { bodegas y } \\
\text { mayoristas }\end{array}$ & $\begin{array}{l}\text { Identificando } \\
\text { método de } \\
\text { evaluación de } \\
\text { almacenes de } \\
\text { bodegas y } \\
\text { mayoristas; y } \\
\text { proporcionar } \\
\text { feedback de } \\
\text { mejora para cada } \\
\text { uno de ellos }\end{array}$ & $\begin{array}{l}\text { Realizando búsqueda } \\
\text { de método de } \\
\text { evaluación de } \\
\text { almacenes de producto } \\
\text { terminado, visita anual } \\
\text { a los almacenes y } \\
\text { realizando } \\
\text { capacitación de buenas } \\
\text { prácticas de } \\
\text { almacenamiento de } \\
\text { alimentos a los } \\
\text { trabajadores de las } \\
\text { bodegas y mayoristas. }\end{array}$ & $\begin{array}{l}\text { Se logró } \\
\text { método de } \\
\text { evaluación de } \\
\text { almacenes de } \\
\text { producto } \\
\text { terminado }\end{array}$ & $90 \%$ & Jefe de Logística \\
\hline
\end{tabular}

Fuente: elaboración propia 


\section{Capítulo XI. Planificación financiera}

\subsection{La inversión}

\subsubsection{Inversión preoperativa}

La inversión pre- operativa (Ver Tabla 42) está conformada por el valor del terreno, equipo y maquinaria, equipo de oficina, obras civiles e imprevistos (se ha estimado un $3.14 \%$ ) los cuales dan un total de S/ 2,366,333 Soles.

Tabla 42. Inversión pre-operativa.

\begin{tabular}{|c|c|}
\hline Terreno & Monto (S/.) \\
\hline Lurín $(1,105 \mathrm{~m} 2)$ & 884,000 \\
\hline \multicolumn{2}{|l|}{ Equipo y maquinaria } \\
\hline Tostadora & 148,590 \\
\hline Descascarillador & 77,220 \\
\hline Pre-refinadora & 51,090 \\
\hline Refinadora & 138,450 \\
\hline Prensa & 92,820 \\
\hline Homogenizador & 9,260 \\
\hline Conchadora & 85,020 \\
\hline Temperadora & 27,445 \\
\hline Túnel de enfriamiento & 30,000 \\
\hline Selladora pedal & 1,050 \\
\hline Computadora (3 unid) & 1,797 \\
\hline Incubadora & 2,100 \\
\hline Mesas de acero inoxidable (8) & 4,800 \\
\hline Balanza analítica & 1,200 \\
\hline Balanza de pie (4) & 1,200 \\
\hline Estantes de acero inoxidable (6) & 5,700 \\
\hline Parihuela (12) & 132 \\
\hline Total & 677,874 \\
\hline \multicolumn{2}{|l|}{ Equipo de oficina } \\
\hline Computadoras (6) & 3,594 \\
\hline Impresora (3) & 420 \\
\hline Mesa de plático (3) & 450 \\
\hline Celular (8) & 72 \\
\hline Silla de oficina (9) & 1,260 \\
\hline Escritrorios (12) & 3,000 \\
\hline Silla de plástico (35) & 770 \\
\hline Estantes de melamine (3) & 960 \\
\hline Total & 10,526 \\
\hline \multicolumn{2}{|l|}{ Obras civiles } \\
\hline Construcciones y edificaciones & 652610 \\
\hline Nivelación, acondicionamiento, cerco, accesos & 28640 \\
\hline Total & 681250 \\
\hline \multicolumn{2}{|l|}{ Seguridad y salud ocupacional } \\
\hline Extintores portátiles & 1320 \\
\hline Luces de emergencia & 3800 \\
\hline Señalética & 350 \\
\hline Sistema de alarma y detección contra incendios & 33615 \\
\hline $\begin{array}{l}\text { Equipos de Protección Personal por puesto de trabajo } \\
\text { (mandiles, gorros, botas de seguridad, botas blancas de jebe, } \\
\text { fajas) }\end{array}$ & 1464 \\
\hline Total & 40549 \\
\hline \multicolumn{2}{|l|}{ Imprevistos } \\
\hline $3.14 \%$ del total de inversión fija & 72133.517 \\
\hline Total inversión fija & $2,366,333$ \\
\hline
\end{tabular}

Fuente: elaboración propia. 


\subsubsection{Inversión en capital de trabajo}

Para tener éxito en la implementación y puesta en marcha de este plan de negocios, una inversión fundamental es la que se debe hacer en capital de trabajo. El proyecto puede considerar la inversión en todos los activos fijos necesarios para poder funcionar adecuadamente, pero si no contempla la inversión en el capital necesario para financiar los desfases de caja durante su operación, probablemente fracase (Sapag, 2011).

El capital de trabajo permite operar durante un ciclo productivo. Financia la producción del producto final y las actividades administrativas.

Para el cálculo del capital de trabajo en el presente plan de negocios, se considerarán tres conceptos.

- Desembolsos para materia prima e insumos (Ver Tabla 43)

- Desembolsos en sueldos y salarios (Ver Tabla 44)

- Desembolsos diversos (Ver Tabla 45)

El monto total de capital de trabajo al mes asciende a S/ 533,679 Soles, los que se estimaron para un período de 3 meses.

Tabla 43.

Desembolsos para materia prima e insumos

\begin{tabular}{lrrrr}
\hline \multicolumn{1}{c}{ Rubro } & Cantidad/mes & $\begin{array}{c}\text { Precio } \\
(\mathrm{S} / . / \mathrm{Kg})\end{array}$ & $\begin{array}{r}\text { Total/mes } \\
(\mathrm{S} / .)\end{array}$ & Total/año (S/.) \\
\hline Cacao (kg.) & 3080.00 & 10.00 & 30,800 & 369,600 \\
Manteca de cacao (kg) & 880.00 & 5.00 & 4,400 & 52,800 \\
Azúcar blanca (kg) & 1056.00 & 3.70 & 3,907 & 46,886 \\
Leche en polvo (kg) & 352.00 & 29.00 & 10,208 & 122,496 \\
Gomitas fortificadas & 275.00 & 30.00 & 8,250 & 99,000 \\
Bolsa foil (unid) & 91432.00 & 0.05 & 4,572 & 54,859 \\
Caja principal (unid.) & 1905.00 & 0.40 & 762 & 9,144 \\
Caja distribución (unid.) & 204.00 & 4.00 & 816 & 9,792 \\
Bolsa pack x 6 (unid) & 7619.00 & 0.10 & 762 & 9,143 \\
\hline TOTAL & & & 64,477 & 773,720 \\
\hline
\end{tabular}

Fuente: elaboración propia. 
Tabla 44.

Sueldos y salarios.

\begin{tabular}{|c|c|c|c|c|c|c|}
\hline Cargo & $\begin{array}{c}\text { REM } \\
\text { mensual } \\
(\mathrm{S} / .)\end{array}$ & $\begin{array}{c}\text { REM anual } \\
\text { (por } 15 \text { pagos) } \mathrm{S} / .\end{array}$ & $\begin{array}{l}\text { Pago a } \\
\text { Essalud y } \\
\text { trabajador } \\
\quad(\mathrm{S} / .)\end{array}$ & $\begin{array}{l}\text { Total/año } \\
\text { (S/.) }\end{array}$ & $\begin{array}{c}\text { Cantidad } \\
\text { en el } \\
\text { puesto }\end{array}$ & $\begin{array}{l}\text { Total/año } \\
\text { (S/.) }\end{array}$ \\
\hline Gerente General & 7,000 & 105,000 & 8,820 & 227,640 & 1 & 227,640 \\
\hline $\begin{array}{l}\text { Asistente de } \\
\text { Gerencia }\end{array}$ & 1,800 & 27,000 & 2,268 & 29,268 & 1 & 29,268 \\
\hline $\begin{array}{l}\text { Jefe de } \\
\text { Producción }\end{array}$ & 3,000 & 45,000 & 3,780 & 48,780 & 1 & 48,780 \\
\hline $\begin{array}{l}\text { Asistentes de } \\
\text { Laboratorio }\end{array}$ & 1,800 & 27,000 & 2,268 & 29,268 & 2 & 58,536 \\
\hline $\begin{array}{l}\text { Auxiliares de } \\
\text { Producción }\end{array}$ & 1,000 & 15,000 & 1,260 & 16,260 & 2 & 32,520 \\
\hline $\begin{array}{l}\text { Operarios } \\
\text { producción, } \\
\text { almacén y } \\
\text { mantenimiento }\end{array}$ & 850 & 12,750 & 1,071 & 13,821 & 22 & 304,062 \\
\hline $\begin{array}{l}\text { Jefe de } \\
\text { Mantenimiento }\end{array}$ & 3,000 & 45,000 & 3,780 & 48,780 & 1 & 48,780 \\
\hline Jefe de Logística & 3,000 & 45,000 & 3,780 & 48,780 & 1 & 48,780 \\
\hline $\begin{array}{l}\text { Asistente de } \\
\text { Logística }\end{array}$ & 1,800 & 27,000 & 2,268 & 29,268 & 1 & 29,268 \\
\hline $\begin{array}{l}\text { Jefe de } \\
\text { Administración y } \\
\text { Gestión Humana }\end{array}$ & 3,000 & 45,000 & 3,780 & 48,780 & 1 & 48,780 \\
\hline $\begin{array}{l}\text { Asistente de } \\
\text { Gestión Humana }\end{array}$ & 1,800 & 27,000 & 2,268 & 29,268 & 1 & 29,268 \\
\hline Jefe Comercial & 3,000 & 45,000 & 3,780 & 48,780 & 1 & 48,780 \\
\hline Vendedor & 5,600 & 84,000 & 7,056 & 91,056 & 1 & 91,056 \\
\hline Mercaderistas & 1,200 & 18,000 & 1,512 & 19,512 & 2 & 39,024 \\
\hline TOTAL & & & & & 38 & $1,084,542$ \\
\hline
\end{tabular}

Fuente: elaboración propia.

Tabla 45. Desembolsos diversos

\begin{tabular}{lrr}
\hline \multicolumn{1}{c}{ Detalle } & Monto/mes (S/.) & Monto/año (S/.) \\
\hline Alquiler de transporte & 2,600 & 31,200 \\
Gastos de seguridad & 2,000 & 24,000 \\
Gastos de luz, agua, teléfono & 5,000 & 60,000 \\
Gastos de mantenimiento & 1,000 & 12,000 \\
Gastos de Marketing & & \\
$\quad$ Feria de salón de cacao & 1,417 & 17,000 \\
$\quad$ Feria expoalimentaria & 1,417 & 17,000 \\
$\quad$ Implementación de página web & 417 & 5,000 \\
$\quad$ Mantenimiento de la página wb & 167 & 2,000 \\
$\quad$ Suscripción a revistas Industria Alimentaria y & 50 & 600 \\
$\quad$ Agronegocios & & 6,000 \\
Contador & 500 & 49,384 \\
Seguridad y Salud Ocupacional & 4,115 & 224,184 \\
\hline TOTAL & 18,682 & \\
\hline
\end{tabular}

Fuente: elaboración propia. 


\subsubsection{Costo del proyecto}

El costo del proyecto incluye inversión fija, inversión en intangibles y capital de trabajo, el cual es de S/ 2,962,093 Soles.

Tabla 46.

Inversión Total.

\begin{tabular}{ll}
\hline Inversión fija & Monto (S/.) \\
\hline Terreno & 884,000 \\
Equipo y maquinaria & 677,874 \\
Equipo de oficina & 10,526 \\
Equipo de transporte & 0 \\
Obras civiles (edificaciones) & 681,250 \\
Seguridad y Salud Ocupacional & 40,549 \\
Sub-total & $2,294,199$ \\
Imprevistos (3.14\% del sub-total) & 72,134 \\
\hline Total & $2,366,333$ \\
\hline Inversión en intangibles & Monto (S/.) \\
\hline Estudio de pre-inversión & 5,000 \\
Gastos de gestión & 52,900 \\
Gastos de organización y constitución & 1,225 \\
Sub-total & 59,125 \\
Imprevistos (5\% del sub-total) & 2,956 \\
\hline Total & 62,081 \\
\hline Inversión en capital de trabajo (3 meses) & Monto (S/.) \\
\hline Sueldos y salarios & 271,136 \\
Materia prima e insumos & 193,430 \\
Desembolsos diversos & 56,046 \\
Sub-total & 520,612 \\
Imprevistos (2.5\% del sub-total) & 13,067 \\
\hline Total & 533,679 \\
Inversión total & Monto (S/.) \\
\hline Inversión Fija & $2,366,333$ \\
Inversión en Intangibles & 62,081 \\
Inversión en Capital de Trabajo & 533,679 \\
\hline Total & $2,962,093$ \\
\hline & \\
\hline & \\
\hline
\end{tabular}

Fuente: elaboración propia.

\subsubsection{Inversiones futuras}

A partir del quinto año se podría adquirir un homogenizador (productividad $25 \mathrm{~kg} / \mathrm{h}$ ) y conchadora (productividad $50 \mathrm{~kg} / \mathrm{h}$ ) que reduciría el tiempo de elaboración de chocolates y/o 
permitiría contar con dos líneas de procesamiento de masa de chocolate, es decir no sólo contar con chocolate de leche sino chocolate bitter o una línea de chocolate orgánico.

\subsection{Presupuesto base}

\subsubsection{Presupuesto de ventas}

Para el presupuesto de ventas (Ver Tabla 47) se ha considerado dos presentaciones; caja por 24 unidades y bolsa pack por 6 unidades, como ventas adicionales se ha considerado la cascarilla que es el sobrante del proceso de descascarillado el cual se venderá como abono para la agricultura y el otro producto es la cocoa que es subproducto del proceso de extracción de manteca, el cual tiene una alta demanda en el mercado para bebidas instantáneas y repostería.

Tabla 47.

Presupuesto de ventas del 2019 al 2028.

\begin{tabular}{|c|c|c|c|c|c|c|c|c|c|c|}
\hline \multirow[b]{2}{*}{ Tipo de producto } & \multicolumn{10}{|c|}{ AÑO } \\
\hline & 2019 & 2020 & 2021 & 2022 & 2023 & 2024 & 2025 & 2026 & 2027 & 2028 \\
\hline Caja x 24 unid (unid.) & 25098 & 25851 & 26626 & 27425 & 28248 & 29095 & 29968 & 30867 & 31793 & 32747 \\
\hline Valor de venta (S/.) & 45.76 & 45.76 & 45.76 & 45.76 & 45.76 & 45.76 & 45.76 & 45.76 & 45.76 & 45.76 \\
\hline Ingresos anuales (S/.) & $1,148,484$ & $1,182,939$ & $1,218,427$ & $1,254,980$ & $1,292,629$ & $1,331,408$ & $1,371,351$ & $1,412,491$ & $1,454,866$ & $1,498,512$ \\
\hline Bolsa x 6 unid (unid.) & 93665 & 96475 & 99369 & 102350 & 105421 & 108583 & 111841 & 115196 & 118652 & 122212 \\
\hline Valor de venta (S/.) & 11.8 & 11.8 & 11.8 & 11.8 & 11.8 & 11.8 & 11.8 & 11.8 & 11.8 & 11.8 \\
\hline Ingresos anuales (S/.) & $1,105,247$ & $1,138,404$ & $1,172,557$ & $1,207,733$ & $1,243,965$ & $1,281,284$ & $1,319,723$ & $1,359,314$ & $1,400,094$ & $1,442,097$ \\
\hline Ingresos de ventas (S/.) & $2,253,731$ & $2,321,343$ & $2,390,984$ & $2,462,713$ & $2,536,595$ & $2,612,692$ & $2,691,073$ & $2,771,805$ & $2,854,960$ & $2,940,608$ \\
\hline \multicolumn{11}{|l|}{ Otras ventas } \\
\hline Cascarilla (kg) & 5,814 & 5,989 & 6,168 & 6,353 & 6,544 & 6,740 & 6,942 & 7,151 & 7,365 & 7,586 \\
\hline Valor de venta (S/.) & 1.00 & 1.00 & 1.00 & 1.00 & 1.00 & 1.00 & 1.00 & 1.00 & 1.00 & 1.00 \\
\hline Ingresos anuales (S/.) & 5,814 & 5,989 & 6,168 & 6,353 & 6,544 & 6,740 & 6,942 & 7,151 & 7,365 & 7,586 \\
\hline Cocoa $(\mathrm{kg})$ & 11,610 & 11,959 & 12,318 & 12,687 & 13,068 & 13,460 & 13,864 & 14,279 & 14,708 & 15,149 \\
\hline Valor de venta (S/.) & 18.00 & 18.00 & 18.00 & 18.00 & 18.00 & 18.00 & 18.00 & 18.00 & 18.00 & 18.00 \\
\hline Ingresos anuales (S/.) & 208,989 & 215,258 & 221,716 & 228,368 & 235,219 & 242,275 & 249,544 & 257,030 & 264,741 & 272,683 \\
\hline Ingresos de otras ventas (S/.) & 214,803 & 221,247 & 227,884 & 234,721 & 241,763 & 249,015 & 256,486 & 264,181 & 272,106 & 280,269 \\
\hline Ingresos totales (S/.) & $2,468,534$ & $2,542,590$ & $2,618,868$ & $2,697,434$ & $2,778,357$ & $2,861,708$ & $2,947,559$ & $3,035,986$ & $3,127,066$ & $3,220,878$ \\
\hline
\end{tabular}

Fuente: Elaboración propia.

\subsubsection{Presupuesto de costos de producción}

Debido a que el 2018 el proyecto estará en la etapa de implementación, se ha calculado el costo de producción para el año 2019 hasta el 2028 (Ver Tabla 48), tanto para la presentación de caja por 24 unidades y bolsa por 6 unidades costo de producción aumenta en el año 2023 y el año 2026 en $1 \%$ debido a que la materia prima e insumos tienden a un alza en sus precios. El costo de ventas de caja por 24 unidades para el 2019 al 2022 es de S/30.00 Soles y la bolsa por 6 unidades tiene un costo de ventas para el 2019 al 2022 de S/7.50 Soles. 
Tabla 48.

Presupuesto de costo de producción.

\begin{tabular}{lrrrrrrrrrr}
\hline \multicolumn{1}{c}{ Descripción } & \multicolumn{1}{c}{ AÑO } \\
\hline Caja x 24 unid (unid.) & 2019 & 2020 & 2021 & 2022 & 2023 & 2024 & 2025 & 2026 & 2027 & 2028 \\
\hline Costo de producción (S/) & $25,098.00$ & $25,850.94$ & $26,626.47$ & $27,425.26$ & $28,248.02$ & $29,095.46$ & $29,968.32$ & $30,867.37$ & $31,793.40$ & $32,747.20$ \\
Costo de producción (S/) & 30.00 & 30.00 & 30.00 & 30.00 & 30.30 & 30.30 & 30.30 & 30.30 & 30.60 & 30.60 \\
\hline Bolsa x 6 unid (unid.) & $752,940.00$ & $775,528.20$ & $798,794.05$ & $822,757.87$ & $855,915.01$ & $881,592.46$ & $908,040.23$ & $935,281.44$ & $972,877.90$ & $1,002,064.24$ \\
\hline Costo de producción(S/) & $93,665.00$ & $96,474.95$ & $99,369.20$ & $102,350.27$ & $105,420.78$ & $108,583.41$ & $111,840.91$ & $115,196.14$ & $118,652.02$ & $122,211.58$ \\
Costo de producción(S/) & 7.50 & 7.50 & 7.50 & 7.50 & 7.58 & 7.58 & 7.58 & 7.58 & 7.65 & 7.65 \\
\hline Costo de producción total (S/) & $1,455,427.50$ & $1,499,090.331$, & $544,063.03$ & $1,590,384.93$ & $1,655,004.54$ & $, 704,654.68$ & $1,755,794.32$ & $1,808,468.15$ & $1,880,565.85$ & $1,936,982.83$ \\
\hline
\end{tabular}

Fuente: Elaboración propia.

\subsubsection{Presupuesto de compras}

En el presupuesto de compras se ha considerado las compras de materia prima directa cuyo monto para el año 2019 es de S/ 690,782 Soles y para el 2028 aumenta a S/ 949,866.98

Soles (Ver tabla 49). Además, se consideró el presupuesto de compras de materiales

indirectos cuyo monto es de S/ 103,149.00 Soles para el 2019 y S/ 193,286.07 Soles para el

año 2028 (Ver Tabla 50)

Tabla 49.

Presupuesto de compras de materia prima directa para el año 2019 hasta 2028.

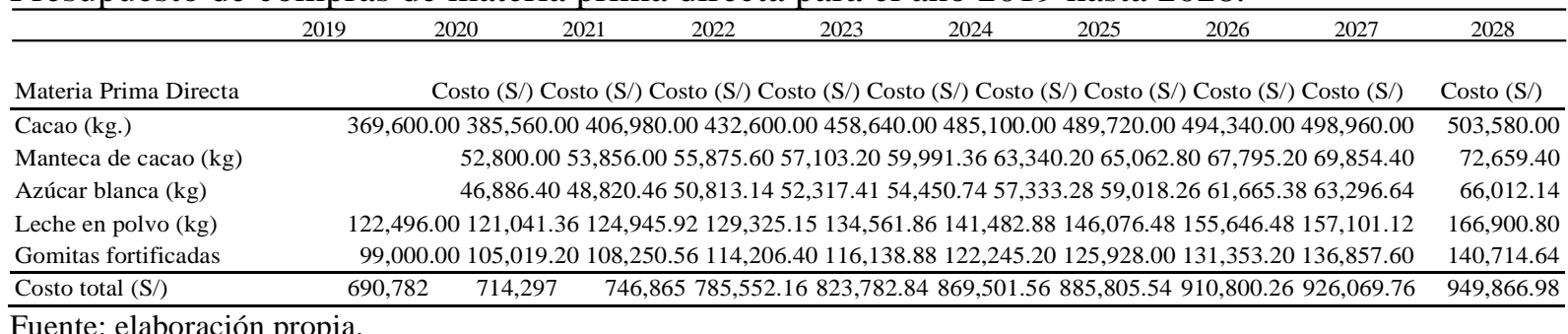

Tabla 50.

Presupuesto de compras de materiales indirectos de fabricación para el año 2019 hasta 2028 .

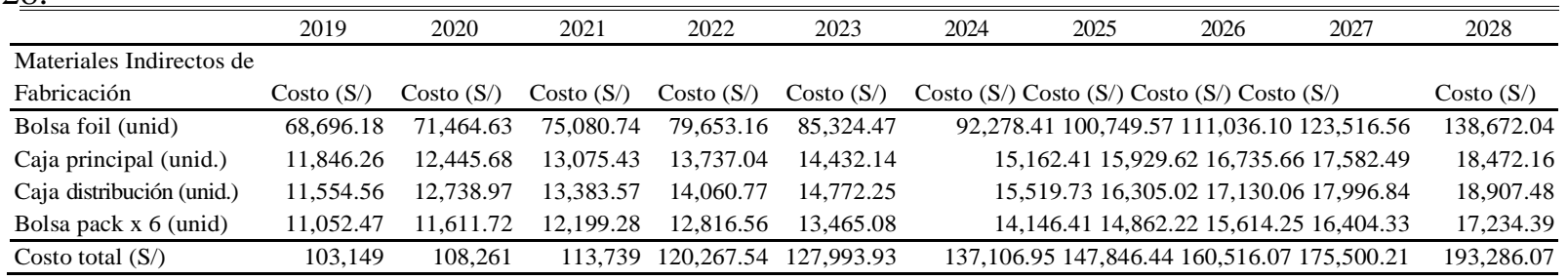

Fuente: elaboración propia.

\subsubsection{Presupuesto de costo de ventas}

El presupuesto de costo de ventas incluye valor de materia prima, mano de obra directa

(MOD), mano de obra indirecta (MOI), materiales indirectos (MI) y costos de gastos de 
fabricación (CGF) cuyo monto para el 2019 es de S/ 1,371,810.00 Soles y S/ 1,721,031 Soles para el 2028 (Ver Tabla 51).

Tabla 51.

Presupuesto de costo de ventas para el año 2019 hasta 2028.

\begin{tabular}{|c|c|c|c|c|c|c|c|c|c|c|}
\hline & 2019 & 2020 & 2021 & 2022 & 2023 & 2024 & 2025 & 2026 & 2027 & 2028 \\
\hline Materia prima & 690,782 & 714,297 & \multicolumn{8}{|c|}{$746,865785,552.16823,782.84869,501.56885,805.54910,800.26926,069.76949,866.98$} \\
\hline MOD & 234,957 & 234,957 & 234,957 & 234,957 & 234,957 & 234,957 & 234,957 & 234,957 & 234,957 & 234,957 \\
\hline MOI & $257,721.00$ & $257,721.00$ & $257,721.00$ & $257,721.00$ & $257,721.00$ & $257,721.002$ & $257,721.00$ & $257,721.002$ & $257,721.00$ & $257,721.00$ \\
\hline MI & 103,149 & 108,261 & 113 & 739120,267 & $7.54127,993$ & $93137,106.9$ & $95147,846.4$ & $14160,516.07$ & $175,500.21$ & $193,286.07$ \\
\hline CGF & 85,200 & 85,200 & 85,200 & 85,200 & 85,200 & 85,200 & 85,200 & 85,200 & 85,200 & 85,200 \\
\hline Total & $1,371,810$ & $1,400,436$ & & $1,438,482$ & $21,483,698$ & $1,529,6551,5$ & $84,4871,61$ & $1,5301,649,1$ & $941,679,44$ & $81,721,031$ \\
\hline
\end{tabular}

Fuente: elaboración propia.

\subsubsection{Presupuesto de gastos administrativos}

En el presupuesto de gastos administrativos se ha considerado la planilla de trabajadores administrativos (sin considerar a los trabajadores del área Comercial, quienes se detallarán en el presupuesto de gastos de ventas en el siguiente ítem). Además, se incluyen los gastos de seguridad, transporte, servicios de luz, agua y teléfono (el que representa para el caso de las oficinas administrativas el 30\% del total. El 70\% está en los CIF), gastos de mantenimiento, la asesoría del contador, a quien se le contratará para que realice el servicio una vez al mes para la declaración de impuestos y elaboración de los estados financieros. Finalmente, se incluye los útiles de escritorio y limpieza. En la Tabla 52 se presenta el presupuesto para los 10 años, para lo cual se ha estimado un crecimiento del gasto en un $3 \%$. 
Tabla 52.

Presupuesto de Gastos Administrativos.

\begin{tabular}{|c|c|c|c|c|c|c|c|c|c|c|}
\hline Conceptos & 2019 & 2020 & 2021 & 2022 & 2023 & 2024 & 2025 & 2026 & 2027 & 2028 \\
\hline $\begin{array}{l}\text { Planilla trabajadores } \\
\text { administrativos }\end{array}$ & \multicolumn{10}{|c|}{$413,004425,394438,156451,301464,840478,785$ 493,148 507,943 523,181 538,877 } \\
\hline Alquiler de transporte & 31,200 & 32,136 & 33,100 & 34,093 & 35,116 & 36,169 & 37,254 & 38,372 & 39,523 & 40,709 \\
\hline Seguridad & 24,000 & 24,720 & 25,462 & 26,225 & 27,0 & 27,8 & 28,6 & 29,517 & 30 & 31,315 \\
\hline Luz, agua, teléfono & 18,000 & 18,540 & 19,096 & 19,669 & 20,259 & 20,867 & 21,493 & 22,138 & 22,802 & 23,486 \\
\hline Mantenimiento & 12,000 & 12,360 & 12,731 & 13,113 & 13,506 & 13,911 & 14,329 & 14,758 & 15,201 & 15,657 \\
\hline Asesoría Contador & 6,000 & 6,180 & 6,365 & 6,556 & 6,753 & 6,956 & 7,164 & 7,379 & 7,601 & 7,829 \\
\hline Útiles de escritorio & 1,200 & 1,236 & 1,273 & 1,311 & 1,351 & 1,391 & 1,433 & 1,476 & 1,520 & 1,566 \\
\hline Útiles de limpieza & 2,400 & 2,472 & 2,546 & 2,623 & 2,701 & 2,782 & 2,866 & 2,952 & 3,040 & 3,131 \\
\hline Total & \multicolumn{10}{|c|}{$\begin{array}{llllllllll}507,804 & 523,038 & 538,729 & 554,891 & 571,538 & 588,684 & 606,345 & 624,535 & 643,271 & 662,569\end{array}$} \\
\hline
\end{tabular}

Fuente: Elaboración propia

\subsubsection{Presupuesto de gastos de seguridad y salud ocupacional}

De acuerdo a las actividades planificadas para el Sistema de Gestión de Seguridad y Salud

Ocupacional descritas en el punto 8.5, se detallan los gastos a incurrir del año 2019 al 2028.

Tabla 53.

Presupuesto de Gastos de Seguridad y Salud Ocupacional.

\begin{tabular}{|c|c|c|c|c|c|c|c|c|c|c|}
\hline Conceptos & 2019 & 2020 & 2021 & 2022 & 2023 & 2024 & 2025 & 2026 & 2027 & 2028 \\
\hline Vigilancia Médica Ocupacional & 11,520 & 11,520 & 11,520 & 11,520 & 11,520 & 11,520 & 11,520 & 11,520 & 11,520 & 11,520 \\
\hline $\begin{array}{l}\text { Evaluaciones médicas ocupacionales } \\
\text { administrativo }\end{array}$ & 1,820 & 1,820 & 1,820 & 1,820 & 1,820 & 1,820 & 1,820 & 1,820 & 1,820 & 1,820 \\
\hline es médicas ocunacionales onerarios & 5,280 & 5,280 & 5,280 & 5,280 & 5,280 & 5,280 & 5,280 & 5,280 & 5,280 & 5,280 \\
\hline STR & 000 & 6,000 & 6,000 & 6,000 & 6,000 & 6,000 & 6,000 & 6,000 & 6,000 & 6,000 \\
\hline $\begin{array}{l}\text { Certificado de Defensa Civil } \\
\text { Realización del monitoreo de agentes físicos, } \\
\text { químicos, biológicos, factores de riesgo } \\
\text { disergonómicos y sicosociales }\end{array}$ & \multicolumn{10}{|c|}{$12,50012,50012,50012,50012,50012,50012,50012,50012,50012,500$} \\
\hline Capac & 200 & 200 & 200 & 200 & 200 & 200 & 200 & 200 & 200 & 200 \\
\hline Manten & 100 & 100 & 100 & 100 & 100 & 100 & 100 & 100 & 100 & 100 \\
\hline $\begin{array}{l}\text { Otros EPP (guantes, mascarilla, redecilla para el } \\
\text { cabello) }\end{array}$ & 8,424 & 8,424 & 8,424 & 8,424 & 8,424 & 8,424 & 8,424 & 8,424 & 8,424 & 8,424 \\
\hline $\begin{array}{l}\text { Realización de la auditoría de evaluación } \\
\text { periódica del Sistema de Gestión de Seguridad y } \\
\text { Salud en el Trabajo (MINTRA). }\end{array}$ & 3,000 & 3,000 & 3,000 & 3,000 & 3,000 & 3,000 & 3,000 & 3,000 & 3,000 & 3,000 \\
\hline Total & & & & & & & & & & \\
\hline
\end{tabular}

Fuente: Elaboración propia

\subsubsection{Presupuesto de gastos de marketing y ventas}

Para la elaboración del presupuesto de gastos de marketing y ventas (Ver Tabla 54), se consideró el monto a pagar a los trabajadores del área comercial. Los gastos asociados a la participación de dos ferias en el año: Del Salón del Cacao y Expo Alimentaria. Gastos de creación e implementación de la página web (única vez en el 1er año), luego los gastos anuales son por mantenimiento. Finalmente, suscripción a dos revistas para la realización de 
publicidad. En la siguiente tabla se presenta el presupuesto. Se ha estimado un crecimiento del gasto de un $3 \%$ anual.

Tabla 54.

Presupuesto de Gastos Marketing y Ventas.

\begin{tabular}{|c|c|c|c|c|c|c|c|c|c|c|}
\hline Conceptos & 2019 & 2020 & 2021 & 2022 & 2023 & 2024 & 2025 & 2026 & 2027 & 2028 \\
\hline $\begin{array}{l}\text { Planilla } \\
\text { trabajadores } \\
\text { área comercial }\end{array}$ & 178,860 & 184,226 & 189,753 & 195,445 & 201,309 & 207,348 & 213,568 & 219,975 & 226,574 & 233,372 \\
\hline $\begin{array}{l}\text { Feria del salón } \\
\text { del cacao }\end{array}$ & 17,000 & 17,510 & 18,035 & 18,576 & 19,134 & 19,708 & 20,299 & 20,908 & 21,535 & 22,181 \\
\hline $\begin{array}{l}\text { Feria } \\
\text { expoalimentaria }\end{array}$ & 17,000 & 17,510 & 18,035 & 18,576 & 19,134 & 19,708 & 20,299 & 20,908 & 21,535 & 22,181 \\
\hline $\begin{array}{l}\text { Creación e } \\
\text { implementación } \\
\text { de la web }\end{array}$ & 5,000 & 0 & 0 & 0 & 0 & 0 & 0 & 0 & 0 & 0 \\
\hline $\begin{array}{l}\text { Mantenimiento } \\
\text { anual de la web }\end{array}$ & 2,000 & 2,060 & 2,122 & 2,185 & 2,251 & 2,319 & 2,388 & 2,460 & 2,534 & 2,610 \\
\hline $\begin{array}{l}\text { Suscripción a } \\
\text { revistas Industria } \\
\text { Alimentaria y } \\
\text { Agronegocios }\end{array}$ & 600 & 618 & 637 & 656 & 675 & 696 & 716 & 738 & 760 & 783 \\
\hline Total & 220,460 & 221,924 & 228,582 & 235,439 & 242,5022 & 9,7772 &, 271264 & 989272,9 & 38281,12 & \\
\hline
\end{tabular}

Fuente: Elaboración propia.

\subsubsection{Presupuesto de gastos financieros}

En el presupuesto de gastos financieros (Ver Tabla 55) se han considerado los intereses del préstamo bancario realizado para el financiamiento de la inversión y puesta en marcha del plan de negocios.

Tabla 55.

Presupuesto de Gastos Financieros.

\begin{tabular}{llllll}
\hline Conceptos & 2018 & 2019 & 2020 & 2021 & 2022 \\
\hline Interés $(\mathrm{S} /)$. & 173,926 & 149,884 & 116,746 & 76,984 & 29,276 \\
\hline
\end{tabular}

Fuente: Elaboración propia

\subsection{Financiamiento}

\subsubsection{Endeudamiento y condiciones}

La inversión total del presente plan de negocios es de S/ 2,962,093 Soles, como se presentó en la Tabla 46. El 68\% (S/ 2,000,000 Soles) se financiará con capital propio, siendo el aporte de 2 accionistas del 30\% cada uno (S/. 600,000 Soles) y el tercer accionista aportará el 40\% (S/. 800,000 Soles). El 32\% que falta para cubrir la implementación y puesta en 
marcha del proyecto es de S/ 962,093 Soles. Para ello será necesario buscar financiamiento a través de una entidad financiera, se pondrá en garantía el terreno y la maquinaria.

Se evaluaron las tasas de los principales bancos y entidades financieras, visitando una sección de la Superintendencia de Banca y Seguros, en la que se pueden comprar las tasas que se ofrecen. (https://www.sbs.gob.pe/app/retasas/paginas/retasasInicio.aspx)

Luego de la evaluación se decidió optar por la alternativa del Banco BBVA Continental, quien otorgará una tasa efectiva anual (TEA) de 20\%, TEM de $1.53 \%$. Se negociará el préstamo a 5 años con pagos mensuales constantes y período de gracia de 6 meses (sólo se abonarán los intereses correspondientes). En el anexo 18 se presenta el servicio de la deuda para los 5 años.

En la Tabla 56 se presentan los pagos de intereses y amortizaciones en cada uno de los 5 años.

Tabla 56.

Pago de intereses y amortización del préstamo.

\begin{tabular}{lrlllr}
\hline Conceptos & \multicolumn{1}{c}{2018} & 2019 & \multicolumn{1}{l}{2020} & \multicolumn{1}{c}{2021} & \multicolumn{1}{c}{2022} \\
\hline Préstamo a inicio de año & 962,093 & 889,856 & 724,053 & 525,112 & 286,410 \\
Amortización & 72,237 & 165,802 & 198,941 & 238,702 & 286,410 \\
Interés & 173,926 & 149,884 & 116,746 & 76,984 & 29,276 \\
Saldo final del préstamo & 889,856 & 724,053 & 525,112 & 286,410 & 0 \\
Monto a pagar & 246,163 & 315,686 & 315,686 & 315,686 & 315,686 \\
\hline
\end{tabular}

Fuente: elaboración propia.

\subsubsection{Capital y costo de oportunidad}

Para el cálculo del costo de oportunidad del proyecto en Perú (COK) se siguió el Modelo

\section{CAPM.}

Paso 1. Cálculo del Beta del Proyecto

Primero se ingresó a la página web de los Betas en Los Estados Unidos para poder obtener el beta (Unlevered beta) del sector. El beta que le corresponde a este plan de negocios es el del sector de "Food Processing" indicado en 0.61. 


\begin{tabular}{|c|c|c|c|c|c|c|c|}
\hline Industry Name & Number of firms & Beta & D/ERatio & Tax rate & Unlevered beta & Cash/Firm value & Unlevered beta corrected for cash \\
\hline Advertising & 41 & 1.36 & $62.98 \%$ & $5.10 \%$ & 0.85 & $6.27 \%$ & 0.91 \\
\hline Aerospace/Defense & 96 & 1.07 & $23.53 \%$ & $10.86 \%$ & 089 & $5.21 \%$ & 0.94 \\
\hline Air Tronsport & 18 & 1.12 & $70.12 \%$ & $22.99 \%$ & 073 & $4.23 \%$ & 0.76 \\
\hline Apporel & 58 & 0.88 & $34.21 \%$ & $10.95 \%$ & 0.67 & $4.30 \%$ & 0.71 \\
\hline Auto \& Truck & 15 & 0.85 & $150.42 \%$ & $8.14 \%$ & 0.35 & $6.46 \%$ & 0.38 \\
\hline Auto Parts & 63 & 1.12 & $35.22 \%$ & $10.40 \%$ & 0.85 & $8.90 \%$ & 0.94 \\
\hline Bank (Money Center) & 10 & 0.86 & $188.03 \%$ & $27.90 \%$ & 0.37 & $9.89 \%$ & 0.41 \\
\hline Banks (Regional) & 645 & 0.47 & $60.51 \%$ & 25.4356 & 033 & $10.76 \%$ & 0.36 \\
\hline Beverage (Alcoholic) & 25 & 0,79 & $29.02 \%$ & $10.86 \%$ & 063 & $1130 \%$ & 0.71 \\
\hline Beverage (Soft) & 36 & 0.91 & $24.51 \%$ & $5.87 \%$ & 0.74 & $4.84 \%$ & 0.78 \\
\hline Broadcasting & 30 & 122 & $95.92 \%$ & $18.54 \%$ & 0.68 & $217 \%$ & 0.70 \\
\hline Brokerage \& Investment: Dank & 45 & 1.08 & $232.21 \%$ & $13.59 \%$ & 0.56 & $14.97 \%$ & 0.42 \\
\hline Buliding Materials & 41 & 1.01 & $26.98 \%$ & $23.39 \%$ & 083 & $4.05 \%$ & 0.87 \\
\hline Business \& Consumer Service: & 165 & 1.07 & $35.10 \%$ & $12.61 \%$ & 0.82 & $3.52 \%$ & 0.85 \\
\hline \begin{tabular}{|l|} 
Cable TV \\
\end{tabular} & 14 & 1.12 & $49.24 \%$ & $20.28 \%$ & 0.80 & $2.32 \%$ & 0.82 \\
\hline Chemical (Basic) & 45 & 1.00 & $58.62 \%$ & $7.71 \%$ & 0.65 & $4.00 \%$ & 0.68 \\
\hline Chem ical (Diversified) & 8 & 1.52 & $35.52 \%$ & $6.59 \%$ & 114 & $6.50 \%$ & 1.22 \\
\hline Chemical (Spe cialty) & 100 & 1.20 & $29.98 \%$ & $9.58 \%$ & 0.94 & $3.97 \%$ & 0.98 \\
\hline Coal \& Related Energy & 38 & 1.36 & $138.55 \%$ & $0.43 \%$ & 0.57 & $5.34 \%$ & 0.61 \\
\hline Computer Senvices & 117 & 0.99 & $28.33 \%$ & $11.18 \%$ & 079 & $5.24 \%$ & 0.83 \\
\hline computers/Peripherals & 55 & 1.06 & $19.60 \%$ & $5.63 \%$ & 0.89 & $5.61 \%$ & 0.94 \\
\hline Construction Supplies & 51 & 1.31 & $42.57 \%$ & $18.44 \%$ & 0.98 & $4.68 \%$ & 1.02 \\
\hline Diversified & 24 & 0.76 & $35.98 \%$ & $11.55 \%$ & 0.58 & $7.84 \%$ & 0.65 \\
\hline Drugs (Biotechnology) & 426 & 1.40 & $19.45 \%$ & $1.44 \%$ & 118 & $5.54 \%$ & 1.25 \\
\hline Drugs (Pharmaceutical) & 164 & 1.02 & $14.58 \%$ & $2.54 \%$ & 089 & 3.9896 & 0.93 \\
\hline Education & 36 & 1.23 & $33.38 \%$ & $9.29 \%$ & 094 & $10.16 \%$ & 1.05 \\
\hline Electrical Equipment & 119 & 1.14 & $19.15 \%$ & $5.87 \%$ & 097 & $6.42 \%$ & 1.04 \\
\hline Electronics (Consumer \& Offic & 24 & 1.08 & $19.39 \%$ & $3.81 \%$ & 091 & $5.99 \%$ & 0.97 \\
\hline Electronics (Genera) & 164 & 0.86 & $1787 \%$ & $8.85 \%$ & 074 & $1002 \%$ & a.83 \\
\hline Eng ineering/Construction & 48 & 1.18 & $32.45 \%$ & $15.15 \%$ & 093 & $8.26 \%$ & 1.01 \\
\hline Entertainment & 79 & 120 & $30.83 \%$ & $5.50 \%$ & 0.93 & $3.59 \%$ & 0.97 \\
\hline Environmental \& Waste Servid & 89 & 0.85 & $38.98 \%$ & $5.07 \%$ & 0.62 & $0.95 \%$ & 0.65 \\
\hline Farming/Agriculture & 37 & 0.92 & $60.04 \%$ & $7.89 \%$ & 0.59 & $3.88 \%$ & 0.62 \\
\hline Finoncial Svcs. (Non-bonk \& In & 258 & 0.65 & $1124,41 \%$ & 20.8016 & 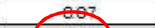 & $2.29 \%$ & 0.07 \\
\hline Food Processing & 87 & 0.75 & $26.84 \%$ & $14.66 \%$ & $0.61)$ & $2.57 \%$ & 0.63 \\
\hline Food Wholesalers & 16 & 1.20 & $36.34 \%$ & $11.77 \%$ & 091 & $1.76 \%$ & 0.93 \\
\hline Furn/Home Furnishings & 30 & 0.84 & $29.01 \%$ & $14.58 \%$ & 0.67 & $3.39 \%$ & 0.69 \\
\hline
\end{tabular}

Figura 45. Betas by Sector US. Recuperado de

http://pages.stern.nyu.edu/ adamodar/New_Home_Page/datafile/Betas.html

Con el beta del sector, se procede a hallar el beta para el proyecto:

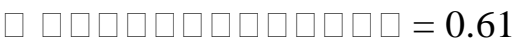

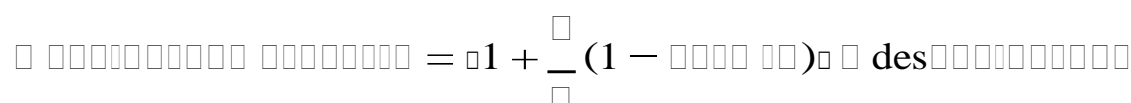

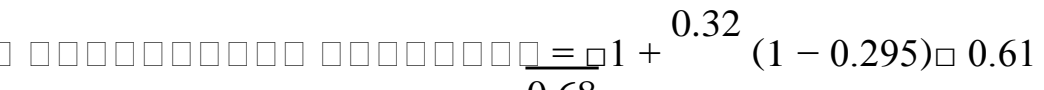

$$
0.68
$$

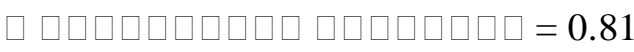

Considerando la estructura Deuda / Capital de (32\%/68\% y la tasa del impuesto a la renta de $29.5 \%$. El beta para el proyecto es de 0.81 .

Paso 2. Obtener los parámetros rf y rm

Siendo rf, la tasa libre de riesgo y $\mathrm{rm}$ el rendimiento del mercado.

Se ingresó a la página en los Estados Unidos donde se encuentra el rendimiento de las acciones y bonos en los últimos años, para obtener estos datos (rm y rf) y se realizó un 
cálculo aritmético promediando los valores de los últimos años, tomando el índice S\&P500

para el rendimiento del mercado (rm) y 10-year T.Bond rendimiento de los bonos soberanos

(rf). (Ver Tabla 57).

\section{Annual Returns on Stock, T.Bonds and T.Bills: 1928 - Current}

\begin{tabular}{|c|c|c|c|c|c|c|c|c|}
\hline \multirow[b]{2}{*}{ Year } & \multicolumn{3}{|c|}{ Annual Returns on Investments in } & \multicolumn{3}{|c|}{ Compounded Value of $\$ 100$} & \multirow[b]{2}{*}{ Stocks - Bills } & \multirow[b]{2}{*}{ Stocks - Bonds } \\
\hline & S\&P 500 & 3-month T.B.ll & 10-year T. Bond & stocks & T.Eills & T.Bonds & & \\
\hline 1928 & $49.31 \%$ & $3.08 \%$ & $0.84 \%$ & $\$ 143.81$ & $\$ 103.03$ & $\$ 100.84$ & $40.73 \%$ & $42.98 \%$ \\
\hline 1929 & $-8.30 \%$ & $3.16 \%$ & $4.20 \%$ & $\$ 131.88$ & 5106.34 & $\$ 105.07$ & $-11.46 \%$ & $-12.50 \%$ \\
\hline 1930 & $-25.12 \%$ & $4.55 \%$ & $4.54 \%$ & $\$ 9875$ & $\$ 111.18$ & $\$ 109.85$ & $-29.67 \%$ & $-29.66 \%$ \\
\hline 1931 & $-43.84 \%$ & $2.31 \%$ & $-2.56 \%$ & $\$ 5546$ & $\$ 113,74$ & $\$ 107.03$ & $-46.15 \%$ & $-41.28 \%$ \\
\hline 1532 & $-8.64 \%$ & $1.07 \%$ & $8.79 \%$ & $\$ 5066$ & $\$ 114.95$ & $\$ 116.44$ & $-971 \%$ & $-17.43 \%$ \\
\hline 1593 & $49.98 \%$ & $0.96 \%$ & $1.86 \%$ & $\$ 7599$ & $\$ 116.06$ & $\$ 11860$ & $49.02 \%$ & $48.13 \%$ \\
\hline 1934 & $-1.19 \%$ & $0.32 \%$ & $7.96 \%$ & $\$ 7509$ & $\$ 116.44$ & $\$ 128.05$ & $-1.51 \%$ & $9.15 \%$ \\
\hline 1935 & $46.74 \%$ & $0.18 \%$ & $4.47 \%$ & $\$ 110.18$ & $\$ 116.64$ & $\$ 133.78$ & $46.57 \%$ & 42.2796 \\
\hline 1986 & $31.94 \%$ & $0.17 \%$ & $5.02 \%$ & $\$ 145,38$ & $\$ 116.84$ & $\$ 140,49$ & $31.77 \%$ & $26.93 \%$ \\
\hline 1987 & $.35 .34 \%$ & $0.30 \%$ & $1.38 \%$ & $\$ 9400$ & $\$ 117.19$ & $\$ 14243$ & 356446 & $-36.72 \%$ \\
\hline 1998 & $29.28 \%$ & $0.08 \%$ & $4.21 \%$ & $\$ 121.53$ & $\$ 117.29$ & $\$ 148.48$ & $29.21 \%$ & $25.07 \%$ \\
\hline 1959 & $-1.10 \%$ & $0.04 \%$ & $4.41 \%$ & $\$ 120.20$ & $\$ 117.30$ & $\$ 154.98$ & $-1.14 \%$ & $-5.51 \%$ \\
\hline 1940 & $-10.57 \% 6$ & $0.03 \%$ & $5.40 \%$ & $\$ 107.37$ & $\$ 117.35$ & $\$ 163: 35$ & $-10.70 \%$ & $-16.08 \%$ \\
\hline 1991 & $-12.77 \%$ & $0.08 \%$ & $-2.02 \%$ & $\$ 93.66$ & $\$ 117.45$ & $\$ 160.04$ & $-12.85 \%$ & $-10.75 \%$ \\
\hline 1942 & $19.17 \%$ & $0.34 \%$ & $2.29 \%$ & $\$ 111.61$ & $\$ 117.85$ & $\$ 163.72$ & $18.84 \%$ & $16.88 \%$ \\
\hline 1943 & $25.06 \%$ & $0.38 \%$ & $2.49 \%$ & $\$ 139.59$ & 5118.30 & $\$ 167.79$ & $24.68 \%$ & $22.57 \%$ \\
\hline 1944 & $19.03 \%$ & $0.38 \%$ & $2.58 \%$ & $\$ 166.15$ & $\$ 118.75$ & $\$ 17212$ & $18.65 \%$ & $16.45 \%$ \\
\hline 1945 & $35.82 \%$ & $0.38 \%$ & $3.80 \%$ & $\$ 225.67$ & $\$ 119.20$ & $\$ 178.67$ & $35.44 \%$ & $32.02 \%$ \\
\hline 1946 & $-8.63 \%$ & $0.38 \%$ & $3.13 \%$ & $\$ 206.65$ & $\$ 11965$ & $\$ 18426$ & $-8.81 \%$ & $-11.56 \%$ \\
\hline 1947 & $520 \%$ & $0.57 \%$ & $0.92 \%$ & $\$ 21739$ & $\$ 120.33$ & $\$ 185.95$ & $463 \%$ & $428 \%$ \\
\hline 1948 & $5.70 \%$ & $1.02 \%$ & $1.95 \%$ & $\$ 229.79$ & $\$ 121.56$ & $\$ 189.58$ & $4.68 \%$ & $375 \%$ \\
\hline 1949 & $18.30 \%$ & $1,10 \%$ & $4.66 \%$ & $\$ 271.85$ & $\$ 122.90$ & $\$ 198<2$ & $17.20 \%$ & $13.640 \%$ \\
\hline 1950 & $30.81 \%$ & $1.17 \%$ & $0.43 \%$ & $\$ 355.60$ & $\$ 124.34$ & $\$ 199.27$ & $29.63 \%$ & $30.38 \%$ \\
\hline 1951 & $23.68 \%$ & $1.48 \%$ & $-0.30 \%$ & $\$ 439.80$ & $\$ 126.18$ & $\$ 198.68$ & $22.20 \%$ & $23.97 \%$ \\
\hline 1952 & $18.15 \%$ & $1.67 \%$ & $2.27 \%$ & $\$ 519.62$ & $\$ 128.29$ & $\$ 20319$ & $16.48 \%$ & $15.88 \%$ \\
\hline 1553 & $-1.21 \%$ & $1.89 \%$ & $4.14 \%$ & $\$ 513.35$ & $\$ 130.72$ & $\$ 211.61$ & $-3.10 \%$ & $-5.35 \%$ \\
\hline 1554 & $52.56 \%$ & $0.96 \%$ & $3.29 \%$ & $\$ 733.18$ & $\$ 131.93$ & $\$ 218.57$ & $51.60 \%$ & $49.27 \%$ \\
\hline 1955 & $32.60 \%$ & $1.66 \%$ & $-1.34 \%$ & 51,03847 & $\$ 154.17$ & $\$ 215.65$ & $30.94 \%$ & $33.93 \%$ \\
\hline 1550. & $7499 \%$ & 2.7695 & -2265 & 5311573 & $5137=0$ & 501070 & $488 \%$ & $9702 \%$ \\
\hline
\end{tabular}

Figura 46. Annual Returns on Stock, T.Bonds and T.Bills: 1928 - Current. Recuperado de http://pages.stern.nyu.edu/ adamodar/New_Home_Page/datafile/histretSP.html

Tabla 57.

Valores promediados para el cálculo del rm y rf.

\begin{tabular}{lll}
\hline Años & S\&P500 & 10 -year T.Bonds \\
\hline $1928-2016$ & $11.42 \%$ & $5.18 \%$ \\
\hline $1967-2016$ & $11.45 \%$ & $7.08 \%$ \\
\hline $2007-2016$ & $8.65 \%$ & $5.03 \%$ \\
\hline
\end{tabular}

$\square \square=8.65 \%$ : rendimiento del mercado

$\square \square=5.03 \%$ : tasa libre de riesgo en Estados Unidos

Paso 3. Cálculo del COK del proyecto

Se aplica la ecuación CAPM:

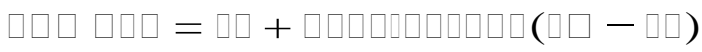

$$
=0.0503+0.81(0.0865-0.0503)
$$


$\square \square \square \square \square \square=7.97 \%$

Este valor significa lo que los accionistas pedirían de ejecutar el proyecto en los Estados Unidos.

Para el cálculo de costo de oportunidad para el proyecto en Perú, se debe ajustar la tasa de rentabilidad por el riesgo país. Utilizando la aproximación simple, es decir sumando al COK USA el riesgo país Perú y en un escenario conservador, corrigiendo el riesgo país por un factor $\square$.

El riesgo país 1.62\% para el 2017, según fuente de Diario Gestión. Y 1.2 para el valor $\square$.

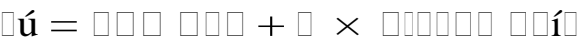

$$
\begin{aligned}
& u ́=7.97 \%+1.2 \times 1.62 \% \\
& \text { ú }=9.91 \%
\end{aligned}
$$

El costo de oportunidad para el proyecto es de $9.91 \%$.

\subsubsection{Costo de capital promedio ponderado}

El costo de capital promedio ponderado (CCPP) o también llamado WACC por sus siglas en inglés se calcula considerando la deuda (D), aporte de capital (C), tasa de interés del banco (i), la tasa del costo de oportunidad (COK), y la tasa del impuesto a la renta (IR).

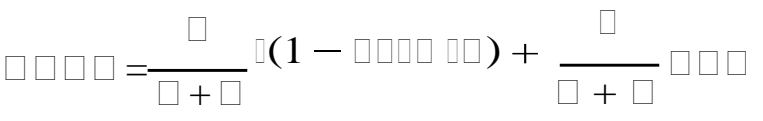

Tabla 58.

Costo de Capital Promedio Ponderado.

\begin{tabular}{lllll}
\hline Fuentes & Inversión & Financiamiento (\%) & TASA (\%) & WACC (\%) \\
\hline Capital propio & $2,000,000$ & $68 \%$ & $9.91 \%$ & $6.74 \%$ \\
Banco Continental & 962,093 & $32 \%$ & $20.00 \%$ & $4.51 \%$ \\
\hline Total & $2,962,093$ & $100 \%$ & & $11.25 \%$ \\
\hline
\end{tabular}

Fuente: elaboración propia.

El costo de capital promedio ponderado (CCPP) es de $11.25 \%$ 


\subsection{Presupuestos de resultados}

\subsubsection{Estado de resultados proyectado}

El estado de resultado para el 2018 (ver Tabla 59) se tiene una inversión de S/173,926

Soles, pero para el 2019 presenta ganancias de S/ 176,220 Soles y estas ganancias continúan en crecimiento hasta el 2028 cuyo monto es de S/ 481,547 Soles. Esto debido a que el primer año es de implementación y la venta se inicia en el 2019.

\section{Tabla 59.}

Estado de resultados del 2018 al 2028.

\begin{tabular}{|c|c|c|c|c|c|c|c|c|c|c|c|}
\hline & 2018 & 2019 & 2020 & 2021 & 2022 & 2023 & 2024 & 2025 & 2026 & 2027 & 2028 \\
\hline Ventas & 0 & $2,468,5342$ & $2,542,590$ & $2,618,8682$ & $2,697,4342$ & $2,778,357 \quad 2$ & $2,861,708$ & $2,947,559 \quad 3$ & $3,035,9863$ & $3,127,066 \quad 3$ & $3,220,878$ \\
\hline (Costo de ventas) & 0 & $1,455,428$ & $1,499,090$ & $1,544,063 \quad 1$ & $1,590,385 \quad 1$ & $1,655,005 \quad 1$ & $1,704,655 \quad 1$ & $1,755,794$ & $1,808,468 \quad 1$ & $1,880,566$ & $1,936,983$ \\
\hline Utilidad Bruta & 0 & $1,013,107$ & $1,043,500$ & $1,074,805$ & $1,107,049$ & $1,123,353$ & $1,157,053$ & $1,191,765$ & $1,227,518$ & $1,246,500$ & $1,283,895$ \\
\hline (Gastos Operativos) & 0 & 506,000 & 506,000 & 506,000 & 506,000 & 506,000 & 506,000 & 506,000 & 506,000 & 506,000 & 506,000 \\
\hline (Depreciación) & 0 & 94,849 & 94,849 & 94,849 & 94,849 & 94,849 & 94,849 & 94,849 & 94,849 & 94,849 & 94,849 \\
\hline (Amortización) & 0 & 12,416 & 12,416 & 12,416 & 12,416 & 12,416 & 0 & 0 & 0 & 0 & 0 \\
\hline Utilidad Operativa & 0 & 399,842 & 430,235 & 461,540 & 493,784 & 510,088 & 556,205 & 590,916 & 626,669 & 645,651 & 683,046 \\
\hline (Gastos Financieros) & 173,926 & 149,884 & 116,746 & 76,984 & 29,276 & 0 & 0 & 0 & 0 & 0 & 0 \\
\hline Utilidad antes de impuestos & $-173,926$ & 249,958 & 313,489 & 384,556 & 464,508 & 510,088 & 556,205 & 590,916 & 626,669 & 645,651 & 683,046 \\
\hline (Impuesto $29.5 \%$ ) & 0 & $73,738^{\top}$ & $92,479^{r}$ & $113,444^{\top}$ & $137,030^{\top}$ & $150,476^{\top}$ & $164,080^{\prime}$ & $174,320^{\circ}$ & 184,867 & 190,467 & 201,499 \\
\hline Utilidad Neta & $-173,926$ & 176,220 & 221,010 & 271,112 & 327,478 & 359,612 & 392,124 & 416,596 & 441,802 & 455,184 & 481,547 \\
\hline
\end{tabular}

Fuente: Elaboración propia.

\subsubsection{Estado de situación financiera proyectado}

El estado de situación financiera proyectado para el 2018 muestra la compra de terreno y maquinaria, la conformación del patrimonio y el ingreso de activo corriente debido al préstamo bancario (Ver Tabla 60). El estado de situación financiera proyectado para el 2019 registra las ventas del primer año, pago a proveedores y otras cuentas, amortización de intangibles, depreciación de maquinarias y equipos e impuestos que se van a pagar en el 2020 (Ver Tabla 61). 
Tabla 60.

Estado de situación financiera proyectado al 2018.

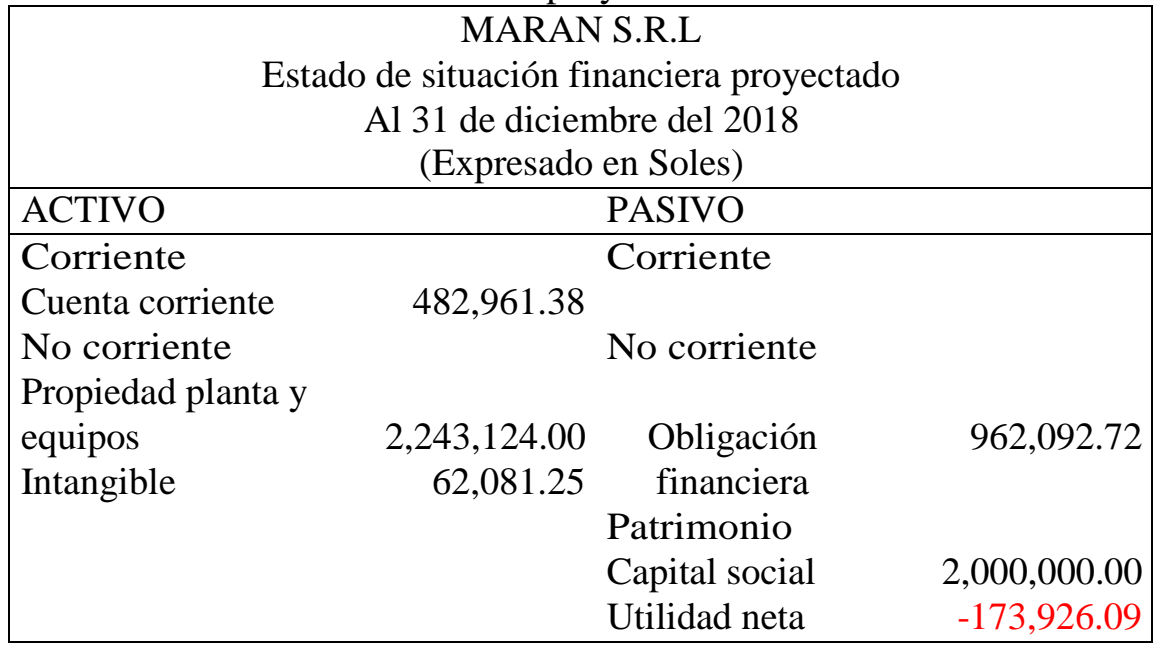

Fuente: Elaboración propia.

Tabla 61.

Estado de situación financiera proyectado al 2019.

\begin{tabular}{|c|c|c|}
\hline & $\begin{array}{l}\text { MARAN S.R.L } \\
\text { stado de situación financiera proyectado } \\
\text { Al } 31 \text { de diciembre del } 2019 \\
\text { (Expresado en Soles) }\end{array}$ & \\
\hline ACTIVO & PASIVO & \\
\hline Corriente & Corriente & \\
\hline Cuenta corriente & 2,801,611.86 Proveedores & $1,499,090.325$ \\
\hline Existencias & $\begin{array}{c}\text { 43,662.82 Otras cuentas por pagar } \\
\text { Impuesto por pagar }\end{array}$ & $\begin{array}{r}506,000.00 \\
73,737.60\end{array}$ \\
\hline No corriente & No corriente & \\
\hline $\begin{array}{l}\text { Propiedad planta y } \\
\text { equipos } \\
\text { Depreciación } \\
\text { Intangible }\end{array}$ & $\begin{array}{l}\text { 2,243,124.00 Obligación financiera } \\
-94,848.75 \\
\text { 62,081.25 Patrimonio }\end{array}$ & $962,092.72$ \\
\hline Amortización & $\begin{array}{l}\text {-12,416.25 Capital social } \\
\text { Resultados acumulados } \\
\text { Utilidad neta }\end{array}$ & $\begin{array}{r}2,000,000.00 \\
-173,926.09 \\
176,220.38\end{array}$ \\
\hline
\end{tabular}

Fuente: Elaboración propia.

11.5. Flujo de caja proyectado

11.5.1. Flujo de caja económico

El flujo de caja del proyecto (ver Tabla 62) presenta una inversión de S/2,962,093 Soles para el 2018, a partir del 2019 al 2028 presenta un flujo positivo. 
Tabla 62.

Flujo de caja económico del 2018 al 2028.

\begin{tabular}{|c|c|c|c|c|c|c|c|c|c|c|c|}
\hline & 2018 & 2019 & 2020 & 2021 & 2022 & 2023 & 2024 & 2025 & 2026 & 2027 & 2028 \\
\hline Ingresos por Ventas & & $2,253,731$ & $2,321,343$ & $2,390,984$ & $2,462,713$ & $2,536,595$ & $2,612,692$ & $2,691,073$ & $2,771,805$ & $2,854,960$ & $2,940,608$ \\
\hline Otras ventas & & 214,803 & 221,247 & 227,884 & 234,721 & 241,763 & 249,015 & 256,486 & 264,181 & 272,106 & 280,269 \\
\hline Ingresos Totales & & $2,468,534$ & $2,542,590$ & $2,618,868$ & $2,697,434$ & $2,778,357$ & $2,861,708$ & $2,947,559$ & $3,035,986$ & $3,127,066$ & $3,220,878$ \\
\hline Costos variables & & $1,455,428$ & $1,499,090$ & $1,544,063$ & $1,590,385$ & $1,655,005$ & $1,704,655$ & $1,755,794$ & $1,808,468$ & $1,880,566$ & $1,936,983$ \\
\hline Costos fijos & & 506,000 & 506,000 & 506,000 & 506,000 & 506,000 & 506,000 & 506,000 & 506,000 & 506,000 & 506,000 \\
\hline Depreciación & & 94,849 & 94,849 & 94,849 & 94,849 & 94,849 & 94,849 & 94,849 & 94,849 & 94,849 & 94,849 \\
\hline Amortización Intang. & & 12,416 & 12,416 & 12,416 & 12,416 & 12,416 & & & & & \\
\hline Egresos Totales & & $2,068,693$ & $2,112,356$ & $2,157,328$ & $2,203,650$ & $2,268,270$ & $2,305,504$ & $2,356,643$ & $2,409,317$ & $2,481,415$ & $2,537,832$ \\
\hline Utilidad antes Imp. & & 399,842 & 430,235 & 461,540 & 493,784 & 510,087 & 556,204 & 590,916 & 626,669 & 645,651 & 683,046 \\
\hline Impuestos & & 117,953 & 126,919 & 136,154 & 145,666 & 150,476 & 164,080 & 174,320 & 184,867 & 190,467 & 201,498 \\
\hline Utilidad neta & & 281,888 & 303,316 & 325,386 & 348,118 & 359,612 & 392,124 & 416,596 & 441,802 & 455,184 & 481,547 \\
\hline Depreciación & & 94,849 & 94,849 & 94,849 & 94,849 & 94,849 & 94,849 & 94,849 & 94,849 & 94,849 & 94,849 \\
\hline Amortización Intang. & & 12,416 & 12,416 & 12,416 & 12,416 & 12,416 & & & & & \\
\hline Inversión inicial & $2,428,414$ & & & & & & & & & & \\
\hline Inversión de reemplazo & & 0 & 0 & 0 & 0 & 11,052 & 0 & 0 & 0 & 0 & 722,820 \\
\hline Inversión capital trabajo & 533,679 & 16,010 & 16,491 & 16,985 & 23,695 & 18,206 & 18,752 & 19,315 & 26,437 & 20,687 & \\
\hline Valor residual & & & & & & & & & & & $4,278,873$ \\
\hline Flujo de Caja & $-2,962,093$ & 373,143 & 394,090 & 415,665 & 431,688 & 437,619 & 468,221 & 492,130 & 510,213 & 529,345 & $4,132,449$ \\
\hline
\end{tabular}

Fuente: elaboración propia.

El flujo de caja mensual del proyecto para el año 2019 y 2020 se presentan en la Tabla 63

y Tabla 64.

Tabla 63.

Flujo de caja económico mensual para el año 2019.

\begin{tabular}{|c|c|c|c|c|c|c|c|c|c|c|c|c|}
\hline & Ene-19 & Feb-19 & Mar-19 & Abr-19 & May-19 & Jun-19 & Jul-19 & Ago-19 & Set-19 & Oct-19 & Nov-19 & Dic-19 \\
\hline Ingresos por Ventas & 187,811 & 187,811 & 187,811 & 187,811 & 187,811 & 187,811 & 187,811 & 187,811 & 187,811 & 187,811 & 187,811 & 187,811 \\
\hline Otras ventas & 17,900 & 17,900 & 17,900 & 17,900 & 17,900 & 17,900 & 17,900 & 17,900 & 17,900 & 17,900 & 17,900 & 17,900 \\
\hline Ingresos Totales & 205,711 & 205,711 & 205,711 & 205,711 & 205,711 & 205,711 & 205,711 & 205,711 & 205,711 & 205,711 & 205,711 & 205,711 \\
\hline Costos variables & 121,286 & 121,286 & 121,286 & 121,286 & 121,286 & 121,286 & 121,286 & 121,286 & 121,286 & 121,286 & 121,286 & 121,286 \\
\hline Costos fijos & 42,167 & 42,167 & 42,167 & 42,167 & 42,167 & 42,167 & 42,167 & 42,167 & 42,167 & 42,167 & 42,167 & 42,167 \\
\hline Depreciación & 7,904 & 7,904 & 7,904 & 7,904 & 7,904 & 7,904 & 7,904 & 7,904 & 7,904 & 7,904 & 7,904 & 7,904 \\
\hline Amortización Intang. & 1,035 & 1,035 & 1,035 & 1,035 & 1,035 & 1,035 & 1,035 & 1,035 & 1,035 & 1,035 & 1,035 & 1,035 \\
\hline Egresos Totales & 14,366 & 14,366 & 14,366 & 14,366 & 14,366 & 14,366 & 14,366 & 14,366 & 14,366 & 14,366 & 14,366 & 14,366 \\
\hline Utilidad antes Imp. & 33,320 & 33,320 & 33,320 & 33,320 & 33,320 & 33,320 & 33,320 & 33,320 & 33,320 & 33,320 & 33,320 & 33,320 \\
\hline Impuestos & 9,829 & 9,829 & 9,829 & 9,829 & 9,829 & 9,829 & 9,829 & 9,829 & 9,829 & 9,829 & 9,829 & 9,829 \\
\hline Utilidad neta & 23,491 & 23,491 & 23,491 & 23,491 & 23,491 & 23,491 & 23,491 & 23,491 & 23,491 & 23,491 & 23,491 & 23,491 \\
\hline Depreciación & 7,904 & 7,904 & 7,904 & 7,904 & 7,904 & 7,904 & 7,904 & 7,904 & 7,904 & 7,904 & 7,904 & 7,904 \\
\hline Amortización Intang. & 1,035 & 1,035 & 1,035 & 1,035 & 1,035 & 1,035 & 1,035 & 1,035 & 1,035 & 1,035 & 1,035 & 1,035 \\
\hline Inversión capital trabajo & 1,334 & 1,334 & 1,334 & 1,334 & 1,334 & 1,334 & 1,334 & 1,334 & 1,334 & 1,334 & 1,334 & 1,334 \\
\hline Flujo de Caja & 31,095 & 31,095 & 31,095 & 31,095 & 31,095 & 31,095 & 31,095 & 31,095 & 31,095 & 31,095 & 31,095 & 31,095 \\
\hline
\end{tabular}

Fuente: Elaboración propia 
Tabla 64.

Flujo de caja económico mensual para el año 2020.

\begin{tabular}{|c|c|c|c|c|c|c|c|c|c|c|c|c|}
\hline & Ene-19 & Feb-19 & Mar-19 & Abr-19 & May-19 & Jun-19 & Jul-19 & Ago-19 & Set-19 & Oct-19 & Nov-19 & Dic-19 \\
\hline Ingresos por Ventas & 193,445 & 193,445 & 193,445 & 193,445 & 193,445 & 193,445 & 193,445 & 193,445 & 193,445 & 193,445 & 193,445 & 193,445 \\
\hline Otras ventas & 18,437 & 18,437 & 18,437 & 18,437 & 18,437 & 18,437 & 18,437 & 18,437 & 18,437 & 18,437 & 18,437 & 18,437 \\
\hline Ingresos Totales & 211,883 & 211,883 & 211,883 & 211,883 & 211,883 & 211,883 & 211,883 & 211,883 & 211,883 & 211,883 & 211,883 & 211,883 \\
\hline Costos variables & 124,924 & 124,924 & 124,924 & 124,924 & 124,924 & 124,924 & 124,924 & 124,924 & 124,924 & 124,924 & 124,924 & 124,924 \\
\hline Costos fijos & 42,167 & 42,167 & 42,167 & 42,167 & 42,167 & 42,167 & 42,167 & 42,167 & 42,167 & 42,167 & 42,167 & 42,167 \\
\hline Depreciación & 7,904 & 7,904 & 7,904 & 7,904 & 7,904 & 7,904 & 7,904 & 7,904 & 7,904 & 7,904 & 7,904 & 7,904 \\
\hline Amortización Intang. & 1,035 & 1,035 & 1,035 & 1,035 & 1,035 & 1,035 & 1,035 & 1,035 & 1,035 & 1,035 & 1,035 & 1,035 \\
\hline Egresos Totales & 176,030 & 176,030 & 176,030 & 176,030 & 176,030 & 176,030 & 176,030 & 176,030 & 176,030 & 176,030 & 176,030 & 176,030 \\
\hline $\begin{array}{l}\text { Utilidad antes Imp. } \\
\text {. }\end{array}$ & 35,853 & 35,853 & 35,853 & 35,853 & 35,853 & 35,853 & 35,853 & 35,853 & 35,853 & 35,853 & 35,853 & 35,853 \\
\hline Impuestos & 10,577 & 10,577 & 10,577 & 10,577 & 10,577 & 10,577 & 10,577 & 10,577 & 10,577 & 10,577 & 10,577 & 10,577 \\
\hline Utilidad neta & 25,276 & 25,276 & 25,276 & 25,276 & 25,276 & 25,276 & 25,276 & 25,276 & 25,276 & 25,276 & 25,276 & 25,276 \\
\hline Depreciación & 7,904 & 7,904 & 7,904 & 7,904 & 7,904 & 7,904 & 7,904 & 7,904 & 7,904 & 7,904 & 7,904 & 7,904 \\
\hline Amortización Intang. & 1,035 & 1,035 & 1,035 & 1,035 & 1,035 & 1,035 & 1,035 & 1,035 & 1,035 & 1,035 & 1,035 & 1,035 \\
\hline Inversión capital trabajo & 1,374 & 1,374 & 1,374 & 1,374 & 1,374 & 1,374 & 1,374 & 1,374 & 1,374 & 1,374 & 1,374 & 1,374 \\
\hline Flujo de Caja & 32,841 & 32,841 & 32,841 & 32,841 & 32,841 & 32,841 & 32,841 & 32,841 & 32,841 & 32,841 & 32,841 & 32,841 \\
\hline
\end{tabular}

Fuente: Elaboración propia

\subsubsection{Flujo de caja financiero}

El flujo de caja financiero (ver Tabla 65) presenta una inversión de S/2,246,163 Soles para

el 2018, a partir del 2019 al 2028 presenta un flujo positivo.

Tabla 65.

Flujo de caja financiero del 2018 al 2028.

\begin{tabular}{|c|c|c|c|c|c|c|c|c|c|c|c|}
\hline & 2018 & 2019 & 2020 & 2021 & 2022 & 2023 & 2024 & 2025 & 2026 & 2027 & 2028 \\
\hline Ingresos por Ventas & & $2,253,731$ & $2,321,343$ & $2,390,984$ & $2,462,713$ & $2,536,595$ & $2,612,692$ & $2,691,073$ & $2,771,805$ & $2,854,960$ & $2,940,608$ \\
\hline Otras ventas & & 214,803 & 221,247 & 227,884 & 234,721 & 241,763 & 249,015 & 256,486 & 264,181 & 272,106 & 280,269 \\
\hline Ingresos Totales & & $2,468,534$ & $2,542,590$ & $2,618,868$ & $2,697,434$ & $2,778,357$ & $2,861,708$ & $2,947,559$ & $3,035,986$ & $3,127,066$ & $3,220,878$ \\
\hline Costos variables & & $1,455,428$ & $1,499,090$ & $1,544,063$ & $1,590,385$ & $1,655,005$ & $1,704,655$ & $1,755,794$ & $1,808,468$ & $1,880,566$ & $1,936,983$ \\
\hline Costos fijos & & 506,000 & 506,000 & 506,000 & 506,000 & 506,000 & 506,000 & 506,000 & 506,000 & 506,000 & 506,000 \\
\hline Interés del prétamo & 173,926 & 149,884 & 116,746 & 76,984 & 29,276 & 0 & 0 & 0 & 0 & 0 & 0 \\
\hline Depreciación & & 94,849 & 94,849 & 94,849 & 94,849 & 94,849 & 94,849 & 94,849 & 94,849 & 94,849 & 94,849 \\
\hline Amortización Intang. & & 12,416 & 12,416 & 12,416 & 12,416 & 12,416 & & & & & \\
\hline Egresos Totales & 173,926 & $2,218,577$ & $2,229,101$ & $2,234,313$ & $2,232,926$ & $2,268,270$ & $2,305,504$ & $2,356,643$ & $2,409,317$ & $2,481,415$ & $2,537,832$ \\
\hline $\begin{array}{l}\text { Utilidad antes Imp. } \\
\text {. }\end{array}$ & $-173,926$ & 249,958 & 313,489 & 384,556 & 464,508 & 510,087 & 556,204 & 590,916 & 626,669 & 645,651 & 683,046 \\
\hline Impuestos & & 73,738 & 92,479 & 113,444 & 137,030 & 150,476 & 164,080 & 174,320 & 184,867 & 190,467 & 201,498 \\
\hline $\begin{array}{l}\text { Utilidad neta } \\
\end{array}$ & $-173,926$ & 176,220 & 221,010 & 271,112 & 327,478 & 359,612 & 392,124 & 416,596 & 441,802 & 455,184 & 481,547 \\
\hline Depreciación & & 94,849 & 94,849 & 94,849 & 94,849 & 94,849 & 94,849 & 94,849 & 94,849 & 94,849 & 94,849 \\
\hline Amortización Intang. & & 12,416 & 12,416 & 12,416 & 12,416 & 12,416 & 0 & 0 & 0 & 0 & 0 \\
\hline Inversión inicial & $2,428,414$ & & & & & & & & & & \\
\hline Inversión de reemplazo & & 0 & 0 & 0 & 0 & 11,052 & 0 & 0 & 0 & 0 & 722,820 \\
\hline Inversión capital trabajo & 533,679 & & & & & & & & & & \\
\hline Préstamo & 962,093 & & & & & & & & & & \\
\hline Amortización de deuda & 72,237 & 165,802 & 198,941 & 238,702 & 286,410 & & & & & & \\
\hline Valor residual & & & & & & & & & & & $4,278,873$ \\
\hline Flujo de Caja & $-2,246,163$ & 117,683 & 129,334 & 139,675 & 148,333 & 455,824 & 486,973 & 511,444 & 536,650 & 550,033 & $4,132,449$ \\
\hline
\end{tabular}

Fuente: elaboración propia.

La evaluación del tiempo de recuperación se realizó mediante dos métodos, el método de

tiempo de recuperación simple o contable y descontado. Para la evaluación del tiempo de

recuperación simple se tomó el flujo de caja económico de la tabla 62 y se calculó el

acumulado (ver Tabla 66), aplicando la fórmula de tiempo de recuperación se determinó un

tiempo de 6 años con 10 meses. 


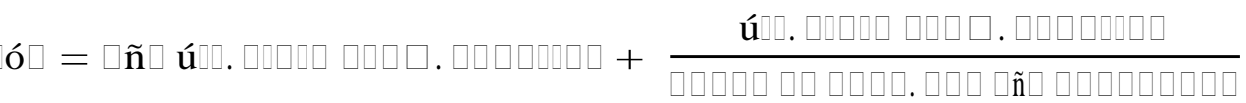

Tabla 66.

Flujo de caja económico y acumulado proyectado a diez años.

\begin{tabular}{rrr} 
Año & $\begin{array}{c}\text { Flujo de caja } \\
\text { económico }\end{array}$ & \multicolumn{1}{l}{ Acumulado } \\
\hline 0 & $-2,962,093$ & -2962092.718 \\
1 & 373143.021 & -2588949.697 \\
2 & 394089.922 & -2194859.775 \\
3 & 415665.229 & -1779194.546 \\
4 & 431687.913 & -1347506.633 \\
5 & 437618.555 & -909888.0775 \\
6 & 468220.797 & -441667.2803 \\
7 & 492129.915 & 50462.6347 \\
8 & 510213.359 & 560675.9934 \\
9 & 529345.421 & 1090021.414 \\
10 & $4,132,449$ & $5,222,471$ \\
\hline
\end{tabular}

Fuente: elaboración propia.

Para la evaluación del tiempo de recuperación descontado se tomó el flujo de caja económico de la tabla 62, se calculó el valor presente o descuento utilizando el wacc (11.25\%) como tasa de actualización, y se calculó el acumulado (ver Tabla 67). Utilizando la fórmula de recuperación se determinó el tiempo de recuperación para el proyecto de 9 años con 4 meses.

Tabla 67.

Flujo de caja económico, descuento y acumulado proyectado a diez años Flujo de caja

\begin{tabular}{rrrr} 
Año & económico & Descuento & Acumulado \\
\hline 0 & -2962093 & -2962093 & -2962093 \\
1 & 373143 & 335397 & -2626696 \\
2 & 394090 & 318393 & -2308302 \\
3 & 415665 & 301853 & -2006449 \\
4 & 431688 & 281778 & -1724672 \\
5 & 437619 & 256753 & -1467918 \\
6 & 468221 & 246919 & -1220999 \\
7 & 492130 & 233275 & -987724 \\
8 & 510213 & 217383 & -770341 \\
9 & 529345 & 202720 & -567621 \\
10 & 4786718 & 1647703 & 1080082 \\
\hline
\end{tabular}

Fuente: elaboración propia. 


\section{Capítulo XII. Evaluación económica financiera}

\subsection{Evaluación financiera}

\subsubsection{TIR}

Producto de la evaluación del flujo de caja económico y financiero se obtuvo los valores para la Tasa interna de retorno económico (TIRE): $15.77 \%$ y la Tasa interna de retorno financiero (TIRF): 15.76\%. El TIRE es mayor al costo de capital promedio ponderado de $11.25 \%$ y el TIRF es mayor al costo de oportunidad del inversionista de $9.91 \%$. Esto demuestra que el proyecto es recomendable de ejecución.

\subsubsection{VAN}

El Valor actual neto económico es de S/ 854,867 Soles y el Valor actual neto financiero es de S/ 1,091,381, ambos cumplen el requisito de ser mayor a cero. El proyecto es rentable.

\subsection{3. $\mathrm{ROE}$}

Se evaluó la rentabilidad del patrimonio del 2019 al 2028, el proyecto cuenta con capacidad para generar utilidades netas a partir de los recursos de la empresa desde el 2020 al 2028 (ver Tabla 68). El valor que debería tener una empresa como mínimo para efectos del ROE es del $10 \%$.

Tabla 68.

Determinación del ROE en los diez años proyectados.

\begin{tabular}{rrrrrrrrrrr}
\hline & 2019 & 2020 & 2021 & 2022 & 2023 & 2024 & 2025 & 2026 & 2027 & 2028 \\
\hline ROE & $9 \%$ & $11 \%$ & $13 \%$ & $16 \%$ & $18 \%$ & $19 \%$ & $21 \%$ & $22 \%$ & $23 \%$ & $24 \%$ \\
\hline
\end{tabular}

Fuente: elaboración propia

\subsubsection{Ratios}

Para este estudio se ha considerado como principales ratios de evaluación la liquidez corriente, prueba ácida, margen operativo y margen neto (Ver Tabla 69). 
Tabla 69.

Evaluación económica financiera de ratios.

\begin{tabular}{ccc}
\hline Ratios & Fórmula & Resultados \\
\hline \multirow{2}{*}{ Liquidez corriente } & Activo corriente & 1.37 \\
\cline { 2 - 3 } & $\begin{array}{c}\text { Pasivo corriente } \\
\text { Pctivo corriente - Existencias } \\
\text { Prueba ácida }\end{array}$ & \multirow{2}{*}{1.33} \\
\hline Pasivo corriente & \multirow{2}{*}{ Utilidad operativa } \\
\hline Margen operativo & Ventas & $7 \%$ \\
\hline Margen neto & Utilidad neta & \\
\cline { 2 - 3 } & Ventas & \\
\hline
\end{tabular}

Fuente: elaboración propia.

En cuanto a la liquidez corriente, la empresa dispone de S/1.37 Soles de activo corriente para pagar S/1.0 Sol de obligaciones a corto plazo, con lo que se demuestra que tiene cierta capacidad para cumplir con los pagos. Para mejorar este indicador, se debe incrementar el activo corriente para no tener problema en atender las obligaciones a corto plazo,

La prueba ácida nos indica que la empresa dispone de S/1.33 Soles de activo líquido para pagar cada S/1.0 Sol de obligaciones a corto plazo. Se encuentra en un nivel esperado.

La empresa genera utilidad operativa y utilidad neta en base a las ventas totales. El margen operativo resulta ser aceptable mientras que, el margen neto está en un nivel de precaución.

12.2. Análisis de riesgo

12.2.1. Análisis de punto de equilibrio

Para hallar el punto de equilibrio se utilizaron dos métodos, el primero fue el método para mezclas de productos, en vista que se tienen dos presentaciones (caja x 24 unidades y bolsas x 6 unidades). En la Tabla 70 se presentan los resultados.

Donde q equilibrio (x): punto de equilibrio de la mezcla de productos.

MCUx: margen de contribución unitario de la mezcla de productos. 
El MCUx se obtiene de ponderar los márgenes de contribución unitario de cada presentación por su razón de ventas.

$$
\square \square \square \square=\square \square \square 1 \times \square \square 1+\square \square \square 2 \times \square \square 2
$$

Tabla 70.

Cálculo del punto de equilibrio para dos presentaciones de chocolate.

Presentación

Caja x 24 unid. Bolsa x 6 unid.

\begin{tabular}{llll}
\hline Precio venta & PV & 45.76 & 11.80 \\
Costo de venta unitario & CVU & 30.00 & 7.50 \\
Margen de contribución unitario & MCU & 15.76 & 4.30 \\
Ventas en unidades (año 1) & & 25,098 & 93,665 \\
$\mathrm{~N}^{\circ}$ unid totales (año 1) & & 118,763 & \\
Razón de ventas & RV & 0.21 & 0.79 \\
Costo Fijo (año 1) & $\mathrm{CF}$ & 600,849 & \\
Margen de contribución unitario & & & \\
de la mezcla & MCU x & 6.72 & \\
Punto de equilibrio de la mezcla & q equilibrio x & 89,388 & \\
Punto de equilibrio & & 18,890 & 70,498 \\
\hline
\end{tabular}

Fuente: Elaboración propia

Resultó el margen de contribución de la mezcla en 6.72. Por lo que el punto de equilibrio es 89,388 unidades. Finalmente se obtuvo el punto de equilibrio para cada presentación. Para la caja x 24 son 18,890 unidades y para las bolsas x 6 son 70,498 unidades.

El otro método utilizado fue el de margen de contribución, para lo cual se determinó que el costo unitario de una tableta de $30 \mathrm{~g}$ es de S/.1.25 Soles, el precio por $\mathrm{kg}$ de chocolate es de S/.64 Soles, el costo fijo del año 2 es de S/. 506,000, el total de ingresos por ventas para el año 2 es de S/.2,253,731 Soles, el total de egresos para el año 2 es de S/.1,961,428 Soles, los resultados se presentan en la tabla 71. 
Tabla 71.

Cálculo del punto de equilibrio por kilo de chocolate.

\begin{tabular}{|c|c|c|}
\hline Cálculo & Fórmula & Resultados \\
\hline Relación & 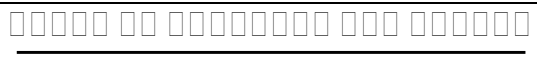 & 1.15 \\
\hline & 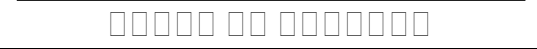 & \\
\hline $\begin{array}{l}\text { Valor del punto de } \\
\text { equilibrio }(\mathrm{S} / .)\end{array}$ & 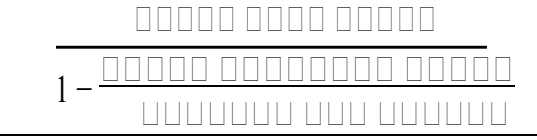 & $1,445,714$ \\
\hline $\begin{array}{l}\text { Cantidad del punto de } \\
\text { equilibrio }(\mathrm{kg})\end{array}$ & 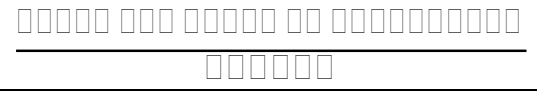 & 22,589 \\
\hline
\end{tabular}

Fuente: elaboración propia.

\subsubsection{Análisis de sensibilidad}

Se realizó un análisis bidimensional ya que se tienen dos presentaciones que se venderán al mercado (tiendas especializadas, bodegas y supermercados) para las combinaciones de precio de las dos presentaciones: caja con 24 unidades (precio unitario S/ 45.76) y bolsa con 6 unidades (precio unitario S/ 11.80). Se consideró una variación en el precio de S/ 5 hacia arriba y hacia abajo para la presentación de 24 unidades y de S/ 2 para la presentación de 6 unidades.

En la Tabla 72 se presenta el análisis de sensibilidad, con un VANE S/ 854,867 Soles.

Tabla 72.

Análisis de Sensibilidad de Precios

\begin{tabular}{|c|c|c|c|c|c|c|c|c|c|}
\hline & & \multirow{3}{*}{$\begin{array}{c}\text { VANE } \\
854,867\end{array}$} & \multicolumn{7}{|c|}{ Precio caja x 24 unid } \\
\hline & & & \multicolumn{3}{|c|}{ Precio disminuye en $\mathrm{S} / 1$} & \multirow{2}{*}{$\begin{array}{c}\text { P.actual } \\
45.76\end{array}$} & \multicolumn{3}{|c|}{ Precio aumenta en S/ 1} \\
\hline & & & 30.76 & 35.76 & 40.76 & & 50.76 & 55.76 & 60.76 \\
\hline \multirow{7}{*}{$\begin{array}{r}\text { Bolsa x } \\
6 \text { unid }\end{array}$} & Precio & 5.80 & $-5,498,383$ & $-4,648,832$ & $-3,799,282$ & $-2,949,731$ & \multicolumn{3}{|c|}{$-2,100,180-1,250,630-401,079$} \\
\hline & disminuye & 7.80 & $-4,230,184$ & $-3,380,633$ & $-2,531,082$ & $-1,681,532$ & $-831,981$ & 17,570 & 867,120 \\
\hline & & 9.80 & $-2,961,985$ & $-2,112,434$ & $-1,262,883$ & $-413,332$ & 436,218 & $1,285,769$ & $2,135,320$ \\
\hline & P.actual & 11.80 & $-1,693,785$ & $-844,235$ & 5,316 & 854,867 & \multicolumn{3}{|c|}{$1,704,4182,553,9683,403,519$} \\
\hline & Precio & 13.80 & $-425,586$ & \multirow{2}{*}{$\begin{array}{c}423,965 \\
1,692,164\end{array}$} & \multicolumn{5}{|c|}{$1,273,5152,123,0662,972,6173,822,1684,671,718$} \\
\hline & aumenta en & 15.80 & 842,613 & & $2,541,7153,3$ & $91,2654,240$, & \multicolumn{3}{|c|}{$165,090,3675,939,918$} \\
\hline & $\mathrm{S} / 1$ & 17.80 & \multicolumn{7}{|c|}{$2,110,8132,960,3633,809,9144,659,4655,509,0156,358,5667,208,117$} \\
\hline
\end{tabular}

Fuente: elaboración propia.

Se concluye que, se puede incrementar el precio de la presentación de caja x 24 unidades hasta S/ 60.76 y bajar el precio hasta S/ 7.80 para la bolsa x 6 unidades. Por otro lado, se podría bajar el precio de la caja x 24 unidades hasta S/ 30.76 y bajando el precio hasta S/ 
15.80 de la bolsa x 6 unidades. En ambos casos con VAN positivo. En la tabla, la parte sombreada es donde podrían fluctuar los precios.

\subsubsection{Análisis de escenarios}

Para el análisis de escenarios se eligieron dos variables: Ingreso Total y Egreso Total. Para el año 2 (2019) el Ingreso Total es de S/. 2,468,534 y los Egresos Totales S/ 2,068,693. En un escenario optimista se consideró un incremento del ingreso en un 40\% y reducción de los egresos también del 40\%. En el escenario pesimista también se tomó la variación en un 40\%. Siendo el componente principal del Ingreso la variable precio y para los Egresos el componente principal es el costo variable. Sin embargo, se tomaron las variables Ingreso y Egreso, puesto que este plan de negocios tiene dos precios de venta unitario y una estructura de costos variables por cada presentación. Se realizó la corrida utilizando la herramienta de Excel, considerando las variables económicas VANE (S/ 854,867) y TIRE (15.77\%) y se obtuvo el siguiente resumen mostrado en la Tabla 73.

Tabla 73.

Resumen de escenarios.

\begin{tabular}{lrrr}
\hline & $\begin{array}{c}\text { Valores } \\
\text { actuales: }\end{array}$ & Optimista & Pesimista \\
\hline Ingreso total año 1 & $2,468,534$ & $3,455,948$ & $1,481,121$ \\
Egreso total año 1 & $2,068,693$ & $1,241,216$ & $2,896,170$ \\
VANE & 854,867 & $2,004,935$ & $-295,202$ \\
TIRE & $15.77 \%$ & $24.68 \%$ & $9.96 \%$ \\
\hline
\end{tabular}

Fuente: Elaboración propia

Se concluye que para el escenario optimista el VANE es positivo y el TIRE mayor al costo de oportunidad del proyecto $(9.91 \%)$ pero para el escenario pesimista el VANE es negativo y el TIRE es ligeramente mayor al costo de oportunidad del proyecto.

12.2.4. Análisis y evaluación de riesgos financieros

Para poder controlar, mitigar o eliminar los riesgos financieros a los que podría estar expuesto el proyecto, se ha establecido la siguiente metodología.

- Riesgo: Es la posibilidad de ocurrencia de eventos que impacten negativamente 
sobre los objetivos de la empresa. Se mide en términos de probabilidad e impacto

- Exposición al riesgo: Nivel de probabilidad de ocurrencia de un evento negativo y el impacto resultante del mismo al momento de materializarse

- Probabilidad: Es la posibilidad de ocurrencia de un evento, en un período de tiempo dado (Ver Tabla 74).

- Impacto: Consecuencia o consecuencias de un evento, expresado en términos cualitativos y/o cuantitativos. Mayormente se expresa en términos monetarios, como pérdidas financieras. La organización ha determinado que una pérdida del $8 \%$ anual de la Utilidad Neta sería un nivel muy alto, y en ese sentido es que se definen los niveles descritos en la Tabla 75 .

Tabla 74.

Niveles de probabilidad de ocurrencia.

\begin{tabular}{lcc}
\hline & Nivel & Descripción \\
\hline 1 & Muy Bajo & $<=15 \%$ de las veces en un año \\
\hline 2 & Bajo & $<=30 \%$ de las veces en un año \\
\hline 3 & Medio & $<=50 \%$ de las veces en un año \\
\hline 4 & Alto & $<=75 \%$ de las veces en un año \\
\hline 5 & Muy Alto & $100 \%$ de las veces en un año \\
\hline & Fuente: Elaboración propia
\end{tabular}

Tabla 75.

Niveles de impacto.

\begin{tabular}{lc|c}
\hline & Nivel & Descripción \\
\hline 1 & Muy Bajo & Pérdida anual hasta S/ 2,000 \\
\hline 2 & Bajo & Pérdida anual hasta S/ 3,000 \\
\hline 3 & Medio & Pérdida anual hasta S/ 5,000 \\
\hline 4 & Alto & Pérdida anual hasta S/ 10,000 \\
\hline 5 & Muy Alto & Pérdidas de S/ 20,000 a más \\
\hline
\end{tabular}

Fuente: Elaboración propia

- Nivel de riesgo: Para definir los niveles de riesgo se han considerado 5 niveles:

Muy Bajo, Bajo, Medio, Alto y Muy Alto. Se utiliza un mapa de calor (ver Tabla

76). Se calcula el nivel de riesgo multiplicando la Probabilidad por el Impacto. 
Tabla 76.

Mapa de calor.

\begin{tabular}{|c|c|c|c|c|c|c|c|}
\hline \multirow{5}{*}{$\begin{array}{c}\text { Probabilidad } \\
\text { (que el riesgo } \\
\text { se materialice } \\
\text { en unaño) }\end{array}$} & Muy Alto & $100 \%$ & 2 & 3 & 5 & 10 & 20 \\
\hline & Alto & $75 \%$ & 1.5 & 2.25 & 3.75 & 7.5 & 15 \\
\hline & Medio & $50 \%$ & 1 & 1.5 & 2.5 & 5 & 10 \\
\hline & Bajo & $30 \%$ & 0.6 & 0.9 & 1.5 & 3 & 6 \\
\hline & Muy Bajo & $15 \%$ & 0.3 & 0.45 & 0.75 & 1.5 & 3 \\
\hline & & & 2 & 3 & 5 & 10 & 20 \\
\hline & & & \multicolumn{5}{|c|}{$\begin{array}{l}\text { Impacto (Monto de pérdida proyectado en el año por la } \\
\text { ocurrencia del riesgo (miles de soles) }\end{array}$} \\
\hline
\end{tabular}

Fuente: Elaboración propia

La empresa define un apetito al riesgo de S/ 2,500 al año, es decir, se tratarán los riesgos

con calificación Media, definiendo los controles apropiados, como consta en la Tabla 77.

Tabla 77.

Matriz de riesgos financieros.

\begin{tabular}{|c|c|c|c|c|c|c|c|c|}
\hline Descripción del riesgo C & Causa (debido a) & $\begin{array}{l}\text { Detalle de } \\
\text { probabilida p }\end{array}$ & $\begin{array}{l}\text { Nivel de } \\
\text { grobabilida }\end{array}$ & Detalle del & Nivel de & \multicolumn{2}{|c|}{ Nivel de riesgo } & Controles \\
\hline Devaluación de activos de & $\begin{array}{l}\text { Caída de precios de } \\
\text { commodities }\end{array}$ & & & Pérdida & & & & \\
\hline la cartera nronia & $\begin{array}{c}\text { Aumento de la tasa } \\
\text { de interés del } \\
\text { mercado }\end{array}$ & $\begin{array}{l}\text { a las veces en } \\
\text { un año }\end{array}$ & Muy Bajo & $\begin{array}{c}\text { anual hasta } \\
\text { S/ 5,000 }\end{array}$ & Medio & 750 & Muy bajo & No se trata \\
\hline $\begin{array}{l}\text { Variación tipo de cambio, } \\
\text { afectando precio de } \\
\text { compra de los insumos } \\
\text { importados }\end{array}$ & $\begin{array}{l}\text { Inestabilidad } \\
\text { económica }\end{array}$ & $\begin{array}{l}<=50 \% \text { de } \\
\text { las veces en } \\
\text { un año }\end{array}$ & Medio & $\begin{array}{c}\text { Pérdida } \\
\text { anual hasta } \\
\text { S/ } 5,000\end{array}$ & M & 2,500 & Bajo & No se trata \\
\hline $\begin{array}{l}\text { Impago por parte de los } \\
\text { clientes (morosidad) }\end{array}$ & $\begin{array}{l}\text { Mala gestión de la } \\
\text { cobranza }\end{array}$ & un año & Bajo & $\begin{array}{c}\text { Pérdida } \\
\text { anual hasta } \\
\text { S/ } 10,000 \\
\end{array}$ & Alto & 3,000 & ivieuio & $\begin{array}{c}\text { Calendarizar los pagos del año } \\
\text { y generar alertas }\end{array}$ \\
\hline $\begin{array}{c}\text { Incremento de los gastos } \\
\text { operativos (requerir más } \\
\text { personal) }\end{array}$ & $\begin{array}{c}\text { Aumento de la } \\
\text { demanda del } \\
\text { mercado }\end{array}$ & $\begin{array}{l}<=30 \% \text { de } \\
\text { las veces en } \\
\text { un año }\end{array}$ & Bajo & $\begin{array}{l}\text { Pérdidas de } \\
\text { S/ 20,000 a } \\
\text { más }\end{array}$ & Muy alto & 6,000 & Alto & $\begin{array}{l}\text { Contar con provisiones para } \\
\text { poder cubrir una planilla } \\
\text { adicional de trabajadores }\end{array}$ \\
\hline $\begin{array}{l}\text { No vender todo lo } \\
\text { proyectado }\end{array}$ & $\begin{array}{l}\text { Disminución de la } \\
\text { demanda }\end{array}$ & un año & Muy Bajo & $\begin{array}{l}\text { Pérdidas de } \\
\text { S/ 20,000 a } \\
\text { más }\end{array}$ & Alto & 3,000 & Medio & $\begin{array}{l}\text { Campañas promocionales y } \\
\text { ofertas. Convenios para lanzar } \\
\text { con otro producto en conjunto }\end{array}$ \\
\hline $\begin{array}{c}\text { Incumplimiento de } \\
\text { obligaciones con el banco }\end{array}$ & $\begin{array}{c}\text { Falta de liquidez, por } \\
\text { falta de pagos } \\
\text { clientes, incremento } \\
\text { de gastos) } \\
\end{array}$ & $\begin{array}{l}\mathrm{r}<=15 \% \text { de } \\
\text { las veces en } \\
\text { un año }\end{array}$ & Muy Bajo & $\begin{array}{c}\text { Pérdida } \\
\text { anual hasta } \\
\text { S/ } 10,000\end{array}$ & Alto & 1,500 & Muy bajo & No se trata \\
\hline Devaluación de la moneda & $\begin{array}{l}\text { Inestabilidad } \\
\text { ernnómica }\end{array}$ & $\begin{array}{l}\text { las veces en } \\
\text { un año }\end{array}$ & Muy Bajo & $\begin{array}{c}\text { Pérdida } \\
\text { anual hasta } \\
\text { S/ } 10,000 \\
\end{array}$ & Alto & 1,500 & Muy bajo & No se trata \\
\hline $\begin{array}{c}\text { Multas por } \\
\text { incumplimientos legales }\end{array}$ & $\begin{array}{l}\text { Incumplimiento de las } \\
\text { normativas laborales, li } \\
\text { tributarias, SSO }\end{array}$ & $\begin{array}{c}<=15 \% \text { de } \\
\text { las veces en } \\
\text { un año }\end{array}$ & Muy Bajo & $\begin{array}{l}\text { Pérdidas de } \\
\text { S/ 20,000 a } \\
\text { más }\end{array}$ & Alto & 3,000 & Medio & $\begin{array}{c}\text { Tener listado normativo de } \\
\text { todas las leyes aplicables, junto } \\
\text { con las multas por } \\
\text { incumplimiento, para } \\
\text { implementar lo que falte }\end{array}$ \\
\hline
\end{tabular}

Fuente: Elaboración propia 


\section{Conclusiones y recomendaciones}

Conclusiones

Para el presente estudio se tienen las siguientes conclusiones:

a) Se logró crear y desarrollar un producto saludable, el cual es una tableta de chocolate con $50 \%$ cacao con gomitas fortificadas con hierro, zinc y vitamina C cuyo nombre es Chocovit, según la encuesta realizada tiene alta aceptación comercial.

b) Del estudio cuantitativo se concluye que, el producto Chocovit, chocolate fortificado con hierro, vitamina $\mathrm{C}$ y zinc, tendría una aceptación del $80 \%$ y solo el $5 \%$ no estaría dispuesto a comprarlo. Existe un $15 \%$ que no sabe, y para efectos de este plan de negocios resulta retador poder captarlo.

c) Para la instalación de una fábrica de chocolates se va requerir una inversión de S/ 2,962,093 Soles, el primer año se va destinar para la compra del terreno, construcción de la fábrica, adquisición de maquinarias y equipos e implementación, a partir del segundo año se inicia la producción y venta de chocolates a nivel nacional.

d) Según la investigación cuantitativa el consumidor está dispuesto a pagar entre S/ 1.50 a S/2.00 por unidad, por lo que el producto se va vender a mayoristas en presentación de caja por 24 unidades a S/45 soles, el precio unitario será de S/2.00 soles.

e) En cuanto a la rentabilidad, los indicadores como VAN, TIR y ROE indican que el proyecto es rentable. El VAN económico es de S/ 854,867 Soles y el VAN financiero es de S/ 1,091,381 Soles, ambos mayor a 0. El TIR económico es $15.77 \%$, valor mayor al costo de capital promedio ponderado (11.25\%) y el TIR financiero es $15.76 \%$, valor mayor al costo de oportunidad del inversionista 
(9.91\%). El ROE para el proyecto es de $9 \%$ para el 2019 y de $24 \%$ para el 2028 . El tiempo de recuperación descontado de la inversión es de 9 años y 4 meses.

\section{Recomendaciones}

a) Se recomienda diversificar la cartera de productos. De manera introductoria se lanzará un solo producto en distintas presentaciones. Sin embargo, a futuro y considerando las recomendaciones de los potenciales consumidores, se debería incursionar en otras alternativas en chocolate, como chocolate orgánico, bitter en distintos porcentajes (al 50\%, al 70\%), chocolates con incrustaciones como el aguaymanto, quinua, sal de maras, etc. Siguiendo las tendencias en alimentación y gustos de los consumidores, y aprovechando la capacidad de planta hasta llegar al $100 \%$ de su capacidad.

b) Existen dudas sobre las gomitas, por lo que se recomienda realizar una campaña de difusión indicando que las gomitas que se usan en este producto son de jugos de fruta y no 100\% colorantes e indicar claramente el porcentaje de azúcar que tendrá no sería muy alto.

c) Existe un solo proveedor de gomitas para este producto, por lo que se recomienda buscar otros proveedores o alternativas de solución ante una ausencia de oferta temporal.

d) Se recomienda tener relaciones estrechas y buenas con los productores de cacao, y asegurar el abastecimiento oportuno y de calidad para garantizar la calidad total del producto que llega al consumidor final.

e) Se recomienda hacer una o varias alianzas estratégicas con ONGs para poder llegar a más territorio en el país y hacerse más conocidos. Dentro de las alianzas estratégicas, podría aprovecharse una oportunidad y financiarse a través de ellas para los futuros proyectos. 
f) También se recomienda tener negociaciones con entidades del estado, como el Ministerio de Salud o Ministerio de la Producción, y poder formar parte de sus programas, no solo como proveedores sino para poder aprovechar las diferentes capacitaciones.

g) Se recomienda buscar convenio con proveedores calificados para el mantenimiento correctivo y preventivo de las máquinas, para asegurar la continuidad del negocio y poder atender oportunamente al mercado demandante.

h) Se recomienda evaluar alguna alternativa para poder amortizar el préstamo en menor tiempo y ahorra en los intereses.

i) Se recomienda aumentar el nivel de producción al 70\%, ya que al momento solo se utiliza el 50\% de la capacidad instalada. Con esto incrementarían las utilidades, por lo tanto, la rentabilidad del accionista.

j) Actualizar y revisar la matriz de riesgos financieros anualmente para fortalecer la gestión de riesgos y así minimizar cualquier evento que pudiera impactar negativamente en la empresa. 


\section{Referencias}

América Economía (2012). Las 500 mayores empresas del Perú 2012. Recuperado de https://rankings.americaeconomia.com/2012/las-500-mayores-empresas-deperu/ranking-500-peru-451-500.php

América Economía (2014). Alimentos. Recuperado de https://rankings.americaeconomia.com/las-500-mayores-empresas-de-peru2014/ranking-500/las-mayores-empresas-del-peru/alimentos/

Andina (2017). Perú: Consumo de chocolate de alto contenido de cacao crece.

(2017, 11 de julio). Recuperado de http://andina.pe/agencia/noticia-peru-consumochocolates-alto-contenido-cacao-crece-674397.aspx

Barja, S., Capo, E., Briceño, L., Jakubson, L., Méndez, M. \& Becker, A. (2013, May-Jun, Vol. 28 Issue 3, p787-793. 7p). Anemia y déficit de hierro en niños con enfermedades respiratorias. Nutrition Hospitalaria. DOI: 10.3305/nh.2013.28.3.6452

Banco Central de Reserva. (2017). Reporte de Inflación Junio 2017. Panorama actual y proyecciones macroeconómicas 2017.2018. Recuperado de http://www.bcrp.gob.pe/docs/Publicaciones/Reporte-Inflacion/2017/junio/reporte-deinflacion-junio-2017.pdf

Banco Mundial en Perú. (2017). Perú Panorama General. Recuperado de http://www.bancomundial.org/es/country/peru/overview\#3

Compañía Peruana de Estudios de Mercado Opinión Pública (CPI). (2017). Market Report. Perú Población 2017. Recuperado de http://cpi.pe/images/upload/paginaweb/archivo/26/mr_poblacion_peru_2017.pdf

FAO/OMS. (1981). Norma para el chocolate y los productos del chocolate (CODEX STAN 87 (Rev. 1-2003) del Codex Alimentarius), 12 pp 
David, F (2008). Conceptos de Administración Estratégica, decimoprimera edición, México. Editorial Pearson educación.

Delgado, K. (2001). Efecto de tratamiento con hierro hemínico sobre ganancia de hemoglobina y peso en niños anémicos y con peso-talla $<1$ D.E. Recuperado de http://forticao.pe/docs/AbstracFinalKaremDelgado.pdf

Dirección de Estudios Económicos de Mypee Industria (2016). Lima, sumario regional. Recuperado de http://demi.produce.gob.pe/Content/files/doc_03/Regionales/Lima.pdf

EUROMONITOR INTERNATIONAL (Julio del 2016). Reporte de la industria de chocolatería en Perú. Recuperado de http://www.euromonitor.com/chocolate$\underline{\text { confectionery-in-peru/report }}$

García-Casal, M., Landaeta, M., Adrianza, G., Murillo, C., Rincón, M., Bou, L., et al. (2013, diciembre, Vol. 63 Issue 4, p338-361. 24p). Valores de referencia de hierro, yodo, zinc, selenio, cobre, molibdeno, vitamina $\mathrm{C}$, vitamina $\mathrm{E}$, vitamina $\mathrm{K}$, carotenoides y polifenoles para la población venezolana. Archivos Latinoamericanos de Nutrición. Recuperado de PROQUEST el 20 de agosto de 2017. García, Y., Gonzáles, R., García, A., Ángeles, S., Carmona, A., Cárdenas, R. (2013, Vol. 44 Issue 3, p14-22. 9p). Efecto de la suplementación con diferentes fuentes de hierro durante la recuperación de ratas anémicas. Revista CENIC Ciencias Biológicas. Recuperado de EBSCO el 19 de agosto de 2017.

"Gobernabilidad democrática frente a la corrupción" será el tema de la Cumbre de las Américas de Perú 2018 (20 de junio de 2017). Centro de Noticias de Organización de los Estados Americanos (OEA). Recuperado de http://www.oas.org/es/centro_noticias/comunicado_prensa.asp?sCodigo=C-048/17

Gómez-Juaristi, M., González-Torres, L., Bravo, L., Vaquero, P. Bastida, S., SanchezMuñiz, F.J. (2011, marzo-abril, Vol. 26 Issue 2, p289-292. 4p). Efectos beneficiosos 
del chocolate en la salud cardiovascular. Nutrición Hospitalaria. DOI:

10.3305/nh.2011.26.2.5016

Guerrero, D., Girón, C., Madrid, A., Mogollón, C., Quiroz, C., Villena, D (2012) Diseño de la línea de Producción de chocolates orgánicos. Perú, Universidad de Piura. 111 $\mathrm{pp}$

Gutiérrez, B. (2002) Chocolate, polifenoles y protección a la salud. Argentina. Acta Farmacéutica Bonaerense 21 (2), p 149-152.

Hernández, C. \& Izquierdo, A. (2009, Jul-Dic, Vol. 19 Issue 2, p281-289. 9p. 3 Charts). Beneficios de la suplementación con zinc en la rehabilitación nutricional de los lactantes desnutridos. Revista Cubana de Alimentación y Nutrición. Recuperado de EBSCO el 20 de agosto del 2017.

Instituto Nacional de Calidad (INACAL). (2017). Normas Técnicas Peruanas de Agroindustria. Recuperado de https://www.inacal.gob.pe/repositorioaps/data/1/1/1/jer/prensa/files/AGROINDUSTR

$\underline{\text { IA.pdf }}$

Industria Alimenticia. (2017, julio, Vol. 28 Issue 7, p19-20. 2p). La innovación abunda en la industria de confitería y chocolates. Industria Alimenticia. Recuperado de EBCO el 30 de agosto de 2017.

Industria Alimenticia. (2008, diciembre. Vol. 19, p20-20. 1/2p). Un siglo de experiencia en chocolates. Industria Alimenticia. Recuperado de EBSCO el 3 de setiembre de 2017

Instituto Nacional de Estadística e Informática (INEI). (2017) Encuesta demográfica y de salud familiar. Perú.

Instituto de estudios económicos y sociales. (2016). Reporte sectorial: industria del cacao, chocolate y otros derivados. Recuperado de http://www.sni.org.pe/wp- 
content/uploads/2017/01/Junio-2016-Industria-del-cacao-chocolate-y-otros-

derivados.pdf

Kotler, P. \& Armstrong, G. (2012) Marketing, decimocuarta edición, México. Editorial Pearson educación.

Lavaggi, L., Mori, G. \& Rozas, M. (2016) Plan de negocio para una empresa de exportación de chocolate orgánico (tesis de maestría). Universidad del Pacífico, Lima, Perú.

León, J. (2016, 06 de Junio). Consumo per cápita de chocolate se duplicaría en dos años. Agencia Agraria de Noticias. Recuperado de http://agraria.pe/noticias/consumo-percapita-de-chocolate-en-peru-11257

Malhotra, N (2008). Investigación de mercados. México. Pearson Educación. Quinta edición.

Martín Vizcarra: ¿Cuántos ministros han salido del Gobierno de PPK? (22 de mayo de 2017). Perú 21. Recuperado de https://peru21.pe/politica/martin-vizcarra-ministroshan-salido-gobierno-ppk-77356

Ministerio de Economía y Finanzas (2017). Marco Macro Económico Multianual 20182021. Recuperado de https://www.mef.gob.pe/contenidos/pol_econ/marco_macro/MMM_2018_2021.pdf

Ministerio de Economía y Finanzas. (2017). Economía se habría acelerado en mayo, disipándose parcialmente los efectos del Niño Costero. Recuperado de https://www.mef.gob.pe/es/noticias/notas-de-prensa-y-comunicados?id=5321

Ministerio de Economía y Finanzas. (2017). Panorama Económico, Agosto 2017. Recuperado de https://www.mef.gob.pe/contenidos/archivosdescarga/panorama economico 14082017.pdf 
Ministerio de la Producción. (2015). Anuario estadístico industrial, mipyme y comercio interno. Recuperado de http://www.produce.gob.pe/documentos/estadisticas/anuarios/anuario-estadisticomype-2015.pdf

Ministerio de Salud (2017). Plan Nacional para la Reducción y Control de la Anemia Materno Infantil y la Desnutrición Crónica Infantil en el Perú: 2017 - 2021.

Recuperado de http://www.minsa.gob.pe/portada/especiales/2015/nutriwawa/directivas/005_plan_red uccion.pdf

Ministerio de Salud (2015). Estado nutricional en niños y gestantes de los establecimientos de salud. Recuperado de http://www.portal.ins.gob.pe/es/component/rsfiles/preview?path=cenan\%252FVigilan cia\%2BAlimentaria\%2By\%2BNutricional\%252F2015\%252FInforme\%2BGerencial \%2BAnual\%2BSIEN\%2B2015.pdf

Ortiz, M. (23 de mayo de 2012). Más del $80 \%$ de peruanos se inclina por los productos naturales. El Comercio. Recuperado de http://archivo.elcomercio.pe/economia/peru/mas-80-peruanos-se-inclina-productos$\underline{\text { naturales-noticia-1418451 }}$

Pajuelo, J., Miranda, M., Zamora, R. (2015, Vol. 32 Issue 2, p245-251. 7p). Prevalencia de deficiencia de vitamina A y anemia en niños menores de cinco años de Perú. Revista Peruana de Medicina Experimental y Salud Pública. Recuperado de EBSCO el 18 de agosto de 2017

Perú Retail (8 de marzo del 2016). Ventas de La Ibérica crecieron un 24\% en 2015. Perú Retail. Recuperado de http://www.peru-retail.com/ventas-la-iberica-2015/ 
Pierdant, M., \& Gordillo, A. (Octubre del 2014) Absorción y efectividad del aporte de hierro de un producto comercial de gomita de grenetina enriquecida. En Food Technology Summit \& Expo. Congreso llevado a cabo en México DF, México.

Pomareda, C. (2013, enero-febrero, Vol. 28 Issue 186, p24-26. 2p). Del cacao al chocolate: Muchos sabores gratos y otros no tanto. Agro Enfoque. Recuperado de EBSCO el 20 de agosto del 2017.

PPK promulgó ley de imprescriptibilidad para delitos de corrupción. (19 de agosto de 2017). Gestión. Recuperado de https://gestion.pe/politica/ppk-promulgo-leyimprescriptibilidad-delitos-corrupcion-2198118

Quijano, A. (1998) Efectividad del empleo sinérgico de la cocoa fortificada con hierro hemínico más antiparasitario en escolares de Alto Shumbuyacu-Lamas-San Martín. Recuperado de http://forticao.pe/docs/EstudiodeAnaQuijano.pdf

Sapag, N., Sapag, R. (2008). Preparación y Evaluación de Proyectos. Bogotá, Colombia: McGraw-Hill Interamericana S.A.

Sapag, N. (2011). Proyectos de Inversión. Formulación y Evaluación. Chile: Pearson Educación

Sapena, J., Picó, L., Morera, M., Rivero, M. (2015, 73(8): 186-193). Betaglucanos de «Pleurotus ostreatus» en la prevención de infecciones respiratorias recurrentes. Acta Pediatr Esp. Recuperado de EBSCO el 20 de agosto de 2017.

Selva, L., Ochoa, A. (2011, Jul-Sep, Vol. 37 Issue 3, p200-206. 7p). Acciones para la prevención y control de la anemia por deficiencia de hierro en niños hasta cinco años. Revista Cubana de Salud Pública. Recuperado de EBSO el 18 de agosto de 2017. Sotomayor, M (2009). Estudio del mercado interno para determinación y caracterización del consumo actual y potencial de derivados industriales del cacao. Recuperado de http://infocafes.com/portal/wp-content/uploads/2016/08/mercado cacao.pdf 
Velásquez, J., Rodríguez, Y., Gonzáles, M., Astete, L., Loyola-Romaní, J., Vigo, W., et al. (2013). Factores asociados con anemia en niños menores de tres años en el Perú: análisis de ENDES 2007-2013.

Villar, P. (7 de agosto de 2017). Minagri: reglamento técnico del chocolate se aprobaría en la quincena de setiembre. El Comercio. Recuperado de http://elcomercio.pe/economia/peru/minagri-reglamento-tecnico-chocolate- aprobariasetiembre-noticia-448309

16 claves para entender la operación 'Lava Jato' (19 de mayo de 2017). RPP Noticias. Recuperado de http://rpp.pe/mundo/latinoamerica/que-es-la-operacion-lava-jato-6-clavespara-entender-este-caso-noticia-943263 
Anexo 1. Importación de cacao, chocolate y otros derivados, según partida arancelaria (distribución porcentual).

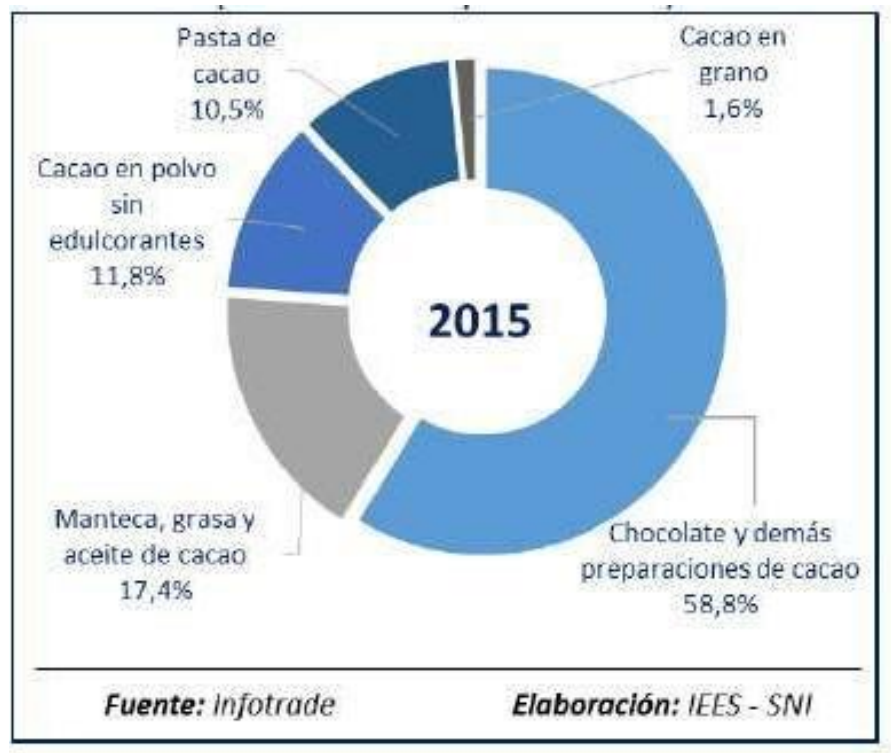

Fuente: IEES (2016). Recuperado de http://www.sni.org.pe/wp-content/uploads/2017/01/Junio-2016Industria-del-cacao-chocolate-y-otros-derivados.pdf 
Anexo 2. Importación de cacao, chocolate y sus derivados por países

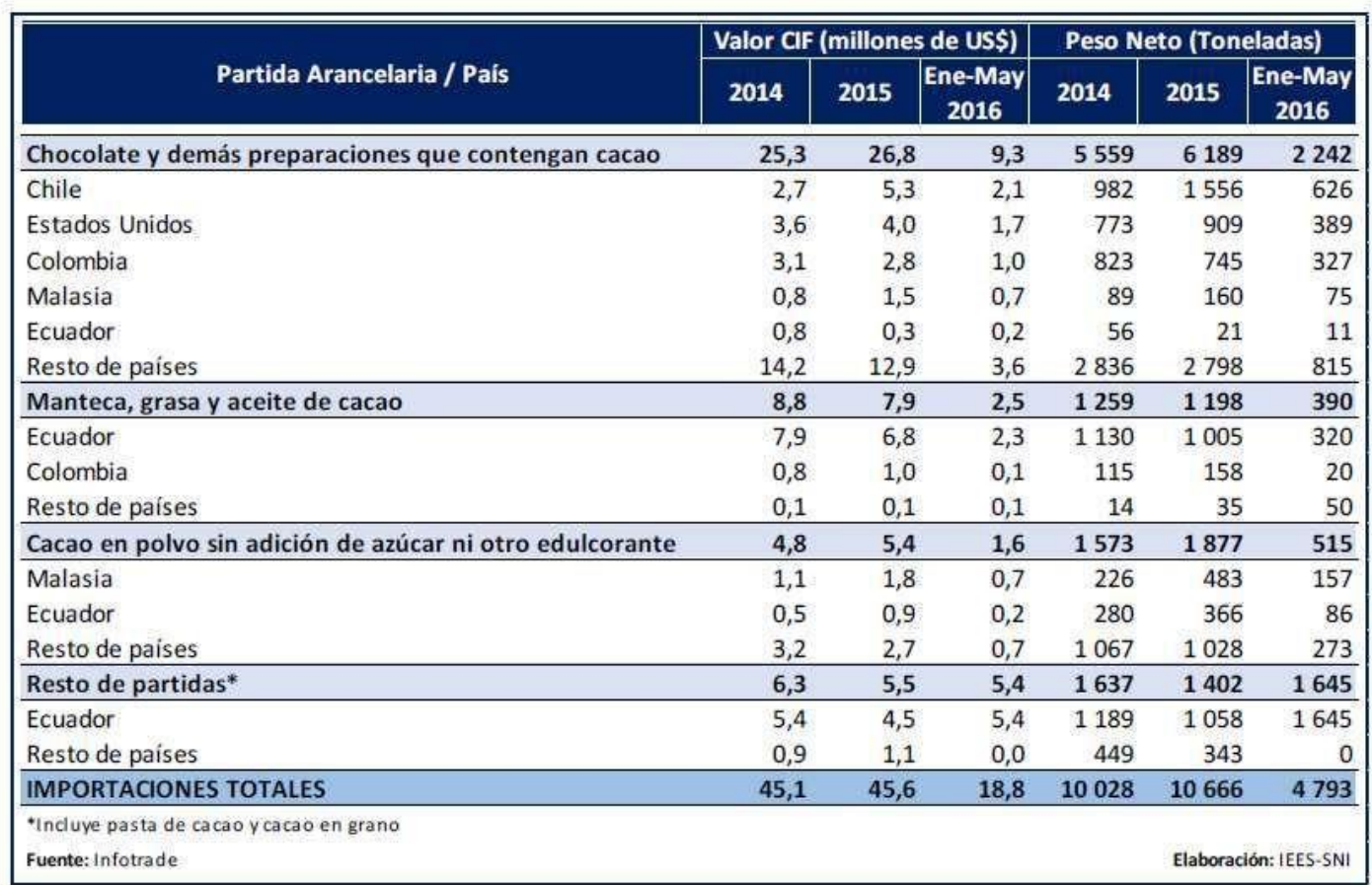

Fuente: IEES (2016). Recuperado de http://www.sni.org.pe/wp-content/uploads/2017/01/Junio-2016Industria-del-cacao-chocolate-y-otros-derivados.pdf 
Anexo 3. Importación de cacao, chocolate y sus derivados por países

\begin{tabular}{|c|c|c|c|c|c|c|}
\hline \multirow[b]{2}{*}{ Partida Arancelarla / Empresa } & \multicolumn{3}{|c|}{ Valor CfF (millones de USS) } & \multicolumn{3}{|c|}{ Peso Neto (Toneladas) } \\
\hline & 2014 & 2015 & $\begin{array}{c}\text { Ene-May } \\
2016\end{array}$ & 2014 & 2015 & $\begin{array}{c}\text { Ene-May } \\
2016\end{array}$ \\
\hline Chocolate y demás preparaciones que contengan cacao & 25,3 & 26,8 & 9,3 & 5559 & 6189 & 2242 \\
\hline ARCOR DE PERUSA & 3,7 & 2,9 & 0,9 & 782 & 629 & 224 \\
\hline KING DAVID DELICATESSES DEL PERU S.A.C. & 2,7 & 2,8 & 0,4 & 224 & 227 & 21 \\
\hline MASTER FOODS PERU SOCIEDAD COMERCIAL DE RESPONSAB & 1,1 & 2,1 & 0,8 & 285 & 510 & 178 \\
\hline NESTLE MARCAS PERU S.A.C. & 1,6 & 1,8 & 0,9 & 655 & 616 & 282 \\
\hline COMPANIA NACIONAL DE CHOCOLATES DE PERU S.A. & 1,9 & 1,7 & 0,6 & 433 & 402 & 184 \\
\hline DXN INTERNATIONAL. PERU S.A.C. & 0,8 & 1,3 & 0,7 & 88 & 144 & 73 \\
\hline PURATOS PERU S.A. & 1,0 & 1,2 & 0,4 & 263 & 366 & 138 \\
\hline KRAFT FOODS PERU S.A. & 0,8 & 0,7 & 0,3 & 283 & 309 & 137 \\
\hline MOLITALIA S.A & 0,5 & 0,3 & 0,2 & 95 & 62 & 43 \\
\hline NESTLE PERU SA & 0,0 & 0,1 & 0,0 & 4 & 13 & 0 \\
\hline Resto de empresas & 11,0 & 11,9 & 4,2 & 2447 & 2911 & 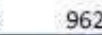 \\
\hline Manteca, grasa y aceite de cacao & 8,8 & 7,9 & 2,5 & 1259 & 1198 & 390 \\
\hline NESTLE PERU SA & 6,7 & 6,0 & 2,2 & 980 & 881 & 301 \\
\hline MOLITALIA S.A & 0,9 & 0,8 & 0,2 & 113 & 134 & 69 \\
\hline PURATOS PERU S.A. & 0,0 & 0,0 & 0,0 & 1 & 1 & 0 \\
\hline COMPAÑIA NACIONAL DE CHOCOLATES DE PERU S.A. & 0,1 & & & 15 & & \\
\hline Resto de empresas & 1,1 & 1,1 & 0,1 & 150 & 183 & 20 \\
\hline Cacao en polvo sin adición de azúcar ni otro edulcorante & 4,8 & 5,4 & 1,6 & 1573 & 1877 & $\mathbf{5 1 5}$ \\
\hline KRAFT FOODS PERU S.A. & 2,7 & 2,6 & 0,6 & 636 & 706 & 147 \\
\hline MOLITALIA S.A & 0,3 & 0,5 & 0,2 & 180 & 195 & 75 \\
\hline COMPAÑIA NACIONAL DE CHOCOLATES DE PERU S.A. & 0,0 & 0,2 & 0,0 & 10 & 100 & 5 \\
\hline PURATOS PERU S.A. & 0,0 & 0,0 & & 0 & 0 & \\
\hline Resto de empresas & 1,7 & 2,1 & 0,8 & 748 & 877 & 289 \\
\hline Resto de partidas* & 6,3 & 5,5 & 5,4 & 1637 & 1402 & 1645 \\
\hline NESTLE PERU SA & 4,1 & 2,9 & 1,5 & 900 & 659 & 319 \\
\hline MOLITALIA S.A. & 0,6 & 0,5 & 0,1 & 144 & 126 & 36 \\
\hline Resto de empresas & 1,6 & 2,1 & 3,7 & 594 & 617 & 1290 \\
\hline IMPORTACIONES TOTALES & 45,1 & 45,6 & 18,8 & 10028 & 10666 & 4793 \\
\hline \multicolumn{7}{|l|}{ "Inciuye pasta de cacao y cacao en grano } \\
\hline Fuente: Infotrade & & & & & \multicolumn{2}{|c|}{ Elaboración: IEES-SN| } \\
\hline
\end{tabular}

Fuente: IEES (2016). Recuperado de http://www.sni.org.pe/wp-content/uploads/2017/01/Junio-2016Industria-del-cacao-chocolate-y-otros-derivados.pdf 


\section{Anexo 4. Ficha Técnica}

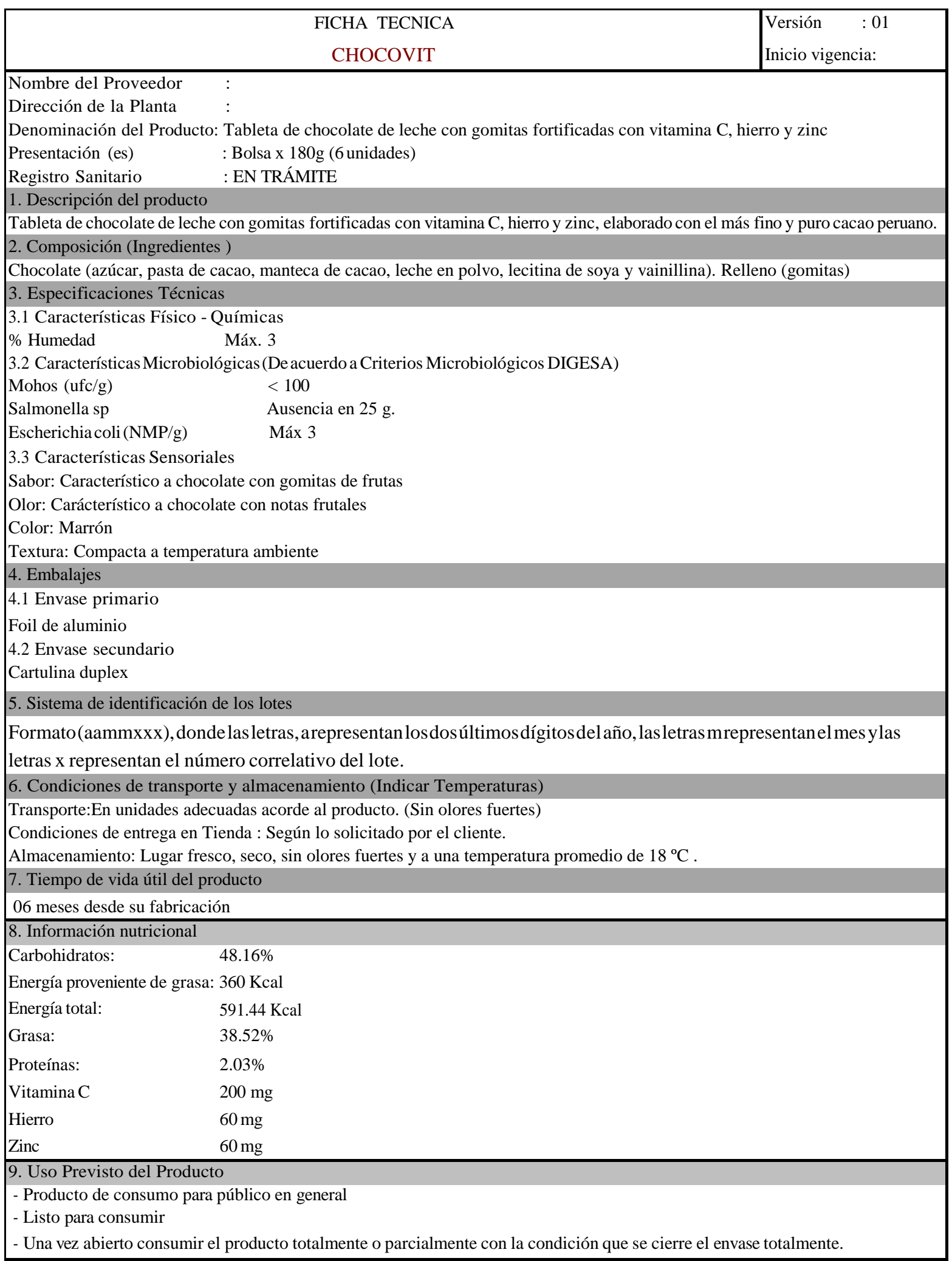


Anexo 5: Cadena productiva del cacao, chocolate y derivados

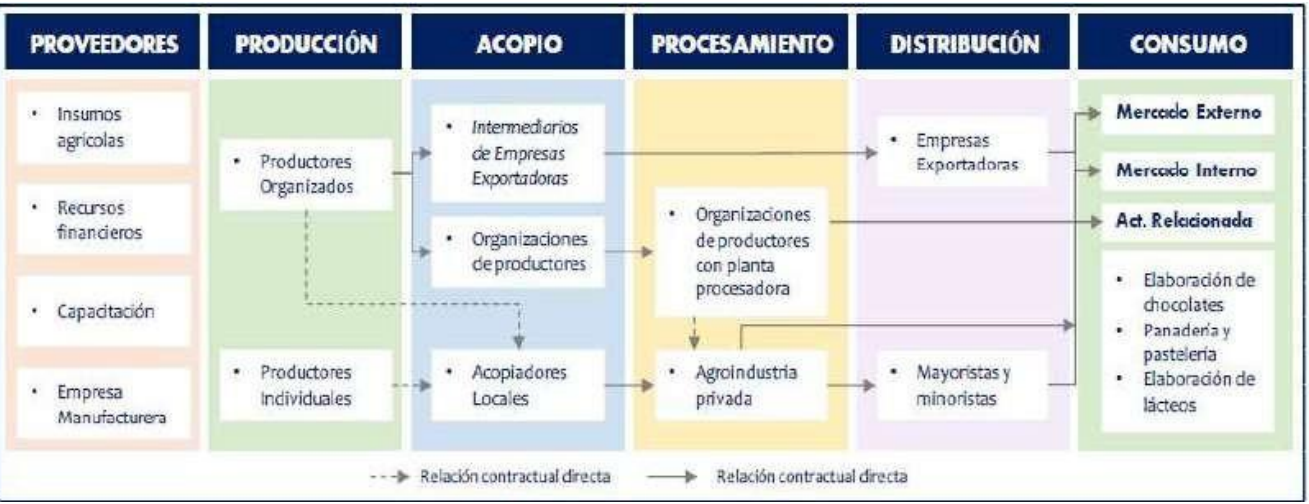

Fuente: IEES (2016). Recuperado de http://www.sni.org.pe/wp-content/uploads/2017/01/Junio-2016Industria-del-cacao-chocolate-y-otros-derivados.pdf 
Anexo 6. Composición química, dosis, ingredientes por presentación de Forticao

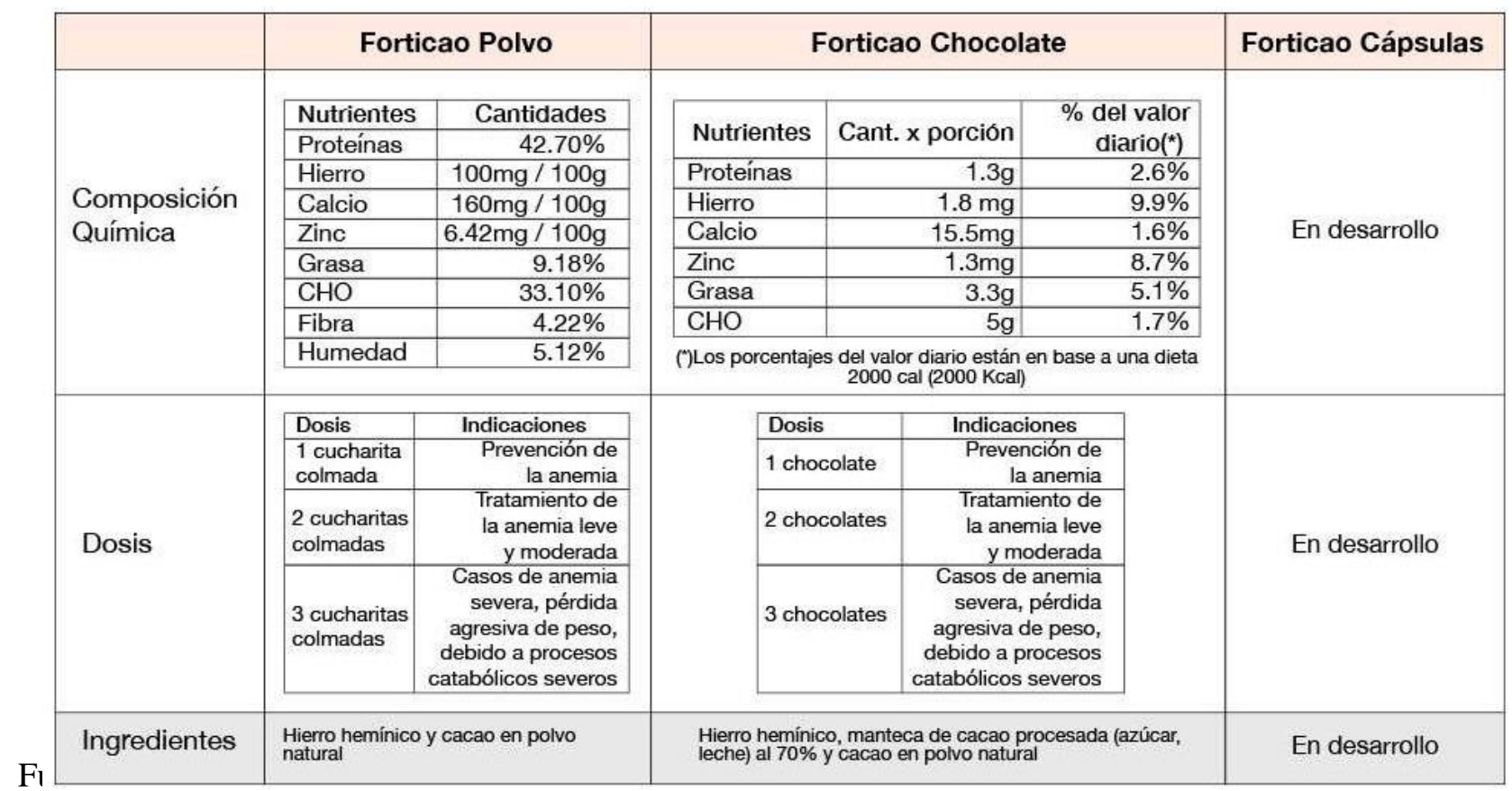

Fuente: Forticao. Recuperado de: http://forticao.pe/ 
Anexo 7. FODA

\begin{tabular}{c}
\hline FORTALEZAS (F) \\
\hline 1. Producto nutritivo e \\
innovador que va acorde a la tendencia \\
industrial \\
$2 . \quad$ Producto para prevenir la \\
anemia, la cual es una enfermedad con \\
alta prevalencia en nuestro país. \\
3. Compra directa a \\
comunidades nativas, sin \\
intermediarios. \\
4. Conocimiento técnico en el \\
procesamiento de chocolates. \\
5. Ser sujetos de crédito ante \\
entidades financieras \\
6. Competitividad en precios. \\
7. Infraestructura propia. \\
8. Maquinaria importada con \\
tecnología de punta que nos permitirá \\
tener productos de alta calidad
\end{tabular}

DEBILIDADES (D)

fábrica

1. Falta de capital para instalar la

2. Ser nueva en el mercado y no disponer de clientes

3. Elevada dependencia de personal operativo para el área de envasado

4. Dificultad para conseguir repuestos debido a que son máquinas especializadas e importadas

5. Dificultad para conseguir servicio de mantenimiento a tiempo debido a que las máquinas son importadas

6. Falta de capital para mantener una publicidad activa y continua

7. Altos inventarios al inicio del proyecto

8. Falta de facilidades de pago para los compradores: crédito

9. Procesos no documentados

10. Falta de proveedores calificados por parte de la empresa

\section{OPORTUNIDADES (O)}

1. Pocos competidores directos

2. Plan Nacional para la desnutrición crónica infantil y la prevención de la anemia en el país para el periodo 2017-2021

3. Nuevo estilo de vida en el mercado peruano con tendencia al consumo de comida saludable.

4. Ferias nacionales e internacionales que van a permitir hacer más conocido en el mercado.

5. Proyecto de reglamento técnico del uso de cacao del MINAGRI que va permitir tener clientes informados y con capacidadde elegir un mejor producto, favoreciéndonos con el crecimiento de nuestro mercado

6. Comunidades nativas con disposición a trabajar en conjunto con el sectorindustrial

7. Gran número de proveedores de azúcar, leche en polvo y empaques con quienes se puede negociar buen precio

8. El estado Peruano brinda servicios de capacitación en gestión de la calidad para la mejora de la productividad.

9. Tecnología de comunicación: internet, marketing digital y redes sociales permite hacer conocido el producto.

10. Tendencia de las empresas a tener estándares de calidad y procesos estandarizados.

\section{ESTRATEGIAS DO}

1. Préstamo banco y/o

1. Implementar plan de marketing para lanzamiento de producto $(\mathrm{F} 1, \mathrm{O} 1$, $\mathrm{O} 3, \mathrm{O} 4)$

2. Hacer alianza estratégica con organizaciones para llegar a zonas con altos índices de anemia (F2, O2)

3. Diferenciar la marcar (F2, F4, O5)

4. Negociar buen precio del cacao (F3, O1, O6)

5. Alianza estratégica con proveedores de insumos: precio, plazos de pago, créditos (F7, O7)

6. Alianzas estratégicas con comunidades productoras de cacao (F3, O8)

\section{financiamiento a través de ONG(D1,} $\mathrm{O} 2)$

2. Campaña de difusión debondades del producto $(\mathrm{D} 2, \mathrm{O} 3, \mathrm{O} 4)$

3. Tener contratos con proveedores para tener mayor tiempo de pago y poder otorgar ese tiempo al comprador (O7, D8)

4. Marketing digital. Difusión a través de redes sociales, crear fan page del producto (D2, D6, O3, O9)

5. Documentar y estandarizar los procesos productivos, comerciales y administrativos. (O10, D9)

6. Implementar indicadores de gestión y productividad (O10, D9) 


\begin{tabular}{|c|c|c|}
\hline AMENAZAS (A) & ESTRATEGIAS FA & ESTRATEGIAS DA \\
\hline $\begin{array}{l}\text { 1. Falta de tecnología de punta en el } \\
\text { país para la producción de derivados de } \\
\text { cacao }\end{array}$ & $\begin{array}{l}\text { 1. Asegurar la alianza estratégica } \\
\text { con una cadena de supermercados (F2, } \\
\text { A2, A3) }\end{array}$ & $\begin{array}{l}\text { 1. Acogerse a programas de } \\
\text { capacitación del Estado para tener una } \\
\text { ventaja diferenciadora (D2, A2, A3). }\end{array}$ \\
\hline $\begin{array}{l}\text { 2. Ingreso de más competidores que } \\
\text { ofrezcan productos similares }\end{array}$ & $\begin{array}{l}\text { 2. Realizar inspecciones aleatorias } \\
\text { en el año a nivel de bodegas para } \\
\text { garantizar la calidad del producto (F4, } \\
\text { A7) }\end{array}$ & $\begin{array}{l}\text { 2. Búsqueda de alternativa ante la } \\
\text { falta de desabastecimiento de las } \\
\text { gomitas (A5) }\end{array}$ \\
\hline $\begin{array}{l}\text { 3. Crecimiento del mercado de productos } \\
\text { sustitutos }\end{array}$ & $\begin{array}{l}\text { 3. Estrategia publicitaria orientada } \\
\text { a informar sobre las bondades del } \\
\text { producto y las desventajas de los } \\
\text { productos informales (F1, F2, A2, A3, } \\
\text { A6) }\end{array}$ & $\begin{array}{l}\text { 3. Contar con plan de contingencia } \\
\text { ante diversos escenarios: a nivel político, } \\
\text { económico (A8) }\end{array}$ \\
\hline $\begin{array}{l}\text { 4. Dificultad para obtener licencia de } \\
\text { funcionamiento }\end{array}$ & $\begin{array}{l}\text { 4. Buena asesoría legal para } \\
\text { trámites administrativos y legales (A4, } \\
\text { F7) }\end{array}$ & $\begin{array}{l}\text { 4. Evaluar alternativas de leasing } \\
\text { con proveedores de maquinaria (A1,D4, } \\
\text { D5) }\end{array}$ \\
\hline $\begin{array}{l}\text { 5. Sólo hay un proveedor de gomitas } \\
\text { fortificadas en el mercado }\end{array}$ & & $\begin{array}{l}\text { 6. Implementar evaluación de } \\
\text { proveedores para garantizar la calidad de } \\
\text { producto (A5, D10) }\end{array}$ \\
\hline $\begin{array}{l}\text { 6. Competencia informal y desleal en el } \\
\text { sector de chocolatería } \\
\text { 7. Las bodegas y mayoristas nocuentan } \\
\text { con sistema de ventilación y control de } \\
\text { temperatura en sus almacenes, nuestro } \\
\text { producto es sensible a temperaturas altas } \\
\text { (mayor a } 20^{\circ} \mathrm{C} \text { ) sobre todo en verano. } \\
\text { 8. Inestabilidad por la desaceleración de } \\
\text { la economía nacional. }\end{array}$ & & \\
\hline
\end{tabular}




\section{Anexo 8. Método de Gourchelt}

Determinación de la superficie estática, superficie de gravitación, superficie de evolución y superficie total.

\begin{tabular}{|c|c|c|c|c|c|c|c|c|c|c|}
\hline Equipos & $\operatorname{Largo}(\mathrm{m})$ & Ancho (m) & Altura (m) & Nro & $\mathrm{N}$ & Ss $(\mathrm{m} 2)$ & m2) $\mathrm{S}$ & n2) $\mathrm{St}$ & n2) ST & n2) \\
\hline Balanza de pie & 0.40 & 0.40 & 0.80 & 4 & 4 & 0.16 & 0.64 & 0.47 & 1.27 & 5.09 \\
\hline Mesa de trabajo & 1.20 & 0.60 & 2.10 & 8 & 4 & 0.72 & 2.88 & 2.13 & 5.73 & 45.80 \\
\hline Parihuela & 1.00 & 1.20 & 0.12 & 12 & 4 & 1.20 & 4.80 & 3.54 & 9.54 & 114.50 \\
\hline Estante & 0.90 & 0.50 & 2.10 & 6 & 1 & 0.45 & 0.45 & 0.53 & 1.43 & 8.59 \\
\hline Escritorio pequeño & 0.70 & 1.20 & 0.75 & 4 & 2 & 0.84 & 1.68 & 1.49 & 4.01 & 16.03 \\
\hline Escritorio grande & 1.80 & 1.80 & 0.75 & 1 & 2 & 3.24 & 6.48 & 5.74 & 15.46 & 15.46 \\
\hline Tostador & 2.30 & 1.60 & 2.40 & 1 & 1 & 3.68 & 3.68 & 4.34 & 11.70 & 11.70 \\
\hline Refinador & 1.10 & 0.90 & 1.60 & 1 & 1 & 0.99 & 0.99 & 1.17 & 3.15 & 3.15 \\
\hline Pre-refinador & 0.90 & 1.22 & 1.13 & 1 & 1 & 1.10 & 1.10 & 1.30 & 3.49 & 3.49 \\
\hline Descascarillador & 2.00 & 1.00 & 2.00 & 1 & 1 & 2.00 & 2.00 & 2.36 & 6.36 & 6.36 \\
\hline Prensa & 0.81 & 1.06 & 1.79 & 1 & 3 & 0.86 & 2.58 & 2.03 & 5.46 & 5.46 \\
\hline Homogenizador & 1.50 & 1.50 & 1.80 & 1 & 3 & 2.25 & 6.75 & 5.31 & 14.31 & 14.31 \\
\hline Túnel de enfriamiento & 0.70 & 6.00 & 1.80 & 1 & 2 & 4.20 & 8.40 & 7.44 & 20.04 & 20.04 \\
\hline Conchadora & 1.10 & 1.00 & 1.50 & 1 & 3 & 1.10 & 3.30 & 2.60 & 7.00 & 7.00 \\
\hline Temperadora & 0.51 & 0.76 & 1.56 & 1 & 1 & 0.39 & 0.39 & 0.46 & 1.23 & 1.23 \\
\hline Selladora de pedal & 0.86 & 0.67 & 0.35 & 1 & 1 & 0.58 & 0.58 & 0.68 & 1.83 & 1.83 \\
\hline TOTAL & & & & & & & & & & 280.05 \\
\hline
\end{tabular}

Determinación del valor h y $\mathrm{H}$

\begin{tabular}{lccr}
\hline \multicolumn{1}{c}{ Equipos } & Altura $(\mathrm{m})$ & Número & $\mathrm{A} * \mathrm{~N}$ \\
\hline Balanza de pie & 0.80 & 4 & 3.2 \\
\hline Mesa de trabajo & 2.10 & 8 & 16.8 \\
\hline Parihuela & 0.12 & 12 & 1.44 \\
\hline Estante & 2.10 & 6 & 12.6 \\
\hline Escritorio pequeño & 0.75 & 4 & 3 \\
\hline Escritorio grande & 0.75 & 1 & 0.75 \\
\hline Tostador & 2.40 & 1 & 2.4 \\
\hline Refinador & 1.60 & 1 & 1.6 \\
\hline Pre-refinador & 1.13 & 1 & 1.13 \\
\hline Descascarillador & 2.00 & 1 & 2 \\
\hline Prensa & 1.79 & 1 & 1.79 \\
\hline Homogenizador & 1.80 & 1 & 1.8 \\
\hline Túnel de enfriamiento & 1.80 & 1 & 1.8 \\
\hline Conchadora & 1.50 & 1 & 1.5 \\
\hline Temperadora & 1.56 & 1 & 1.56 \\
\hline Selladora de pedal & 0.35 & 1 & 0.35 \\
\hline Total & & 45 & 53.72 \\
\hline Promedio & 1.41 & & 1.19 \\
\hline
\end{tabular}

Determinación del valor de $\mathrm{k}$

\begin{tabular}{cccc}
\hline & $\mathrm{h}$ & $\mathrm{H}$ & $\mathrm{k}$ \\
\hline $\mathrm{K}=\mathrm{h} /(2 * \mathrm{H})$ & 1.41 & 1.19 & 0.59 \\
\hline
\end{tabular}

Determinación del área total mínima

\begin{tabular}{ccccc}
\hline Equipos & Muros 10\% & $\begin{array}{l}\text { Movimientos } \\
15 \%\end{array}$ & Espacios libres 10\% & TOTAL \\
\hline 280.05 & 28.00 & 42.01 & 28.00 & 378.07 \\
\hline
\end{tabular}


Anexo 9. Política de Seguridad y Salud en el Trabajo de MARAN S.R.L.

\begin{tabular}{|l|l|l|}
\hline \multirow{3}{*}{ MARAN S.R.L } & Política de Seguridad y Salud en el Trabajo & Código: SST-01 \\
\hline & & Versión: 01 \\
\hline
\end{tabular}

MARAN S.R.L desarrolla sus actividades de Producción de Chocolatería, promoviendo la Protección a la Vida y la Salud de sus colaboradores propios, contratistas, visitantes y partes interesadas. El compromiso de la Alta Dirección garantiza la identificación, evaluación, control y/o eliminación de los riesgos presentes en todas las actividades desarrolladas en la organización, así como el mejoramiento continuo en su gestión de Prevención de Riesgos Laborales.

Promover y mantener una cultura de seguridad y salud laboral como valor y principio de actuación, es una responsabilidad por convicción de todos los colaboradores de MARAN, que se refleja en el cumplimiento de las normas y procedimientos establecidos en la legislación peruana vigente. 
Anexo 10. Plan para el logro de los Objetivos de SSO

\begin{tabular}{|c|c|c|c|c|c|c|c|c|}
\hline \multirow[b]{2}{*}{ MARAN S.R.L. } & \multirow{2}{*}{\multicolumn{6}{|c|}{ Planificación para el Logro de los Objetivos de Seguridad y Salud Ocupacional }} & \multicolumn{2}{|l|}{ Código: SST-02 } \\
\hline & & & & & & & Versión: 01 & \\
\hline AÑo & 2018 & & & & & & & \\
\hline Politica & Objetivos & Indicadores & Frecuencia & Valor Meta $\%$ & Recursos & $\begin{array}{l}\text { Acciones a efectuarse para su } \\
\text { cumplimiento }\end{array}$ & $\begin{array}{l}\text { Fecha de ejecución para las } \\
\text { acciones }\end{array}$ & Responsable \\
\hline 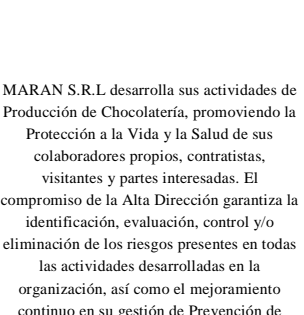 & $\begin{array}{c}100 \% \text { de los colaboradores } \\
\text { participan en las } \\
\text { actividades y conocen el } \\
\text { Sistem de Gestín de }\end{array}$ & $\begin{array}{c}=\mathrm{N}^{\circ} \text { de colaboradores que } \\
\text { participaron } / \text { Número } \\
\text { total de colaboradores } \\
\text { presentes }\end{array}$ & Anual & 100 & $\begin{array}{c}\text { Plan de Emergencia actualizado } \\
\text { Bombero instructor Mensaje } \\
\text { a los colaboradores con } \\
\text { instrucciones Sala, Cartel, listas } \\
\text { actualizadas, cronómetro, } \\
\text { cámara fotográfica, botiquines } \\
\text { de emergencia }\end{array}$ & $\begin{array}{c}\text { Diseño y ejecución del Programa } \\
\text { de Capacitación de SSO } \\
\text { Programa ción y ejecución de } \\
\text { Simulacros } \\
\text { Monitoreo y seguimiento a } \\
\text { participación de colaboradores. } \\
\text { Presentación de indicadores a } \\
\text { comité de gerencia. }\end{array}$ & $\begin{array}{l}\text { De acuerdo al Programa de SSO } \\
\text { (capacitaciones, evaluaciones, } \\
\text { exámenes mécicos, simulacros, } \\
\text { etc.) }\end{array}$ & \begin{tabular}{c|} 
Jefe de \\
Administración
\end{tabular} \\
\hline $\begin{array}{l}\text { seguridad y salud laboral como valor y } \\
\text { principio de actuacion, es una } \\
\text { responsabilidad por convicción de todos los } \\
\text { colaboradores de MARAN, que se refleja en } \\
\text { el cumplimiento de las normas y } \\
\text { procedimientos establecilos en la legislación } \\
\text { peruana vigente. }\end{array}$ & & $\begin{array}{l}{ }^{\prime}=\mathrm{N}^{\circ} \text { de Colaboradores que } \\
\text { tienen conocimiento } / \mathrm{N}^{\circ} \\
\text { Total de Colaboradores }\end{array}$ & & & $\begin{array}{c}\text { PC } \\
\text { Proveedores en temas } \\
\text { especializados relativos a SSO } \\
\text { Listas de asistencia } \\
\text { Material para la Capacitación }\end{array}$ & $\begin{array}{c}\text { Programación y ejecución de las } \\
\text { charlas a realizarse en el año. } \\
\text { Evaluación de conocimientos a } \\
\text { colaboradores. } \\
\text { Monitoreo y seguimiento a } \\
\text { participación de colaboradores. } \\
\text { Presentación de indicadores a } \\
\text { comité de gerencia. }\end{array}$ & $\begin{array}{l}\text { De acuerdo al Programa de } \\
\text { Capacitaciones }\end{array}$ & \\
\hline & & & & & & & & \\
\hline $\begin{array}{c}\text { Versión } \\
01\end{array}$ & $\begin{array}{c}\text { Fecha de actualización } \\
6 / 01 / 2018\end{array}$ & & & & $\begin{array}{l}\text { Descripción del } \\
\text { Creación del do }\end{array}$ & $\begin{array}{l}\text { cambio } \\
\text { cumento }\end{array}$ & & \\
\hline
\end{tabular}


Anexo 11. Programa Anual de SSO

\begin{tabular}{|c|c|c|c|c|c|c|c|c|c|c|c|c|c|c|c|c|}
\hline \multirow{2}{*}{ MARAN S.R.L. } & \multirow{2}{*}{\multicolumn{15}{|c|}{ Programa Anual de Seguridad y Salud Ocupacional }} & \\
\hline & & & & & & & & & & & & & & & & Versión: 01 \\
\hline & 2019 & & & & & & & & & & & & & & & \\
\hline Objetivo: Cumplir con el $100 \%$ de las actividades del Program & Anual de Segurida & lad y Salud Ocupac & acional en el año. & & & & & & & & & & & & & \\
\hline P: Programada & & $\mathrm{N}^{\circ}$ Actividades prog & ogramadas & 4 & 7 & 7 & 9 & 6 & 10 & 7 & 11 & 9 & 15 & & 99 & \\
\hline R: Realizada & & $\mathrm{N}^{\circ}$ Actividades reali & ali zadas & 4 & 7 & 7 & 9 & 6 & 10 & 7 & 11 & 9 & 15 & & 91 & Anual \\
\hline P: Reprogramado & Cumplimiento: & Indicador & & 100 & 100 & 100 & 100 & 100 & 100 & 100 & 100 & 100 & 100 & & 11.11 & 93 \\
\hline Actividades & Tipo actividad & Impacta a: & Responsables & ENE & FEB & MAR & ABR & MAY & JUN & JUL & $\mathrm{AGO}$ & \begin{tabular}{|l|l|l}
0 & SET \\
\end{tabular} & OCT & NOV & DIC & Observaciones \\
\hline Aprobación de los objectivos y del Plan para el logro de los & & Toda la & & & & & \begin{tabular}{|l|l|l|}
$P$ \\
\end{tabular} & & & ( & 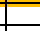 & $=$ & - & 正 & 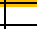 & \\
\hline objetivos de SSO & Documentación & Organización & Comité de SSO & & & & $\mathrm{R}$ & & & & & & & & & \\
\hline Anuncio sobre el área encargada de la Seguridad y Salud & Difusión & Colaboradores & $\mathrm{GH}$ & & & & $\mathrm{P}$ & & & & & & & & & \\
\hline ocupacional & & & & & & & $\mathrm{R}$ & & & & & & & & & \\
\hline & & Colaboradores & & & & $\mathrm{P}$ & & & & & & & & & & \\
\hline Elaborar, revisar y aprobar el Plan Anual de Capacitación & Documentación & Colaboradores & $\mathrm{GH}$ & & & $\mathrm{R}$ & & & & & & & & & & D entro del Progra ma a nual de SSO \\
\hline Elecciones del Comité & Flecciones & Colaboradores & $\mathrm{GH}$ & & & & & $\mathrm{P}$ & & & & & & & & \\
\hline Eiectores act comile & Eiecciones & Coliboracores & $\mathrm{GH}$ & & & & & $\mathrm{R}$ & & & & & & & & \\
\hline Creación de las matrices IPER & Documentación & Colaboradores & $\mathrm{GH}$ & & & & & & & & $\mathrm{P}$ & $\mathrm{P}$ & $\mathrm{P}$ & $\mathrm{P}$ & & \\
\hline Treacion ac has matrecs IFEK & Documentacion & Colaboradores & $\mathrm{GH}$ & & & & & & & & $\mathrm{R}$ & $\mathrm{R}$ & $\mathrm{R}$ & $\mathrm{R}$ & & \\
\hline & & & & & & & & & & & $\mathrm{P}$ & $\mathrm{P}$ & $\mathrm{P}$ & $\mathrm{P}$ & & \\
\hline Creación de los mapas de riesgos & Documentación & Colaboradores & GH & & & & & & & & $\mathrm{R}$ & $\mathrm{R}$ & $\mathrm{R}$ & $\mathrm{R}$ & & \\
\hline & & & & & & & & & & & & $\mathrm{P}$ & & & & \\
\hline Campaña de Salud "Examenes ocupacionales" & EMO & Colaboradores & $\mathrm{GH}$ & & & & & & & & & $\mathrm{R}$ & & & & \\
\hline Entrega de resultados de los exámenes ocupacionales y & & & Comité sso / & & & & & & & & & -5 & & & $\mathrm{P}$ & \\
\hline Vigilancia Médica & EMO & Colaboradores & $\mathrm{MO} / \mathrm{GH}$ & & & & & & & & & & & & $\mathrm{R}$ & \\
\hline Campaña de Salud "Nutrición" & Prevención & Colaboradores & $\mathrm{GH}$ & & & & & & & & & $\mathrm{P}$ & & & & \\
\hline & Prevencion & 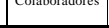 & $\mathrm{GH}$ & & & & & & & & & $\mathrm{R}$ & & & & \\
\hline Campaña de Salud "Hivienc Laboral" & Preyencíón & Colaboradores & $\mathrm{GH}$ & & & & & & & & & & $\mathrm{P}$ & & & \\
\hline Campana de Salud Higlene Laboral & Frevencion & Colaboradores & $\mathrm{GH}$ & & & & & & & & & & $\mathrm{R}$ & & & \\
\hline Campaña de Salud "Recuerda qué hacer en caso de sismo e & Prevención & Colaboradores & $\mathrm{GH}$ & & & & & & & & & & & $\mathrm{P}$ & & \\
\hline incendio" & Frevencion & Colaboradores & $\mathrm{GH}$ & & & & & & & & & & & $\mathrm{R}$ & & \\
\hline Campaña de Salud "Ergonomía" & Prevención & Colaboradores & $\mathrm{GH}$ & & & & & & & & & & & & $\mathrm{P}$ & \\
\hline Creación y Difusión del Reglamento de Seguridad y Salud & & & & & $\mathrm{P}$ & & & & & & & & & & & \\
\hline $\begin{array}{l}\text { Ocupacional a todos los colaboradores (y proveedores cuando lo } \\
\text { amertite) }\end{array}$ & $\begin{array}{c}\text { Doumentusion } \\
\text { Difusion }\end{array}$ & $\begin{array}{c}\text { (y algunos } \\
\text { Proveedores) }\end{array}$ & GH & & $\mathrm{R}$ & & & & & & & & & & & \\
\hline Charla de Evacuación y Lucha contra incendios & Capacitación & $\mid$ Brigada LCI-EVA & $\mathrm{GH}$ & & & $\mathrm{P}$ & & & & & & & & & & \\
\hline Charra de Evacuacion y Lucha contra incendios & especializada & Brigada LCI-EVA & $\mathrm{GH}$ & & & $\mathrm{R}$ & & & & & & & & & & \\
\hline Capacitación especializada Primeros Auxilios (certificación) & Capacitación & Brigada PA & $\mathrm{GH}$ & & & & & & $\mathrm{P}$ & & & & & & & \\
\hline 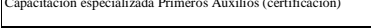 & especializada & Bngada PA & $\mathrm{GH}$ & & & & & & $\mathrm{R}$ & & & & & & & \\
\hline Capacitación térica-practica en uso de extintores & Capacitación & Brigada LCI & $\mathrm{GH}$ & & & & & & & & $\mathrm{P}$ & & & & 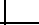 & \\
\hline apactlacion leorica-practica en uso de extintores & especializada & Bngaaa LCl & & & & & & & & & $\mathrm{R}$ & & & & & \\
\hline 1 Primeros auxilios & Capacitación & Colaboradores & GH & & & & & & & \begin{tabular}{|l|l}
$P$ \\
$R$
\end{tabular} & 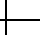 & & & & 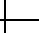 & \\
\hline be & & & & & & & - & & & & & & $P$ & & & \\
\hline 2 Evacuación en caso de Incendio & Capacitación & Colaboradores & GH & & & & & & & & & & $\mathrm{R}_{\mathrm{R}}$ & & & \\
\hline 3 Cunpcitacín en ecoeficienci & Cuncitución & Colaboradores & $\mathrm{GH}$ & & & & & & & & & & $\mathrm{P}$ & & & \\
\hline 3 Capacitación en ecoeficiencia & Capacitación & Colaboradores & GH & & & & & & & & & & $\mathrm{R}$ & & & \\
\hline 4 Canacitación en trabios cn caliente & Canacitución & Colahoradores & $\mathrm{GH}$ & & & & & & & & & & & $\mathrm{P}$ & & \\
\hline 4 Capacitación en trabajos en caliente & Capacitación & Colaboradores & $\mathrm{GH}$ & & & & & & & & & & & $\mathrm{R}$ & & \\
\hline Análisis e investigación de accidentes & Capacitación & Comité Sso & GH & & & & & & $\mathrm{P}$ & & & & & & & \\
\hline & & & & & & & & & $\mathrm{R}$ & & & & & & & \\
\hline Metodología para análisis de riesgos & Capacitación & Comité SSO & $\mathrm{GH}$ & & & & & & $\mathrm{P}$ & & & & & & 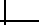 & \\
\hline & & & & & & & & & $\mathrm{R}$ & & & & & & & \\
\hline Salud ocupacional para no especialistas & Capacitación & Comité SSO & $\mathrm{GH}$ & & & & & & & & & & $\mathrm{P}$ & & 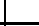 & \\
\hline & & & & & & & & & & & & & $\mathrm{R}$ & & & \\
\hline Panorama general de factores de riesgos & Canacitación & Comité Sso & $\mathrm{GH}$ & & & & & & & & & & $\mathrm{P}$ & & & \\
\hline & Capactiacion & Comile sSo & & & & & & & & & & & $\mathrm{R}$ & & & \\
\hline Simulacro de Incendios & Prevención & Colaboradores & $\mathrm{GH}$ & & & & & & & & & $\mathrm{P}$ & & & & \\
\hline & Prevencion & Colaboradores & $\mathrm{GH}$ & & & & & & & & & $\mathrm{R}$ & & & & \\
\hline Simulacro de Sismos & Prevención & Colahoradores & $\mathrm{GH}$ & & & $\mathrm{P}$ & & $\mathrm{P}$ & & & & & $P$ & $\mathrm{P}$ & 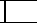 & \\
\hline Simulacro de Sismos & Prevencion & |Colaboradores & $\mathrm{GH}$ & & & $\mathrm{R}$ & & $\mathrm{R}$ & & & & & $\mathrm{R}$ & $\mathrm{R}$ & & \\
\hline Peuriogs Menules delComí de SSO & Gestín & Colahoradores & Comís $s \mathrm{so}$ & $\mathrm{P}$ & $\mathrm{P}$ & $\mathrm{P}$ & $\mathrm{P}$ & $\mathrm{P}$ & $\mathrm{P}$ & $\mathrm{P}$ & $\mathrm{P}$ & $\mathrm{P}$ & $\mathrm{P}$ & $\mathrm{P}$ & $\mathrm{P}$ & \\
\hline Kemiones siensuales aer Comite de sso & Gestron & Coliboradores & Comile $>300$ & $\mathrm{R}$ & $\mathrm{R}$ & $\mathrm{R}$ & $\mathrm{R}$ & $\mathrm{R}$ & $\mathrm{R}$ & $\mathrm{R}$ & $\mathrm{R}$ & $\mathrm{R}$ & $\mathrm{R}$ & $\mathrm{R}$ & & \\
\hline Inspecciones de Seguridad a planta y oficinas & Inspección & Colaboradores & Comisión de & & & & $\mathrm{P}$ & & & & $\mathrm{P}$ & & $P$ & & & \\
\hline Inspecciones de Seguridad a planta y oficinas & Inspección & Colaboradores & Inspección & & & & $\mathrm{R}$ & & & & $\mathrm{R}$ & & $\mathrm{R}$ & & & \\
\hline 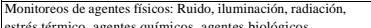 & Monitoreos & Colaboradores & $\mathrm{GH}$ & & & & & & $\mathrm{P}$ & $\mathrm{P}$ & $\mathrm{P}$ & & & & & \\
\hline ergonómico, psicosociales. & & & & & & & & & $\mathrm{R}$ & $\mathrm{R}$ & $\mathrm{R}$ & & & & & \\
\hline Realizar la Inspección del Estado de la Infraestructura del & 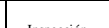 & $D_{C O}$ & I & & $\mathrm{P}$ & & $\mathrm{P}$ & & $\mathrm{P}$ & & $\mathrm{P}$ & & $\mathrm{P}$ & & $\mathrm{P}$ & \\
\hline Edificio y mobiliario & Inspección & Colaboradores & Mantenimiento & & $\mathrm{R}$ & & $\mathrm{R}$ & & $\mathrm{R}$ & & $\mathrm{R}$ & & $\mathrm{R}$ & & & \\
\hline Realizar la Inspección de las rutas de evacuación & Inspección. & Colaboradores & Mantenimiento & & $\mathrm{P}$ & & $\mathrm{P}$ & & $\mathrm{P}$ & & $\mathrm{P}$ & & $\mathrm{P}$ & & $\mathrm{P}$ & \\
\hline Realizar la Inspección de las rutas de evacuación & Inspección & Colaboradores & Mantenimiento & & $\mathrm{R}$ & & $\mathrm{R}$ & & $\bar{R}$ & & $\mathrm{R}$ & & $\mathrm{R}$ & & & \\
\hline Realizar el Control de Plagas (Fumigación, Desinfección y & Mantenimiento & Colaboradores & Mantenimiento & & & & & & & $\mathrm{P}$ & & & & & $\mathrm{P}$ & \\
\hline Desratización) & Mantenimiento & Colaboradores & Mantenimiento & & & & & & & ${ }_{\mathrm{R}}$ & & & & & & \\
\hline Realizar la inspección del Sistema de Alarma y detección contra & Inspección. & Colaboradores & Mantenimiento & $\mathrm{P}$ & $\mathrm{P}$ & $\mathrm{P}$ & $\mathrm{P}$ & $\mathrm{P}$ & $\mathrm{P}$ & $\mathrm{P}$ & $\mathrm{P}$ & $\mathrm{P}$ & $\mathrm{P}$ & $\mathrm{P}$ & $\mathrm{P}$ & \\
\hline |incendios y equipos de seguridad & Inspección & Colaboradores & & $\mathrm{R}$ & $\mathrm{R}$ & $\mathrm{R}$ & R & R & R & $\mathrm{R}$ & R & R & $\mathrm{R}$ & R & & \\
\hline Realizar la inspección de los Extintores y Gabinetes contra & & & Mantenimiento & $\mathrm{P}$ & $\mathrm{P}$ & $\mathrm{P}$ & $\mathrm{P}$ & $\mathrm{P}$ & $\mathrm{P}$ & $\mathrm{P}$ & $\mathrm{P}$ & $\mathrm{P}$ & $\mathrm{P}$ & $\mathrm{P}$ & $\mathrm{P}$ & \\
\hline incendios & Inspección & Colaboradores & Mantenimiento & $\mathrm{R}$ & $\mathrm{R}$ & $\mathrm{R}$ & $\mathrm{R}$ & $\mathrm{R}$ & $\mathrm{R}$ & $\mathrm{R}$ & $\mathrm{R}$ & $\mathrm{R}$ & $\mathrm{R}$ & $\mathrm{R}$ & & \\
\hline 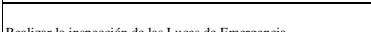 & Jnopecion & Colaboraros t & Nonerimient & $\mathrm{P}$ & $\mathrm{P}$ & $\mathrm{P}$ & $\mathrm{P}$ & $\mathrm{P}$ & $\mathrm{P}$ & $\mathrm{P}$ & $P$ & $P$ & $P$ & $P$ & $\mathrm{P}$ & \\
\hline Realizar la inspección de las Luces de Emergencia & Inspección & Colaboradores & Mantenimiento & $\mathrm{R}$ & $\mathrm{R}$ & $\mathrm{R}$ & $\mathrm{R}$ & $\mathrm{R}$ & $\mathrm{R}$ & $\mathrm{R}$ & $\mathrm{R}$ & $\mathrm{R}$ & $\mathrm{R}$ & $\mathrm{R}$ & & \\
\hline
\end{tabular}


Anexo 12. Ubicación de extintores en el primer nivel

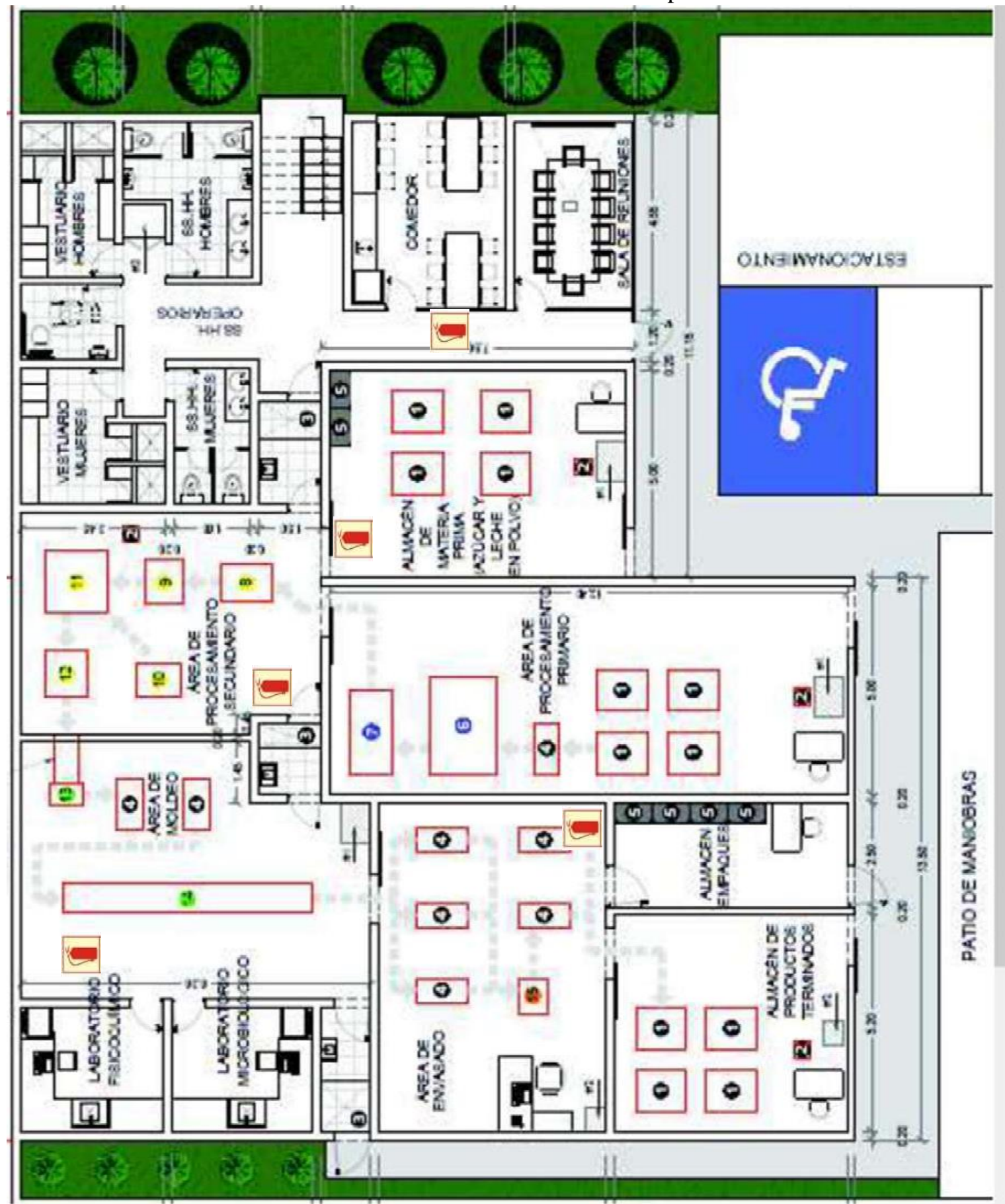


Anexo 13. Ubicación de extintores en el segundo nivel

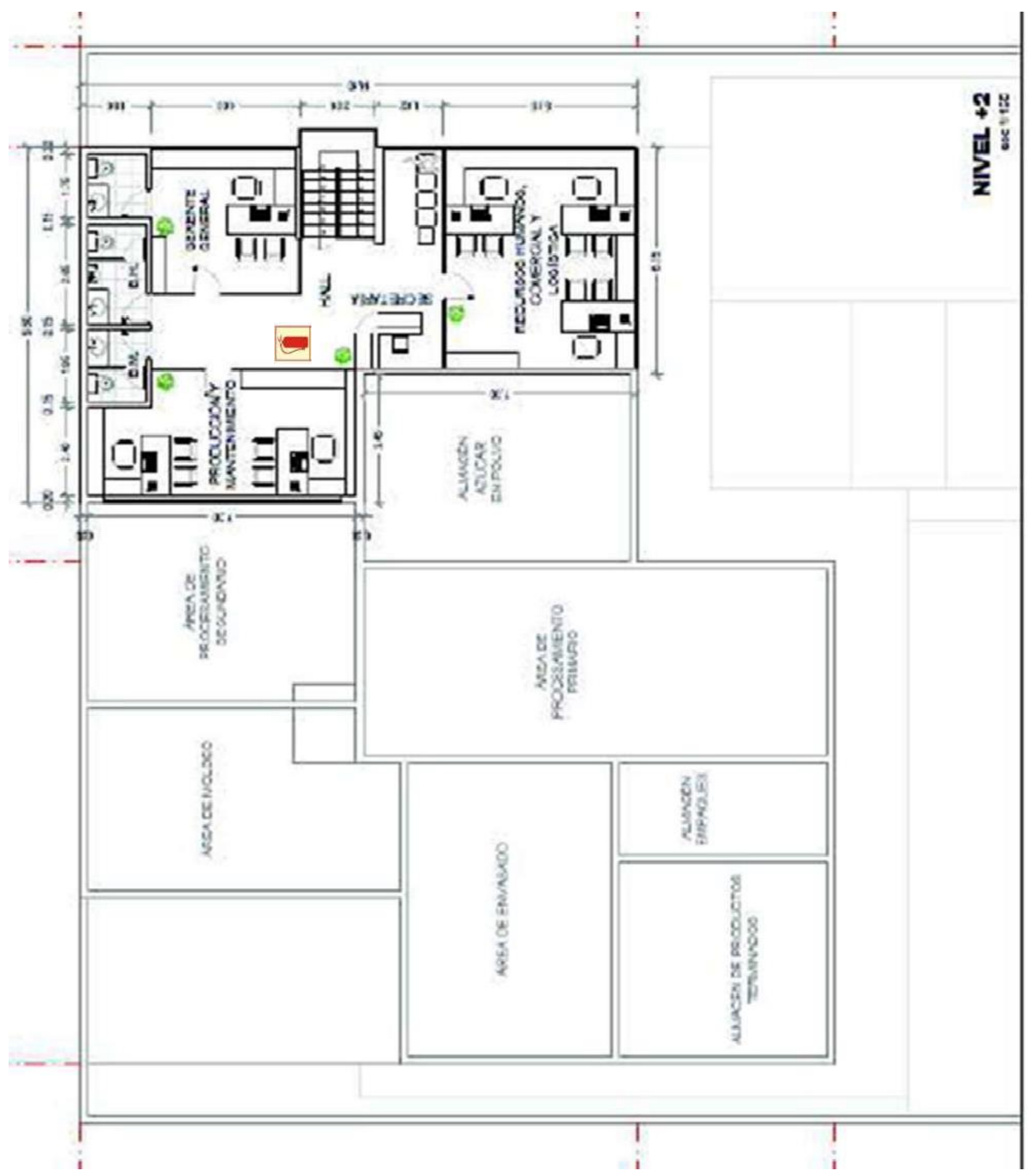


Anexo 14. Señalización en la Fábrica Chocovit

Señales de prohibición o de seguridad contra incendios

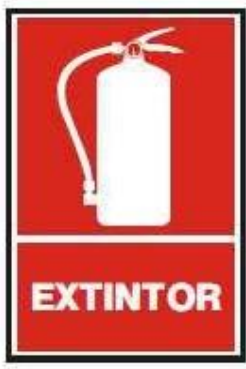

Extintor

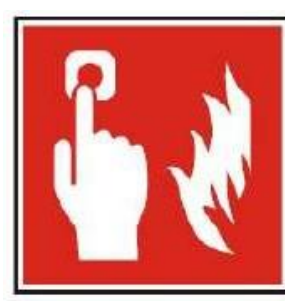

Alarma contra incendios

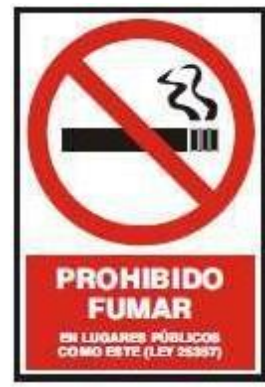

Prohibido fumar

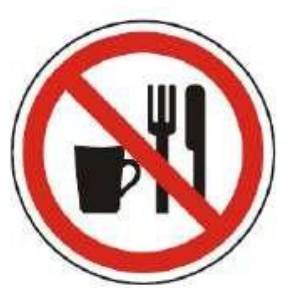

Prohibido comer o bebe

Señales de peligro

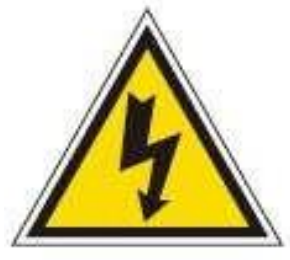

Riesgo eléctrico

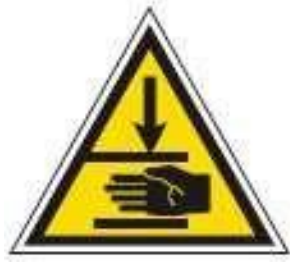

Cuidado con sus manos

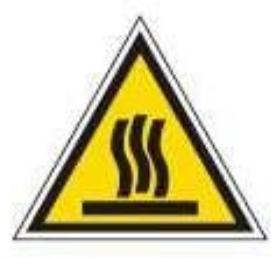

Cuidado superficie caliente

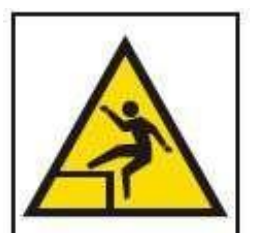

Atención peligro de caídas

Señales de obligación

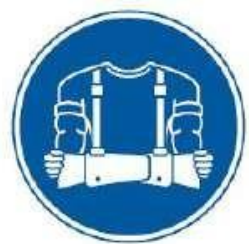

Uso obligatorio de faja

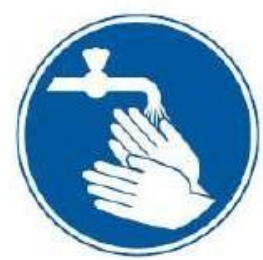

Es obligatorio lavarse las manos

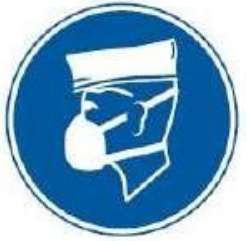

Uso obligatorio de mascarilla y gorro

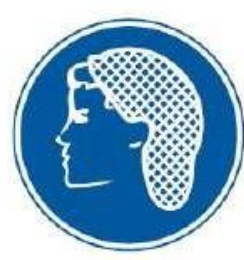

Uso obligatorio de redecilla 


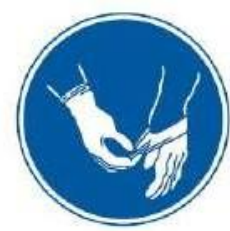

Uso

obligatorio

de guantes

Señales de seguridad

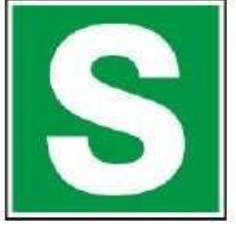

Zona

segura en

caso de

sismo
SAIDA

Salida 


\section{Anexo 15. Descripciones de Puestos}

\section{Gerencia General}

DESCRIPCIÓN DE PUESTO

\begin{tabular}{|c|c|c|c|}
\hline NOMBRE DEL PUESTO & REEMPLAZADO POR: & REPORTAA: & Numero de colaboradores en el puesto \\
\hline GERENTE GENERAL & Jefe de Administración y Gestón Humana & Directorio & 1 \\
\hline
\end{tabular}

\section{MISION DEL PUESTO:}

Es h máxima autoridad ejectutiva encargada de planificar, organizar, dirigir y controlar hadministración y marcha general de la empresa con el fin de cumplix con los objetivos, metas y polficas planteadas por ol Directorio

\begin{tabular}{|c|c|c|c|c|c|}
\hline \multicolumn{6}{|c|}{ FUNCIONES } \\
\hline \multicolumn{6}{|c|}{ Planificación estralégica de los servicios que brinda ha organización } \\
\hline \multicolumn{6}{|c|}{ Seguimicanto a resultados de los processos productives, comerciales, bogisticos y administrafivos } \\
\hline \multicolumn{6}{|c|}{ Liderar la implenertación de las actividades de mejora continas de bs procesos de toda la orgarización } \\
\hline \multicolumn{6}{|c|}{ Dar cuenta al Directorio sobre la marcha y desemipeno de k enpresa } \\
\hline \multicolumn{6}{|c|}{ Responsable del clima laboral de toda h orgarización } \\
\hline Carrera & \multicolumn{2}{|c|}{$\begin{array}{l}\text { Ingenieria Industrial, Administración, Contabìdad, } \\
\text { Economk }\end{array}$} & \multirow{2}{*}{\multicolumn{2}{|c|}{5 anos de experiencia en posiciones simulares. }} & \multirow{2}{*}{$\begin{array}{c}\text { Plarificación estratégica } \\
\text { Gestión y administración de entpresas } \\
\text { Maestria en Admininistración }\end{array}$} \\
\hline Egressido & Bachiller ఐ & Títulbdo $\square$ & & & \\
\hline \multicolumn{5}{|c|}{ COMPETENCIAS REQUERIDAS } & \multirow{2}{*}{ OBSERVACIONES } \\
\hline \multicolumn{2}{|c|}{ De la organización } & \multicolumn{2}{|c|}{ De Liderazgo } & Del Puesto & \\
\hline \multicolumn{2}{|c|}{ Mejora Continua } & \multicolumn{2}{|c|}{ Visión y anticipación } & Trabajo bajo presión & \\
\hline \multicolumn{2}{|c|}{ Trabajo en equipo } & \multicolumn{2}{|c|}{ Orientación a resultados } & Capacidad de Análisis & \\
\hline \multicolumn{2}{|c|}{ Orientación al cliente } & \multicolumn{2}{|c|}{ Liderargo } & Proactividad & \\
\hline
\end{tabular}

\begin{tabular}{|c|c|}
\hline \multicolumn{2}{|c|}{ DOMINIO DE OFFICE } \\
\hline $\begin{array}{c}\text { Word, Escel, power } \\
\text { point }\end{array}$ & Internedin \\
\hline Outlook & Internedio \\
\hline
\end{tabular}

CONOCIMIENTOS INFORMATICOS ADICIONALES REQUERIDOS

\begin{tabular}{|c|c|}
\hline \multicolumn{2}{|c|}{ DOMINIO DEL IDIOMA } \\
\hline INGLES & Avarado \\
\hline
\end{tabular}

\begin{tabular}{|c|c|c|c|}
\hline Elaboró: & Revisó: & Aprobó: & Fecha de Aprobación \\
\hline Gerente General & Gerente General & Gerente General & $20 / 10 / 2017$ \\
\hline
\end{tabular}




\begin{tabular}{|c|c|c|c|}
\hline \multicolumn{4}{|c|}{ DESCRIPCIÓN DE PUESTO } \\
\hline NOMBRE DEL PUESTO & REEMPLAZADO POR: & REPORTA A: & Número de colaboradores en el puesto \\
\hline ASIS TENTEDE GERENCIA & Assistente de Gestión Humana & Gerencin General & 1 \\
\hline Gerencia General & SECCION & $\begin{array}{r}\text { REEMPLAZA A: } \\
\text { NINGUNO }\end{array}$ & SUPERVISA A: \\
\hline
\end{tabular}

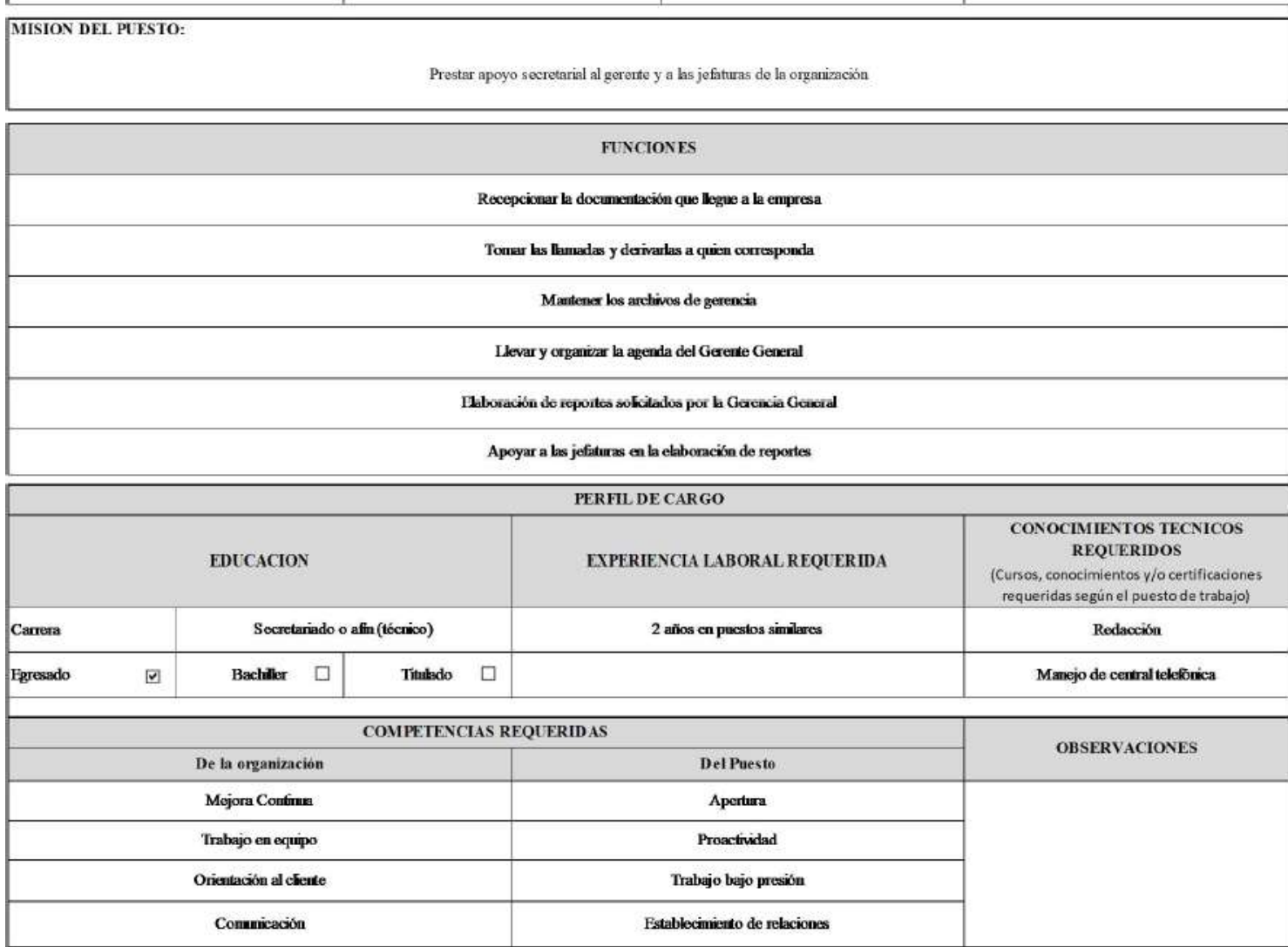

\begin{tabular}{|c|c|}
\hline \multicolumn{2}{|c|}{ DOMINIO DE OFFICE } \\
\hline $\begin{array}{c}\text { Word, Excel, power } \\
\text { point }\end{array}$ & Internedio \\
\hline Outlook & Internedio \\
\hline
\end{tabular}

CONOCIMIENTOS INFORMITICOS ADICIONALES REQUFRIDOS

\begin{tabular}{|c|}
\hline CONOCIMIENTOS INFORMLITICOS ADICIONALES REQUERIDOS \\
\hline nimguo \\
\hline
\end{tabular}

\begin{tabular}{|c|c|}
\hline \multicolumn{2}{|c|}{ DOMINIO DEL IDIOMA } \\
\hline INGLES & Intermedio \\
\hline
\end{tabular}

\begin{tabular}{|l|l|l|r|}
\hline Elaboró: & $\begin{array}{l}\text { Revisó: } \\
\text { Gerencin General }\end{array}$ & Gereate Geueral & Fecha de Aprobación \\
& & & $20 / 10 / 2017$ \\
\hline
\end{tabular}


Área de Producción

\begin{tabular}{|c|c|c|c|}
\hline \multicolumn{4}{|c|}{ DESCRIPCIÓN DE PUESTO } \\
\hline NOMBRE DEL PIESTO & REEMPLAZADO POR: & REPORTAA: & Número de colaboradores en el puesto \\
\hline JEFE DE PRODUCCIÓN & Jefe de Logítica & Gerenci General & 1 \\
\hline Producción & SECCOON & $\begin{array}{l}\text { REFMPLAZA A: } \\
\text { Jefé de Logistica }\end{array}$ & 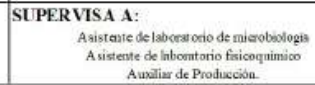 \\
\hline
\end{tabular}

\begin{tabular}{|c|c|c|c|c|c|}
\hline \multicolumn{6}{|c|}{ Coordinar, organizar, drigiri y ejecutar la gestión de h producción de la fabrica de chocolates } \\
\hline \multicolumn{6}{|c|}{ FUNCIONES } \\
\hline \multicolumn{6}{|c|}{ 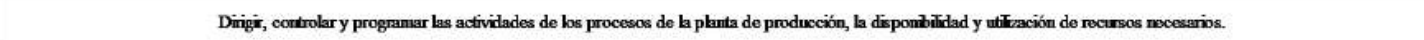 } \\
\hline \multicolumn{6}{|c|}{ Defectar has fallas técricas o potencizles que se pueden presentar en el desarrollo de la producción e imformar oportunamente } \\
\hline \multicolumn{6}{|c|}{ Coordinar el saministro oportuno de los recansos necesanios pura garantizar el nomal desarrolo de los procesos de prodacción } \\
\hline \multicolumn{6}{|c|}{ Electuar anf́lisis a las órdenes de fábricaciön y establecer variaciones presentadas, identificar sus causas y evilar su ocurrencia } \\
\hline \multicolumn{6}{|c|}{ 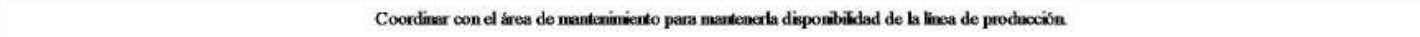 } \\
\hline \multicolumn{6}{|c|}{ PERFIL DE CARGO } \\
\hline \multicolumn{3}{|c|}{ EDLCACION } & \multicolumn{2}{|c|}{ EXPERIENCIA LABORAL REQIERIDA } & $\begin{array}{l}\text { CONOCIMIENTOS TECNICOS } \\
\text { REQUERIDOS } \\
\text { (Cursos, conocimientos } v / 0 \text { certificaciones } \\
\text { requeridas según el puestode trabajo) }\end{array}$ \\
\hline Camera & \multicolumn{2}{|c|}{$\begin{array}{l}\text { Ingenieria de Almentos, Industrial, Agroindustrial o } \\
\text { afines. }\end{array}$} & \multicolumn{2}{|c|}{$\begin{array}{l}3 \text { - } 5 \text { años de experiencia en posicioness simikres. Ideal (no exchluyente) } \\
\text { en el nubro de chocolates y sucedinneos }\end{array}$} & \multirow{2}{*}{$\begin{array}{l}\text { Gestía de indicadors } \\
\text { Planficación de be producución }\end{array}$} \\
\hline Egresado & Bachller ఐ & Titutsdo $\square$ & & & \\
\hline \multicolumn{5}{|c|}{ COMPETENAAS REQUERIDAS } & \multirow{2}{*}{ OBSERVACIONES } \\
\hline \multicolumn{2}{|c|}{ De la organización } & \multicolumn{2}{|c|}{ De Liderazgo } & Del Puesto & \\
\hline
\end{tabular}

\begin{tabular}{|c|c|c|}
\hline $\begin{array}{l}\text { Word, Excel, power } \\
\text { point }\end{array}$ & Intermedio & SAP o FRP a nivel usuario \\
\hline
\end{tabular}

\begin{tabular}{|c|c|}
\hline \multicolumn{2}{|c|}{ DOMINIO DEL IDIOMA } \\
\hline INGLES & Imemedio. Inglés técuīo \\
\hline
\end{tabular}

\begin{tabular}{|l|l|l|l|}
\hline $\begin{array}{l}\text { Elaboró: } \\
\text { Jefo de Producción }\end{array}$ & $\begin{array}{l}\text { Reviśó: } \\
\text { Jefe de Producción }\end{array}$ & Fecha de Aprobación \\
& Gerente General & $20 / 10 / 2017$ \\
\hline
\end{tabular}




\begin{tabular}{|c|c|c|c|}
\hline \multicolumn{4}{|c|}{ DESCRIFCIÓN DE PUESTO } \\
\hline $\begin{array}{l}\text { NOMBRE DEL PUESTO } \\
\text { ASISTENTE DE LABORATORIO DE } \\
\text { MICROBIOLOGIA }\end{array}$ & $\begin{array}{r}\text { REEMPLAZADO POR: } \\
\text { Jefe de Producción }\end{array}$ & $\begin{array}{l}\text { REPORTA A: } \\
\text { Jefe de Producción }\end{array}$ & Número de colaboradores en el puesto \\
\hline AREA & SECCTON & $\begin{array}{l}\text { REEMPLAZA A: } \\
\text { NINGUNO }\end{array}$ & SUPERVISA A: \\
\hline
\end{tabular}

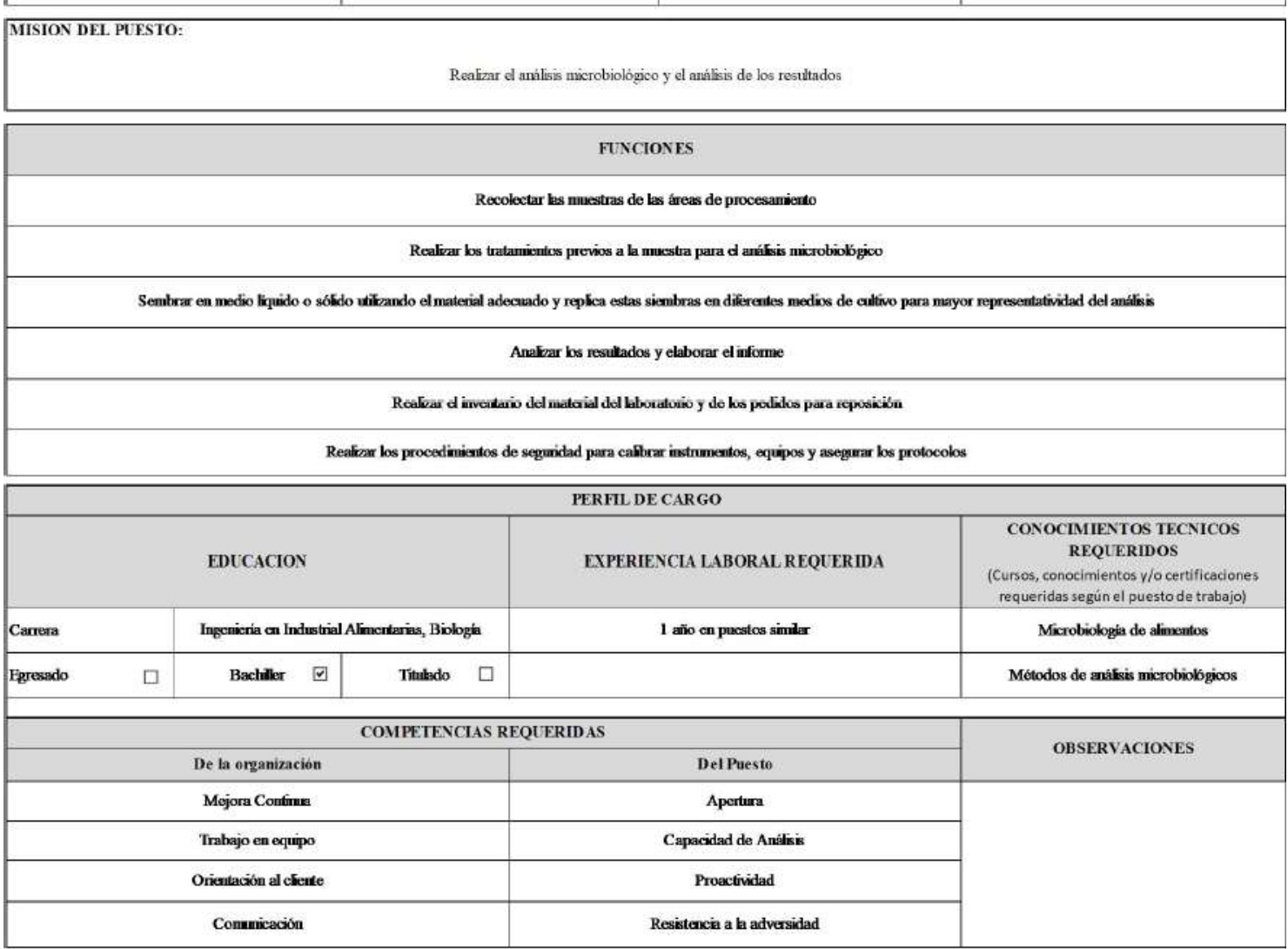

\begin{tabular}{|c|c|}
\hline \multicolumn{2}{|c|}{ DOMINIO DE OFFICE } \\
\hline $\begin{array}{c}\text { Word, Excel, power } \\
\text { point }\end{array}$ & Internedio \\
\hline Outlook & Internedio \\
\hline
\end{tabular}

CONOCIMIENTOS INFORMITICOS ADICIONALES REQUERIDOS

ningumo

\begin{tabular}{|c|c|}
\hline \multicolumn{2}{|c|}{ DOMINIO DEL IDIOMA } \\
\hline INGLES & Internedio \\
\hline
\end{tabular}

\begin{tabular}{|l|l|l|l|}
\hline $\begin{array}{l}\text { Elaboro: } \\
\text { Jefe de Producción }\end{array}$ & $\begin{array}{l}\text { Revisó: } \\
\text { Jefe de Producción }\end{array}$ & $\begin{array}{l}\text { Aprobó: } \\
\text { Gerente General }\end{array}$ & $20 / 10 / 2017$ \\
\hline
\end{tabular}




\begin{tabular}{|c|c|c|c|}
\hline \multicolumn{4}{|c|}{ DESCRIFCIÓN DE PUESTO } \\
\hline $\begin{array}{l}\text { NOMBRE DEL PUESTO } \\
\text { ASISTENTE DE LABORATORIO } \\
\text { FISICO QUIMICO }\end{array}$ & $\begin{array}{r}\text { REEMPLAZADO POR: } \\
\text { Jefe de Producción }\end{array}$ & $\begin{array}{l}\text { REPORTA A: } \\
\text { Jefe de Producción }\end{array}$ & Número de colaboradores en el puesto \\
\hline AREA & SECCTON & $\begin{array}{l}\text { REEMPLAZA A: } \\
\text { NINGUNO }\end{array}$ & SUPERVISA A: \\
\hline
\end{tabular}

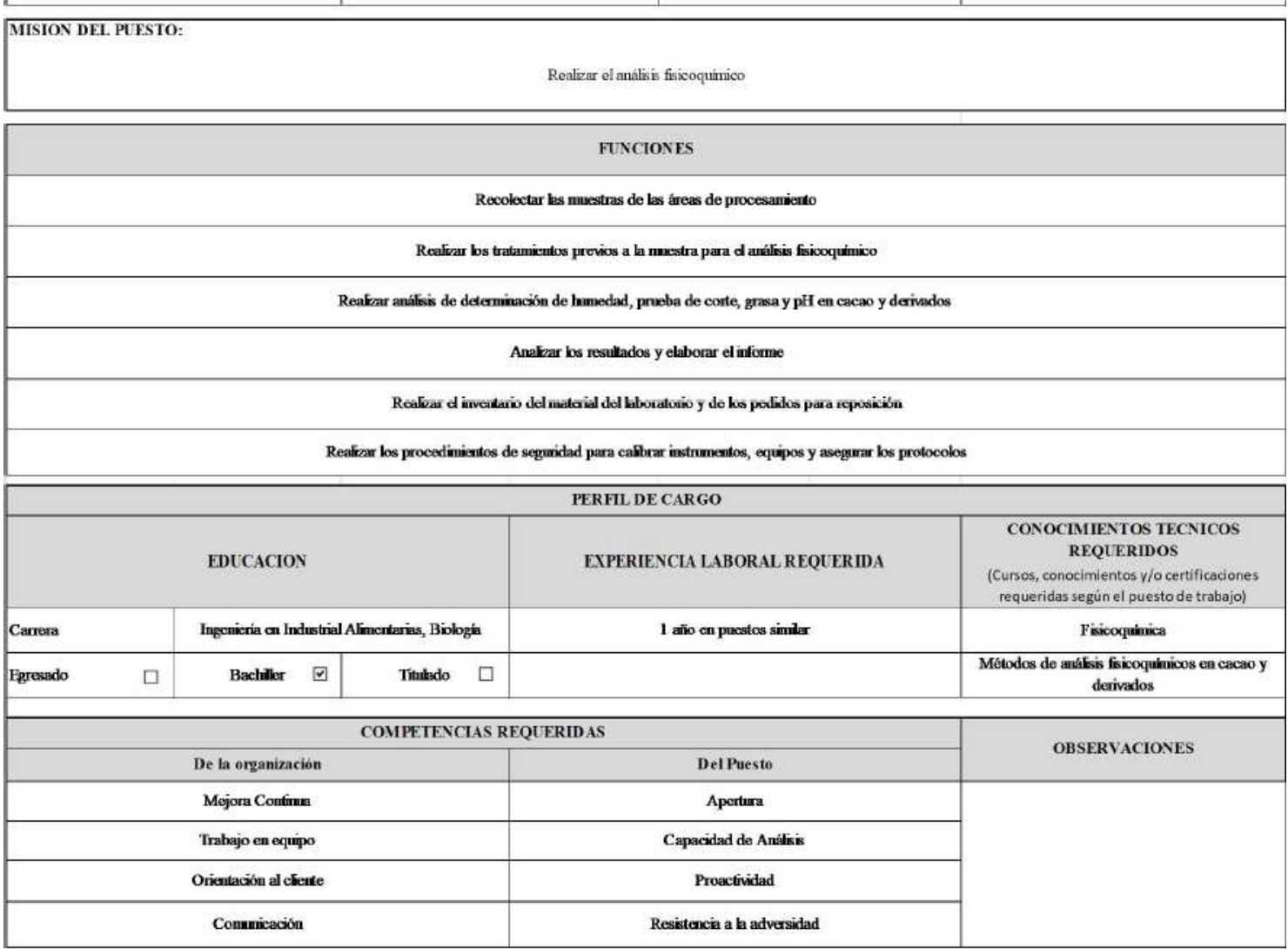

\begin{tabular}{|c|c|}
\hline \multicolumn{2}{|c|}{ DOMINIO DE OFFICE } \\
\hline $\begin{array}{c}\text { Word, Excel, power } \\
\text { point }\end{array}$ & Internedio \\
\hline Outlook & Internedio \\
\hline
\end{tabular}

CONOCIMIENTOS INFORMITICOS ADICIONALES REQUERIDOS

ningumo

\begin{tabular}{|c|c|}
\hline \multicolumn{2}{|c|}{ DOMINIO DEL IDIOMA } \\
\hline INGLES & Internedio \\
\hline
\end{tabular}

\begin{tabular}{|l|l|l|l|}
\hline $\begin{array}{l}\text { Elaboro: } \\
\text { Jefe de Producción }\end{array}$ & $\begin{array}{l}\text { Revisó: } \\
\text { Jefe de Producción }\end{array}$ & $\begin{array}{l}\text { Aprobó: } \\
\text { Gerente General }\end{array}$ & $20 / 10 / 2017$ \\
\hline
\end{tabular}




\begin{tabular}{|c|c|c|c|}
\hline \multicolumn{4}{|c|}{ DESCRIFCIÓN DE PUESTO } \\
\hline NOMBRE DEL PUESTO & REEMPLAZADO POR: & REPORTA A: & Número de colaboradores en el puesto \\
\hline AUXILIAR DE PRODUCCIÓN & Ausciliar de Producción & Jefe de Producción & 2 \\
\hline Producción & $\begin{array}{l}\text { SECCTON } \\
\text { Area de procesamicnto primario, secundario, } \\
\text { moldoo y euvasado }\end{array}$ & $\begin{array}{l}\text { REEMPLAZA A: } \\
\text { Auxiliar de Producción }\end{array}$ & SUPERVISA A: \\
\hline
\end{tabular}

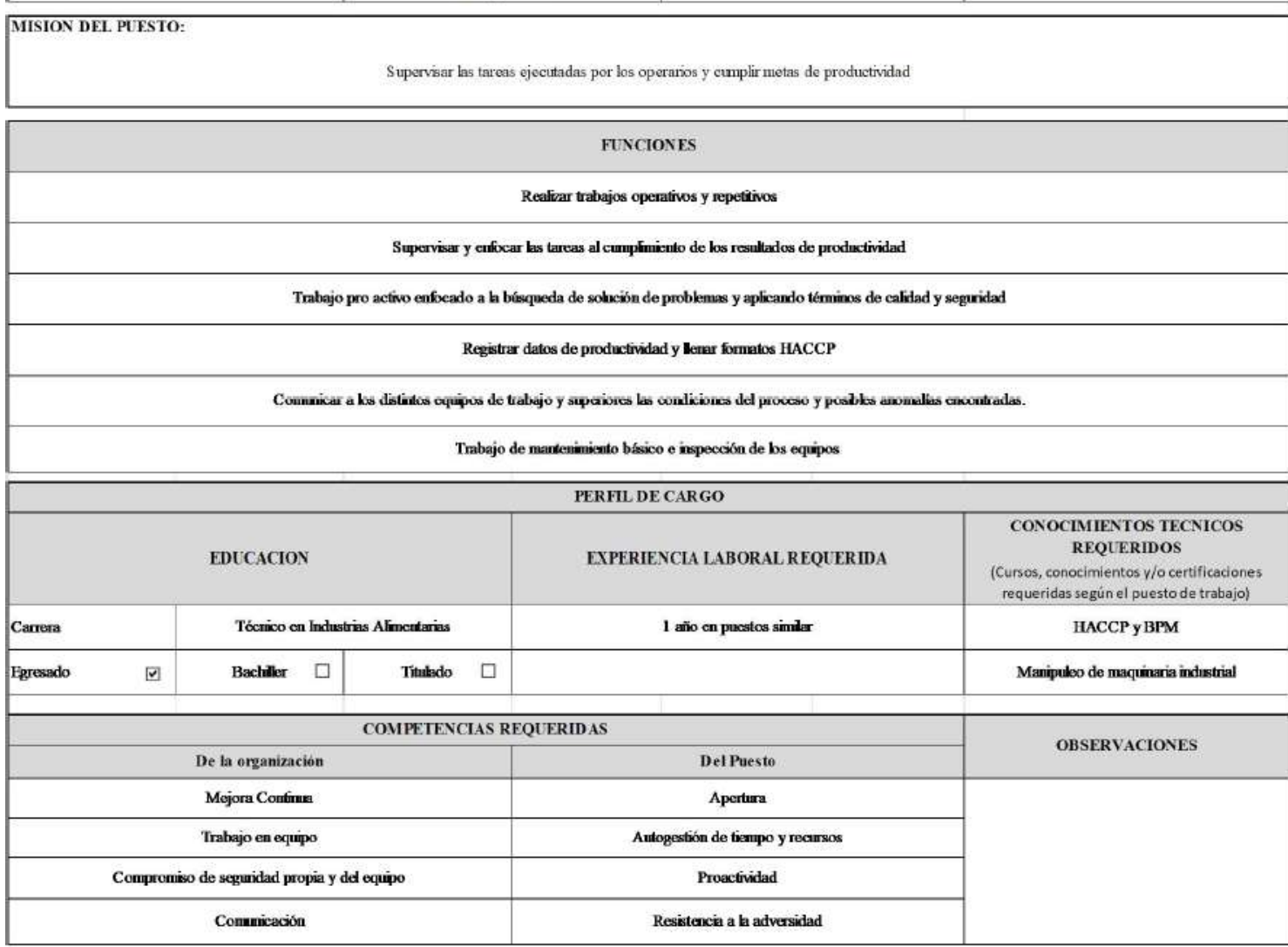

\begin{tabular}{|c|c|}
\hline \multicolumn{2}{|c|}{ DOMINIO DE OFFICE } \\
\hline $\begin{array}{c}\text { Word, Excel, power } \\
\text { point }\end{array}$ & Internedio \\
\hline Outlook & Internedio \\
\hline
\end{tabular}

CONOCIMIENTOS INFORMITICOS ADICIONALES REQUERIDOS

ningumo

\begin{tabular}{|c|c|}
\hline \multicolumn{2}{|c|}{ DOMINIO DEL IDIOMA } \\
\hline INGLES & Intermedio \\
\hline
\end{tabular}

\begin{tabular}{|l|l|l|r|}
\hline $\begin{array}{l}\text { Elaboró: } \\
\text { Jefe de Producción }\end{array}$ & $\begin{array}{l}\text { Revisó: } \\
\text { Jefe de Producción }\end{array}$ & $\begin{array}{l}\text { Aprobó: } \\
\text { Gerente General }\end{array}$ & $20 / 10 / 2017$ \\
\hline
\end{tabular}




\begin{tabular}{|c|c|c|c|}
\hline \multicolumn{4}{|c|}{ DESCRIIPCIÓN DE PUESTO } \\
\hline $\begin{array}{l}\text { NOMBRE DEL PIESTO } \\
\text { OPERARIO DE PROCESAMIENTO } \\
\text { PRMARIO }\end{array}$ & $\begin{array}{r}\text { REEMIPLAZADO POR: } \\
\text { Operario }\end{array}$ & $\begin{array}{l}\text { REPORTA A: } \\
\text { Auxiliar de Produeción }\end{array}$ & Número de colaboradores en el puesto \\
\hline Producciỏn & $\begin{array}{l}\text { SECCION } \\
\text { Área de procesaniento primanio }\end{array}$ & $\begin{array}{r}\text { REEMPLAZA A: } \\
\text { Operaio }\end{array}$ & SUPERVISA A: \\
\hline
\end{tabular}

MISION DEL PUESTO:
Desenpeñarse como operador en turno de producción con capacidad de desarollar distintas tareas as ociadas a h operación.

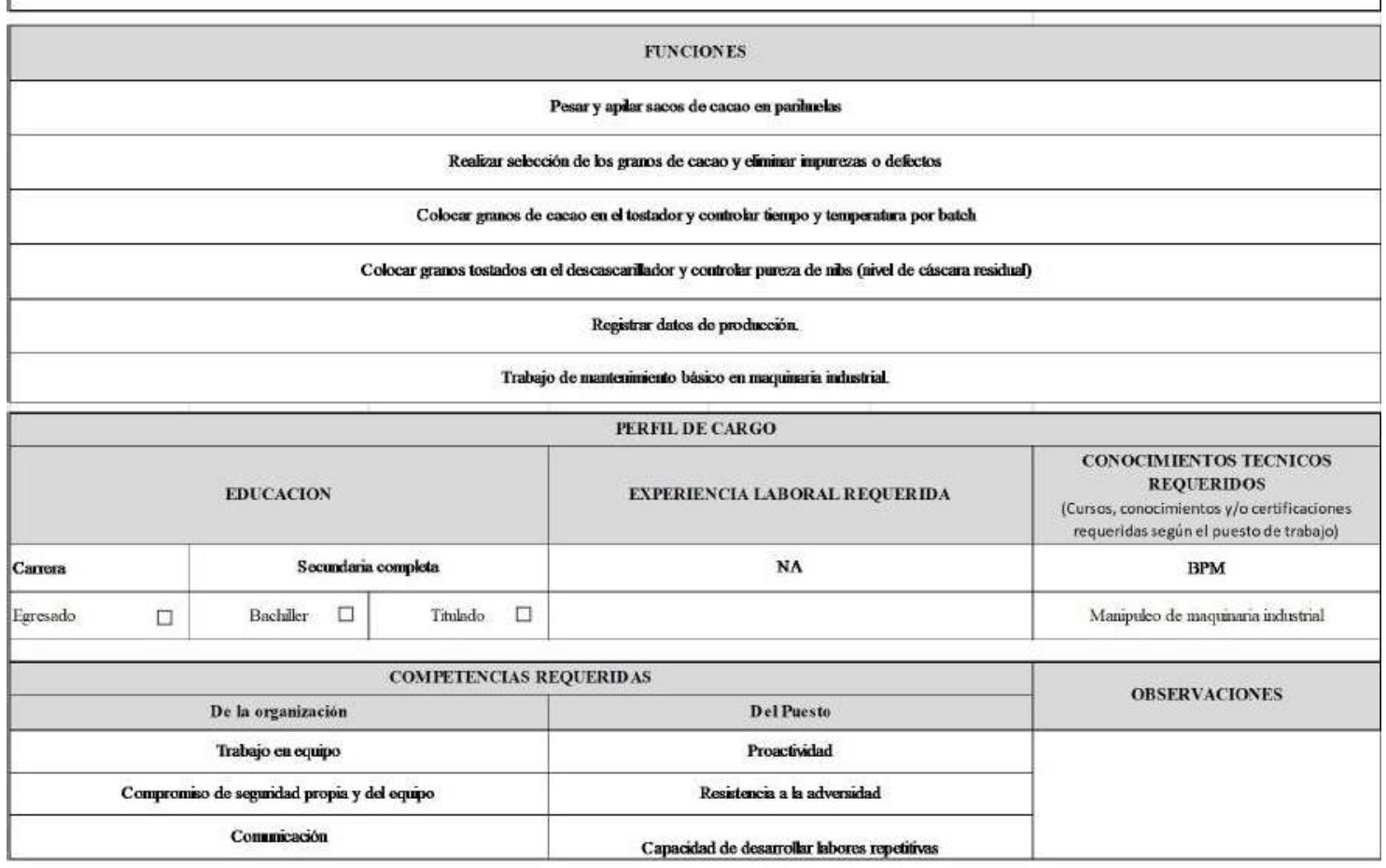

\begin{tabular}{|c|c|}
\hline \multicolumn{2}{|c|}{ DOMINIO DE OFFCE } \\
\hline $\begin{array}{c}\text { Word, Excel, power } \\
\text { point }\end{array}$ & NA \\
\hline Outlook & NA \\
\hline
\end{tabular}

CONOCIMIENTOS INFORMATICOS ADICIONALES REQLERIDOS

\begin{tabular}{|c|c|}
\hline \multicolumn{2}{|c|}{ DOMINIO DEL IDIOMA } \\
\hline INGLES & NA \\
\hline
\end{tabular}

\begin{tabular}{|l|l|l|l|}
\hline $\begin{array}{l}\text { Elaboró: } \\
\text { Jefe de Producción }\end{array}$ & $\begin{array}{l}\text { Revisó: } \\
\text { Jefe de Producción }\end{array}$ & $\begin{array}{l}\text { Fecha de Aprobación } \\
\text { Gerente General }\end{array}$ \\
\hline
\end{tabular}




\begin{tabular}{|c|c|c|c|}
\hline \multicolumn{4}{|c|}{ DESCRIPCIÓN DE PUESTO } \\
\hline $\begin{array}{l}\text { NOMBRE DEL PLESTO } \\
\text { OPERARIO DE PROCESAMIENTO } \\
\text { SECUNDARIO }\end{array}$ & $\begin{array}{r}\text { REEMIPLAZADO POR: } \\
\text { Operano }\end{array}$ & $\begin{array}{l}\text { REPORTA A: } \\
\text { Auxiliar de Producción }\end{array}$ & Número de colaboradores en el puesto \\
\hline Producciòn & $\begin{array}{l}\text { SECCIÓN } \\
\text { Área de procesamiento secundario }\end{array}$ & $\begin{array}{l}\text { REEMPLAZA A: } \\
\text { Operano }\end{array}$ & SUPERVISA A: \\
\hline
\end{tabular}

\section{MISION DEL PUESTO}

Desempeñarse como operador en turno de producción con capacidad de desarrollar distintas tareas as ociadas a h operación.

\begin{tabular}{|c|c|c|c|c|c|}
\hline \multicolumn{6}{|c|}{ Maripuleo de máquina pre-refinadora, refinadora, prensa, homogenizador y conchado } \\
\hline \multicolumn{6}{|c|}{ Pesar materia prima y derivados de cacao segín formmbción indicada } \\
\hline \multicolumn{6}{|c|}{ Registrar datos de produxciön. } \\
\hline \multicolumn{6}{|c|}{ PERFIL DE CARGO } \\
\hline \multicolumn{4}{|c|}{ EDUCACION } & EXPERIENCIA LABORAL REQUERIDA & $\begin{array}{l}\text { CONOCIMIENTOS TECNICOS } \\
\text { REQUERIDOS } \\
\text { (Cursos, conocimientos y/o certificaciones } \\
\text { requeridas segunnel puesto de trabajo) }\end{array}$ \\
\hline \multicolumn{5}{|c|}{ COMPETENCIAS REQUERIDAS } & \multirow{2}{*}{ OBSERVACIONES } \\
\hline \multicolumn{4}{|c|}{ De la organizacion } & Del Puesto & \\
\hline \multicolumn{4}{|c|}{ Trabajo en equipo } & Prosetividad & \\
\hline \multicolumn{4}{|c|}{ Compromiso de seguridad propia y del equipo } & Resistencin a b adversidad & \\
\hline \multicolumn{4}{|c|}{ Conmicación } & Capacidad de desarrollar kabores repetitivas & \\
\hline
\end{tabular}

\begin{tabular}{|c|c|}
\hline \multicolumn{2}{|c|}{ DOMINIO DE OFFICE } \\
\hline $\begin{array}{c}\text { Word, Excel, power } \\
\text { point }\end{array}$ & NA \\
\hline Outlook & NA \\
\hline
\end{tabular}

CONOCIMIENTOS INFORMATICOS ADICIONALES REQUERIDOS

ningumo

\begin{tabular}{|r|r|}
\hline & DOMINIO DEL IDIOMA \\
\hline INGLE & NA \\
\hline
\end{tabular}

\begin{tabular}{|l|l|l|r|}
\hline $\begin{array}{l}\text { Elaboró: } \\
\text { Jefe de Producción }\end{array}$ & $\begin{array}{l}\text { Revisó: } \\
\text { Jefe de Producción }\end{array}$ & $\begin{array}{r}\text { Aprobó: } \\
\text { Gerente General de Aprobación } \\
20 / 10 / 2017\end{array}$ \\
\hline
\end{tabular}




\begin{tabular}{|c|c|c|c|}
\hline \multicolumn{4}{|c|}{ DESCRIPCIÓN DE PUESTO } \\
\hline $\begin{array}{l}\text { NOMBRE DEL PUESTO } \\
\text { OPERARIO DE MOLEO }\end{array}$ & $\begin{array}{r}\text { REENIPLAZADO POR: } \\
\text { Operario }\end{array}$ & $\begin{array}{l}\text { REPORTA A: } \\
\text { Auxiliar de Producción }\end{array}$ & Número de colaboradores en el puesto \\
\hline ÁREA & SECCIÓN & $\begin{array}{r}\text { REEMPLAZA A: } \\
\text { Operaio }\end{array}$ & SUPERVISA A: \\
\hline
\end{tabular}

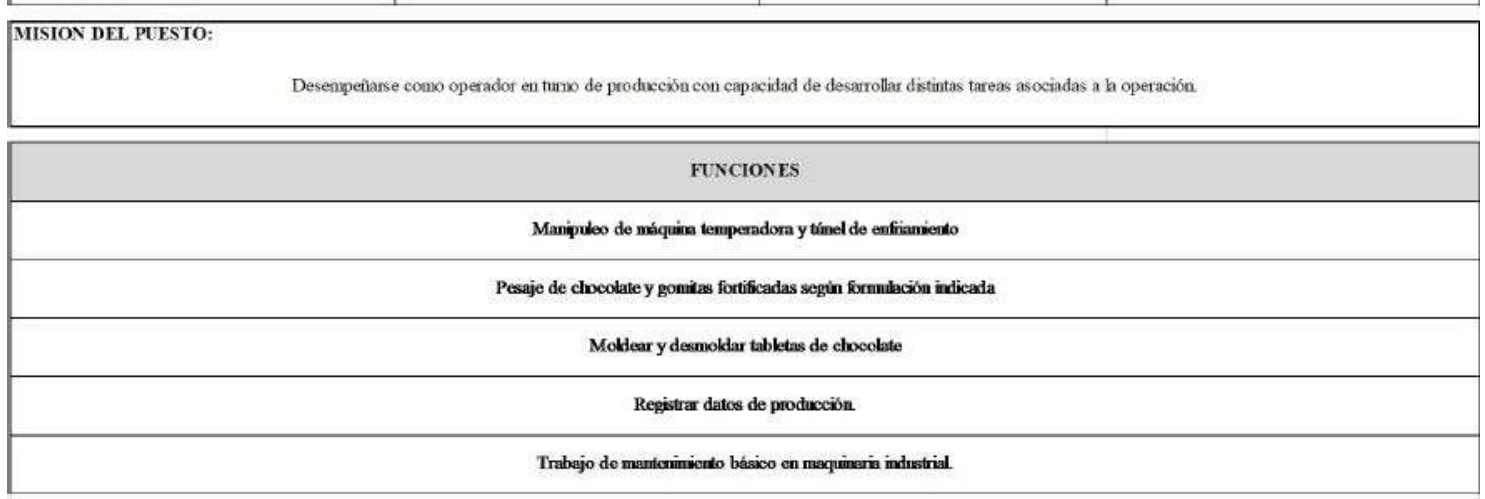

\begin{tabular}{|c|c|c|c|c|c|}
\hline \multicolumn{6}{|c|}{ Mantener linpia y ordensada el área de trabajo. } \\
\hline \multicolumn{6}{|c|}{ PERFIL DE CARGO } \\
\hline \multicolumn{4}{|c|}{ EDUCACION } & EXPERIENCIA LABORAL REQUERIDA & $\begin{array}{l}\text { CONOCIMIENTOS TECNICOS } \\
\text { REQUERIDOS } \\
\text { (Cursos, conocimientos y/o certificaciones } \\
\text { requeridas según el puesto de trabajo) }\end{array}$ \\
\hline Carrera & & \multicolumn{2}{|c|}{ Secundaria completa } & NA & BPM \\
\hline Egresedo & $\square$ & Bachiller $\square$ & Tituludo $\square$ & & \\
\hline \multicolumn{5}{|c|}{ COMPETENCLAS REQUERID AS } & \multirow{2}{*}{ OBSERVACIONES } \\
\hline \multicolumn{4}{|c|}{ De la organización } & Del Puesto & \\
\hline \multicolumn{4}{|c|}{ Trabajo en equipo } & Proactividad & \\
\hline \multicolumn{4}{|c|}{ Compromiso de segunidad propia y del equipo } & Resistencin a badversidad & \\
\hline \multicolumn{4}{|c|}{ Conumicación } & Capacidad de desamolkr babores repetitivas & \\
\hline
\end{tabular}

\begin{tabular}{|c|c|}
\hline \multicolumn{2}{|c|}{ DOMINIO DE OFFCE } \\
\hline $\begin{array}{c}\text { Word, Ercel, power } \\
\text { point }\end{array}$ & NA \\
\hline Outlook & NA \\
\hline
\end{tabular}

CONOCIMIENTOS INFORMATICOS ADICIONALES REQLERIDOS

Ninguno

\begin{tabular}{|c|r|}
\hline \multicolumn{2}{|c|}{ DOMINIO DEL IDIOMA } \\
\hline INGLES & NA \\
\hline
\end{tabular}

\begin{tabular}{|l|l|l|l|}
\hline $\begin{array}{l}\text { Elaboró: } \\
\text { Jefe de Producción }\end{array}$ & $\begin{array}{l}\text { Revisó: } \\
\text { Jefe de Producción }\end{array}$ & $\begin{array}{l}\text { Fecha de Aprobación } \\
\text { Gerente General }\end{array}$ \\
\hline
\end{tabular}


Área de Mantenimiento

\begin{tabular}{|c|c|c|c|}
\hline \multicolumn{4}{|c|}{ DESCRIFCIÓN DE PUESTO } \\
\hline NOMBRE DEL PUESTO & REEMIPLAZADO POR: & REPORTA A: & Súmero de colaboradores en el puesto \\
\hline JEFE DE MANTENIMIENTO & Jefe de Logistica & Gerencia General & 1 \\
\hline AREA & SECCIÓN & REEMPLAZAA: & SUPERVISA A: \\
\hline Logistica & & Jefe de Logistica & Auxiliar de Limpieza \\
\hline
\end{tabular}

MISION DEL PUESTO:
Gestionar la correcta aduinistración y control de los servicios de mantenimiento de maquinara, equipos e infiaestructura de la organización

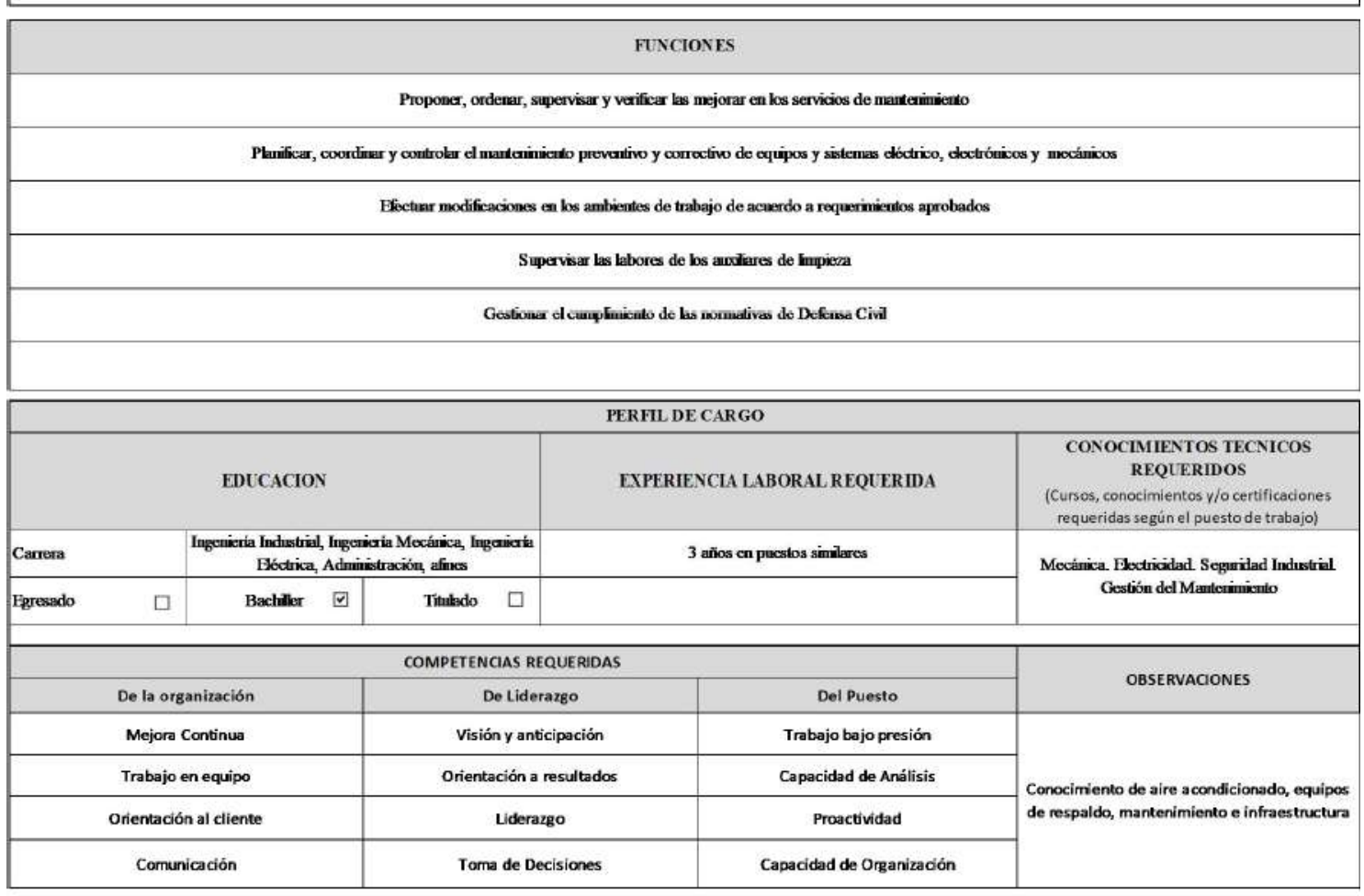

\begin{tabular}{|c|c|}
\hline \multicolumn{2}{|c|}{ DOMINIO DE OFFICE } \\
\hline $\begin{array}{c}\text { Word, Excel, power } \\
\text { point }\end{array}$ & Internedio \\
\hline Outlook & Internedio \\
\hline
\end{tabular}

CONOCIMIENTOS INFORMATICOS ADICIONALES REQUFRIDOS

\begin{tabular}{|l|c|}
\hline \multicolumn{2}{|c|}{ DOMINIO DEL IDIOMA } \\
\hline INGLES & Internedio \\
\hline
\end{tabular}

\begin{tabular}{|l|l|l|l|}
\hline $\begin{array}{l}\text { Elaboró: } \\
\text { Jefe de Mantenimiento }\end{array}$ & $\begin{array}{l}\text { Revisó: } \\
\text { Jefe de Mantenumiento }\end{array}$ & $\begin{array}{r}\text { Fecha de Aprobación } \\
\text { Gerente General } \\
20 / 10 / 2017\end{array}$ \\
\hline
\end{tabular}




\begin{tabular}{|c|c|c|c|}
\hline \multicolumn{4}{|c|}{ DESCRIFCIÓN DE PUESTO } \\
\hline NOMBRE DEL PUESTO & REEMPLAZADO POR: & REPORTA A: & Número de colaboradores en el puesto \\
\hline AUXIIIAR DE LIMPIFZA & Auxiar de Limpieza & Jefe de Mantenimiento & 2 \\
\hline Mantenimiento & SECCION & $\begin{array}{l}\text { REEMPLAZA A: } \\
\text { Auxilinr de Limpieza }\end{array}$ & SUPERVISA A: \\
\hline
\end{tabular}

MISION DEL PUESTO:
Realizar has taress de linpieza de las áreas de producción, almacenes, administrativas, servicios higiénicos, cambiadores y áreas coununes de ha phnta

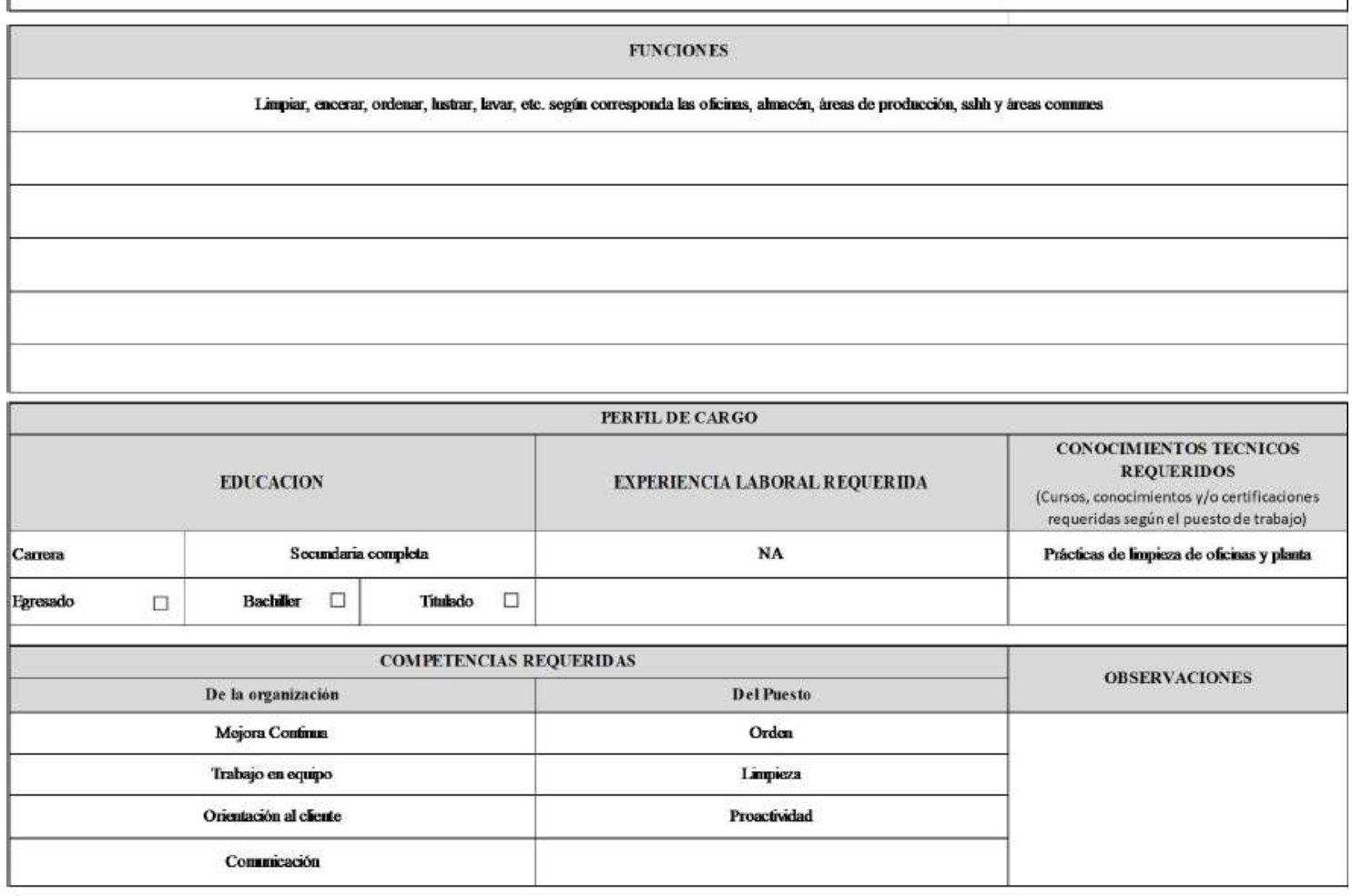

\begin{tabular}{|c|c|}
\hline \multicolumn{2}{|c|}{ DOMINIO DE OFFICE } \\
\hline $\begin{array}{c}\text { Word, Excel, power } \\
\text { point }\end{array}$ & no requerido \\
\hline Outlook & no requerido \\
\hline
\end{tabular}

CONOCIMIENTOS INFORMITICOS ADICIONALES REQUERIDOS

no requerido

\begin{tabular}{|c|c|}
\hline \multicolumn{2}{|c|}{ DOMINIO DEL IDIOMA } \\
\hline INGLES & no requerido \\
\hline
\end{tabular}

\begin{tabular}{|l|l|l|l|}
\hline $\begin{array}{l}\text { Elaboró: } \\
\text { Jefe de Mautenimiento }\end{array}$ & $\begin{array}{l}\text { Revisó: } \\
\text { Jefe de Mantenumiento }\end{array}$ & $\begin{array}{l}\text { Fecha de Aprobación } \\
\text { Gerente General }\end{array}$ & $20 / 10 / 2017$ \\
\hline
\end{tabular}




\section{Área de Logística}

\begin{tabular}{|c|c|c|c|}
\hline \multicolumn{4}{|c|}{ DESCRIFCIÓN DE PUESTO } \\
\hline NOMBRE DEL PUESTO & REEMPLAZADO POR: & REPORTA A: & Númere de colaboradores en el puesto \\
\hline JEFE DE LOGISTICA & Jefe de Producción & Gerencia General & 1 \\
\hline Logistica & SECCION & $\begin{array}{l}\text { REEMPLAZA A: } \\
\text { Jefe de Produccián }\end{array}$ & $\begin{array}{l}\text { SUPERVISA A: } \\
\text { Asistente de Logistica }\end{array}$ \\
\hline
\end{tabular}

MISION DEL PISSTO:
Coordinar, organizar, drigiz y ejecunar ha gestión logéstica referente a la adquisición de bienes y contratación de servicios, bajo las mejores condiciones técnicas, comerciales, con la finalidad de optàizar hs operaciores de he empresa a través de un abastecimiento oportuno e innovacón en la gestión de compras.

\begin{tabular}{|c|c|c|c|c|c|}
\hline \multicolumn{6}{|c|}{ FUNCIONES } \\
\hline \multicolumn{6}{|c|}{ Gestionar todo el processo logistico: almacin y compras } \\
\hline \multicolumn{6}{|c|}{ 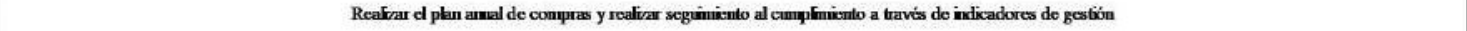 } \\
\hline \multicolumn{6}{|c|}{ Gestión de compras: Analezar e iniciar el proceso de compras atenciendo solicindes de pedidos de conplan de bienes y contratación de servicios } \\
\hline \multicolumn{6}{|c|}{$\begin{array}{l}\text { Negociar condiciones comerciales con proveedores (precios, phaos de entrega, formas de pago, garanth, Serv. Post Venta, etc.) y proceder con ta adquisición del bien o contratación de servicio al mejor } \\
\text { postor. }\end{array}$} \\
\hline \multicolumn{6}{|c|}{ 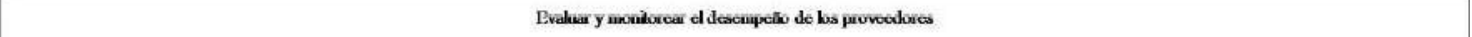 } \\
\hline \multicolumn{6}{|c|}{ Haborar informes periódicos para la gerencia general } \\
\hline \multicolumn{6}{|c|}{ PERFIL DE CARGO } \\
\hline \multicolumn{3}{|c|}{ EDUCACION } & \multicolumn{2}{|c|}{ EXPERIENCLA LABORAL REQUERIDA } & $\begin{array}{l}\text { CONOCIMIENTOS TECNICOS } \\
\text { REQLERIDOS } \\
\text { (Cursos, conocimientos y/o certificadiones } \\
\text { requeridas según el puesto de trabajo) }\end{array}$ \\
\hline Camera & $\begin{array}{r}\text { Ingenieria Industrial, Inge } \\
\text { Fóctrica, Admi }\end{array}$ & $\begin{array}{l}\text { xánica, Ingaricúa } \\
\text { n, afines }\end{array}$ & \multicolumn{2}{|c|}{ 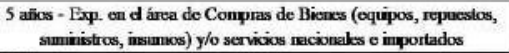 } & \multirow{2}{*}{ 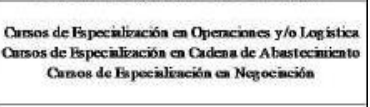 } \\
\hline Fgressido & Bachliler $\square$ & Títulsdo $\square$ & Haber labr & $\begin{array}{l}\text { ndustriales con compras superiores a } \\
20 \text { milones }\end{array}$ & \\
\hline \multicolumn{5}{|c|}{ COMPETENCIAS REQUERIDAS } & \multirow{2}{*}{ OBSERVACIONES } \\
\hline \multicolumn{2}{|c|}{ De la organización } & \multicolumn{2}{|c|}{ De Liderazgo } & Del Puesto & \\
\hline \multicolumn{2}{|c|}{ Mejore Continua } & \multicolumn{2}{|c|}{ Visión y anticipación } & Trabajo bajo presión & \multirow{4}{*}{$\begin{array}{l}\text { Conocimientos de Contabilidad Presupuestos. } \\
\text { Conocimientos Gestón de Indicadores } \\
\text { Conocimientos Tácnicas de Nhaciación }\end{array}$} \\
\hline Trabajo & en equipo & Orientación a & esultados & Capacidad de Análisis & \\
\hline Orientacic & nal cliente & Lidera & & Proactividad & \\
\hline \multicolumn{2}{|c|}{ Cornunicación } & \multicolumn{2}{|c|}{ Torna de Decisiones } & Capacidad de Organizacón & \\
\hline
\end{tabular}

\begin{tabular}{|c|c|}
\hline \multicolumn{2}{|c|}{ DOMINIO DE. OFFICE } \\
\hline $\begin{array}{c}\text { Word, Excel, power } \\
\text { point }\end{array}$ & Internedio \\
\hline Outlook & Internedio \\
\hline
\end{tabular}

CONOCIMIENTOS INFORMLITICOS ADICIONALES REQUERIDOS

\begin{tabular}{|c|c|}
\hline \multicolumn{2}{|c|}{ DOMINIO DEL IDIOMA } \\
\hline INGLES & Internedio \\
\hline
\end{tabular}

\begin{tabular}{|l|l|l|l|}
\hline $\begin{array}{l}\text { Elaboró: } \\
\text { Jefe de Logistica }\end{array}$ & $\begin{array}{l}\text { Revisó: } \\
\text { Jefe de Logistica }\end{array}$ & $\begin{array}{r}\text { Fecha de Aprobación } \\
\text { Gerente General } \\
20 / 10 / 2017\end{array}$ \\
\hline
\end{tabular}




\begin{tabular}{|c|c|c|c|}
\hline \multicolumn{4}{|c|}{ DESCRIFCIÓN DE PUESTO } \\
\hline $\begin{array}{l}\text { NOMBRE DEL PUESTO } \\
\text { ASISTENTE DE LOGISTICA }\end{array}$ & $\begin{array}{l}\text { REEMPLAZADO POR: } \\
\text { Jefe de Logistica }\end{array}$ & $\begin{array}{r}\text { REPORTA A: } \\
\text { Jefe de Logistica }\end{array}$ & Número de colaboradores en el puesto \\
\hline $\begin{array}{l}\text { AREA } \\
\text { Logistica }\end{array}$ & SECCTON & $\begin{array}{r}\text { REEMPLAZA A: } \\
\text { Jefe de Logistica }\end{array}$ & $\begin{array}{l}\text { SUPERVISA A: } \\
\text { Opeiarios de Almacén (3) }\end{array}$ \\
\hline
\end{tabular}
MISION DEL PUESTO:

Asistir a la jefatura en la gestión logistica referente a la adquisición de bienes y contratación de servicios, bajo las mejores condiciones téenicas, comerciales, con la frabidad de optimizar las operaciones de la empresa a través de mi abastecinicnto oportuso e iniovación en la gestión de compras.

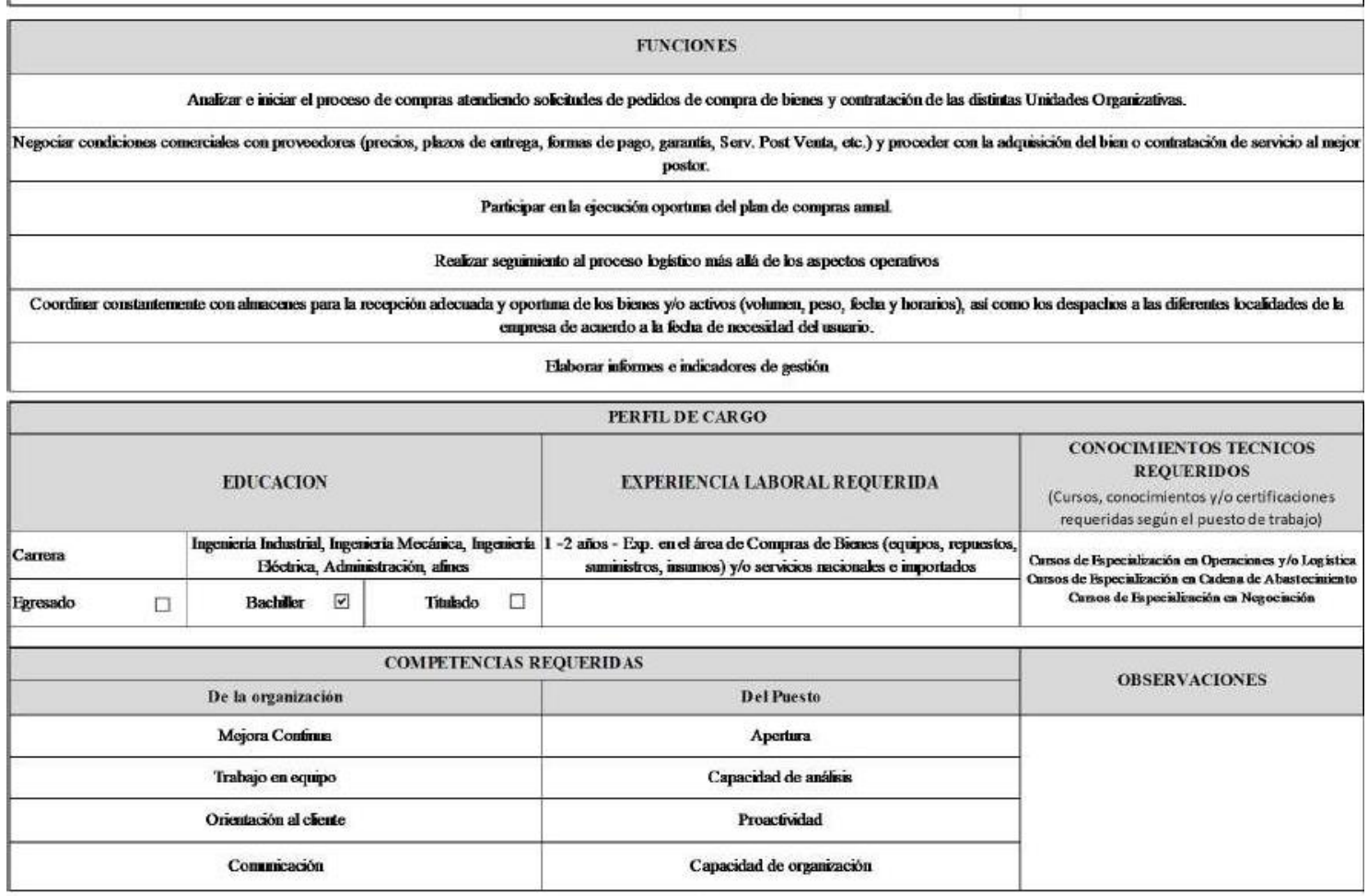

\begin{tabular}{|c|c|}
\hline \multicolumn{2}{|c|}{ DOMINIO DE OFFCE } \\
\hline $\begin{array}{c}\text { Word, Exceh, power } \\
\text { point }\end{array}$ & Internedio \\
\hline Outlook & Internedio \\
\hline
\end{tabular}

CONOCIMIENTOS INFORMLITICOS ADICIONALES REQUERIDOS

SAP o ERP a nivel usuanio

\begin{tabular}{|c|c|}
\hline \multicolumn{2}{|c|}{ DOMINIO DEL IDIOMA } \\
\hline INGLES & Básico \\
\hline
\end{tabular}

\begin{tabular}{|l|l|l|l|}
\hline $\begin{array}{l}\text { Elaboro: } \\
\text { Jefe de Logística }\end{array}$ & $\begin{array}{l}\text { Revisó: } \\
\text { Jefe de Logistica }\end{array}$ & $\begin{array}{l}\text { Aprobó: } \\
\text { Gerente General }\end{array}$ & $20 / 10 / 2017$ \\
\hline
\end{tabular}




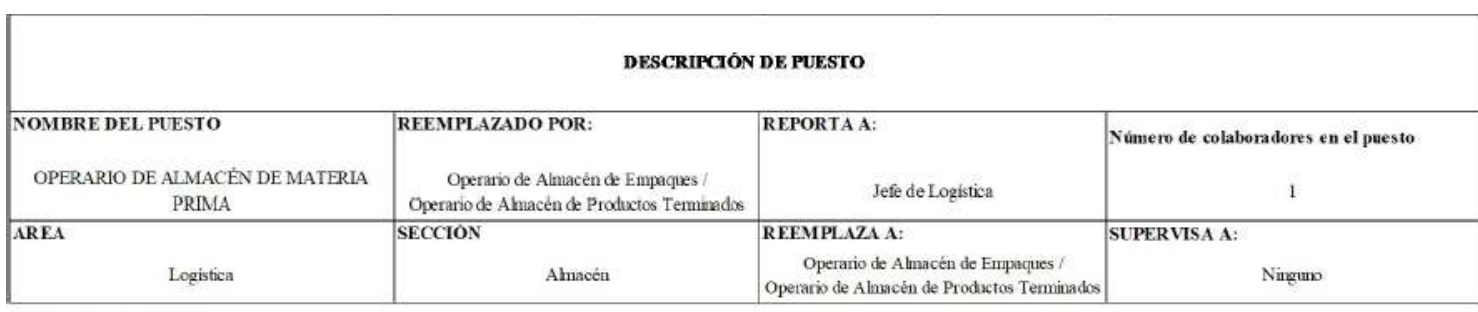

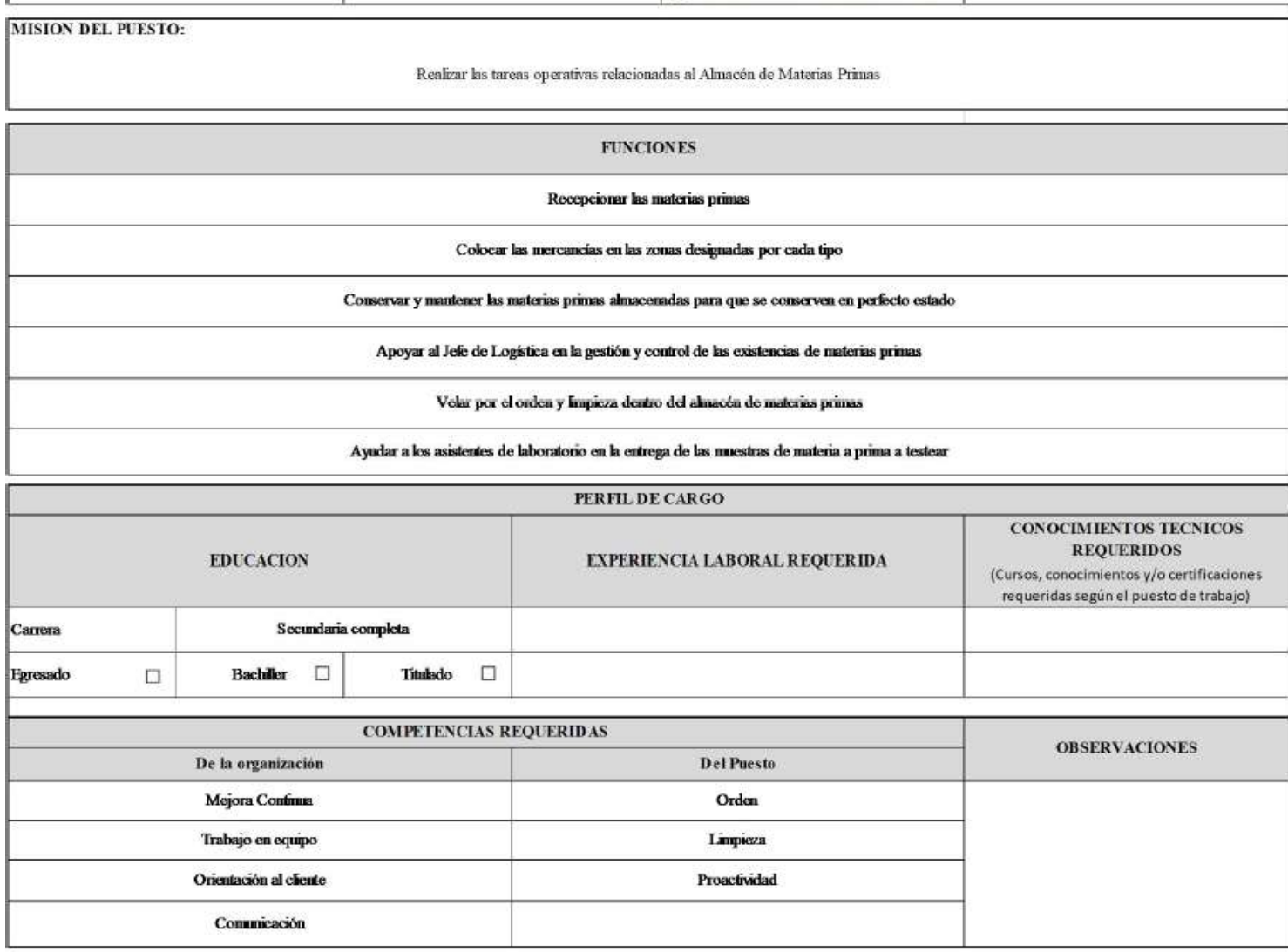

\begin{tabular}{|c|c|}
\hline \multicolumn{2}{|c|}{ DOMINIO DE OFFICE } \\
\hline $\begin{array}{c}\text { Word, Excel, power } \\
\text { point }\end{array}$ & no requerido \\
\hline Outlook & no requerido \\
\hline
\end{tabular}

CONOCIMIENTOS INFORMATICOS ADICIONALES REQUERIDOS

no requerido

\begin{tabular}{|c|c|}
\hline \multicolumn{2}{|c|}{ DOMINIO DEL IDIOMA } \\
\hline INGLES & no requerido \\
\hline
\end{tabular}

\begin{tabular}{|c|c|c|c|}
\hline Elaboro: & Revisó: & Aprobo: & Fecha de Aprobación \\
\hline Jefe de Logistica & Jefe de Logistica & Gerente General & $20 / 10 / 2017$ \\
\hline
\end{tabular}




\begin{tabular}{|c|c|c|c|}
\hline \multicolumn{4}{|c|}{ DESCRIFCIÓN DE PUESTO } \\
\hline NOMBRE DEL PUESTO & REEMPLAZADO POR: & REPORTA A: & Número de colaboradores en el puesto \\
\hline OPERARIO DE ALMACEN DE EMPAQUES & $\begin{array}{l}\text { Operario de Almacén de Materia Prima } \\
\text { Operario de Almacén de Productos Terminadro }\end{array}$ & Jefe de Logistica & 1 \\
\hline AREA & SECCION & REEMPLAZA A: & SUPERVISA A: \\
\hline
\end{tabular}

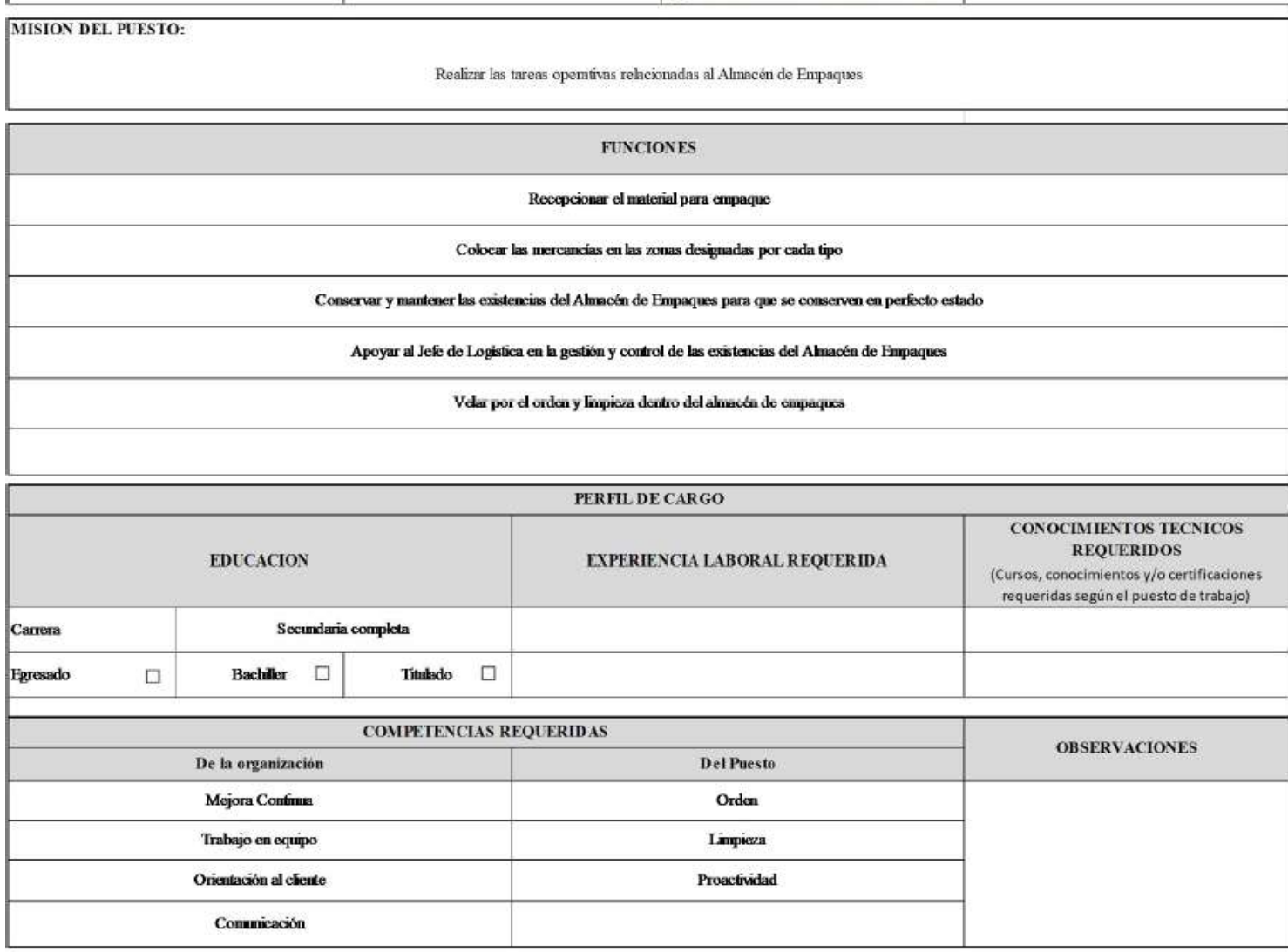

\begin{tabular}{|c|c|}
\hline \multicolumn{2}{|c|}{ DOMINIO DE OFFICE } \\
\hline $\begin{array}{c}\text { Word, Excel, power } \\
\text { point }\end{array}$ & no requerido \\
\hline Outlook & no requerido \\
\hline
\end{tabular}

CONOCIMIENTOS INFORMATICOS ADICIONALES REQUERIDOS

no requerido

\begin{tabular}{|c|c|}
\hline \multicolumn{2}{|c|}{ DOMINIO DEL IDIOMA } \\
\hline INGLES & no requerido \\
\hline
\end{tabular}

\begin{tabular}{|c|c|c|c|}
\hline Elaboro: & Revisó: & Aprobo: & Fecha de Aprobación \\
\hline Jefe de Logistica & Jefe de Logistica & Gerente General & $20 / 10 / 2017$ \\
\hline
\end{tabular}




\begin{tabular}{|c|c|c|c|}
\hline \multicolumn{4}{|c|}{ DESCRIFCIÓN DE PUESTO } \\
\hline $\begin{array}{l}\text { NOMBRE DEL PUESTO } \\
\text { OPERARIO DE ALMACÉN DE PRODUCTOS } \\
\text { TERMINADOS }\end{array}$ & $\begin{array}{l}\text { REEMPLAZADO POR: } \\
\text { Operario de Amacén de Materia Prima / } \\
\text { Operanio de Almacen de Empaques }\end{array}$ & $\begin{array}{r}\text { REPORTA A: } \\
\text { Jefe de Logistica }\end{array}$ & Número de colaboradores en el puesto \\
\hline AREA & SECCION & $\begin{array}{l}\text { REEMPLAZA A: } \\
\text { Operanio de Almacén de Materin Priua } \\
\text { Operario de Almacén de Empaques }\end{array}$ & SUPERVISA A: \\
\hline
\end{tabular}

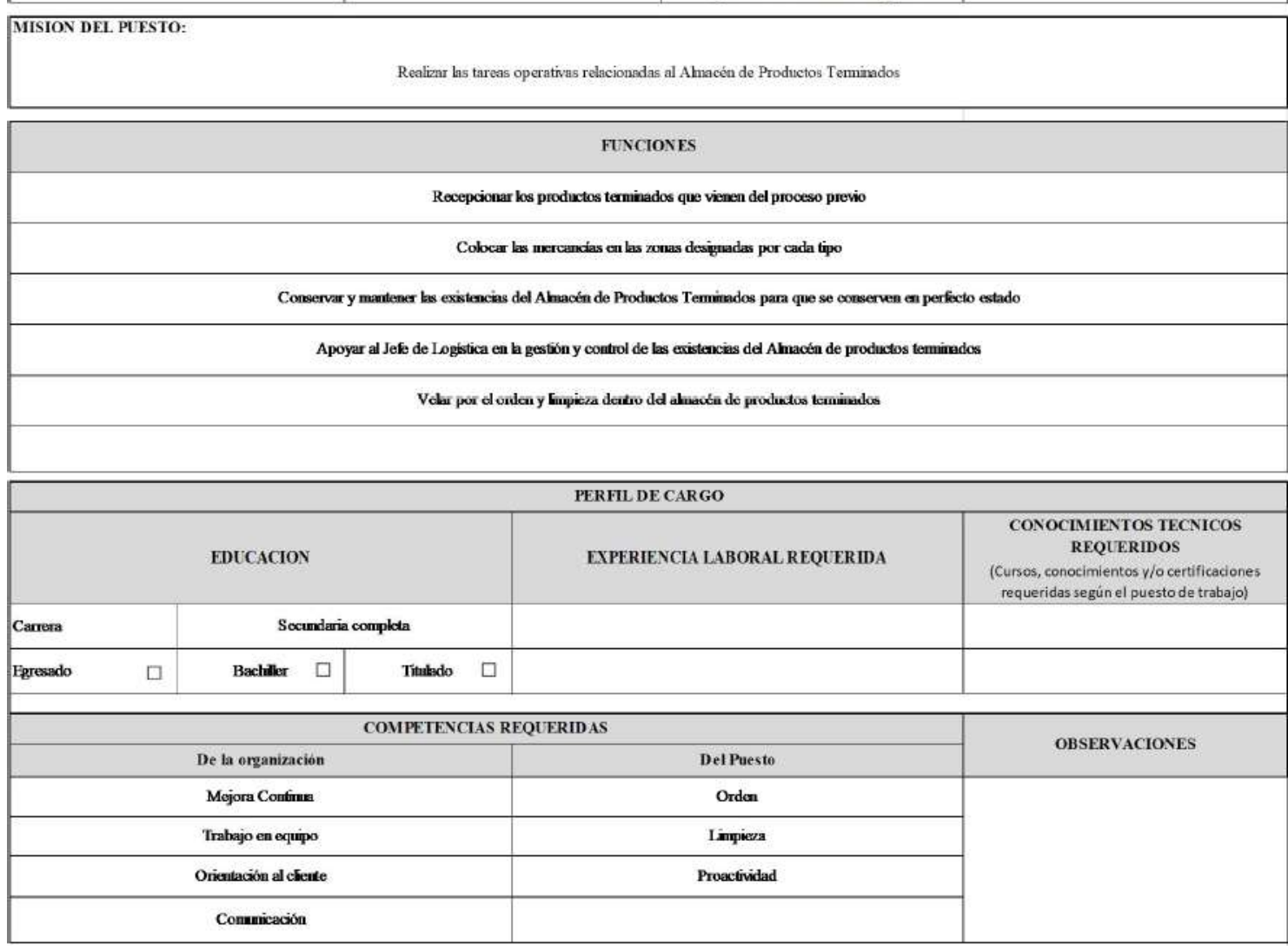

\begin{tabular}{|c|c|}
\hline \multicolumn{2}{|c|}{ DOMINIO DE OFFICE } \\
\hline $\begin{array}{c}\text { Word, Excel, power } \\
\text { point }\end{array}$ & no requerido \\
\hline Outlook & no requerido \\
\hline
\end{tabular}

CONOCIMIENTOS INFORMITICOS ADICIONALES REQUERIDOS

no requerido

\begin{tabular}{|c|c|}
\hline \multicolumn{2}{|c|}{ DOMINIO DEL IDIOMA } \\
\hline INGLES & no requerido \\
\hline
\end{tabular}

\begin{tabular}{|l|l|l|l|}
\hline $\begin{array}{l}\text { Elaboró: } \\
\text { Jefe de Logistica }\end{array}$ & $\begin{array}{l}\text { Revisó: } \\
\text { Jefe de Logistica }\end{array}$ & $\begin{array}{r}\text { Fecha de Aprobación } \\
\text { Gerente General } \\
20 / 10 / 2017\end{array}$ \\
\hline
\end{tabular}




\begin{tabular}{|c|c|c|c|}
\hline \multicolumn{4}{|c|}{ DESCRIPCIÓN DE PUESTO } \\
\hline $\begin{array}{l}\text { NOMBRE DEL PUESTO } \\
\text { JEFE DE ADMINISTRACIÓN Y GESTIÓN } \\
\text { HUMANA }\end{array}$ & $\begin{array}{l}\text { REEMPLAZADO POR: } \\
\text { Assitente de Gestión Humana }\end{array}$ & $\begin{array}{r}\text { REPORTA A: } \\
\text { Gerenca General }\end{array}$ & $\begin{array}{c}\text { Número de colaboradores en el puesto } \\
1\end{array}$ \\
\hline $\begin{array}{l}\text { AREA } \\
\end{array}$ & SECCION & $\begin{array}{l}\text { REEMPLAZA A: } \\
\text { Asistenre de Gestičn Humana }\end{array}$ & $\begin{array}{l}\text { SLPERVISA A: } \\
\text { Assitente de Gestión Humana }\end{array}$ \\
\hline
\end{tabular}

\section{MISION DEL PUESTO:}

Responsable de h gestión administrativa, contable-fruanciera y de recursos humanos de ha organización

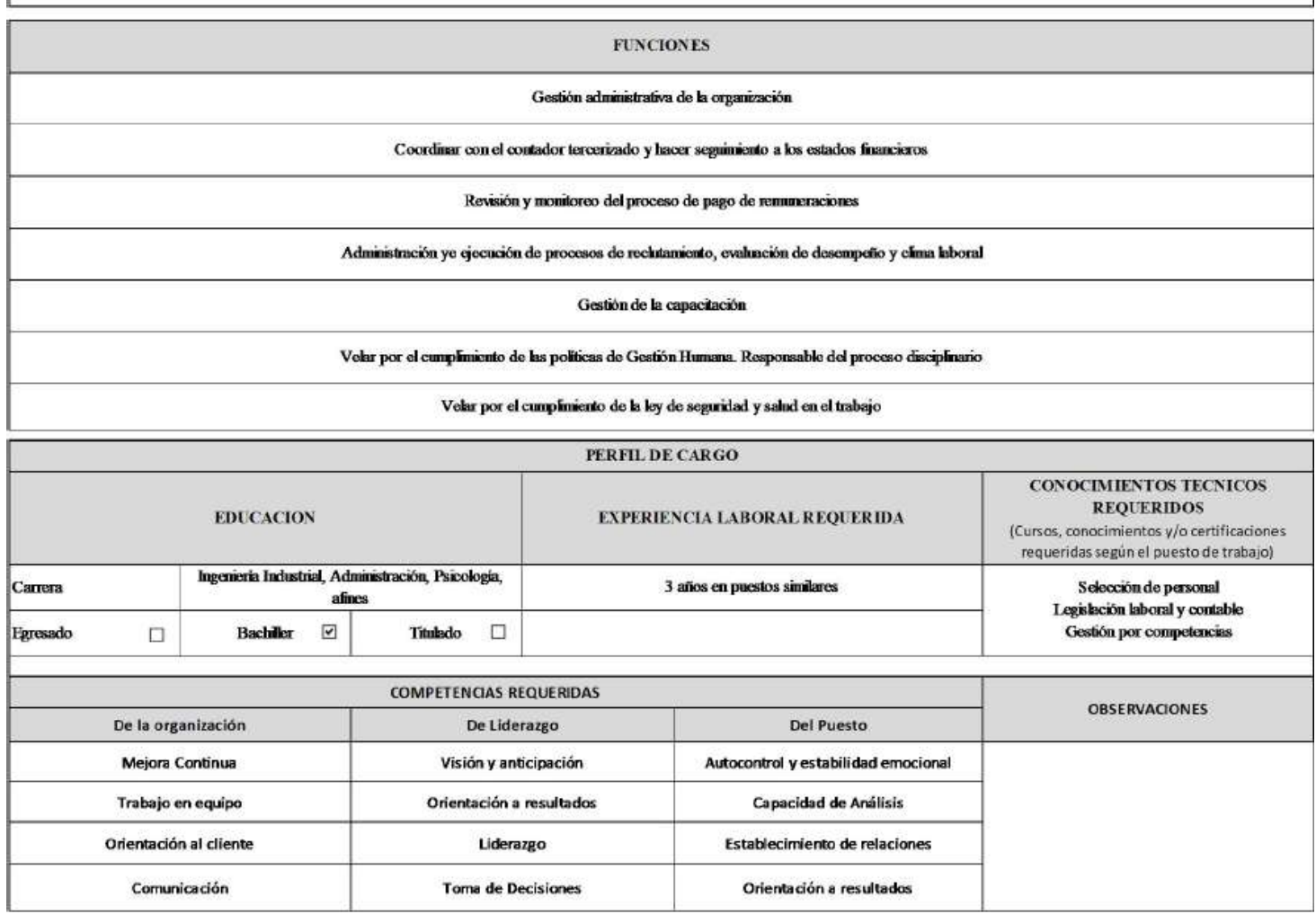

\begin{tabular}{|c|c|}
\hline \multicolumn{2}{|c|}{ DOMINIO DE OFFICE } \\
\hline $\begin{array}{c}\text { Word, Excel, power } \\
\text { point }\end{array}$ & Internedio \\
\hline Outlook & Internedio \\
\hline
\end{tabular}

\begin{tabular}{|c|}
\hline CONOCIMIENTOS INFORMATICOS ADICIONALES REQUERIDOS \\
Soltware de plamilas \\
\hline PDT Sumat \\
\hline
\end{tabular}

\begin{tabular}{|c|c|}
\hline \multicolumn{2}{|c|}{ DOMINIO DEL IDIOMA } \\
\hline INGLES & Intermedio \\
\hline
\end{tabular}

\begin{tabular}{|c|c|c|c|}
\hline Elaborv: & Revisó: & Aprobo: & Fecha de Aprobación \\
\hline Jefe de Adninistración y Gestión Humaana & Jefe de Aduninistración y Gestión Humaan & Gerente General & $20 / 10 / 2017$ \\
\hline
\end{tabular}




\begin{tabular}{|c|c|c|c|}
\hline \multicolumn{4}{|c|}{ DESCRIPCIÓN DE PUESTO } \\
\hline Gestión Humana & SECCION & $\begin{array}{l}\text { REFMPL.AZA A: } \\
\text { Jefe de Administración y Gestikn Humana }\end{array}$ & SUPERVISA A: \\
\hline
\end{tabular}
MISION DEL PUESTO:

A sistir a la Jefistura de Admiristración y Gestión Humana de acuerdo a las normas legales vigentes y politicas de la organización

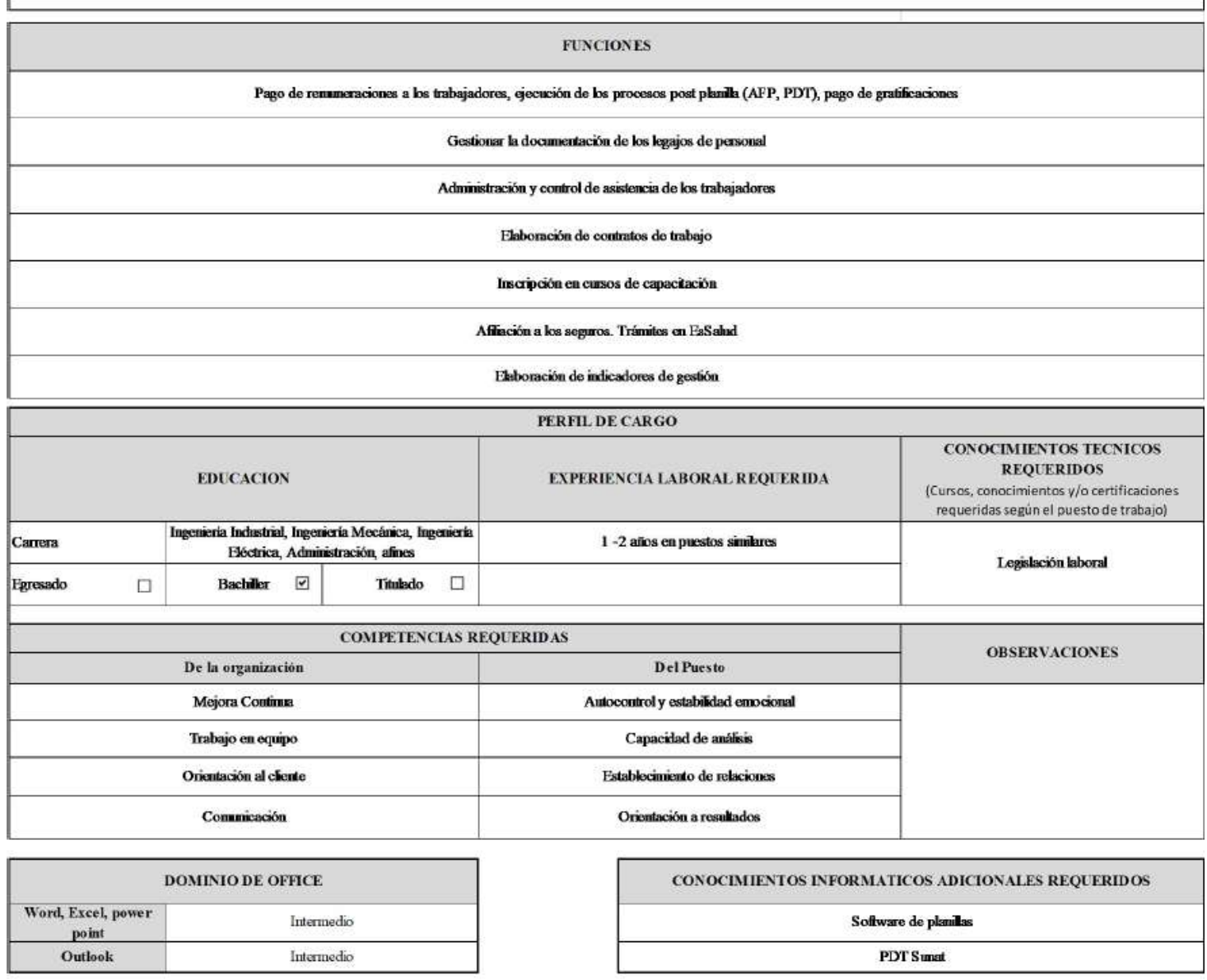

\begin{tabular}{|c|c|}
\hline \multicolumn{2}{|c|}{ DOMINIO DEL IDIOMA } \\
\hline INGLES & Básico \\
\hline
\end{tabular}

\begin{tabular}{|c|c|c|c|}
\hline Elaboro: & Revisó: & Aprobó: & Fecha de Aprobación \\
\hline Jefo de Adrministración y Gestión Humana & Jefe de Aduninistración y Gestión Humana & Gerente General & $20 / 10 / 2017$ \\
\hline
\end{tabular}




\section{Área Comercial}

\begin{tabular}{|c|c|c|c|}
\hline \multicolumn{4}{|c|}{ DESCRIICIÓN DE PUESTO } \\
\hline $\begin{array}{l}\text { NOMBRE DEL PUESTO } \\
\text { JEFE COMERCIAL. }\end{array}$ & $\begin{array}{l}\text { REEMPLAZADO POR: } \\
\text { Jefe de Administración y Gestión hmmana }\end{array}$ & $\begin{array}{r}\text { REPORTA A: } \\
\text { Gerente General }\end{array}$ & $\begin{array}{c}\text { Número de colaboradores en el puesto } \\
1\end{array}$ \\
\hline AREA & SECCION & $\begin{array}{l}\text { REEMPLAZA A: } \\
\text { Jefo de Administración y Gestión humana }\end{array}$ & $\begin{array}{l}\text { SUPERVISA A: } \\
\text { Vendedor de Limn y Provincias }\end{array}$ \\
\hline
\end{tabular}

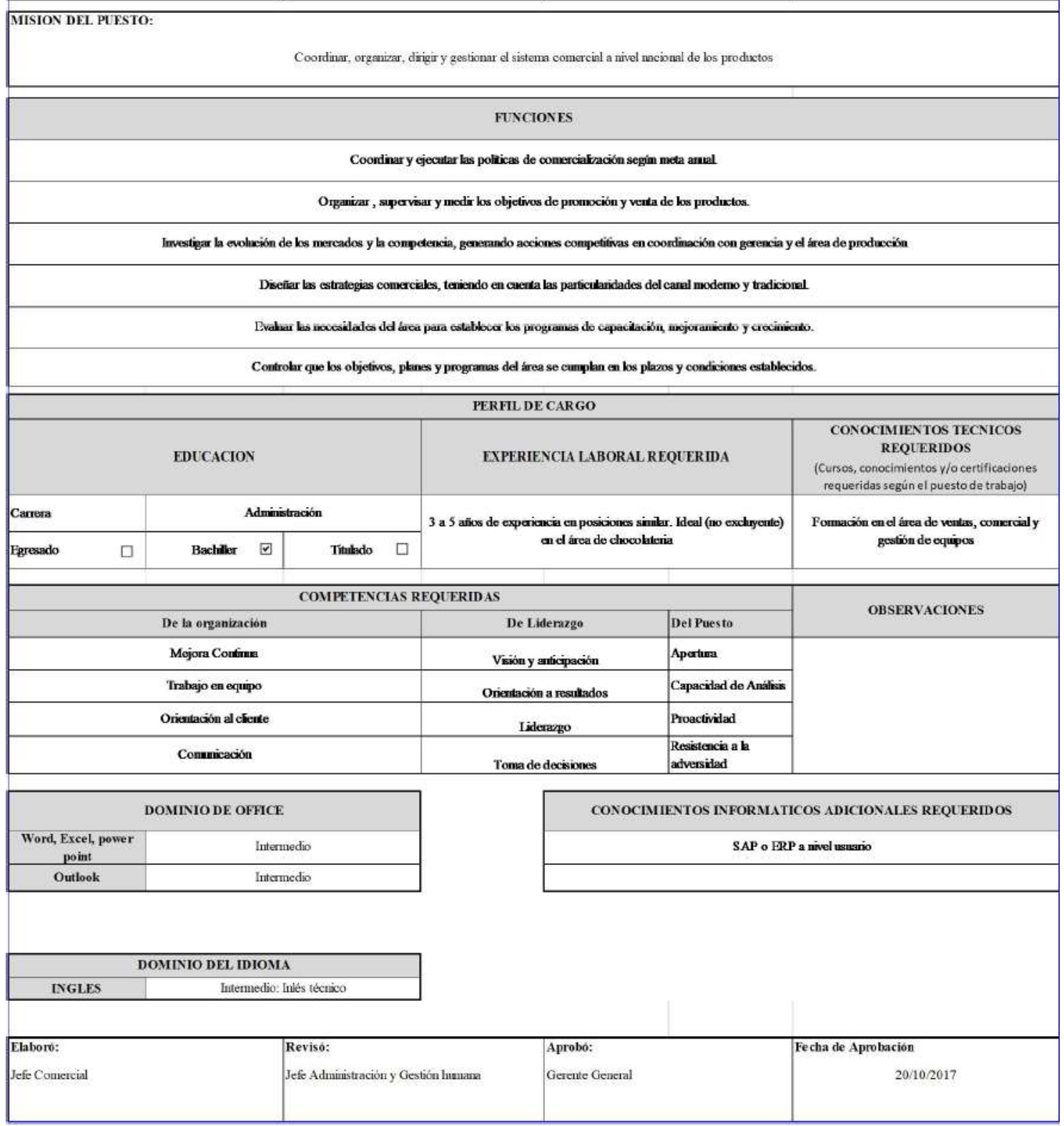




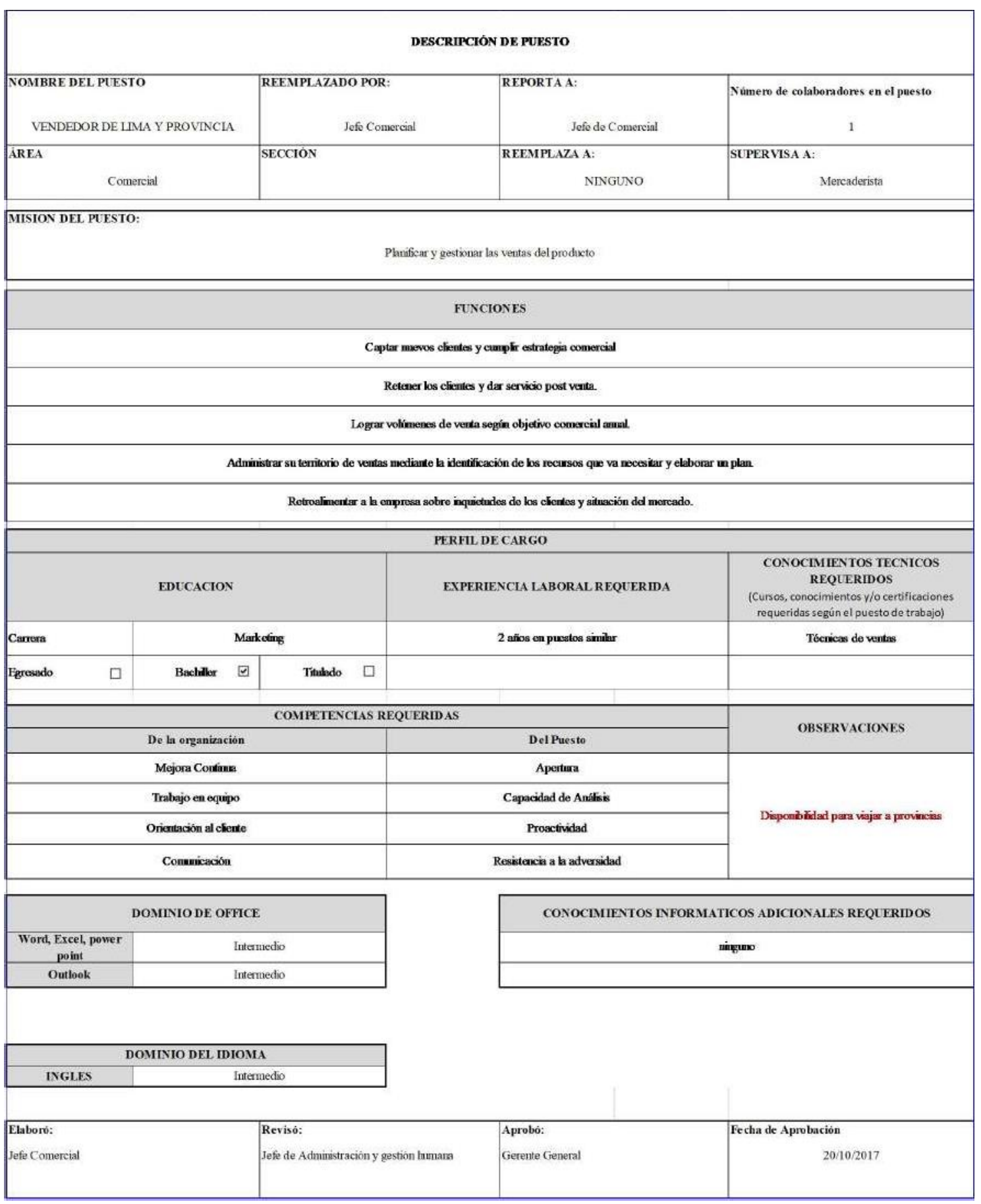




\begin{tabular}{|c|c|c|c|}
\hline \multicolumn{4}{|c|}{ DESCRIPCIÓN DE PUVSTO } \\
\hline $\begin{array}{l}\text { NOMBRE DEL PLESTO } \\
\text { MERCADERISTA }\end{array}$ & $\begin{array}{r}\text { REEMPLAZADO POR: } \\
\text { Mercaderista }\end{array}$ & $\begin{array}{l}\text { REPORTA A: } \\
\text { Vendedor de Lima y Provincia }\end{array}$ & Número de colaboradores en el puesto \\
\hline ÁREA & SECCION & $\begin{array}{r}\text { REEMPLAZA A: } \\
\text { Mercaderista }\end{array}$ & SUPERVISA A: \\
\hline
\end{tabular}

MISION DEL PUESTO:

Deserpeñarse en los supermercados $y$ bodegas orientando e infomando a bs clientes acerca de los beneficios y caracteristicas del producto.

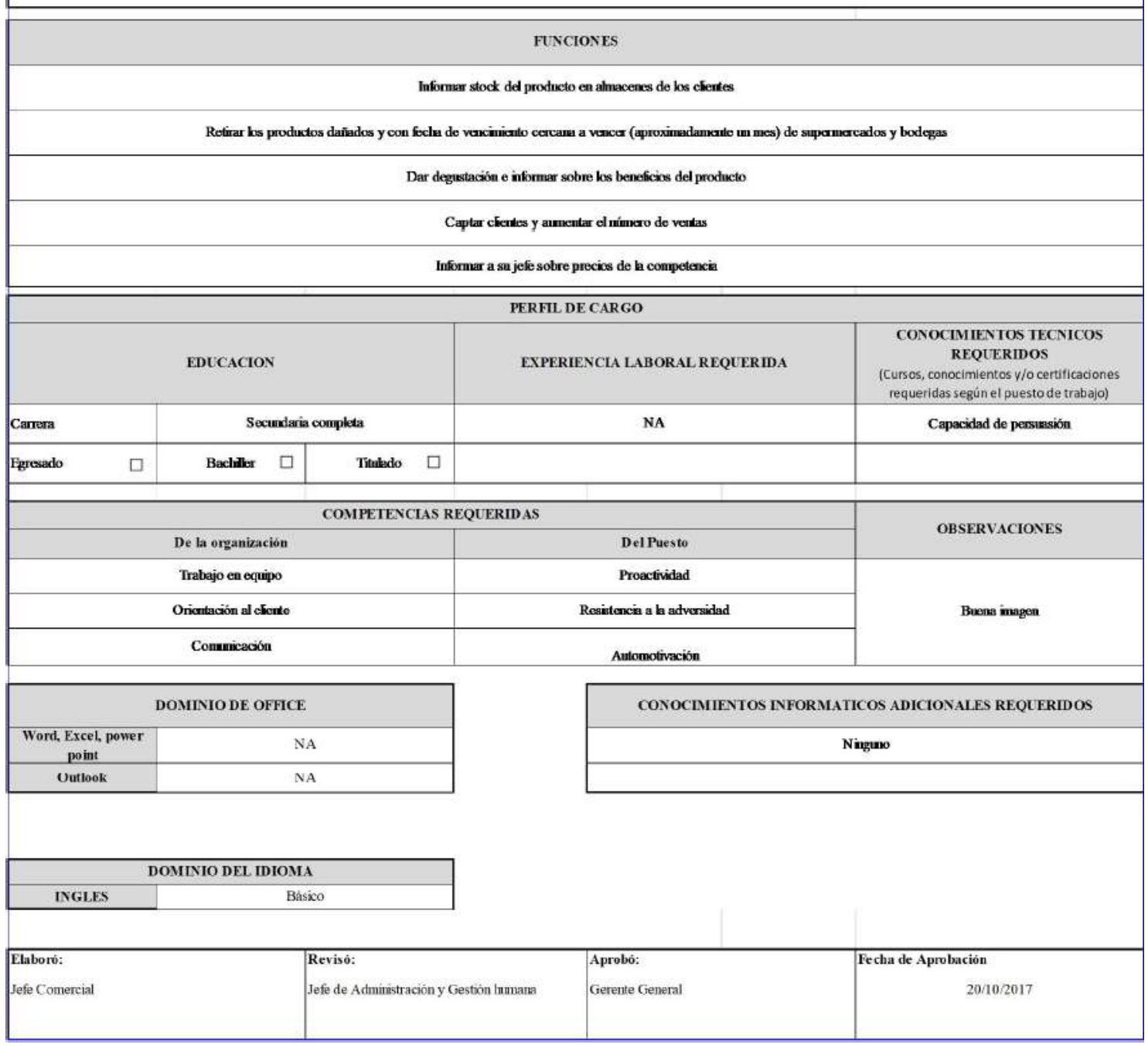


Anexo 16. Lista de Puestos y Remuneración

\begin{tabular}{|c|c|c|c|c|c|c|c|}
\hline Puesto & Área & Sección & Planilla & $\begin{array}{c}\mathrm{N}^{\circ} \\
\text { colaboradores }\end{array}$ & Categoría & Nivel & Remuneración \\
\hline I. & & . & $\mathrm{L}$ & en el puestor & 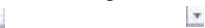 & L & 12 \\
\hline Gerente General & Gerencia General & ---------- & Administrativo & 1 & Gerente General & 1 & 7,000 \\
\hline Asistente de Gerencia & Gerencia General & -.---.--.- & Administrativo & 1 & Asistente & 5 & 1,800 \\
\hline Jefe de Producción & Producción & -.---o--- & Administrativo & 1 & Jefatura & 3 & 3,000 \\
\hline Asistente de Laboratorio de Microbiología & Producción & Laboratorio & Administrativo & 1 & Asistente & 5 & 1,800 \\
\hline Asistente de Laboratorio Fisicoquímico & Producción & Laboratorio & Administrativo & 1 & Asistente & 5 & 1,800 \\
\hline Auxiliar de Producción & Producción & --o--o- & Operario & 2 & Auxiliar Operario & 7 & 1,000 \\
\hline Operario de Procesamiento Primario & Producción & Procesamiento primario & Operario & 4 & Operario de producción & 8 & 850 \\
\hline Operario de Procesamiento Secundario & Producción & Procesamiento secundario & Operario & 3 & Operario de producción & 8 & 850 \\
\hline Operario de Moldeo & Producción & Moldeo & Operario & 4 & Operario de producción & 8 & 850 \\
\hline Operario de Envasado & Producción & Envasado & Operario & 6 & Operario de producción & 8 & 850 \\
\hline Jefe de Mantenimiento & Mantenimiento & -.--o--- & Administrativo & 1 & Jefatura & 3 & 3,000 \\
\hline Auxiliar de Limpieza & Mantenimiento & -.--o--- & Operario & 2 & Operario de limpieza & 10 & 850 \\
\hline Jefe de Logística & Logística & ----------- & Administrativo & 1 & Jefatura & 3 & 3,000 \\
\hline Asistente de Logística & Logística & ---------- & Administrativo & 1 & Asistente & 5 & 1,800 \\
\hline Operario de Almacén de Materia Prima & Logística & Almacén & Operario & 1 & Operario de almacén & 9 & 850 \\
\hline Operario de Almacén de Empaques & Logística & Almacén & Operario & 1 & Operario de almacén & 9 & 850 \\
\hline Operario de Almacén de Productos Terminados & Logística & Almacén & Operario & 1 & Operario de almacén & 9 & 850 \\
\hline Jefe de Administración y Gestión Humana & Gestión Humana & -.------ & Administrativo & 1 & Jefatura & 3 & 3,000 \\
\hline Asistente de Gestión Humana & Gestión Humana & -.---.--.- & Administrativo & 1 & Asistente & 5 & 1,800 \\
\hline Jefe Comercial & Comercial & ---------- & Administrativo & 1 & Jefatura & 3 & 3,000 \\
\hline Vendedor Lima y Provincias & Comercial & -..--..-- & Administrativo & 1 & Asistente & 5 & 850 más comisiones \\
\hline Mercaderista & Comercial & ---------- & Administrativo & 2 & Auxiliar Administrativo & 6 & 1,200 \\
\hline
\end{tabular}


Anexo 17. Proceso de Constitución de la Empresa

Tarea: Redacción y aprobación de la minuta de constitución. Responsable: Socios y Abogado

Tarea: Presentar la minuta a una notaría para que ésta, sea ingresada a Registros Públicos para su inscripción y elevación a escritura pública.

Responsables: Notario Público y socio responsable.

Tarea: Con la copia de la minuta en donde consta su ingreso a una notaría se solicita inscripción en el Registro Único de Contribuyentes (RUC).

Responsables: SUNAT y socio responsable.

Tarea: Con la copia de la minuta en donde consta su ingreso a una notaría y el número del RUC se solicita la apertura de una cuenta corriente.

Responsables: Banco y socio responsable.

Tarea: Proporcionar al notario el RUC y la boleta de depósito bancaria en donde consta

el depósito del capital para que culmine el trámite de inscripción.

Responsables: Notario y socio responsable.

Inscripción en Registros Públicos.

Empresa finalmente constituida.

Fuente: elaboración propia 
Anexo 18. Servicio de la deuda por el crédito solicitado al BBVA

\begin{tabular}{|c|c|c|c|c|c|}
\hline AÑO & MENSUAL & $\begin{array}{l}\text { SALDO DEL } \\
\text { PRÉSTAMO }\end{array}$ & $\begin{array}{l}\text { CUOTA DE } \\
\text { INTERÉS }\end{array}$ & $\begin{array}{c}\text { CUOTA DE } \\
\text { AMORTIZACIÓN }\end{array}$ & $\begin{array}{l}\text { CUOTA } \\
\text { TOTAL }\end{array}$ \\
\hline 0 & & 962,093 & & & \\
\hline \multirow{12}{*}{1} & 1 & 962,093 & 14,720 & 0 & 14,720 \\
\hline & 2 & 962,093 & 14,720 & 0 & 14,720 \\
\hline & 3 & 962,093 & 14,720 & 0 & 14,720 \\
\hline & 4 & 962,093 & 14,720 & 0 & 14,720 \\
\hline & 5 & 962,093 & 14,720 & 0 & 14,720 \\
\hline & 6 & 962,093 & 14,720 & 0 & 14,720 \\
\hline & 7 & 950,506 & 14,720 & $11,587.2$ & $26,307.2$ \\
\hline & 8 & 938,741 & 14,543 & $11,764.5$ & $26,307.2$ \\
\hline & 9 & 926,797 & 14,363 & $11,944.5$ & $26,307.2$ \\
\hline & 10 & 914,669 & 14,180 & $12,127.2$ & $26,307.2$ \\
\hline & 11 & 902,357 & 13,994 & $12,312.8$ & $26,307.2$ \\
\hline & 12 & 889,856 & 13,806 & $12,501.1$ & $26,307.2$ \\
\hline \multirow{12}{*}{2} & 13 & 877,163 & 13,615 & $12,692.4$ & $26,307.2$ \\
\hline & 14 & 864,276 & 13,421 & $12,886.6$ & $26,307.2$ \\
\hline & 15 & 851,193 & 13,223 & $13,083.8$ & $26,307.2$ \\
\hline & 16 & 837,909 & 13,023 & $13,283.9$ & $26,307.2$ \\
\hline & 17 & 824,422 & 12,820 & $13,487.2$ & $26,307.2$ \\
\hline & 18 & 810,728 & 12,614 & $13,693.5$ & $26,307.2$ \\
\hline & 19 & 796,825 & 12,404 & $13,903.1$ & $26,307.2$ \\
\hline & 20 & 782,709 & 12,191 & $14,115.8$ & $26,307.2$ \\
\hline & 21 & 768,377 & 11,975 & $14,331.7$ & $26,307.2$ \\
\hline & 22 & 753,826 & 11,756 & $\begin{array}{l}14,551.0 \\
\end{array}$ & $26,307.2$ \\
\hline & 23 & 739,053 & 11,534 & $14,773.7$ & $26,307.2$ \\
\hline & 24 & 724,053 & 11,308 & $14,999.7$ & $26,307.2$ \\
\hline \multirow{12}{*}{3} & 25 & 708,824 & 11,078 & $15,229.2$ & $26,307.2$ \\
\hline & 26 & 693,362 & 10,845 & $15,462.2$ & $26,307.2$ \\
\hline & 27 & 677,663 & 10,608 & $15,698.8$ & $26,307.2$ \\
\hline & 28 & 661,724 & 10,368 & $15,939.0$ & $26,307.2$ \\
\hline & 29 & 645,541 & 10,124 & $16,182.8$ & $26,307.2$ \\
\hline & 30 & 629,111 & 9,877 & $16,430.4$ & $26,307.2$ \\
\hline & 31 & 612,429 & 9,625 & $16,681.8$ & $26,307.2$ \\
\hline & 32 & 595,492 & 9,370 & $16,937.0$ & $26,307.2$ \\
\hline & 33 & 578,296 & 9,111 & $17,196.2$ & $26,307.2$ \\
\hline & 34 & 560,836 & 8,848 & $17,459.3$ & $26,307.2$ \\
\hline & 35 & 543,110 & 8,581 & $17,726.4$ & $26,307.2$ \\
\hline & 36 & 525,112 & 8,310 & $17,997.6$ & $26,307.2$ \\
\hline \multirow{12}{*}{4} & 37 & 506,839 & 8,034 & $18,273.0$ & $26,307.2$ \\
\hline & 38 & 488,287 & 7,755 & $18,552.6$ & $26,307.2$ \\
\hline & 39 & 469,451 & 7,471 & $18,836.4$ & $26,307.2$ \\
\hline & 40 & 450,326 & 7,183 & $19,124.6$ & $26,307.2$ \\
\hline & 41 & 430,909 & 6,890 & $19,417.2$ & $26,307.2$ \\
\hline & 42 & 411,194 & 6,593 & $19,714.3$ & $26,307.2$ \\
\hline & 43 & 391,178 & 6,291 & $20,015.9$ & $26,307.2$ \\
\hline & 44 & 370,856 & 5,985 & $20,322.2$ & $26,307.2$ \\
\hline & 45 & 350,223 & 5,674 & $20,633.1$ & $26,307.2$ \\
\hline & 46 & 329,274 & 5,358 & $20,948.8$ & $26,307.2$ \\
\hline & 47 & 308,005 & 5,038 & $21,269.3$ & $26,307.2$ \\
\hline & 48 & 286,410 & 4,712 & $21,594.7$ & $26,307.2$ \\
\hline \multirow{12}{*}{5} & 49 & 264,485 & 4,382 & $21,925.1$ & $26,307.2$ \\
\hline & 50 & 242,225 & 4,047 & $22,260.6$ & $26,307.2$ \\
\hline & 51 & 219,624 & 3,706 & $22,601.2$ & $26,307.2$ \\
\hline & 52 & 196,677 & 3,360 & $22,947.0$ & $26,307.2$ \\
\hline & 53 & 173,379 & 3,009 & $23,298.0$ & $26,307.2$ \\
\hline & 54 & 149,724 & 2,653 & $23,654.5$ & $26,307.2$ \\
\hline & 55 & 125,708 & 2,291 & $24,016.4$ & $26,307.2$ \\
\hline & 56 & 101,324 & 1,923 & $24,383.9$ & $26,307.2$ \\
\hline & 57 & $\begin{array}{l}76,567 \\
\end{array}$ & 1,550 & $24,756.9$ & $26,307.2$ \\
\hline & 58 & 51,431 & 1,171 & $25,135.7$ & $26,307.2$ \\
\hline & 59 & 25,911 & 787 & $25,520.3$ & $26,307.2$ \\
\hline & 60 & 0 & 396 & $25,910.8$ & $26,307.2$ \\
\hline
\end{tabular}

